\title{
Molecular Diversity and Regulation of Renal Potassium Channels
}

\author{
STEVEN C. HEBERT, GARY DESIR, GERHARD GIEBISCH, and WENHUI WANG \\ Department of Cellular and Molecular Physiology, Yale University School of Medicine, New Haven, \\ and Department of Medicine, Yale University and VA CT Medical Center, West Haven, Connecticut; \\ and Department of Pharmacology, New York Medical College, Valhalla, New York
}

\begin{abstract}
$\mathrm{K}^{+}$channels are widely distributed in both plant and animal cells where they serve many distinct functions. $\mathrm{K}^{+}$channels set the membrane potential, generate electrical signals in excitable cells, and regulate cell volume and cell movement. In renal tubule epithelial cells, $\mathrm{K}^{+}$channels are not only involved in basic functions such as the generation of the cell-negative potential and the control of cell volume, but also play a uniquely important role in $\mathrm{K}^{+}$secretion. Moreover, $\mathrm{K}^{+}$channels participate in the regulation of vascular tone in the glomerular circulation, and they are involved in the mechanisms mediating tubuloglomerular feedback. Significant progress has been made in defining the properties of renal $\mathrm{K}^{+}$channels, including their location within tubule cells, their biophysical properties, regulation, and molecular structure. Such progress has been made possible by the application of single-channel analysis and the successful cloning of $\mathrm{K}^{+}$channels of renal origin.
\end{abstract}

\section{INTRODUCTION}

\section{A. Physiological Roles for $\mathrm{K}^{+}$Channels in Kidney}

1. Overview of renal $\mathrm{K}^{+}$transport in $\mathrm{K}^{+}$homeostasis-The physiological regulation of the body's internal and external $\mathrm{K}^{+}$balance depends on maintenance of unequal distribution between the intra- and extracellular fluid compartments and on effective renal excretion. Constancy of the small extracellular pool of $\mathrm{K}^{+}$and its low extracellular concentration depend ultimately on effective mechanisms of regulated renal $\mathrm{K}^{+}$excretion. Renal $\mathrm{K}^{+}$excretion is the result of three mechanisms: free filtration in the glomerulus, extensive reabsorption in the proximal nephron segments, and controlled net $\mathrm{K}^{+}$secretion in distal nephron largely determining $\mathrm{K}^{+}$excretion $(164,165,169,593)$. $\mathrm{K}^{+}$reabsorption in certain distal nephron segments has also been observed in states of $\mathrm{K}^{+}$deficiency.

Figure 1 provides an overview of $\mathrm{K}^{+}$transport along the nephron. The bulk of filtered $\mathrm{K}^{+}$is reabsorbed as tubule fluid passes through the proximal convoluted tubule. Some $\mathrm{K}^{+}$enters the descending segments of the loop of Henle passively because of the increasing $\mathrm{K}^{+}$concentration along the corticomedullary axis $(15) . \mathrm{K}^{+}$leaves the ascending limb of Henle, again passively, as $\mathrm{K}^{+}$declines in the interstitium towards the corticomedullary region. $\mathrm{K}^{+}$is further reabsorbed in the thick ascending limb of Henle (TAL) by a specific cotransporter $\left(\mathrm{Na}^{+}-\mathrm{K}^{+}-2 \mathrm{Cl}^{-}\right)$. Modest $\mathrm{K}^{+}$secretion takes place in the distal convoluted tubule and is followed by regulated, more extensive secretion in the initial and cortical collecting ducts. The connecting tubule of deep juxtamedullary nephrons has also been shown to secrete $\mathrm{K}^{+}(227)$. The direction of $\mathrm{K}^{+}$transport reverses as fluid passes the outer medullary and terminal papillary collecting duct. Variable

Address for reprint requests and other correspondence: S. C. Hebert, C.N.H. Long Professor and Chair, Dept. of Cellular and Molecular Physiology, Yale University School of Medicine, 333 Cedar St., SHM B147, PO Box 208026, SA115, New Haven, CT 06520-8026 (steven.hebert@yale.edu). 
net reabsorption has been demonstrated in these nephron segments (111). $\mathrm{K}^{+}$reabsorption in the terminal segments of the nephron, together with passive entry of $\mathrm{K}^{+}$into the descending limb of Henle, constitutes the pathways of $\mathrm{K}^{+}$recycling in the renal medulla (15).

2. Other physiological roles for $\mathbf{K}^{+}$channels in kidney-Figure 2 shows the basic functions of $\mathrm{K}^{+}$channels in various tubule cells along the nephron in the mammalian kidney. In addition to the roles of $\mathrm{K}^{+}$channels in mediating net $\mathrm{K}^{+}$secretion or absorption, these channels serve to 1 ) maintain the cell-negative potential at rest providing a driving force for electrogenic transport processes and stabilizing the membrane potential during large fluxes of cations into, or anions out of, tubule cells; 2) help in recovery of cell volume after swelling; 3 ) recycle $\mathrm{K}^{+}$back to tubule fluid in the TAL where $\mathrm{K}^{+}$entered cells via the $\mathrm{Na}^{+}-\mathrm{K}^{+}-2 \mathrm{Cl}^{-}$ cotransporter; and 4) recycle $\mathrm{K}^{+}$across basolateral membranes in conjunction with $\mathrm{Na}^{+}-\mathrm{K}^{+}$ATPase turnover. Detailed descriptions of these functions for the various cells along the nephron are given in section II.

\section{B. Overview of Renal $\mathrm{K}^{+}$Channel Diversity and Structure}

Although the molecular structure of many $\mathrm{K}^{+}$channels has been defined, our knowledge of their location along the nephron and their polarized expression and functions in native renal epithelial cells is incomplete. The current state of our understanding of the distribution of specific $\mathrm{K}^{+}$channel types along the nephron is shown in Figure 3. While the assignment of cloned $\mathrm{K}^{+}$channels to specific functions in tubule cells remains a major problem, the exceptions are as follows. ROMK, an inwardly rectifying $\mathrm{K}^{+}$channel with two membrane-spanning domains, has been identified as one of the main secretory $\mathrm{K}^{+}$channels; $\mathrm{Ca}^{2+}$-activated maxi$\mathrm{K}^{+}$channels are involved in volume control and flow-dependent $\mathrm{K}^{+}$secretion in the collecting duct; and voltage-sensitive $\mathrm{K}^{+}$channels play a role in the stabilization of the membrane potential in the face of electrogenic transport processes.

1. Evolution and diversity $-\mathrm{K}^{+}$channels are transmembrane proteins that mediate passive $\mathrm{K}^{+}$movement across cell membranes via a highly selective, aqueous pore. Molecular studies carried out over the past decade have firmly established that $\mathrm{K}^{+}$channels constitute the largest and most diverse class of ion channels. These data are in agreement with numerous electrophysiological studies documenting the existence of a wide variety of $\mathrm{K}^{+}$currents in virtually all cells examined to date. They are unique among cation channels since, unlike $\mathrm{Na}^{+}$and $\mathrm{Ca}^{2+}$ channels, they are found in virtually all living organisms and are widely distributed among cells within each organism. It is likely, therefore, that other cation channels evolved from $\mathrm{K}^{+}$channels and that ionic specificity for $\mathrm{Ca}^{2+} \mathrm{Or} \mathrm{Na}^{+}$was achieved by modifying the pore region (235).

In spite of an extensive knowledge of the cellular and tissue distribution of $\mathrm{K}^{+}$currents and a rapidly growing understanding of the cellular physiology of $\mathrm{K}^{+}$channels, biochemical and structural information lagged behind until 1987. The structure of the $\mathrm{Na}^{+}$channel of excitable tissues had been determined more than 3 years previously $(404,406)$ using $\mathrm{Na}^{+}$channel protein purified from the eel's electric organ, which expresses a large quantity of the protein. Conventional biochemical approaches failed to elucidate the structure of $\mathrm{K}^{+}$channels, in large part because these proteins are expressed in very low amounts and are not readily amenable to large-scale purification, and high-affinity probes had not been yet developed.

A major breakthrough in understanding the molecular structure of $\mathrm{K}^{+}$channels was achieved in 1987. Electrophysiological studies of Drosophila melanogaster mutants (Shaker) that exhibited leg shaking when exposed to ether, a volatile anesthetic, indicated the Shaker locus might encode a structural component of a voltage-dependent $\mathrm{K}^{+}(\mathrm{Kv})$ channel. A combination of mutation mapping and chromosome walking was used to successfully identify the Shaker 
gene $(254,441,498,551)$. Expression of the Shaker gene product in Xenopus oocytes confirmed it mediated Kv currents (553). Subsequently, several other Drosophila $\mathrm{K}^{+}$channel genes (Shal, Shaw, and Shab) were isolated by homology cloning (71). These four proteins had a close evolutionary relationship as evidenced by a high degree of identity $(40 \%)$ at the amino acid level in pairwise comparisons. The first mammalian $\mathrm{K}^{+}$channel was isolated by homology cloning in 1988 and noted to be most closely related to Shaker (70\% amino acid identity; Ref. 550). Subsequently, homologs of each Drosophila gene have been identified in mammals either by homology or expression cloning (190).

Although Shaker-related Kv channels were the first to be identified, they are by no means the only class of $\mathrm{K}^{+}$channels and may not even be the most diverse group of $\mathrm{K}^{+}$channels. Indeed, as will be discussed in more detail, three other major classes of $\mathrm{K}^{+}$channels have been isolated, namely, the calcium-activated $\mathrm{K}^{+}$channels $(124,274,562)$, the inward rectifiers $(213,285)$, and the two-pore (2P) channels $(174,176,309,312$, 415; see Fig. 4). The 2P channels appear to be the most diverse group of $\mathrm{K}^{+}$channels with more than 50 members identified to date. Phylogenetic tree reconstruction, using deduced amino acid sequences of the various known classes of $\mathrm{K}^{+}$channels, suggests that all known $\mathrm{K}^{+}$channels arose from a common ancestor $(101,107,237-239,347)$. It is also noteworthy that the $2 \mathrm{P}$ channels are predicted to be more closely related to the small-conductance calcium-activated $\mathrm{K}^{+}$channel (SK) family in spite of very different secondary structures: 2 pores and 4 transmembrane segments (TM) for TWIK and 1 pore and 6 TM for SK $(101,174,312)$.

Several mechanisms contribute to the observed complexity and diversity of $\mathrm{K}^{+}$channels. Sequence information and chromosomal mapping studies indicate $\mathrm{Kv}$ gene clustering at chromosomal loci in both mouse and human, suggesting that $\mathrm{Kv}$ channel gene subfamilies arose through duplication of a primordial $\mathrm{K}^{+}$channel gene, with subsequent chromosomal duplications and rearrangements (329). Candidates for ancestral $\mathrm{K}^{+}$channel genes are present in a very wide range of organisms including plants, bacteria, ciliate protists, worms, squid, flies, and vertebrates. It is also likely that most $\mathrm{K}^{+}$channels came into existence via primordial gene duplication. For instance, Kv and cyclic nucleotide-gated channels exhibit readily detectable homologies at the amino acid and functional domain levels $(191,239)$.

2. Structural classification and functional domains-Since a very large number a $\mathrm{K}^{+}$channel genes have already been identified, deduced amino acid sequences and secondary structure information can be used to generate a structural classification. Three broad classes emerge from such analysis. The first consists of channels with six or seven transmembrane segments and one pore region (6-TM) including the Shaker-related Kv channels (190), KvLQT1 and $\mathrm{Ca}^{2+}$-activated $\mathrm{K}^{+}$channels $(\mathrm{KCa})$. A schematic representation of a prototypic 6-TM channel is shown in Figure 4A. The deduced amino acid sequences range from 450-900 amino acids in length (see Table 1). Hydropathy analysis indicates that they all contain six transmembrane segments. Because the proteins lack signal peptides, the amino and carboxy termini are both predicted to be located intracellularly. Figure $4 B$ depicts the large-conductance voltage-gated $\mathrm{K}^{+}$channel (hSlo), which unlike $\mathrm{Kv}$ has seven transmembrane segments and an extracellular amino terminus (138). Figure $4 C$ shows the inward rectifiers (inward rectifier family; Kir1-7) that have two transmembrane segments and one pore (2-TM; Ref. 398). The amino and carboxy termini are both predicted to be located intracellularly and provide regulatory domains for modification by nucleotide, $\mathrm{pH}$, phosphorylation, and phosphatidyinositol phosphates [e.g., phosphatidylinositol 4,5-bisphosphate $\left(\mathrm{PIP}_{2}\right)$ ] and $\beta \gamma$ from heterotrimeric $\mathrm{G}$ protein-coupled receptors. This group includes ATP-sensitive channels and ATP-regulated channels such as ROMK (213). The most recently discovered group (Fig. $4 D$ ), and likely the most diverse subfamily, consists of $\mathrm{K}^{+}$channels with four transmembrane segments and two pores (2-P; Refs. 309,415). These channels appear to mediate background leak $\mathrm{K}^{+}$currents in a variety of cells, and some currents are regulated by $\mathrm{pH}$ and membrane 
stretch. MinK or KCNE1 is single transmembrane subunit (Fig. 4E) that was the first " $\mathrm{K}^{+}$ channel" found in kidney but has subsequently been shown to function as a subunit of the $\mathrm{Kv}$ channel, KCNQ1.

3. The pore region: an essential feature of $\mathrm{K}^{+}$channels-All $\mathrm{K}^{+}$channels mediate the rapid ( $>1$ million ions/s) and selective transport of potassium. Before the cloning of the first $\mathrm{K}^{+}$channel, a fairly comprehensive view of the pore and the selectivity filter was constructed based on electrophysiological data (203). It was envisioned that $\mathrm{K}^{+}$entered the channel via a water-filled pore, wide on the outside but narrower as it reached the intracellular face of the membrane. The narrow passage facilitated interactions with stabilizing charges and conferred the high selectivity for $\mathrm{K}^{+}$. It was also predicted that the pore could accommodate several $\mathrm{K}^{+}$lined in single file. These predictions proved to be remarkably accurate. Recent data, obtained from site-directed mutagenesis experiments of known $\mathrm{K}^{+}$channels proteins $(7,8,199,263,354,355)$, have confirmed the model. Moreover, direct structural data not only validated the proposed structure but also provided an exquisitely detailed view of the pore $(119,189,460)$. The 6-TM K ${ }^{+}$channels contain a large hydrophobic core that thwarted repeated attempts at obtaining protein crystals suitable for high-resolution X-ray crystallographic studies. A bacterial channel, KCsA, of the 2-TM class was subsequently used to successfully generate protein crystals for high-resolution studies $(119,460)$. It is assumed that the model derived from these data is relevant to all known $\mathrm{K}^{+}$channel pores. X-ray analysis of KCsA crystals revealed that $\mathrm{K}^{+}$channels are tetramers. The four subunits interact to form a symmetrical structure at the center of which lies an aqueous pore. The critical structural elements of the pore consist of two membrane segments linked by a stretch of $\sim 25$ amino acids, hydrophobic enough to partly penetrate the lipid bilayer, and also containing a highly conserved signature sequence: TxGYG. This latter sequence along with the last membrane segment (M2 and S6 for the 2-TM and 6-TM class) form the lining of the pore and determine permeation and selectivity. The pore is asymmetric and has a wide extracellular vestibule that narrows abruptly to $\sim 3 \AA$. This narrowing represents the selectivity filter and measures $\sim 15 \AA$ in length. The pore then widens briefly, about halfway into the bilayer, to form a water-filled cavity 10 $\AA$ Aide. The selectivity filter provides a binding pocket, lined by negatively charged backbone carbonyl groups of the signature sequence, which provides a better fit for a dehydrated $\mathrm{K}^{+}$than for a $\mathrm{Na}^{+}$. The pore contains three of these $\mathrm{K}^{+}$binding sites arranged in single file and in close enough proximity for electrostatic repulsion.

Crystallization of the KcsA pore under high and low $\mathrm{K}^{+}$conditions indicates that the selectivity filter also functions as an outer gate for the channel (657). High $\mathrm{K}^{+}$maintains the filter in an open configuration, and all four binding sites have similar electron density. Low $\mathrm{K}^{+}$alters the structure of the filter and causes the two binding sites at opposite ends of the filter to have the highest electron density. $\mathrm{K}^{+}$cannot move easily, and channel conductance is low. It has been proposed that $\mathrm{K}^{+}$channels also possess an inner gate, formed by hinging of the inner transmembrane helix at a conserved glycine residue, and that sensors (such as voltage, nucleotides, calcium, and $\mathrm{pH}$ ) may interact with the inner gate and regulate channel function (244). The KcsA pore and selectivity filter are similar to those recently shown for a bacterial Kir homolog Kirbac1.1 (296). This model also appears to provide a reasonable approximation of accurately the more complex pore/selectivity filter structures of the voltage-gated (Kv) 6-TM K ${ }^{+}$channels based on the recent X-ray structure of a voltage-dependent $\mathrm{K}^{+}$channel (KvAP) from Aeropyrum pernix (245). The selectivity filter of KvAP resembles that of KcsA. However, the structures diverge within the intracellular membrane leaflet, and in contrast to KcsA, KvAP has an opened pore. In addition, KvAP's pore is flanked by voltage "sensor paddles," which are postulated to move across the membrane and modulate the opening and closing of the pore.

Most $\mathrm{K}^{+}$channels do not remain open indefinitely but alternate between open and closed states. The movement of $\mathrm{K}^{+}$through these channels is governed by conformational changes resulting 
in channel opening or closing, also referred to as gating. $\mathrm{K}^{+}$channels have evolved an array of gating sensors that respond to membrane voltage and/or a variety of extra- and intracellular molecules or ligands including protons, $\mathrm{Ca}^{2+}$, mono- and dinucleotides, cyclic nucleotides, and membrane phospholipids. For example, Kv channels have the ability to respond to membrane voltage. The fourth membrane domain is a critical part of a complex that participates in sensing changes in membrane voltage. The $S 4$ segment stands out by virtue of having 6-9 positively charged amino acids (either lysine or arginine) out of $\sim 20$. Membrane depolarization is believed to open the channel through an S4-mediated conformational change $(256,302,318,364,425$, $434,514)$. The recent $\mathrm{X}$-ray structure of the voltage-gated $\mathrm{K}^{+}$channel has shown that S1-S4 helices are attached to the pore region and the latter half of S3 and S4 form the voltage sensor (245,246).

It should be noted that there is at least one other mechanism for conferring voltage dependence. The 2-P channels, which lack an S4 segment, are thought to mediate background leak current. Recently, it was demonstrated that phosphorylation of a single amino acid of the 2-P channel, KCNK2 (expressed in the hippocampus), allows the channel to sense changes in membrane voltage (52). Furthermore, some 6-TM channels with conserved S4 segments lack voltage sensitivity $(32,46)$, consistent with voltage sensitivity depending on the complex interaction of S3-S4 and other membrane segments.

In the case of $\mathrm{Kv}$ channels, the activation process is complex and often facilitates transition into an inactivated state. Inactivated channels are not closed but do not carry any current due to a segment of the cytosolic region of the channel "plugging" the inner vestibule of the pore. The first 20 amino acids of the amino terminus form the inactivation gate for fast inactivation $(215,248)$. The positively charged inactivation gate swings toward the cytoplasmic face of the pore and binds to a negatively charged receptor region in the S4-S5 loop which occludes the pore and prevents $\mathrm{K}^{+}$permeation. Interestingly, the inactivation ball can also be formed by soluble cytosolic accessory $(\beta)$ subunits (454).

4. $\mathrm{K}^{+}$channels are heteromultimeric complexes-The basic structure of all $\mathrm{K}^{+}$ channels is a tetramer of membrane-spanning subunits with a central pore. The subunits forming the tetramer may be the same protein (homotetramer) or two different proteins (heterotetramer) (see Table 1). For example, certain Kir channels consist of identical poreforming subunits (Kir1.1 or ROMK) while others contain two different proteins (e.g., Kir4.1 and Kir5.1). In addition, many $\mathrm{K}^{+}$channels exist as heteromeric assemblies of the pore tetramers with accessory proteins. Kv channels are complexes consisting of four $\alpha$-subunits that form the pore and cytosolic $\beta$-subunits that modulate channel inactivation or other channel functions. In addition, calmodulin is complexed with the $\mathrm{Ca}^{2+}$-activated small-conductance $\mathrm{K}^{+}$(SK) channel and through this interaction mediates calcium sensing (493). Moreover, some Kir channel tetramers may form heteromeric complexes with an ATP binding cassette (ABC) protein, like the cystic fibrosis transmembrane conductance regulator (CFTR), or the glibenclamide (sulfonylurea)-binding protein SUR2A/B.

The tetrameric nature of the $\mathrm{K}^{+}$channel pore has been demonstrated using site-directed mutagenesis and $\mathrm{X}$-ray crystallography $(70,233,319,447,464,502)$. $\alpha$-Subunits can coassemble to form either homo- or heteromultimers. Some of the structural elements that control tetrameric assembly have been identified in both $\mathrm{Kv}$ (628) and Kir (634) channels. At the amino terminus of $\mathrm{Kv}$ channels, the $\mathrm{T} 1$ domain is a conserved region $\sim 110$ amino acid long proximal to $\mathrm{S} 1$ that mediates heteromultimeric interactions of $\mathrm{Kv}$ channels. The structure of $\mathrm{T} 1 \mathrm{from}$ Kv1.1 channels has been elucidated $(189,382)$. It is believed that active channels have four T1 domains that hang directly under the cytoplasmic mouth of the pore. They form a sort of platform, $20 \AA$ away form the pore, connected to $\mathrm{S} 1$ by thin protein bands. $\mathrm{K}^{+}$may access or leave the channel pore sideways, through $20-\AA$-long openings defined by that $\mathrm{T} 1$ domain. 
The electrophysiological properties of cloned subunits forming the tetrameric pore may not always match those known for these channels in native tissues (see Table 2). In general, this is due to pore-forming subunits interacting with accessory proteins in native cells that modify their kinetic and pharmacological properties. Furthermore, accessory proteins often modulate the levels of expression of pore-forming tetramers. These latter interactions with $\beta$-subunits have been well-studied for $\mathrm{Kv}$ channels. For example, the $\mathrm{Kv} \beta$ genes encode soluble proteins (367-404 amino acids), related to the $\mathrm{NAD}(\mathrm{P}) \mathrm{H}$-dependent oxidoreductase superfamily, that interact with many Kv $\alpha$-subunits (442). The KChIP genes encode calcium sensors that modify the expression level and kinetic properties of Kv4.2 and Kv4.3 (297). The KChAP proteins act as chaperone for $\mathrm{Kv}$ proteins such as $\mathrm{Kv} 1.3$, Kv2.1, Kv2.2, and Kv4.3 (297,617). The MinKrelated proteins (MiRPs) also interact with Kv channels (1-3,27,471). KCNA4B encodes a soluble protein (141 amino acids) with limited similarity to the NAD(P)H-dependent oxidoreductase superfamily (552). KCNA4B binds to the carboxy terminus of KCNA10, increases KCNA10 current expression by almost threefold, and also alters its sensitivity to cAMP.

\section{FUNCTION AND REGULATION OF POTASSIUM CHANNELS IN THE KIDNEY}

\section{A. Epithelial $\mathrm{K}^{+}$Channels}

\section{1. $\mathrm{K}^{+}$channels along the nephron}

A) FUNCTION OF K ${ }^{ \pm}$CHANNELS IN PROXIMAL TUBULE: The vast majority of filtered $\mathrm{K}^{+}$is reabsorbed passively along the proximal tubule (164). Two mechanisms, passive diffusion and $\mathrm{Na}^{+}$-dependent solvent drag of tubule fluid, have been shown to mediate $\mathrm{K}^{+}$ retrieval from the filtrate. There is at present no convincing evidence that $\mathrm{K}^{+}$reabsorption involves transcellular movement or $\mathrm{K}^{+}$channels; rather, the bulk of $\mathrm{K}^{+}$reabsorption is thought to proceed via paracellular pathways (612).

$\mathrm{K}^{+}$channels in the proximal tubule serve at least three important functions (Fig. 2; Refs. $164,168,498)$. First, they participate in generating the cell negative membrane potential. Since several membrane transport processes are electrogenic, alteration in cell membrane potential can affect the $\mathrm{Na}^{+}$-coupled transport of molecules including glucose, phosphate, amino acids, and bicarbonate. Relevant examples include $\mathrm{Na}^{+}$-coupled phosphate, sulfate, and glucose entry into cells, transport processes which have been shown to be sensitive to membrane depolarization. In the basolateral membrane, $\mathrm{Cl}^{-}$diffusion, $\mathrm{Na}^{+}$-coupled $\mathrm{HCO}_{3}^{-}$cotransporter, and $\mathrm{Na}^{+} / \mathrm{Ca}^{2+}$ exchanger are affected by changes in basolateral membrane potential. Second, $\mathrm{K}^{+}$channels in the proximal tubule are involved in regulating cell volume. For instance, stimulation of $\mathrm{Na}^{+}$-dependent carriers such as $\mathrm{Na}^{+}$-glucose cotransporters is expected to increase intracellular $\mathrm{Na}^{+}$and cell volume. Such cell swelling activates both apical and basolateral $\mathrm{K}^{+}$channels and increases $\mathrm{K}^{+}$loss, restoring the cell volume. Third, $\mathrm{K}^{+}$channels are responsible for $\mathrm{K}^{+}$recycling across the basolateral membranes where they prevent $\mathrm{K}^{+}$ depletion in unstirred fluid layers in the complex system of interstitial spaces adjacent to the basolateral membrane.

In addition to the above-mentioned physiological function, ATP-sensitive $\mathrm{K}^{+}$channels may be involved in hypoxic-induced renal injury (452). It was demonstrated in this latter study that inhibition of $\mathrm{K}^{+}$channels in the proximal tubule by the sulfonylurea glibenclamide attenuates hypoxic injury.

I) $\mathrm{K}^{+}$channels in the basolateral membrane of mammalian proximal tubule: Figure 5 and Table 2 summarize the biophysical properties of, and factors known to regulate, $\mathrm{K}^{+}$channels in the basolateral membrane of the proximal tubule. Three types of $\mathrm{K}^{+}$channels with single- 
channel conductances of $12 \mathrm{pS}$ (405), 36-41 pS (171,172), and 50-60 pS $\left(35,94,172,426,{ }^{441}\right.$, $451,498,529,563)$ have been observed in the basolateral membrane of the rabbit proximal tubule. An important feature of the $50-$ to $60-\mathrm{pS} \mathrm{K}^{+}$channel is its sensitivity to inhibition by millimolar concentrations of ATP $(35,221)$. This may link (356) the function of this $\mathrm{K}^{+}$channel to changes in basolateral $\mathrm{Na}^{+}-\mathrm{K}^{+}$-ATPase activity (also see Fig. 2). Stimulating the apical $\mathrm{Na}^{+}$-glucose cotransporter augments $\mathrm{Na}^{+}$influx, which subsequently causes increased $\mathrm{Na}^{+}-$ $\mathrm{K}^{+}$-ATPase activity in the basolateral membrane. Such enhanced $\mathrm{Na}^{+}-\mathrm{K}^{+}$-ATPase activity is expected to increase the hydrolysis of ATP and to lower intracellular ATP concentrations. With the decrease in intracellular ATP, ATP-sensitive $\mathrm{K}^{+}$channels are relieved from ATP block, resulting in an increase in $\mathrm{K}^{+}$recycling. In this way, the turnover rate of $\mathrm{Na}^{+}-\mathrm{K}^{+}$-ATPase can be tightly linked to the activity of basolateral $\mathrm{K}^{+}$channels. This hypothesis is supported by several observations: 1 ) adding luminal glucose and alanine decreases the intracellular ATP concentrations and simultaneously increases basolateral $\mathrm{K}^{+}$channel activity (563); 2) sulfonylurea agents, inhibitors of the ATP-sensitive $\mathrm{K}^{+}$channels, also abolish the effect of stimulating $\mathrm{Na}^{+}$transport on channel activity (563); and 3) inhibition of $\mathrm{Na}^{+}-\mathrm{K}^{+}$-ATPase increases intracellular ATP concentrations and inhibits basolateral $\mathrm{K}^{+}$channel activity in proximal tubule cell (221).

Basolateral ATP-sensitive $\mathrm{K}^{+}$channels have also been shown to be sensitive to changes in cell $\mathrm{pH}$ : acidic $\mathrm{pH}$ inhibits the activity of these $\mathrm{K}^{+}$channels (35). Moreover, it has been reported that the activity of the basolateral 50- to $60-\mathrm{pS} \mathrm{K}^{+}$channel decreases upon exposure to high extracellular taurine (405). Since cell swelling, as accompanying increased apical $\mathrm{Na}^{+}$entry, is expected to reduce the concentration of taurine, it has been proposed that changes in taurine concentration could mediate the swelling-induced increase in the basolateral $\mathrm{K}^{+}$channel activity and play a role in volume regulation $(63,405)$.

The molecular nature of the ATP-sensitive $\mathrm{K}^{+}$channel in the proximal tubule has been explored. Kir6.1 mRNA is expressed in the proximal tubule (405; see Fig. 3 and Table 1). Moreover, coexpressing Kir6.1 with a sulfonylurea receptor (SUR2A/2B) in oocytes results in an ATP-sensitive $\mathrm{K}^{+}$channel that shares with the native basolateral $\mathrm{K}^{+}$channels inhibition by taurine and gliben-clamide (405). Therefore, it has been suggested that Kir6.1 is an important part of the basolateral 50- to $60-\mathrm{pS} \mathrm{K}^{+}$channel. More discussion regarding the molecular nature of renal ATP-sensitive $\mathrm{K}^{+}$channels can be found in section IVB3.

II) $\mathrm{K}^{+}$channels in the apical membrane of the mammalian proximal tubule: $\mathrm{Ca}^{2+}$-activated large-conductance (200-300 pS; see Figs. 3, 4B, and 5; Table 2) or maxi- $\mathrm{K}^{+}$channels have been identified in the apical membrane of cultured proximal tubule cells $(42,204,205,262$, $380,548)$ and in the brush border of rabbit proximal tubules $(666)$. These channels are activated by mechanical stretch and membrane depolarization. However, since the channel open probability is very low, it is unlikely that these maxi- $\mathrm{K}^{+}$channels contribute significantly to the apical $\mathrm{K}^{+}$conductance under normal circumstances in native cells. However, it may play a role in stabilization of the apical membrane potential following stimulation of $\mathrm{Na}^{+}$-coupled glucose and amino acid transporters, which tend to depolarize the apical membrane. 33- and 63-pS K ${ }^{+}$channels have also been found in the apical membrane of the proximal tubule (171; see Figs. 3 and 5;Table 2), although their physiological roles are unknown. A 42-pS ATPregulated and $\mathrm{pH}$-sensitive inwardly rectifying $\mathrm{K}^{+}$channel has also been identified in the apical membrane of human cultured proximal tubule cells (395).

Molecular cloning has identified several types of voltage-gated $\mathrm{K}^{+}$channels (638) and $\mathrm{Ca}^{2+}-$ dependent maxi-K $\mathrm{K}^{+}$channels $(193,388)$ expressed in proximal tubules. Two voltage-gated $\mathrm{K}^{+}$channels (e.g., KCNQ1, KCNE1, and KCNA10) have been localized to the apical membrane of proximal tubules (Fig. 3;Table 1; Ref. 569). These voltage-gated $\mathrm{K}^{+}$channels may also be involved in stabilization of the apical membrane potential. The properties and 
potential roles of these voltage-gated $\mathrm{K}^{+}$channels in the regulation of proximal tubule epithelial transport are discussed in section IV. The $\mathrm{Ca}^{2+}$-dependent maxi- $\mathrm{K}^{+}$channel $r b s l o l$ was cloned from rabbit renal cells and has homology to mslo; however, it is not clear whether rbslo1 transcripts are expressed in the rabbit proximal tubule ( 1 of 8 tubules gave a PCR signal; Ref. $388)$.

III) $\mathrm{K}^{+}$channels in the basolateral membrane of the amphibian proximal tubule: At least two inward-rectifying $\mathrm{K}^{+}$channels $(27-30 \mathrm{pS}, 47-50 \mathrm{pS}$ ) have been identified in the basolateral membrane of the proximal tubule of the amphibian kidney (Fig. 5 and Table 2; Refs. ${ }^{218},{ }^{261}$, $367,397,397,468,566)$. The activity of the 27 - to $30-\mathrm{pS} \mathrm{K} \mathrm{K}^{+}$channel is increased by depolarization and membrane stretch $(218,260)$ and inhibited by ATP $(367)$. In contrast, the activity of the 47 - to $50-\mathrm{pS} \mathrm{K}^{+}$channel is stimulated by hyperpolarization $(261,468)$. This feature suggests the possibility of metabolic coupling of the activity of $\mathrm{Na}^{+}-\mathrm{K}^{+}$-ATPase to that of basolateral $\mathrm{K}^{+}$channels.

IV) $\mathrm{K}^{+}$channels in the apical membrane of amphibian proximal tubule: $\mathrm{A} \mathrm{Ca}^{2+}$-activated maxi- $\mathrm{K}^{+}$channel has been identified in the apical membrane of the amphibian proximal tubule (147) and found to be activated by depolarization and membrane stretch. In contrast to the behavior of the basolateral stretch-activated $\mathrm{K}^{+}$channels, the effect of mechanical stimulation on channel activity may be indirect and mediated by an increase in intracellular $\mathrm{Ca}^{2+}$. This view is based on the observation that membrane stretch activates a $\mathrm{Ca}^{2+}$-permeant nonselective cation channel in the apical membrane of proximal tubules $(147,260,466,467)$.

B) FUNCTION OF K \pm CHANNELS IN THE TAL: The TAL reabsorbs not only 20-25\% of the filtered $\mathrm{Na}^{+}$load but also plays an important role in reabsorption of divalent cations such as $\mathrm{Mg}^{2+}$ and $\mathrm{Ca}^{2+}$. $\mathrm{K}^{+}$channels in the TAL are important in generating the cell membrane potential, apical $\mathrm{K}^{+}$recycling coupled to $\mathrm{K}^{+}$entry via $\mathrm{Na}^{+}-\mathrm{K}^{+}-2 \mathrm{Cl}^{-}$cotransport, regulating cell volume, and basolateral $\mathrm{K}^{+}$recycling coupled to the activity of $\mathrm{Na}^{+}-\mathrm{K}^{+}$-ATPase (see Figs. 2 and 6).

I) $\mathrm{K}^{+}$channels in the basolateral membrane of mammalian TAL: $\mathrm{Cl}^{-}$efflux across the basolateral membrane of the TAL via $\mathrm{Cl}^{-}$channels is crucial to net $\mathrm{Cl}^{-}$reabsorption (see Fig. 6). Basolateral $\mathrm{K}^{+}$channels are involved in generating and maintaining the membrane potential which provides an important driving force for this passive $\mathrm{Cl}^{-}$exit across the basolateral membrane. Regulation of the basolateral $\mathrm{K}^{+}$channel has not been extensively explored due to technical difficulties in accessing the basolateral membrane using intracellular microelectrodes or patch clamp. However, an inward-rectifying $\mathrm{K}^{+}$channel with a slope conductance between 41 and $43 \mathrm{pS}$ has been detected in the basolateral membrane of the mouse TAL (222) (Fig. 6 and Table 2). This $\mathrm{K}^{+}$channel is inhibited by reductions in cytosolic $\mathrm{pH}$ (431) and cytochrome $P$-450-dependent metabolites of arachidonic acid (183). The activity of the 41- to $43-\mathrm{pS} \mathrm{K}^{+}$ channel increases with depolarization (183). The voltage dependence of this 41- to $43-\mathrm{pS} \mathrm{K}^{+}$ channel would help maintain the driving force for passive $\mathrm{Cl}^{-}$movement across the basolateral membrane during periods of increased transcellular $\mathrm{Cl}^{-}$flux.

II) $\mathrm{K}^{+}$channels in the apical membrane of mammalian TAL: $\mathrm{K}^{+}$channels play a key role in $\mathrm{K}^{+}$recycling across the apical membrane of the TAL. Their importance is underscored by the observation that inhibition of apical $\mathrm{K}^{+}$recycling impairs $\mathrm{NaCl}$ reabsorption in the loop of Henle $(164,180,195,593)$. Several functions are served by $\mathrm{K}^{+}$recycling (see Fig. 6). First, $\mathrm{K}^{+}$recycling hyperpolarizes the cell membrane potential, which is an essential factor for $\mathrm{Cl}^{-}$ diffusion across the basolateral membrane. Second, $\mathrm{K}^{+}$recycling across the apical membrane, coupled to $\mathrm{Cl}^{-}$exit across basolateral membranes, generates the lumen-positive transepithelial potential that is the main driving force for paracellular $\mathrm{Na}^{+}, \mathrm{Ca}^{2+}$, and $\mathrm{Mg}^{2+}$ transport. Third, 
$\mathrm{K}^{+}$recycling maintains an adequate supply of $\mathrm{K}^{+}$for the $\mathrm{Na}^{+}-\mathrm{K}^{+}-2 \mathrm{Cl}^{-}$cotransporter in the cortical TAL.

Three types of $\mathrm{K}^{+}$channels, a low-conductance (30-35 pS), an intermediate-conductance (70$72 \mathrm{pS}$ ), and a large-conductance (140-200 pS) maxi-K ${ }^{+}$channel, have been observed in the apical membrane of the TAL (Fig. 6 and Table 2; Refs. $\left.{ }^{49}, 94,188,589,599\right)$ ). Patch-clamp studies have demonstrated that both the low- and intermediate-conductance $\mathrm{K}^{+}$channels contribute to the apical $\mathrm{K}^{+}$conductance and to $\mathrm{K}^{+}$recycling. Both the large apical membrane conductance and $\mathrm{K}^{+}$recycling can be accounted for by the high open probabilities and channel densities (593). For example, the 70-pS K ${ }^{+}$channel has been estimated to contribute up to $75 \%$ of the total apical $\mathrm{K}^{+}$conductance of the TAL in rat maintained on a high- $\mathrm{K}^{+}$diet (604). In contrast, the open probability of the maxi- $\mathrm{K}^{+}$channel is very low under normal conditions in native cells and therefore is unlikely to play a significant role in apical $\mathrm{K}^{+}$recycling (188, 545). However, the maxi- $\mathrm{K}^{+}$channel in TAL cell culture can be activated by membrane stretch (545) and thus may be involved in regulating cell volume. It has not been explored whether increased flow rate in the TAL could stimulate maxi- $\mathrm{K}^{+}$channels as has been described for principal cells in the cortical collecting duct (CCD) (620). Such a mechanism has been implicated in the $\operatorname{CCD}(546,620)$ and, therefore, could provide an additional $\mathrm{K}^{+}$recycling mechanism in the TAL.

The molecular nature of the low-conductance, $35-\mathrm{pS} \mathrm{K}{ }^{+}$channel is established to be ROMK (Kir1.1; Fig. 2 and Table 1; see sect. III; Refs. 342,593). The ROMK-knockout mouse exhibits a Bartter's-like phenotype $(333,342)$, and these mice lack expression of both the 35 - and 70 $\mathrm{pS} \mathrm{K}^{+}$channels in the TAL (342). Thus it is possible that ROMK may also be involved in forming the $70-\mathrm{pS} \mathrm{K}{ }^{+}$channel.

III) Regulation of $\mathrm{K}^{+}$channels in the TAL: Figure 6 provides a summary of the factors regulating apical and basolateral $\mathrm{K}^{+}$channels in the mammalian TAL $(166,593)$.

A) The apical 35-pS $\mathrm{K}^{+}$channel: Vasopressin increases the activity of this $\mathrm{K}^{+}$channel via a cAMP-dependent pathway, and the channel can be directly stimulated by cAMP-dependent protein kinase (PKA) in the absence of hormone $(451,589)$. Since vasopressin also stimulates $\mathrm{Na}^{+}$reabsorption in the TAL $(180,196,197)$, it is possible that at least part of the vasopressin effect is mediated by increasing apical $\mathrm{K}^{+}$recycling. Consistent with this notion, the arginine vasopressin analog 1-deamino-(8-D-arginine)-vasopressin (DDAVP) increases Kir1.1 (ROMK) abundance in the TAL of the Brattleboro rat (125).

The $35-\mathrm{pS} \mathrm{K}^{+}$channels are inhibited by millimolar intracellular ATP and by acidic $\mathrm{pH}$ (48, 589). The former may be involved in metabolic sensing to coordinate apical and basolateral potassium fluxes as demonstrated in proximal tubule $(563,613)$ and collecting duct principal cells (602). $\mathrm{pH}$ sensing by the $35-\mathrm{pS} \mathrm{K}{ }^{+}$channel may serve to modulate apical $\mathrm{K}^{+}$conductance during acid-base disturbances ( $\mathrm{pH}$ reductions are inhibitory) and also may be involved in the altering of channel activity by other factors [e.g., phosphatidylinositol 4,5-bisphosphate $\left(\mathrm{PIP}_{2}\right)$; see sect. III]. In addition, modulating the activity of the $\mathrm{Na}^{+}-\mathrm{K}^{+}-2 \mathrm{Cl}^{-}$cotransporter may alter intracellular $\mathrm{pH}$ and affect apical $\mathrm{K}^{+}$conductance as in the amphibian diluting segment (93).

Since ROMK encodes the $35-\mathrm{pS} \mathrm{K}{ }^{+}$channel, modulation of its expression by hormones or dietary factors provides information about regulation of this low-conductance channel. Increase in glucocorticoids, protein, or sodium intake enhances ROMK expression in the TAL while low sodium intake reduces channel expression $(125,158)$. In addition, increases in osmolality also enhance ROMK expression ib the medullary TAL (158). 
B) The apical 70-pS $\mathrm{K}^{+}$channel: The 70-pS K ${ }^{+}$channel is also stimulated by PKA and inhibited by millimolar intracellular ATP $(49,589,599)$. Moreover, two eicosanoids, 20hydroxyeicosatetraenoic acid (20-HETE) and $\mathrm{PGE}_{2}$, play important roles in regulating the activity of this $\mathrm{K}^{+}$channel. In the medullary TAL (mTAL), 20-HETE is the major metabolite of cytochrome $P-450 \omega$-oxidation of arachidonic acid, whereas $\mathrm{PGE}_{2}$ is the major product of cyclooxygenase-dependent metabolism of arachidonic acid in the mTAL $(75,76,369)$. Addition of arachidonic acid inhibits the 70-pS K${ }^{+}$channel (596), and this effect can be mimicked by 20-HETE. The latter eicosanoid has also been shown to inhibit the $\mathrm{Na}^{+}-\mathrm{K}^{+}-2 \mathrm{Cl}^{-}$cotransporter (134). Reduction in the activity of the 70-pS K ${ }^{+}$channel may be an additional mechanism by which 20-HETE lowers the activity of the $\mathrm{Na}^{+}-\mathrm{K}^{+}-2 \mathrm{Cl}^{-}$cotransporter via a decrease in apical $\mathrm{K}^{+}$recycling. At low concentrations, $\mathrm{PGE}_{2}$ inhibits the $70-\mathrm{pS} \mathrm{K}^{+}$channels by reducing cAMP level, whereas high concentrations of $\mathrm{PGE}_{2}$ directly inhibit the channel activity by stimulating protein kinase C (PKC) (328).

It has been suggested that extracellular $\mathrm{Ca}^{2+}$-mediated stimulation of the basolateral $\mathrm{G}$ proteincoupled $\mathrm{Ca}^{2+}$-sensing receptor (CaSR) provides a major mechanism for regulation of $\mathrm{NaCl}$ and $\mathrm{Ca}^{2+} / \mathrm{Mg}^{2+}$ transport by the TAL (66). Increased blood/interstitial concentrations of $\mathrm{Ca}^{2+}, \mathrm{Mg}^{2+}$, or aminoglycoside antibiotics (e.g., neomycin) activates the CaSR resulting in reductions in both divalent mineral and $\mathrm{NaCl}$ reabsorption $(99,241,242,446,537,538)$. As a consequence, divalent mineral excretion is enhanced, and countercurrent multiplication and urinary concentrating ability are reduced. $\mathrm{Ca}^{2+}$-mediated activation of the CaSR in the TAL reduces cAMP production by adenylate cyclase (probably type 6 ) and enhances cAMP destruction by phosphodiesterases (PDE) $(241,242)$. This CaSR-mediated reduction in cAMP generation would reduce the activity of both the 70- and 35-pS K ${ }^{+}$channels (Fig. 6). In addition, stimulating the CaSR in the TAL significantly increases 20-HETE production, which inhibits the 70-pS K${ }^{+}$channel (604). Since the CaSR is half-maximally activated at the normal plasma concentration of $\mathrm{Ca}^{2+}$, the CaSR could account for the basal production of 20-HETE. Thus CaSR activation can inhibit both types of $\mathrm{K}^{+}$channels involved in apical $\mathrm{K}^{+}$recycling, consistent with reduction in $\mathrm{NaCl}$ and $\mathrm{Ca}^{2+} / \mathrm{Mg}^{2+}$ transport by the TAL. The potent effect of CaSR activation on apical $\mathrm{K}^{+}$channels in the TAL has been recently supported by the observations that certain activating (gain-of-function) mutations of the human CaSR gene produce a Bartter's-like phenotype $(573,609)$.

It has also been suggested that 20-HETE may mediate the low $\mathrm{K}^{+}$intake-induced decrease in the activity of the 70-pS K${ }^{+}$channel, since the concentration of this eicosanoid is four times higher in the mTAL from rats on a $\mathrm{K}^{+}$-deficient diet than in those from animals on a high$\mathrm{K}^{+}$diet (185). Channel open probability is significantly diminished in mTAL harvested from rats on a $\mathrm{K}^{+}$-deficient diet (185). In contrast, inhibiting cytochrome $P$-450 $\omega$-oxidation increases channel activity to an extent similar to that observed in the high $\mathrm{K}^{+}$adapted animals (185).

The apical 70-pS K${ }^{+}$channel is activated by two gases, nitric oxide (NO) and carbon monoxide (CO) $(327,346)$. Inhibition of NO synthase (NOS) attenuates, whereas addition of NO donors increases, the activity of the 70-pS K ${ }^{+}$channel. The effect of NO is mediated by a cGMPdependent pathway because the effect of NOS inhibitors can be reversed by membranepermeant cGMP analogs (346). The mechanism by which $\mathrm{CO}$ regulates the $70-\mathrm{pS} \mathrm{K}{ }^{+}$channel is unlikely to involve cGMP because $\mathrm{CO}$ effects can also be observed in excised patches (327).

C) The basolateral $\mathrm{K}^{+}$channel: Application of arachidonic acid (AA) reduces the activity of the $41-\mathrm{pS} \mathrm{K}^{+}$channel, and this effect of AA is abolished by blocking the cytochrome $P-450$ metabolic pathway (see Fig. 6). Thus the effect of AA may also be mediated by 20-HETE (183). Given that basolateral $\mathrm{K}^{+}$channels play an important role in maintaining the driving 
force for $\mathrm{Cl}^{-}$exit across the basolateral membrane, inhibition of basolateral $\mathrm{K}^{+}$channels is expected to decrease $\mathrm{Cl}^{-}$transport.

IV) $\mathrm{K}^{+}$channels in the amphibian diluting segment: An inward-rectifying $\mathrm{K}^{+}$channel with a conductance of 25-31 pS has been identified in the apical membrane of the frog diluting segment which shares the properties of the TAL (223-225). This channel is activated by increasing cell $\mathrm{pH}$ from 7.4 to 8.2 and inhibited by acidic $\mathrm{pH}$ (6.6). Furosemide, which inhibits $\mathrm{Na}^{+}-\mathrm{K}^{+}-2 \mathrm{Cl}^{-}$cotransport and increases intracellular $\mathrm{pH}$, activates the apical $\mathrm{K}^{+}$channel (93). With the use of isolated cells from the frog diluting segment, three types of $\mathrm{K}^{+}$channels with differing conductances have been found (24, 45, and $59 \mathrm{pS}$; Ref. 594). However, their membrane location is not known. Of interest is the finding that aldosterone stimulates the 45$\mathrm{pS} \mathrm{K}^{+}$channel that is sensitive to changes in intracellular $\mathrm{pH}$ (594). Because aldosterone raises the cell $\mathrm{pH}$ in frog diluting segment, it is possible that the effect of aldosterone on the 45-pS $\mathrm{K}^{+}$channel results from increasing cell $\mathrm{pH}(594)$.

\section{C) FUNCTION OF K ${ }^{ \pm}$CHANNELS IN THE MAMMALIAN DISTAL CONVOLUTED}

TUBULE: The distal convoluted tubule (DCT) plays an important role in the regulation of $\mathrm{Na}^{+}, \mathrm{Mg}^{2+}$, and $\mathrm{Ca}^{2+}$ transport $(26,95,98)$. However, only a few studies have assessed the properties of $\mathrm{K}^{+}$channels in this nephron segment. A 48- to 60-pS $\mathrm{K}^{+}$channel has been observed in the basolateral membrane of the rabbit distal tubule (547). In addition, an inwardly rectifying $\mathrm{K}^{+}$channel with inward slope conductance of $37 \mathrm{pS}$ has been observed in the cultured mouse distal tubule cells, and this channel is inhibited by acidic $\mathrm{pH}$ (337). Specific roles of these channels in distal tubule function are unknown.

D) FUNCTION OF K ${ }^{ \pm}$CHANNELS IN THE COLLECTING DUCT: The CCD plays a key role in the regulated secretion of $\mathrm{K}^{+}\left(164,168\right.$; see Figs. 1, 2, and 7). $\mathrm{K}^{+}$secretion occurs in principal cells by a two-step process: active entry of $\mathrm{K}^{+}$across the basolateral membrane mediated by $\mathrm{Na}^{+}-\mathrm{K}^{+}$-ATPase, followed by passive diffusion across the luminal membrane via apical $\mathrm{K}^{+}$channels along a favorable electrochemical gradient (164). In addition to playing an important role in the secretion of $\mathrm{K}^{+}$, it has been suggested that apical $\mathrm{K}^{+}$channels are also involved in modulating the process of reabsorption of $\mathrm{K}^{+}$that occurs in cells of the outer medullary collecting duct (OMCD). In these cells, $\mathrm{K}^{+}$channels are coupled to the activity of $\mathrm{K}^{+} / \mathrm{H}^{+}$exchange $\left(\mathrm{H}^{+}-\mathrm{K}^{+}\right.$-ATPase); channel activity is high during $\mathrm{K}^{+}$repletion but decreases sharply during $\mathrm{K}^{+}$depletion $(653,654)$. Thus variable apical recycling of $\mathrm{K}^{+}$, in concert with regulated basolateral $\mathrm{K}^{+}$channel activity, could be an important mechanism modulating the efficacy of active $\mathrm{K}^{+} / \mathrm{H}^{+}$exchange.

Basolateral $\mathrm{K}^{+}$channels are responsible for generating the basolateral membrane potential that determines the magnitude and direction of $\mathrm{K}^{+}$diffusion from cell to peritubular fluid. $\mathrm{K}^{+}$ channels also mediate $\mathrm{K}^{+}$recycling coupled to $\mathrm{K}^{+}$entry into cells by the $\mathrm{Na}^{+}-\mathrm{K}^{+}$-ATPase . Recycling of $\mathrm{K}^{+}$across the basolateral membrane is modest under physiological conditions because of the similar magnitude of the $\mathrm{K}^{+}$equilibrium potential and membrane potential. Accordingly, most of $\mathrm{K}^{+}$entering principal cells exits through the apical membrane. However, stimulation of $\mathrm{Na}^{+}-\mathrm{K}^{+}$-ATPase by mineralocorticoids can hyperpolarize the basolateral membrane and result in a reversal of the electrochemical potential for $\mathrm{K}^{+}$. As a consequence, $\mathrm{K}^{+}$now enters the cell across the basolateral membrane in parallel with active $\mathrm{K}^{+}$transport by $\mathrm{Na}^{+}-\mathrm{K}^{+}$-ATPase (436).

I) $\mathrm{K}^{+}$channels in the apical membrane of mammalian CCD: Low-conductance ( $\left.35 \mathrm{pS}\right)$, maxi$\mathrm{K}^{+}(140 \mathrm{pS})$, and voltage-gated (10-16 pS) channels have been identified in the apical membrane of the CCD (Fig. 7; Refs. $\left.{ }^{152},{ }^{153},{ }^{209}, 220,324,478,483,525,598\right)$. The lowconductance and voltage-gated channels are restricted to principal cells $(153,598)$. However, 
the maxi- $\mathrm{K}^{+}$channel has been observed in both principal and intercalated cells, although it is mostly expressed in intercalated cells $(152,219,220,418)$.

The 35-pS K${ }^{+}$channel mediates the bulk of $\mathrm{K}^{+}$secretion in the $\mathrm{CCD}$ under normal conditions when distal flow is not high $(152,153)$. The $35-\mathrm{pS} \mathrm{K}^{+}$channel is encoded by Kir1.1 (ROMK; Refs. 168,213,342,652). This was demonstrated by the absence of this $35-\mathrm{pS} \mathrm{K} \mathrm{K}^{+}$channel in principal cells in the ROMK knockout mouse (342). The structure, function, and regulation of the ROMK channel are discussed in section III. With high luminal flow rates, the maxi- $\mathrm{K}^{+}$ channel may contribute significantly to net $\mathrm{K}^{+}$secretion $(546,620)$. Moreover, maxi- $\mathrm{K}^{+}$ channels do not contribute significantly to the apical $\mathrm{K}^{+}$conductance under normal physiological conditions because its open probability is very low (152). The maxi- $\mathrm{K}^{+}$channel is encoded by rbsoll, a mslo homolog (388). It is of interest that maxi- $\mathrm{K}^{+}$channels in the perfused Ambystoma collecting duct appear to mediate $\mathrm{K}^{+}$secretion during exposure to high concentrations of $\mathrm{KCl}(526,527)$. Activity of the voltage-gated channels has been shown to be increased by membrane depolarization and may be encoded by Kv1.3, although the membrane localization of this channel is unclear. The voltage-gated $\mathrm{K}^{+}$channel may stabilize the membrane potential whenever high rates of luminal $\mathrm{Na}^{+}$tend to depolarize this membrane (106).

II) Regulation of apical $\mathrm{K}^{+}$channels: Figure 7 illustrates the known mechanisms by which the apical 35-pS, maxi- $\mathrm{K}^{+}$, and voltage-gated $\mathrm{K}^{+}$channels are regulated in the CCD.

A) The maxi- $\mathrm{K}^{+}$channel: The $\mathrm{Ca}^{2+}$-activated maxi- $\mathrm{K}^{+}$channel is sensitive to TEA, ATP, and acidic $\mathrm{pH}(152,207,209,219)$. The sensitivity to ATP and $\mathrm{pH}$ depends on the cell $\mathrm{Ca}^{2+}$; in the presence of $1 \mathrm{mM} \mathrm{Ca}^{2+}$, neither ATP nor acidic $\mathrm{pH}$ can inhibit the channel activity, whereas $1 \mathrm{mM}$ ATP and acidic $\mathrm{pH}$ decrease the $\mathrm{K}^{+}$channel activity in the presence of $1 \mu \mathrm{M} \mathrm{Ca}^{2+}$ (207). The maxi- $\mathrm{K}^{+}$channels are also activated by hypotonic cell swelling (209). In addition, increases in flow rate stimulate $\mathrm{K}^{+}$secretion $(131,359,360)$, which is associated with an increase in intracellular $\mathrm{Ca}^{2+}(621)$. It has been suggested that maxi- $\mathrm{K}^{+}$channels mediate this $\mathrm{Ca}^{2+}$-associated, flow-dependent $\mathrm{K}^{+}$secretion. This is based on the observation that TEA (152) or charybdotoxin (546) inhibits $\mathrm{K}^{+}$secretion with high luminal flow rates. TEA does not alter $\mathrm{K}^{+}$secretion during low flow rates. Moreover, deletion of the gene encoding the $\beta_{1^{-}}$ accessory subunit of maxi- $\mathrm{K}^{+}$channels impairs $\mathrm{K}^{+}$excretion following acute volume expansion, an effect consistent with a role for these channels in $\mathrm{K}^{+}$excretion during high rates of distal tubule flow rate (440). The mechanism, by which a high flow rate increases intracellular $\mathrm{Ca}^{2+}$ and presumably maxi- $\mathrm{K}^{+}$channel activity, is not completely understood but may be related to an increase in cell $\mathrm{Ca}^{2+}$ (546). One hypothesis for coupling flow to increases in intracellular $\mathrm{Ca}^{2+}$ in principal cells involves flow-dependent deformations of the central cilium $(443,620)$. Deformation of the cilium increases intracellular $\mathrm{Ca}^{2+}$ through opening of mechanically sensitive channels that probably reside in the cilium or its base. This influx of $\mathrm{Ca}^{2+}$ is followed by $\mathrm{Ca}^{2+}$ release from inositol 1,4,5-trisphosphate $\left(\mathrm{IP}_{3}\right)$-sensitive stores. Therefore, increase in intracellular $\mathrm{Ca}^{2+}$ would activate maxi- $\mathrm{K}^{+}$channels and increase in $\mathrm{K}^{+}$secretion. Intercalated cells in the CCD lack a central cilium; however, increases in flow rate still raise intracellular $\mathrm{Ca}^{2+}$ in these cells. Therefore, a mechanism other than cilium deformation is likely to be involved in mediating the effect of increasing flow rate on intracellular $\mathrm{Ca}^{2+}$ in intercalated cells.

B) The 35-pS K${ }^{+}$channel: The activity of the $35-\mathrm{pS} \mathrm{K}^{+}$channel is regulated by a large number of factors including nucleotides, phosphatidylinositol phosphates, cytosolic $\mathrm{pH}$, kinases, phosphatases, and arachidonic acid. These factors regulate both channel gating and density in the membrane (see Fig. 7). The activity state of the channel is complexly determined not only by these individual factors but also by the interplay of multiple factors that influence each other. 
The 35-pS K+ channel is regulated by both cytosolic and extracellular ATP. The channel is inhibited by millimolar concentrations of cytosolic $\operatorname{Mg}$-ATP $(592,598)$, and channel sensitivity to ATP could play a role in linking its activity to $\mathrm{Na}^{+}-\mathrm{K}^{+}$-ATPase $(221,563)$. External ATP has also been shown to inhibit the $35-\mathrm{pS} \mathrm{K} \mathrm{K}^{+}$channel via purinergic receptor-mediated effects (340). P2 type purinergic receptors are present on both apical and basolateral membranes of principal cells (304). Stimulating P2Y2 purinergic receptors increases cytosolic $\mathrm{Ca}^{2+}(340)$ which, in turn, enhances cGMP generation by activating $\mathrm{Ca}^{2+}{ }_{-}$-regulated NOS (338). Increasing cGMP activates protein phosphatases and facilitates the dephosphorylation of $\mathrm{K}^{+}$channels. Because the phosphorylation state of the channel in principal cells is an important determinant of its activity $(350,630)$, enhancing dephosphorylation would be expected to lower channel activity.

The 35-pS K+ channel in principal, as in TAL, cells is sensitive to changes in cell $\mathrm{pH}$ in the physiological range. Decreasing $\mathrm{pH}$ from 7.4 to 7.2 reduces channel activity by $50 \%$ (482, 598). $\mathrm{K}^{+}$secretion is inhibited during acidosis and likely contributes to the effect of acidosis on $\mathrm{K}^{+}$excretion (164).

Arachidonic acid inhibits the 35-pS K ${ }^{+}$channel in the CCD (591). The effect of arachidonic acid is specific because other fatty acids such as lenoleic or palmic acid cannot mimic its effect. Moreover, the effect of arachidonic acid is not mediated by its metabolites since inhibiting cyclooxygenase, lipoxygenase, and cytochrome $P-450$ monooxygenase does not block the effect of arachidonic acid.

$\mathrm{Ca}^{2+}$-dependent signal transduction pathway kinases, such as PKC and calmodulin-dependent kinase II (CaMKII), inhibit the $35-\mathrm{pS} \mathrm{K}{ }^{+}$channel (290). Increasing intracellular $\mathrm{Ca}^{2+}$ reduces the activity of the $35-\mathrm{pS} \mathrm{K}{ }^{+}$channel, and this effect is blocked by inhibiting PKC or CaMKII and mimicked by adding the catalytic subunits of PKC and CaMKII (602).

PKA and Mg-ATP play important roles in regulating the activity of the $35-\mathrm{pS} \mathrm{K} \mathrm{K}^{+}$channel. Modulation of kinases by application of cAMP or inhibition of phosphatases stimulates the channel phosphorylation and increases the number of the functional 35-pS K ${ }^{+}$channel in the cell membrane $(77,287)$. PIP $_{2}$ increases the activity of the $35-\mathrm{pS} \mathrm{K}^{+}$channel in the rat CCD (339) as well as ROMK expressed in Xenopus laevis oocytes (217). The stimulatory effect of PKA and Mg-ATP on channel activity involves both a potentiation of the $\mathrm{PIP}_{2}$ effect (294, 339) and modulation of cytosolic $\mathrm{pH}$ sensitivity (305).

Dietary $\mathrm{K}^{+}$intake is also an important regulator of the $35-\mathrm{pS} \mathrm{K}^{+}$channel. Low $\mathrm{K}^{+}$intake decreases, whereas a high $\mathrm{K}^{+}$intake increases, the number of $\mathrm{K}^{+}$channels in principal cells $(421,423)$. Several lines of evidence indicate that protein tyrosine kinase (PTK) mediates the effect of low $\mathrm{K}^{+}$intake on the 35-pS K ${ }^{+}$channel (595, 610, 611; see Figs. 8-10). First, the kidney expression of c-Src and c-yes, members of Src family of tyrosine kinases, increases significantly in rats on a $\mathrm{K}^{+}$-deficient diet. Second, inhibiting PTK increases the number of the $35-\mathrm{pS} \mathrm{K}{ }^{+}$channels to the same extent as that observed in CCD segments harvested from rats on a high- $\mathrm{K}^{+}$diet. Third, in rats on a high- $\mathrm{K}^{+}$diet, inhibiting protein tyrosine phosphatase (PTP) decreases channel activity in principal cells from the CCD. The effect of PTK does not result from direct inhibition of channel activity since adding exogenous c-Src does not affect channel activity in excised membrane patches. Moreover, the effect of inhibiting PTP on the $35-\mathrm{pS} \mathrm{K} \mathrm{K}^{+}$channel is completely blocked by $20 \%$ sucrose, which blocks endocytosis of membrane proteins. Studies performed in oocytes expressing ROMK1 and c-Src further support the thesis that stimulation of PTK-induced phosphorylation enhances channel endocytosis, whereas suppressing PTK-induced phosphorylation facilitates the exocytosis of the 35-pS K ${ }^{+}$channel (see Figs. 9 and 10; Refs. 610,611). 
III) $\mathrm{K}^{+}$channels in the basolateral membrane of mammalian principal cells in the CCD: Basolateral $\mathrm{K}^{+}$channels in principal cells participate in generating the cell membrane potential and are involved in recycling of $\mathrm{K}^{+}$entering via $\mathrm{Na}^{+}-\mathrm{K}^{+}$-ATPase across the basolateral cell membrane (Figs. 2 and 7; Ref. 164). Patch-clamp studies using the cell-attached configuration have identified three types of $\mathrm{K}^{+}$channels in the basolateral membrane: small- (28 pS), intermediate- (63 pS), and large-conductance (145 pS) channels (Fig. 7 and Table 2; Refs. $208,209,605)$. In cell-detached, inside-out patches with symmetrical KCl solutions, the channel conductances of these channels are $18 \mathrm{pS}$ (small), $28 \mathrm{pS}$ (intermediate) and $85 \mathrm{pS}$ (large), respectively.

IV) Regulation of basolateral $\mathrm{K}^{+}$channels in the $\mathrm{CCD}$ : The factors regulating the three types of basolateral $\mathrm{K}^{+}$channels are shown in Figure 7. All channels are stimulated by protein kinase $\mathrm{G}$ (PKG) and inhibited by acidic $\mathrm{pH}(208,344,601)$. The $28-\mathrm{pS} \mathrm{K}{ }^{+}$and $85-\mathrm{pS} \mathrm{K}^{+}$channels are also activated directly by $\mathrm{NO}(210) . \mathrm{Ca}^{2+}$ has been shown to inhibit the basolateral $\mathrm{K}^{+}$channels (345). The mechanism by which $\mathrm{Ca}^{2+}$ inhibits the small-conductance $\mathrm{K}^{+}(18 \mathrm{pS})$ channel depends on the formation of peroxynitrite, a product of interaction between superoxide $\left(\mathrm{O}_{2}^{-}\right)$ and NO (345). The basolateral $\mathrm{K}^{+}$channels play an important role in $\mathrm{K}^{+}$recycling, which is coupled to the $\mathrm{Na}^{+}-\mathrm{K}^{+}$-ATPase activity. Stimulation of apical $\mathrm{Na}^{+}$transport increases the activity of the $\mathrm{Na}^{+}-\mathrm{K}^{+}$-ATPase and augments the basolateral $\mathrm{K}^{+}$channel conductance (338). However, it is unlikely that ATP could be a mediator for coupling the basolateral $\mathrm{K}^{+}$ conductance to $\mathrm{Na}^{+}-\mathrm{K}^{+}$-ATPase because basolateral $\mathrm{K}^{+}$channels are not inhibited by ATP. It has been suggested that the NO-dependent cGMP pathway is responsible for linking the activity of $\mathrm{Na}^{+}-\mathrm{K}^{+}$-ATPase to the basolateral $\mathrm{K}^{+}$conductance (270). Stimulation of $\mathrm{Na}^{+}$transport has been shown to increase the intracellular $\mathrm{Ca}^{2+}$, which stimulates NO and cGMP production in principal cells. An increase in cGMP concentration stimulates PKG, which activates basolateral $\mathrm{K}^{+}$channels.

\section{2. $\mathrm{K}^{+}$channels in cultured renal epithelial cells}

A) PROXIMAL TUBULE CELL CULTURE: Several investigators have reported the presence of an inward-rectifying $\mathrm{K}^{+}$channel with inward conductance of $90 \mathrm{pS}$ in OK proximal tubule cells $(288,409)$. The channel is inhibited by ATP and acidic $\mathrm{pH}(288,409,568)$ and stimulated by PKG (289). Natriuretic peptides (atrial natriuretic peptide, brain natriuretic peptide, and urodilatin) regulate this $\mathrm{K}^{+}$channel in immortalized human proximal tubule cells by cGMP-dependent and independent pathways (211).

B) DISTAL TUBULE CELL CULTURE: $\mathrm{A} \mathrm{Ca}^{2+}$-activated 95- to $127-\mathrm{pS} \mathrm{K}^{+}$channel and a 18-pS $\mathrm{K}^{+}$channel have been identified in the apical membrane of TAL cells cultured from rabbit $(94,188,381)$. Several $\mathrm{K}^{+}$channels have also been detected in the apical membrane of Madin-Darby canine kidney (MDCK) cells: a small- (31 pS), two intermediate- (89 pS, 109 $\mathrm{pS}$ ) and a large-conductance $(220 \mathrm{pS}) \mathrm{K}^{+}$channel (299). $\mathrm{A} \mathrm{Ca}^{2+}$-activated 53- to 60-pS K channel in the basolateral membrane of MDCK cells is thought to be involved in cell migration (494-496).

Two types of apical $\mathrm{K}^{+}$channels, a $\mathrm{Ca}^{2+}$-activated maxi- $\mathrm{K}^{+}$channel and an ATP-sensitive 35pS K $\mathrm{K}^{+}$channel, are expressed in CCD cells cultured from rabbit $(324,475,534)$. The $\mathrm{Ca}^{2+}$ activated maxi- $\mathrm{K}^{+}$channel is activated by both arachidonic acid and $\mathrm{PGE}_{2}(325)$, and these effects may be mediated by stimulating $\mathrm{Ca}^{2+}$ release. The maxi- $\mathrm{K}^{+}$channel is also inhibited by ATP and GTP $(475,534)$. Cyclosporin A, an immunosuppressive agent, has been demonstrated to inhibit the $35-\mathrm{pS} \mathrm{K}{ }^{+}$channel (323). This finding may have clinical relevance since the drug has been reported to decrease kaliuresis $(4,255)$. In cultured A6 kidney cells, cAMP has been shown to activate a 13-pS K ${ }^{+}$channel (192). 


\section{B. Nonepithelial $\mathrm{K}^{+}$Channels}

1. Mesangial $\mathrm{K}^{+}$channels-Mesangial cells are smooth muscle-like pericytes and form a biomechanical unit involved in regulating glomerular filtration rate. Mesangial cell excitability is modulated by a variety of vasoactive hormones such as angiotensin II, which increases intracellular $\mathrm{Ca}^{2+}$ (522). $\mathrm{K}^{+}$channels are responsible not only for the resting cell membrane potential but are also involved in regulating excitability of mesangial cells (see Ref. ${ }^{522}$ for a review). A Ca ${ }^{2+}$-activated and scorpion toxin-sensitive large-conductance $\mathrm{K}^{+}$channel (205 pS) and an ATP-sensitive $\mathrm{K}^{+}$channel have been identified in glomerular mesangial cells $(366,474,476,522)$. Inhibition of ATP-sensitive $\mathrm{K}^{+}$channels with sulfonylurea agents leads to contraction of mesangial cells (476), whereas an inhibitor (iberiotoxin) of $\mathrm{Ca}^{2+}$-activated maxi$\mathrm{K}^{+}$channels was not effective. These results suggest that ATP-sensitive $\mathrm{K}^{+}$channels are active under resting conditions (476). However, the $\mathrm{Ca}^{2+}$-activated maxi- $\mathrm{K}^{+}$channel may regulate mesangial cell contraction by another mechanism. Angiotensin II induces contraction of mesangial cells by raising intracellular $\mathrm{Ca}^{2+}$. Repolarization of the cell membrane by $\mathrm{Ca}^{2+}-$ activated maxi- $\mathrm{K}^{+}$channels would inactivate $\mathrm{Ca}^{2+}$ channels and reduce $\mathrm{Ca}^{2+}$ influx (522). This effect of maxi- $\mathrm{K}^{+}$channels would act as a brake on the contracting effect of angiotensin II. The maxi- $\mathrm{K}^{+}$channel is stimulated by cGMP-dependent protein kinase and inhibited by protein phosphatase 2A-induced dephosphorylation $(474,522)$.

In addition to the $\mathrm{Ca}^{2+}$-activated and $\mathrm{ATP}$-sensitive $\mathrm{K}^{+}$channels, an intermediate-conductance (40-pS) $\mathrm{K}^{+}$channel has also been found in cultured rat mesangial cells (365). This channel is also activated by $\mathrm{Ca}^{2+}$, vasopressin, and angiotensin II. In cultured human mesangial cells, a 9-pS K ${ }^{+}$channel has also been observed in inside-out patches (476). Functional roles of these channels remain unclear.

2. $\mathrm{K}^{+}$channels in juxtaglomerular apparatus-Macula densa cells are a component of the juxtaglomerular apparatus (JGA) that plays a key role in glomerulotubular feedback (41, 484). Macula densa cells located at the junction between the TAL and the DCT can sense changes in luminal fluid $\mathrm{Na}^{+}$and $\mathrm{Cl}^{-}$concentrations, and its basolateral membranes are in close contact with the glomerulus. The properties of the macula densa are very similar to those of the cortical TAL including luminal $\mathrm{Na}^{+}-\mathrm{K}^{+}-2 \mathrm{Cl}^{-}$cotransporters (301). Similar to the TAL, apical $\mathrm{K}^{+}$channels play an important role in $\mathrm{K}^{+}$recycling (301). Patch-clamp studies have demonstrated that the biophysical properties of the apical $\mathrm{K}^{+}$channel in the macula densa are similar to those in the TAL (226). The channel conductance is $41 \mathrm{pS}$, and the channel is inhibited by acidic $\mathrm{pH}$ and high concentrations of $\mathrm{Ca}^{2+}$. In contrast to the $35-\mathrm{pS}$ channel in apical membranes of the TAL, the 41-pS channel in macular dense cells is not blocked by NaATP. The physiological role of the apical $\mathrm{K}^{+}$channels in mediating tubuloglomerular feedback is demonstrated by experiments in which inhibition of the $\mathrm{K}^{+}$channel with $\mathrm{U} 37883 \mathrm{~A}$, an inhibitor of the ATP-sensitive $\mathrm{K}^{+}$channel (587), attenuated tubuloglomerular feedback (570). It is likely that the 41-pS channel in macula densa cells is encoded by ROMK, since mice lacking the ROMK gene exhibit severely impaired glomerulotubular feedback (333).

3. Vascular $\mathrm{K}^{+}$channels $-\mathrm{K}^{+}$channels in smooth muscle cells of renal arteriole determine not only the cell membrane potential but also are involved in mediating the effects of vasoactive substances such as eicosanoids and adenosine on myogenic tone of blood vessels $(160,252$, $444,531,660)$. Several types of $\mathrm{K}^{+}$channels including ATP-sensitive $\mathrm{K}^{+}$, voltage-gated $\mathrm{K}^{+}$, and delayed-rectifier $\mathrm{K}^{+}$channels have been identified in the renal vascular smooth muscles by molecular biological methods $(362,445)$. Only a $\mathrm{Ca}^{2+}$-dependent $\mathrm{K}^{+}$channel and a 4aminopyridine (4-AP)-sensitive delayed rectifier $\mathrm{K}^{+}$channel has been directly identified by electrophysiological techniques. Evidence in support of ATP-sensitive $\mathrm{K}^{+}$channels is indirect and based on the use of pharmacological blockers. In contrast, the role of $\mathrm{Ca}^{2+}$-dependent $\mathrm{K}^{+}$channels in regulating the vasoactivity has been well established. Three types of $\mathrm{Ca}^{2+}$ 
dependent $\mathrm{K}^{+}$channels, with channel conductance of 68,105 , and 195-251 pS, have been identified in the renal vascular smooth muscle $(252,531,645,660)$. TEA blocks all three types

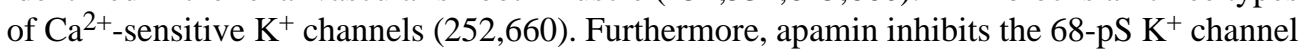
but had no effect on the 252-pS K+ channel (160). 20-HETE inhibits the 105- and 251-pS $\mathrm{K}^{+}$channels $(252,660)$, whereas 11,12 -epoxyeicosatrienoic acid (EET) specifically activates the $251-\mathrm{pS} \mathrm{K}^{+}$channel (665). The regulation of $\mathrm{K}^{+}$channels by eicosanoids may have an important role in modulating renal blood flow. It has been reported that 11,12-EET dilates the small renal vessels, whereas 20 -HETE induces vasoconstriction $(660,665)$. NO also stimulates the $251-\mathrm{pS} \mathrm{K}^{+}$channel, and this effect results from suppressing cytochrome $P$-450 metabolism of arachidonic acid (531). In addition, $\mathrm{CO}$ activates the 105-pS $\mathrm{K}^{+}$channel and causes vasodilation. The action of $\mathrm{CO}$ does not depend on cGMP formation because cyclase inhibitors do not abrogate this response (252).

The delayed rectifier $\mathrm{K}^{+}$channels are open at physiological membrane potentials. Angiotensin II or caffeine inhibits these channels in canine renal artery (162). The effect of angiotensin II on channel activity may be mediated by the associated rise in intracellular $\mathrm{Ca}^{2+}$ because the delayed rectifier $\mathrm{K}^{+}$channel can be directly inhibited by increasing $\mathrm{Ca}^{2+}$ in excised patches.

\section{Major Physiological Role of $\mathrm{K}^{+}$Channels in Renal Epithelial Function}

1. $\mathrm{K}^{+}$secretion-Micropuncture and microperfusion experiments have shown that segments beyond the thick ascending limb are the main sites of $\mathrm{K}^{+}$secretion (see Fig. 1; Refs. ${ }^{130},{ }^{266}$, $358,360,439,519,520,576$ ). In superficial nephrons, the primary sites for $\mathrm{K}^{+}$secretion are the DCT, connecting tubule, and initial collecting duct. In juxtamedullary nephrons, the connecting tubule directly drains into the $\mathrm{CCD}$, and both of these segments contribute to the $\mathrm{K}^{+}$secretory process. Many factors regulate $\mathrm{K}^{+}$secretion including dietary $\mathrm{K}^{+}$intake, distal flow rate, and $\mathrm{Na}^{+}$delivery $(177,266,576)$, mineralocorticoids (146), vasopressin (275), changes in acid base balance, and diuretics $(56,358) . \mathrm{K}^{+}$channels play an important role in mediating such functional modifications.

A) EFFECT OF K $\mathrm{K}^{+}$DIET: $\mathrm{K}^{+}$secretion in the initial cortical and outer medullary collecting ducts responds promptly to changes in dietary $\mathrm{K}^{+}$intake: an increase in $\mathrm{K}^{+}$intake stimulates whereas a decrease in $\mathrm{K}^{+}$intake reduces $\mathrm{K}^{+}$secretion $(322,359,360)$. The augmentation of $\mathrm{K}^{+}$secretion includes changes in apical $\mathrm{K}^{+}$channel activity in distal nephron segments. Augmentation in dietary $\mathrm{K}^{+}$intake increases aldosterone secretion from the zona glomerulosa of the adrenal gland. However, both aldosterone-dependent and -independent pathways contribute to stimulation of $\mathrm{K}^{+}$secretion by a high- $\mathrm{K}^{+}$diet.

At least three factors contribute to the kaliuresis following an increase in $\mathrm{K}^{+}$intake. Both aldosterone-dependent and -independent mechanisms are involved stimulating $\mathrm{K}^{+}$secretion $(595,611)$. First, high plasma $\mathrm{K}^{+}$reduces proximal tubule fluid and $\mathrm{Na}^{+}$reabsorption, and the subsequent increase in distal fluid and salt delivery promotes $\mathrm{K}^{+}$secretion $(61,164)$. Second, the early phase of altered $\mathrm{K}^{+}$secretion occurs at a time when distal $\mathrm{K}^{+}$channel activity is unaltered (421) and appears to be due to mineralocorticoid-mediated stimulation of both basolateral $\mathrm{Na}^{+}-\mathrm{K}^{+}$-ATPase and apical $\mathrm{Na}^{+}$channels which would promote $\mathrm{K}^{+}$secretion. This leads to increased $\mathrm{K}^{+}$secretion by augmenting the driving force for $\mathrm{K}^{+}$exit across the apical membrane and may, additionally, stimulate apical $\mathrm{K}^{+}$channel activity by a "cross-talk" mechanism that depends on increased basolateral $\mathrm{Na}^{+}-\mathrm{K}^{+}$-ATPase (see Fig. 8; Refs. 391, 602). Such a mechanism has also been identified in the proximal tubule $(34,36,563)$. Third, a sustained increase in the $\mathrm{K}^{+}$content of the diet leads to an augmentation of apical $\mathrm{K}^{+}$ conductance in principal cells $(420,421,598)$ due to an increase in the number of apical smallconductance, $35-\mathrm{pS} \mathrm{K}{ }^{+}$channels. While the maxi- $\mathrm{K}^{+}$channel could be activated by the high distal flow that may occur with $\mathrm{K}^{+}$adaptation, direct evidence for this channel playing a 
significant role in $\mathrm{K}^{+}$secretion has not yet been obtained in this condition. The high $\mathrm{K}^{+}$intakeinduced increase in small-conductance channel number is neither related to enhanced transcription of channel protein (154) nor to direct stimulation by aldosterone (421).

High dietary $\mathrm{K}^{+}$intake can increase plasma $\mathrm{K}^{+}$, and this, in turn, can increase aldosterone. Several attempts have been made to separate the independent effects of aldosterone and high plasma K+ $(392,393)$. When the level of circulating aldosterone is clamped in adrenalectomized rats, $\mathrm{K}^{+}$secretion along the perfused initial collecting tubule rises sharply in response to high $\mathrm{K}^{+}$intake $(97,393)$. Simultaneously, both apical $\mathrm{K}^{+}$and $\mathrm{Na}^{+}$conductances rise in principal cells (393). This indicates that an increase in plasma $\mathrm{K}^{+}$per se stimulates $\mathrm{K}^{+}$secretion. Patchclamp studies confirm these conclusions by showing enhanced $35-\mathrm{pS} \mathrm{K}^{+}$channel activity in excised non-perfused CCD.

Changes in dietary $\mathrm{K}^{+}$intake can modulate PTK activity in the CCD. PTK activity is increased in low- $\mathrm{K}^{+}$and reduced in high- $\mathrm{K}^{+}$conditions. A series of approaches, including patch-clamp experiments, confocal microscopy, and biochemical studies $(321,385,595,611)$, demonstrated that stimulation of PTK enhances endocytosis of ROMK1 in the CCD. In contrast, inhibition of PTK has the opposite effect and leads to increased channel activity associated with insertion of ROMK1 channels into oocyte cell membranes (385). Moreover, it has also been shown that tyrosine phosphorylation of 35-pS channels is markedly enhanced in the renal cortex and outer medulla harvested from rats on a $\mathrm{K}^{+}$-deficient diet (321). Figures 9 and 10 illustrate the mechanism by which a low dietary $\mathrm{K}^{+}$intake decreases the apical $\mathrm{K}^{+}$conductance and $\mathrm{K}^{+}$ secretion. Reduced dietary $\mathrm{K}^{+}$intake increases the PTK levels and the tyrosine phosphorylation of ROMK channels, which further initiates endocytosis of ROMK.

$\mathrm{K}^{+}$channels have been shown to modulate the effect of $\mathrm{H}^{+}-\mathrm{K}^{+}$-ATPase on $\mathrm{K}^{+}$absorption in the OMCD and IMCD (see Fig. 2; Ref. 619). The net function of $\mathrm{H}^{+}-\mathrm{K}^{+}$-ATPase is to secrete protons and reabsorb $\mathrm{K}^{+}$. In $\mathrm{K}^{+}$-repleted rabbits, $\mathrm{Ba}^{2+}$-sensitive $\mathrm{K}^{+}$recycling across the apical membrane is required to maintain the function of $\mathrm{H}^{+}-\mathrm{K}^{+}$-ATPase in the OMCD and IMCD. This minimizes the effect of $\mathrm{H}^{+}$secretion by $\mathrm{H}^{+}-\mathrm{K}^{+}$-ATPase on net $\mathrm{K}^{+}$reabsorption in $\mathrm{K}^{+}$repleted animals. In contrast, proton secretion is not altered by luminal $\mathrm{Ba}^{2+}$ in $\mathrm{K}^{+}$-depleted animals. The elimination of apical $\mathrm{K}^{+}$recycling permits net $\mathrm{K}^{+}$reabsorption in this condition. Although the molecular nature of the apical $\mathrm{K}^{+}$recycling channel is not known, ROMK1 is expressed in OMCD and IMCD and is a potential candidate for this function. In $\mathrm{K}^{+}$depletion, $\mathrm{K}^{+}$reabsorption is inhibited by basolateral $\mathrm{Ba}^{2+}$, suggesting that $\mathrm{K}^{+}$entering across the apical membrane by $\mathrm{H}^{+}-\mathrm{K}^{+}$-ATPase may leave the cell across the basolateral membrane by $\mathrm{K}^{+}$ channels. The molecular identity of this basolateral $\mathrm{K}^{+}$exit mechanism is not known.

B) EFFECT OF ACID AND BASE BALANCE: Acidosis reduces and alkalosis increases renal $\mathrm{K}^{+}$excretion and secretion in the initial collecting duct and CCD under conditions of constant flow $(56,358,358,519,557)$. Acid-base disturbances can alter intracellular $\mathrm{pH}$ which in turns affects the activity of the $35-\mathrm{pS} \mathrm{K}^{+}$channel in the $\mathrm{CCD}(482,598)$. Its activity is reduced by $50 \%$ with a decrease in cell $\mathrm{pH}$ from 7.4 to 7.2 . A similar, albeit slightly more acidic, $\mathrm{EC}_{50}$ has been observed with ROMK, the channel protein forming the $35-\mathrm{pS} \mathrm{K}^{+}$channel (84, 140,371,627).

C) HUMORAL REGULATION: Basolateral vasopressin stimulates $\mathrm{K}^{+}$secretion in the distal tubule and CCD $(129,145,480)$ via $\mathrm{V}_{2}$-receptor mediated increases in cAMP (77). Moreover, luminal vasopressin has also been shown to stimulate $\mathrm{K}^{+}$secretion; however, this effect appears to be mediated by $\mathrm{V}_{1}$ receptors (12). Although changes in $\mathrm{K}^{+}$balance do not evoke alterations in vasopressin release, this hormone, nevertheless, is thought to play a role in $\mathrm{K}^{+}$homeostasis by affecting $\mathrm{K}^{+}$channel activity and $\mathrm{K}^{+}$secretion in principal cells (129, 145,480 ). Thus alterations in $\mathrm{K}^{+}$secretion that might occur with changes in sodium and fluid 
delivery into the distal tubule and CCD may be minimized by alterations in vasopressin. (518). For example, expansion of the extracellular fluid inhibits proximal tubule fluid absorption, increases flow rate, and should enhance $\mathrm{K}^{+}$secretion in view of the well-established flow dependence of $\mathrm{K}^{+}$secretion (518). Similarly, a positive water balance is associated with excretion of hypotonic urine associated with enhanced fluid delivery into collecting ducts (518). Accordingly, changes in extracellular fluid and plasma osmolality could alter $\mathrm{K}^{+}$ excretion through coupling of $\mathrm{K}^{+}$secretion to distal flow rate and sodium delivery. However, expansion of the extracellular volume also lowers vasopressin release in experimental animals (but not humans and other primates; Ref. 173), which would decrease $\mathrm{K}^{+}$channel activity. Accordingly, changes in $\mathrm{K}^{+}$excretion would be minimized in experimental animals. In contrast, $\mathrm{K}^{+}$excretion is maintained by an increase in vasopressin levels when either a decline in extracellular fluid volume or dehydration lowers distal flow rate. Taken together, vasopressin thus appears to play a role, not as a primary regulator of excretion, but as a hormone that tends to stabilize $\mathrm{K}^{+}$secretion during changes in $\mathrm{Na}^{+}$and water balance.

Aldosterone increases $\mathrm{K}^{+}$secretion in the distal tubule and $\operatorname{CCD}(473,479,518)$. This action is unlikely to involve a direct effect on apical $\mathrm{K}^{+}$channels. On the one hand, it has been reported that administration of miner-alocorticoids significantly increase the apical $\mathrm{K}^{+}$conductance in rabbit CCD $(412,473)$. On the other hand, such an effect was not observed in the rat CCD $(421,480)$, and it was suggested that the mechanism of stimulation of $\mathrm{K}^{+}$secretion in this species was mediated by a primary increase of apical $\mathrm{Na}^{+}$conductance and increased driving force resulting from depolarization of the apical membrane potential (480). It should also be noted that acute infusions of aldosterone do not increase apical ROMK-like $35-\mathrm{pS} \mathrm{K}{ }^{+}$channel activity in principal cells (421), but the increase in $\mathrm{K}^{+}$channel density observed during prolonged administration of a high- $\mathrm{K}^{+}$diet is blunted by adrenalectomy (421). It is possible that the permissive effects on apical $\mathrm{K}^{+}$channels by mineralocorticoids are secondary to stimulation of $\mathrm{Na}^{+}-\mathrm{K}^{+}$-ATPase activity.

D) PATTERN OF MATURATION: Although the CCD plays a key role in $\mathrm{K}^{+}$secretion in the adult mammalian kidney, $\mathrm{K}^{+}$secretion is absent during the first $2 \mathrm{wk}$ of postnatal rabbit kidney (477). Thus the CCD has a limited capability for $\mathrm{K}^{+}$secretion in the neonatal kidney. This hypothesis has been supported by the patch-clamp experiments in which ROMK-like 35$\mathrm{pS} \mathrm{K}^{+}$channels can be detected only in the CCD isolated from 2-wk-old rabbits (478). With the use of ROMK-specific primers, RT-PCR of the CCD failed to detect mRNA encoding ROMK in 1-wk-old rabbits. In contrast, RT-PCR can detect ROMK in CCD segments dissected from 3-wk-old rabbits (43). A similar temporal pattern of ROMK protein expression has been reported with immunocytochemical staining (659). In addition, maxi- $\mathrm{K}^{+}$channels that may be involved in TEA-inhibitable $\mathrm{K}^{+}$secretion in the CCD during states of high tubular flow are also absent in the kidney of newborn rabbits (622). TEA-sensitive secretion by maxi- $\mathrm{K}^{+}$ channels is observed only after $5 \mathrm{wk}$ of postnatal rabbit kidney development (622). The absence of $\mathrm{K}^{+}$channels in the early postnatal period may be important to limit renal $\mathrm{K}^{+}$losses during this period of rapid body growth.

2. Volume regulation-Cell swelling is known to activate $\mathrm{K}^{+}$channels in a wide variety of cells (33). Mechanical distortion of cell membranes ("stretch activation") as well as exposure to hypotonic media are effective stimuli of both stretch-activated $\mathrm{K}^{+}$channels and of $\mathrm{Ca}^{2+}$ permeant channels that secondarily activate $\mathrm{K}^{+}$channels $(262,525,545,568)$. Stimulation of volume-sensitive $\mathrm{K}^{+}$channels expedites the loss of $\mathrm{K}^{+}$along a favorable electrochemical gradient and tends to restore cell volume (regulatory volume decrease, RVD). Such volume regulatory decrease involving activation of $\mathrm{K}^{+}$channels has been observed in both proximal $(260,466)$ and principal cells $(528)$. The mechanisms involve either direct effects of volume change or activation of $\mathrm{Ca}^{2+}$-permeant cation channels that secondarily stimulate $\mathrm{K}^{+}$channels 
(467). The physiological role of this RVD mechanism is incompletely understood but may be involved in cell volume regulation during enhanced entry of solute into renal epithelial cells.

\section{Pattern of Regulation of $\mathrm{K}^{+}$Channels}

1. Pattern of regulation of apical $\mathrm{K}^{+}$channels in principal cells-Three mechanisms mediate changes of apical $\mathrm{K}^{+}$channel activity in response to a wide variety of physiological stimuli. These are shown in Figure 8 and involve 1 ) alterations in the number of active channels (channel density), modulated by varying insertion into or removal from the membrane; 2) gating of channels in the membrane by factors related to metabolism, protein phosphorylation, lipids and second messengers, and voltage and tubule fluid conditions such as flow rate and $\mathrm{K}^{+}$concentration; and 3) responses to stimuli originating from changes in transport activity in the basolateral membrane ("cross-talk"). Changes in the cytosolic concentrations of ATP, $\mathrm{Ca}^{2+}$, and $\mathrm{pH}$ initiated by changes in basolateral $\mathrm{Na}^{+}-\mathrm{K}^{+}$-ATPase turnover have been proposed as possible mediators of basolateralapical cross-talk.

An example of the first mechanism is the modulation of apical channels by protein tyrosine phosphorylation in response to altered $\mathrm{K}^{+}$balance $(385,595,611)$, a process involving changes in endocytosis. Relevant to the second mechanism are a wide variety of stimuli, for example, changes in cytosolic ATP concentration or $\mathrm{PIP}_{2}$ in regulating the 35-pS channels, tubule flow, or cytosolic $\mathrm{Ca}^{2+}$ activating the maxi- $\mathrm{K}^{+}$channels, and membrane potential altering the voltage-dependent $\mathrm{K}^{+}$channels $(166,593)$. An example of "cross-talk" is the tight coupling between basolateral $\mathrm{Na}^{+}-\mathrm{K}^{+}$-ATPase activity and apical $\mathrm{K}^{+}$channels that has been observed in principal cells. Inhibition of $\mathrm{Na}^{+}-\mathrm{K}^{+}$-ATPase initiates a prompt reduction in apical $\mathrm{K}^{+}$ channel activity (602).

2. Pattern of regulation of basolateral $\mathbf{K}^{+}$channels-Figure 11 shows a cell model incorporating known factors modulating basolateral $\mathrm{K}^{+}$channels in principal cells. In view of the technical difficulty of carrying out patch-clamp studies on basolateral membranes of isolated CCD, information of the factors regulating channel activity is modest. These channels are gated by factors such as cytosolic $\mathrm{pH}$ and PKA, both also modulating apical $\mathrm{K}^{+}$channels (208, 209, 218, 605). In addition, membrane voltage and, importantly, PKG also alter channel activity $(600,601)$.

Interaction between $\mathrm{Na}^{+}-\mathrm{K}^{+}$-ATPase and basolateral $\mathrm{K}^{+}$channels $\left(\mathrm{K}^{+}\right.$recycling; Fig. 11) has also been postulated and may involve changes in the concentration of ATP. Evidence for a role of ATP in mediating pump-related changes in basolateral $\mathrm{K}^{+}$channels has been obtained in studies on proximal tubules $(34,36,563)$ but not yet demonstrated in principal cells. Changes in $\mathrm{NO}$ are also involved in coupling pump activity and basolateral $\mathrm{K}^{+}$channels (338). An example is the sequence of events following an increase in apical $\mathrm{Na}^{+}$entry which initiates a rise in cell $\mathrm{Na}^{+}$concentration and basolateral pump stimulation (338). Increased apical influx of $\mathrm{Na}^{+}$also augments cell $\mathrm{Ca}^{2+}$ levels by slowing basolateral $\mathrm{Na}^{+} / \mathrm{Ca}^{2+}$ exchange. This rise in cytosolic $\mathrm{Ca}^{2+}$, in turn, activates $\mathrm{Ca}^{2+}$-dependent $\mathrm{NOS}$ and the subsequent rise in NO stimulates basolateral $\mathrm{K}^{+}$channels (338).

\section{MOLECULAR PHYSIOLOGY OF ROMK CHANNELS}

\section{A. ROMK Channel Structure and Function}

1. ROMK channel structure-ROMK (Kir1.1; Refs. 53,213,398,652) is the pore-forming protein of the $35-\mathrm{pS} \mathrm{K}{ }^{+}$channel expressed in apical membranes of TAL and principal cells (333, 342; Figs. 3, 6, and 7; Table 1). Far more is known about the structure, localization, and function of this channel than any other $\mathrm{K}^{+}$channel in the kidney. Like all Kir channels, ROMK expressed in Xenopus laevis oocytes exhibits inward rectification, although weak, like that of 
the 35-pS channel in renal tubules. While inward rectification would not seemingly be ideal for $\mathrm{K}^{+}$secretion, the outward conductance of ROMK is significant and together with its high open probability (>0.9) would favor $\mathrm{K}^{+}$secretion.

Recent studies support a tetrameric model for Kir channels $(66,89,139,623,634)$. The X-ray structures of two inward rectifiers have recently been elucidated [GIRK1 or Kir3.1 (400) and the bacterial KirBac1.1 (296)]. The KirBac1.1 channel tetramer forms five regions (see Fig. 12:) 1) an outer selectivity filter, containing the Gly-Tyr-Gly triplet that is conserved in channels with high $\mathrm{K}^{+}$selectivity $(198,236)$, that discriminates between $\mathrm{K}^{+}$and other cations (657); 2) a pore cavity within the membrane; 3 ) a channel gate at the membrane-cytosol interface; 4) flexible linkers connecting the gate to the fifth region; and 5) carboxy-terminal $\beta$-strands forming a cytoplasmic vestibule or pore. The membrane helices form an "inverted teepee" originally identified in the bacterial KcsA channel (119) that come close together at the cytosolic interface to form a gate. The bending of helices at conserved glycine residues in the second membrane helix of each subunit allows the helices to move apart and open the gate $(244,296)$. The initial amino terminus is cytosolic with the distal amino terminus forming a "slide" helix in KirBac1.1 that interacts with the membrane (296; we called this "M0" in the original cloning paper, Ref. 213). This slide helix has been proposed to move laterally in order for M2 to kink and open the channel gate (296).

The carboxy terminus is completely cytosolic and forms the cytoplasmic pore. Acidic residues lining the cytoplasmic pore may interact with positively charged polyamines and divalent minerals (e.g., $\mathrm{Mg}^{2+}$ ), which provides the basis of inward rectification $(296,400)$. Both the amino and carboxy termini provide regulatory domains that can be phosphorylated by kinases $(320,385,630,644)$ and that interact with protons $(84,140,371)$, nucleotides $(114,374,572)$, and phosphatidylinositol phosphates $(201,217,315,326,331,351)$. While specific amino acid residues involved in assembly of ROMK subunits into tetramers have not been identified, multiple interactions in amino and carboxy termini, and in the transmembrane spanning segments (M1 and M2; Ref. 281) and with potassium ions in the selectivity filter (H5 region; Ref. 656) appear to be needed, and this would be consistent with the X-ray structure of the prokaryotic KirBac1.1 (296). In addition, the amino terminus of one KirBac1.1 subunit interacts with the distal carboxy terminus of the adjacent subunit forming another interface that could be involved in subunit assembly (296). Similar interactions between amino- and carboxyterminal segments have been observed in other Kir channels (250).

Although the X-ray structure of ROMK is unknown, the structure of this channel has been probed using other methodologies. Brazier et al. (62) have analyzed the secondary structure of a synthetic peptide containing the two membrane-spanning segments and the selectivity filter regions of ROMK1 using Fourier transform infrared (FTIR) and CD spectroscopy (62). Their analyses indicate that both membrane segments adopt an $\alpha$-helical structure in phospholipids, consistent with the original model for ROMK (213) and the X-ray crystal structures of the KirBac1.1 channel (296). Moreover, Minor et al. (383) have analyzed the packing structure of the two membrane helices using a yeast genetic screening technique. Their analysis suggests that the second membrane helix of each subunit lines the pore and is surrounded by the first membrane helix that also participates in subunit-subunit interactions in the tetrameric channel (see Figs. 12 and 13; Ref. 87). Consistent with this view, both the second membrane helix and the proximal carboxy terminus determine both homo- and heteromultimerization on other Kir channels $(79,348,536,555,633)$. Height fluctuations of ROMK protein have also been observed using the atomic force microscope and the molecular sandwich technique when the channel is exposed to gating agents (e.g., pH and PKA phosphorylation; Ref. 407). Because these molecular fluctuations occurred under conditions that activate ROMK channel, ROMK tetramers appear to change shape with channel gating. Finally, while ROMK permits rapid permeation of $\mathrm{K}^{+}$, net $\mathrm{H}_{2} \mathrm{O}$ movement through the pore is negligible (465). Although water 
may move through the selectivity filter at a rate equal to that of $\mathrm{K}^{+}$, the net volume flux would be small. This is consistent with the high expression of ROMK in $\mathrm{K}^{+}$secretion and low water permeability epithelia in the loop of Henle, distal tubule, and collecting duct.

2. ROMK channel isoforms-The ROMK gene contains several exons producing alternatively spliced transcripts (Fig. 14) and named ROMK1 ( $\left.\mathrm{K}_{\mathrm{IR}} 1.1\right)$, ROMK2 (K $\left.\mathrm{K}_{\mathrm{IR}} 1.1 \mathrm{~b}\right)$, and ROMK3 $\left(\mathrm{K}_{\mathrm{IR}} 1.1 \mathrm{c}\right)$ and ROMK6 (Kir1.1d) $(53,213,276,652)$. ROMK proteins differ at the beginning of the amino terminus with ROMK2 having the shortest amino terminus (rat ROMK6 has the same amino acid sequence as ROMK2; Fig. 14; Ref. 276). ROMK2 and ROMK3 have either 19- or 26-amino acid extensions at the beginning of the amino terminus, respectively (see Fig. 14; mouse ROMK1 has a 20-residue extension). Relative ROMK mRNA abundance assessed by competitive PCR indicates that ROMK2 and ROMK3 are much more abundant than ROMK1 or ROMK6 in rat kidney (37). Moreover, novel ROMK proteins, about one-third the size of native ROMK, may be formed by alternative splicing of the ROMK core exon (38); however, their significance remains unclear. The human ROMK gene, KCNJ1, located on chromosome $11 \mathrm{q} 24$ produces six splice variants $(51,506,637)$ that encode only three distinct polypeptides, two of which are similar to rat ROMK1 and ROMK2 (51). A rat homolog of the third human ROMK isoform has not been identified.

3. ROMK channel localization-ROMK transcripts are widely expressed in the cortex and outer medulla (Fig. 15A). The differential expression of ROMK1-3 transcripts along the nephron from the TAL to the OMCD is shown in Figure $16(53,303)$. The TAL and DCT express ROMK2 and ROMK3 transcripts while principal cells in the CCD express ROMK1 and ROMK2 transcripts (see Fig. 16). The OMCD cells express only ROMK1 transcripts. While the single-channel conductances and open probabilities of ROMK1, -2, and -3 isoforms are similar, the amino-terminal extensions (Fig. 14) add distinct regulatory characteristics to ROMK channels $(352,353)$. Whether tetrameric ROMK channels are composed of different subunits (e.g., heterotetramers of ROMK2 and ROMK1 in the cortical collecting duct; Figs. 12 and 13) or exist only as homotetramers is not known (unfortunately, isoform-specific antibodies are not available). Finally, ROMK transcripts are present in some other tissues (213), including the brain and the early gravid uterus (349). Roles for ROMK in these tissues have not been determined.

Antibody generated to sequences of ROMK shared by all isoforms has demonstrated an apical pattern of channel protein expression, consistent with the ROMK channel providing a $\mathrm{K}^{+}$ secretory pathway in renal epithelia. Specific apical staining has been observed in rat TAL (including macula densa cells), DCT and early connecting tubule cells, and principal cells of the CCD and OMCD (see example in Fig. 15B of staining in the rat TAL; Refs. 273,379, 629).

4. Characteristics of the ROMK channel-The general properties of ROMK channels expressed in Xenopus oocytes include 1 ) weak inward rectification $(80,213,651,652) ; 2)$ activation by PKA-dependent phosphorylation processes $(350,373,630) ; 3)$ inhibition by high concentrations of Mg-ATP $(374,462) ; 4)$ regulation of channel trafficking by protein tyrosine kinase and phosphatase $(321,385)$, as well as by PKC (320); 5) inhibition by slight reductions in cytosolic $\mathrm{pH}(112,140,305,371,463,486,487,561)$; and 6$)$ inhibition by arachidonic acid and PKC $(352,353)$.

A) CHANNEL KINETICS: The single-channel permeation, gating, and regulatory properties of ROMK expressed in oocytes are similar to those of the native 35-pS K ${ }^{+}$channels in TAL cells $(49,589,599)$ and principal cells in the CCD $\left(153,161,167,384,{ }^{483}, 592,593,597,603\right)$. For example, the ionic dependence of gating kinetics is similar in the native $35-\mathrm{pS} \mathrm{K}^{+}$channel in the rat CCD and ROMK2 channels expressed in X. laevis oocytes $(80,422)$. Moreover, ROMK, 
like the native $35-\mathrm{pS} \mathrm{K}{ }^{+}$channel in principal cells $(152,153,161,597,598)$, lacks sensitivity to external $\mathrm{TEA}^{+}(213)$.

All ROMK channel isoforms have high open probabilities $\left(P_{\mathrm{o}}\right)$ of $>0.9(80,83,213,350)$. There are two closed states, but one is very short ( 1 ms; $99 \%$ frequency) and the other, while longer ( $40 \mathrm{~ms}$ ), is very infrequent $(83,350)$. The latter is due to block by divalent cations as it can be abolished by EDTA (83). Choe et al. (83) have also suggested that the closed state of ROMK results from $\mathrm{K}^{+}$transiently blocking its own pathway.

B) CHANNEL RECTIFICATION: Inward rectification of Kir channels, including ROMK, is due to blocking of the cytosolic vestibule or pore of the channel (see Fig. 17A) by $\mathrm{Mg}^{2+}$ $(296,348,397,400)$ or cytosolic polyamines like spermine or spermidine $(144,330)$. Variations in the cytosolic concentrations of these cations provide a mechanism for regulating outward (i.e., $\mathrm{K}^{+}$secretory) current. Kinetic studies of inward rectification by $\mathrm{Mg}^{2+}$ and polyamines indicate that the effect is voltage dependent, depends on the concentration of $\mathrm{K}^{+}$on both sides of the membrane, and varies with the $\mathrm{K}^{+}$reversal potential $(83,397,410,515)$.

The M2 segment and carboxy terminus determine the inward rectifying characteristics of Kir channels $(348,536,616,633)$. Differences in second membrane helix and the loop between the first and second membrane helices account for the distinct channel kinetics of weak (ROMK2; Kir1.1) versus strong (IRK1; Kir2.1) inward rectifier channels (82). Two negatively charged residues are crucial for strong inward rectification (like in IRK1 or Kir2.1): aspartic acid (D172 in IRK1) in the second membrane helix (285) and glutamate (E224) in the carboxy terminus $(348,616)$. In ROMK, the aspartate is replaced by asparagine (N171) and the glutamate by glycine (G223) residues, accounting for the weak rectification (see Fig. 17A). Both exchange of the ROMK carboxy terminus with that on IRK1 and exchange of ROMK1 N171 for Asp produces strong rectification $(536,616)$. Residues lining the cytoplasmic pore are depicted in the structural model of ROMK shown in Figure $17 A\left(31,144,286,296,{ }^{348},{ }^{400}, 535,536,616\right.$, 633). In general, the density of negative charges in this cytoplasmic pore-lining region correlates with the affinity of polycationic blockers (e.g., spermine) and the "strength" of inward rectification.

C) INHIBITORS OF ROMK: Two different extracts of venoms have been shown to inhibit ROMK channels $(228,247)$. Both the snake toxin $\delta$-dendrotoxin $(228)$ and the honey bee venom extract teriapin (247) appear to block ROMK activity by binding to the external vestibule of the channel pore. The ability of the honey bee toxin to inhibit ROMK is sensitive to $\mathrm{pH}$ with alkaline $\mathrm{pH}$ values diminishing the dissociation constant for binding to ROMK1 (450).

Replacing histidine- 12 with alanine eliminates $\mathrm{pH}$ sensitivity of the bee toxin while preserving its affinity for ROMK (450).

\section{B. Regulation of the ROMK Channel Is Similar to the Distal Small-Conductance (35-pS) $\mathrm{K}^{+}$ Secretory Channel}

ROMK channel activity, like that of the native $35-\mathrm{pS} \mathrm{K}^{+}$channel in TAL and principal cells, is regulated by a variety of factors that either activate or inhibit the activity of channels in the membrane or modify membrane expression (Fig. 18). The molecular mechanisms for these alterations in channel function are rapidly being identified.

1. Protein kinases and phosphatases-ROMK channel activity and the number of active channels in the plasma membrane can be modulated by both serine-threonine (PKA and SGK) and tyrosine kinases and phosphatases. These processes involve, but are not limited to, direct phosphorylation of the channel protein at specific sites on either the amino or carboxy terminus. 
A) PKA: Maintenance of ROMK channel activity in excised inside-out patches of oocytes requires activation by PKA-dependent phosphorylation processes (373). Rundown or loss of ROMK channel activity occurs whenever phosphatase-mediated dephosphorylation activity is greater than PKA-mediated phosphorylation (373). Phosphopeptide analysis and mapping have identified three PKA phosphorylation sites on the ROMK channel protein (in ROMK1, Ser-44 on the amino terminus and Ser-219 and Ser-313 on the carboxy terminus; Figs. 14 and $17 B$; Ref. 630). Mutation of any single PKA phosphorylation site on ROMK2 reduces whole cell $\mathrm{K}^{+}$currents by $35-40 \%$ in oocytes; mutation of two or more of the three sites produces nonfunctional channels (630). None of the serine mutations alters the single-channel conductance. Each of the carboxy-terminal PKA phosphorylation site mutations, however, reduces $P_{\mathrm{o}}$ by $\sim 30-40 \%$ (350), which is sufficient to account for the observed reduction in whole oocyte currents (630). The mechanism by which phosphorylation modifies $P_{\mathrm{o}}$ is due, at least in part, to lowering the membrane concentration of $\mathrm{PIP}_{2}$ that is required to activate ROMK (326; see sect. IIIB2B) and a right shift in the $\mathrm{p} K_{\mathrm{a}}$ for cytosolic $\mathrm{pH}$ to more alkaline values (305). Alanine mutation of the amino-terminal Ser-44 does not change $P_{\mathrm{o}}$ but reduces the probability of finding functioning channels by $\sim 60 \%$. Thus phosphorylation of Ser- 44 by PKA is thought to increase the number of functional channels in the plasma membrane. This possibility is supported by observations using another serine-threonine kinase, serum and glucocorticoid regulated kinase (SGK), that phosphorylates Ser-44 leading to increased surface expression of ROMK channels (644). Taken together, these results show that S44 regulates surface expression of ROMK, while S219 and S313 modulate $P_{\mathrm{o}}$.

These studies of the influences of PKA phosphorylation on ROMK channels activity explain the activation of the $35-\mathrm{pS} \mathrm{K}{ }^{+}$channel in principal cells by $\mathrm{G}_{\mathrm{s}}$-coupled receptors or by the addition of cAMP, one of the fundamental characteristics of the native $\mathrm{K}^{+}$channel (593). In addition, activation of ROMK1 channels in X. laevis oocytes by cAMP requires a kinase anchoring protein, like AKAP79 (10). AKAPs are A-kinase-anchoring proteins that bind kinases and maintain the PKA enzyme at specific intracellular sites $(142,432)$, and thus an AKAP appears to be required to direct the PKA to the plasma membrane (432). Several novel AKAPs have recently been cloned from mouse (113), and one of these, AKAP-KL, is expressed in kidney tubules at apical borders.

B) SGK: Aldosterone stimulates SGK1 transcription and has been suggested to regulate the activity of the $\mathrm{Na}^{+}$channel, ENaC, and ROMK in collecting duct principal cells (see Ref. 298 for a review), although this view has been recently challenged (11). Nevertheless, in $X$. laevis oocytes SGK1 phosphorylates Ser-44 (the same site that is phosphorylated by PKA; see Fig. 14) on ROMK shifting the $\mathrm{p} K_{\mathrm{a}}$ for $\mathrm{pH}$ sensitivity of the channel to more acid values, thereby enhancing ROMK activity. The $\mathrm{Na}^{+} / \mathrm{H}^{+}$exchanger regulatory factor NHERF-2 (a.k.a, E3KARP) is a scaffolding protein that synergizes with SGK1 to further stimulate ROMK by enhancing trafficking to the oocyte plasma membrane (646). NHERF-1/2 have two PDZ domains that differ in protein binding specificities (586), allowing for interaction with multiple proteins, and thereby organization of multiprotein complexes at the plasma membrane.

NHERF-2 is expressed in principal cells, colocalizes with ROMK in apical borders of these cells $(580)$, and regulates the trafficking and targeting of proteins to plasma membranes (see Fig. 14; Ref. 503).

C) PKC: PKC phosphorylation processes inhibit the 35-pS $\mathrm{K}^{+}$channel in CCD cells (603). ROMK1, which is exclusively expressed in collecting ducts, has three potential PKC phosphorylation sites involving serine residues: one on the amino terminus (S4) and two on the carboxy-terminal end (S1863 and S201). ROMK2 and ROMK3 only have the two carboxyterminal PKC phosphorylation sites (see Fig. 14). PKC, like PKA, influences many proteins by direct phosphorylation. Indeed, ROMK1 has been shown to be a PKC phosphoprotein with the major phosphorylation sites being S4 and S201 (320). PKC phosphorylation is essential 
for trafficking of ROMK1 to the plasma membrane in oocytes and HEK293 cells (320). This could not account, however, for the reduction in channel activity observed in CCD cells. A mechanism for PKC-mediated reduction in activity was recently suggested (648). PKC decreases plasma membrane $\mathrm{PIP}_{2}$ content in $X$. laevis oocytes and could account for a lower channel activity. However, the PKC activator phorbol 12-myristate 13-acetate (PMA) only reduced ROMK1 whole cell current when the R219 PKA phosphorylation site was mutated (recall that this mutant has a higher requirement for membrane PIP $_{2}$; Ref. 326). Thus an effect of PKC to reduce ROMK1 channel activity in CCD cells would require that the plasma membrane content of $\mathrm{PIP}_{2}$ is lower in oocytes and/or that the channel is in a partially PKA phosphorylated state (648).

D) WNK: Pseudohypoaldosteronism type II (PHAII; Gordon's syndrome) is an autosomal dominant form of hypertension with hyperkalemia that is sensitive to $\mathrm{Cl}^{-}$intake and is ameliorated by thiazide diuretics (178). PHAII is caused by mutations in either of two serinethreonine kinases [WNK1 and WNK4 (577); with no lysine (K); (317)] and these kinases regulate the surface expression of the thiazide-sensitive $\mathrm{Na}^{+}-\mathrm{Cl}^{-}$cotransporter (NCC) mediating salt reabsorption in the DCT $(618,632)$. Wild-type WNK4 reduces the plasma membrane expression of NCC and thus diminishes salt transport by the DCT, while PHAII mutations of WNK4 relieve this inhibition. The modulation of NCC activity by WNK is dependent on the kinase activity of these proteins $(618,632)$. WNK kinases are also expressed in the collecting duct, and a recent study has shown that WNK4 regulates the plasma membrane expression of ROMK in $X$. laevis oocytes by enhancing clathrin-dependent endocytosis (251). In contrast to the mechanism of action of WNK kinases on NCC, the effect of WNK4 on ROMK expression is not dependent on kinase activity. The same WNK4 mutations that relieve NCC inhibition significantly increase inhibition of ROMK (251). Thus WNK kinases join a growing list of kinases that have been postulated (or shown) to regulate $\mathrm{K}^{+}$secretion in the CCD by modulating 35-pS $\mathrm{K}^{+}$channel density in the apical plasma membrane. Moreover, WNK kinases could provide a molecular switch that can vary the balance between salt reabsorption in the DCT and $\mathrm{K}^{+}$secretion in the CCD.

E) PTK-PTP: Dietary $\mathrm{K}^{+}$restriction reduces the number of functioning $35-\mathrm{pS} \mathrm{K}^{+}$channels in the apical membrane of principal cells, thereby limiting secretion of $\mathrm{K}^{+}$into the urine $(166$, 590). This regulatory process is mediated by increasing PTK/PTP-stimulated endocytosis of the $\mathrm{K}^{+}$channel $(85,595,610,611)$. Only the ROMK1 isoform, which is exclusively expressed in the collecting duct principal cells, is regulated by PTK/PTP (385). The reason for this isoform specificity is unknown but likely involves the unique ROMK1 amino terminus. Thus the 35$\mathrm{pS} \mathrm{K}{ }^{+}$channel formed by ROMK2 and ROMK3 in TAL cells is not regulated by this kinase (184). In the TAL, however, increases in PTK/PTP with dietary $\mathrm{K}^{+}$restriction regulate the 70$\mathrm{pS} \mathrm{K}{ }^{+}$channel. The mechanism of regulation of ROMK1 by PTK/PTP involves channel phosphorylation on Tyr-337 (see Fig. 14; ROMK1; Ref. 321) via a dynamin-dependent process (647) using clathrin-coated pits (647). The specificity of the PTK/PTP regulation to ROMK1 is even more intriguing since all ROMK isoforms contain the carboxy-terminal Tyr residue critical to this regulation.

\section{Lipids and products of lipid metabolism}

A) ARACHIDONIC ACID: Like the native 35-pS K ${ }^{+}$channel in the CCD (591), ROMK1 channels are sensitive to arachidonic acid (AA) $(352,353)$. The effect of AA is specific, since other fatty acids fail to mimic the effect (352). However, AA has little-to-no effect on the other two ROMK isoforms (353). Ser-4 in the unique ROMK1 amino terminus is critical to regulation by AA (Fig. 14; Ref. 353), and this action may involve AA stimulation of PKC and phosphorylation of this serine residue (320). 
B) PHOSPHATIDYLINOSITOL PHOSPHATES (PIP 2 ): A growing number of ion channel and transporters are being recognized to be regulated by $\operatorname{PIP}_{2}$ (202). Phospholipids, particularly $\mathrm{PIP}_{2}$, have been shown to modulate $\mathrm{K}_{\text {ATP }}$ channels including ROMK1 $(30,201$, 217). In general, $\mathrm{PIP}_{2}$ functions as a $\mathrm{K}^{+}$channel activator by increasing channel $P_{\mathrm{o}}$. ROMK, like many $\mathrm{K}_{\mathrm{IR}}$ channels $(271,458,459,509,650)$, contains a high density of positively charged (basic) amino acids in the carboxy terminus that interact with the negatively charged head groups of phosphatidylinositol phosphates. PIP $_{2}$-containing liposomes bind to a recombinant ROMK1 carboxy-terminal fusion protein (217,351), and Lys-181, Lys-186, Arg-188, Arg-217, Lys-218, and R311 have been implicated in the interaction of ROMK and $\operatorname{PIP}_{2}(217,331$, 649). Mutation of one of these $\mathrm{PIP}_{2}$-interacting sites, R188, in ROMK1 gives rise to a subconductance state with a lower $P_{\mathrm{O}}$ and an increased sensitivity to intracellular protons (315). The low $P_{\mathrm{o}}$ of the R188Q mutant channel can be increased by alkalinization, but this is not associated with a change in $\mathrm{PIP}_{2}$-channel interaction. Thus $\mathrm{PIP}_{2}$ and cytosolic $\mathrm{pH}$ modulate ROMK channel activity by independent but interacting mechanisms. The mechanism of $\mathrm{pH}-$ mediated inhibition of ROMK channel activity is discussed in the next section.

Since PIP 2 and phosphatidylinositol trisphosphate $\left(\mathrm{PIP}_{3}\right)$ are generated by ATP-dependent lipid kinases [e.g., phosphoinositde (PI) 3-kinase (13)], the stimulatory effect of low concentrations of cytosolic ATP are due, in part, to the generation of $\mathrm{PIP}_{2}$ (217). In addition, receptor-mediated hydrolysis of $\mathrm{PIP}_{2}$ by phospholipases (e.g., phospholipase $\mathrm{A}_{2}$ ) can dramatically alter membrane phospholipids content, and thereby modulate the activity of ROMK channels (271). The latter can be illustrated by the effects of the membrane PIP 2 content on modulation of ROMK activity by serine-threonine kinases, like PKA and PKC $(326,648)$. Thus changes in the membrane content of $\mathrm{PIP}_{2}$ contribute to the inhibition of ROMK activity by PKC and its activation by PKA. In addition, $\mathrm{PIP}_{2}$ dramatically modulates the ATP sensitivity of $\mathrm{K}_{\mathrm{ATP}}$ channels $(508,510)$, and this is due to competition of nucleotide binding by PIP $_{2}$ (351). This latter mechanism likely accounts for the abrogation of ATP-mediated inhibition of $35-\mathrm{pS} \mathrm{K}^{+}$channels in principal cells by phosphatidylinositol phosphates (339). Finally, modulation of $\mathrm{PIP}_{2}$ effects on ROMK has been implicated as a potential mechanism for reduction in channel activity associated with mutations of basic residues in type II Bartter's syndrome (331).

3. Cytosolic pH-Cytosolic, but not extracellular, protons gate ROMK (561). Acidification closes channels while alkalinization opens channels $(84,112,140,371,561)$. Similar responses to cytosolic protons are observed in the $35-\mathrm{pS} \mathrm{K}{ }^{+}$channel in TAL and CCD $(481,597)$. Mutation of Lys-80 on the amino terminus of ROMK1 (Lys-61 on ROMK2; see Figs. 14 and 17C) abolishes or severely reduces the $\mathrm{pH}$ sensitivity of $\operatorname{ROMK}(84,140,371)$. Other residues on the amino and carboxy termini of ROMK also modulate $\mathrm{pH}$ sensitivity: Thr-51 (84) and Arg-41 (486) in the amino terminus (ROMK2; Thr-70 in ROMK1); Arg-311 in the carboxy terminus (ROMK1; Ref. 486). It has been suggested that electrostatic interactions in the Arg-41-Lys-80Arg-311 triad of basic residues form the $\mathrm{pH}$ sensor and provides a basis for understanding some of the channel abnormalities in ROMK (type II) Bartter's syndrome $(463,485,486)$. pH-

dependent closure of ROMK channels is associated with conformational changes in both amino and carboxy termini involving formation of disulfide binds (Cys-49 and Cys-308) that require reducing agents for channel opening with reversal of $\mathrm{pH}$ (487). Cytosolic $\mathrm{pH}$ gating can also be observed when $\mathrm{CO}_{2}$ is increased (hypercapnia; Ref. 658). Modulation of either Lys-53 and one or more of several carboxy-terminal histidine residues (His-225, His-274, His-342, and His-354) alter the inhibitory effect of raising $\mathrm{CO}_{2}(78,627)$.

The sensitivity to cytosolic protons is allosterically linked to the concentration of external $\mathrm{K}^{+}(112,463)$. With low external $\mathrm{K}^{+}$concentrations $\leq 1 \mathrm{mM}$, outward ROMK currents slowly decrease and become undetectable but return to control values when $\mathrm{K}^{+}$(or other permeable cation) is increased $(112,488)$. This is due to an alkaline shift in $\mathrm{pH}$ sensitivity or $\mathrm{IC}_{50}(112$, 
469,470). This interaction between external permeant cations and cytosolic protons does not occur at a single site but depends on different domains. The ability of external permeant cations to gate ROMK depends on an intact $\mathrm{pH}$ sensor (e.g., is abolished by mutating Lys- 80 in ROMK1 or Lys 61 in ROMK2; Refs. 470,488). In addition, removal of $\mathrm{K}^{+}$from both sides of an excised patch does not inactivate ROMK when internal $\mathrm{pH}$ is held at $\mathrm{pH} 8$ (488). Mutation of external residues involving the pore helix can also disrupt the ability of ROMK to be gated by lowering external $\mathrm{K}^{+}$. However, these mutations do not abolish the gating by cytosolic $\mathrm{pH}$. Thus ROMK has been modeled as having two gates: an external gate sensing cations and an inner gate sensing protons. Mutations in either gate can disrupt communication between these two gates. The physiological role of this interaction between external $\mathrm{K}^{+}$and internal $\mathrm{H}^{+}$may be a positive feedback where a rise in luminal $\mathrm{K}^{+}$leads to an increase in $\mathrm{K}^{+}$channel activity at a time when the electrochemical driving force for $\mathrm{K}^{+}$secretion is reduced. In this way, $\mathrm{K}^{+}$ secretion is maintained.

Other factors can modulate cytosolic $\mathrm{pH}$ sensing. As discussed in the previous section, there is a link between phosphorylation of amino- and carboxy-terminal serine residues by PKA (and SGK for the amino-terminal Ser-44) and the $\mathrm{IC}_{50}$ for cytosolic protons $(305,419,492)$. In addition, $\mathrm{PIP}_{2}$ interaction with the channel can modulate $\mathrm{pH}$ sensing (315). The $K_{1 / 2}$ for nucleotide inhibition of ROMK channel activity is not fixed but can be modulated by altering cytosolic side $\mathrm{pH}$. Finally, decreasing the $\mathrm{pH}$ from 7.4 to 7.2 on the cytosolic face of excised patches from oocytes expressing ROMK2 reduced the $K_{1 / 2}$ for Mg-ATP inhibition from 2.5 to $<0.5 \mathrm{mM}$, almost a 10 -fold increase in affinity with this small acidification (371). This effect appears to be independent of the lysine residue implicated in $\mathrm{pH}$-dependent regulation of ROMK channel activity.

4. Nucleotide sensitivity and CFTR-Exposure of ROMK (as well as native 35-pS K+) channels to Mg-ATP activates both stimulatory and inhibitory processes with the net affect on channel function being the complex (and often difficult to sort out) integrated effect of these modulations. Micromolar concentrations of Mg-ATP support kinases that regulate ROMK activity by phosphorylation of the channel and associated molecules (e.g., phosphatidylinositol; see sect. IIIB2; Refs. 166,167,590). These phosphorylation processes either modulate channel gating or trafficking of the channel to or from the plasma membrane (see sect. III, B1-B3). With inside-out patches of ROMK expressed in X. laevis oocytes or of the native $35-\mathrm{pS} \mathrm{K}{ }^{+}$channel in TAL or CCD, addition of micromolar Mg-ATP usually activates the channel by PKA- and lipid kinase-dependent mechanisms $(339,373,592)$.

In contrast, exposure of the renal 35-pS K ${ }^{+}$channel to millimolar concentrations Mg-ATP reproducibly leads to inhibition $(592,603)$. This sensitivity to intracellular nucleotides indicates that ROMK belongs to a functional subgroup of Kir channels referred to as ATP-sensitive or $\mathrm{K}_{\mathrm{ATP}}$ channels $(18,384)$. $\mathrm{K}_{\mathrm{ATP}}$ channels formed by Kir6.x are found in both renal and a number of nonrenal cells including pancreatic $\beta$-cells, cardiac muscle, vascular smooth muscle, and certain neurons. The classic $\mathrm{K}_{\text {ATP }}$ channel $(5,24,68,121,229,500,558,564)$ is a heterooctamer formed by four pore-forming Kir6.x subunits and four regulatory SUR1 (sulfonylurea-binding protein) subunits, $(6,24,68)$. The $4: 4$ stoichiometry for functional $\mathrm{K}_{\mathrm{ATP}}$ channels in plasma membranes is fixed by subunit interactions necessary for shielding ER retention signals on both the Kir and SUR subunits $(89,231,332)$. Kir6.2 channels can be trafficked to the plasma membrane in the absence of SUR when the ER retention signal is removed (e.g., Kir6.2C $\Delta 36$ with truncation of 36 residues from the end of the carboxy terminus), and these channels can be inhibited by ATP (566). The responses of $\mathrm{K}_{\mathrm{ATP}}$ channels to nucleotides, and models derived from this kinetic behavior, suggest that ATP-mediated inhibition requires binding of the nucleotide to the pore-forming (Kir6.x) subunits (see Ref. 132 for a recent review). Nucleotide binding leads to longer closed states resulting in channel inhibition. The direct binding of ATP to Kir6. $\mathrm{x}$ is supported by cross-linking of azido-ATP compounds $(541,542)$ and by interaction 
with fluorescent ATP analogs (572). Nucleotides also interact with the SUR subunits via classical (Walker A and B) nucleotide-binding folds and mediate ADP-dependent increases in $\mathrm{K}_{\mathrm{ATP}}$ channel activity.

Interestingly, it has been more difficult to identify the mechanism for ATP inhibition of the $35-\mathrm{pS} \mathrm{K}{ }^{+}$channel. Despite the ability of the ROMK carboxy terminus to bind fluorescent analogs of ATP (572), only a few studies have found that ATP can inhibit ROMK expressed in $X$. laevis oocytes $(371,374,462)$. The $\mathrm{EC}_{50}$ for ATP-mediated inhibition of ROMK channel activity in $X$. laevis oocytes is reduced by cytosolic acidification (371). This could provide one mechanism for reducing channel activity during cellular acidosis resulting from disturbances in cellular metabolism or during systemic acidosis. As observed with other $\mathrm{K}_{\mathrm{ATP}}$ channels $(18,253,253)$, addition of ADP to ATP inhibited ROMK channels relieved the ATP block (374). These factors (i.e., $\mathrm{pH}$ and ADP) may allow the $\mathrm{K}^{+}$channel to be open at cytosolic ATP concentrations, although other mechanisms may contribute (e.g., channel phosphorylation and $\left.\mathrm{PIP}_{2}\right)$.

Several significant differences, however, exist in the nucleotide sensitivities between the renal $35-\mathrm{pS} \mathrm{K}^{+}$and the pancreatic $\beta$-cell $\mathrm{K}_{\mathrm{ATP}}$ channels $(384,593)$. First, inhibition of the renal $\mathrm{K}_{\mathrm{ATP}}$ channel requires hydrolyzable ATP (i.e., Mg-ATP; Ref. 592), while the $\beta$-cell channel can be inhibited by nonhydrolyzable nucleotides like Na-ATP (18). Second, near-millimolar ATP concentrations are required to inhibit the renal $\mathrm{K}_{\mathrm{ATP}}$ channel while low micromolar ATP can inhibit the $\beta$-cell channel. Third, despite the robust trafficking of ROMK to the $X$. laevis oocyte plasma membrane in the absence of a SUR (or other ABC protein), a direct inhibitory effect of Mg-ATP on channel activity has been difficult to reproduce. This contrasts with the ability of ATP to reproducibly inhibit Kir6.2C $\Delta 36$ in this same oocyte expression system.

\section{A) EVIDENCE THAT AN ABC PROTEIN FORMS A SUBUNIT OF THE 35-pS K ${ }^{ \pm}$} CHANNEL: Another characteristic of $\mathrm{K}_{\mathrm{ATP}}$ channels, including the renal $35-\mathrm{pS} \mathrm{K}^{+}$channel, is sensitivity to inhibition by sulfonylureas like glibenclamide (Glyburide; Refs. 18,19,384). Glibenclamide reduces $\mathrm{NaCl}$ absorption from the loop of Henle in in vivo microperfusion experiments (588), and in conscious rats induces natriuresis without attendant $\mathrm{K}^{+}$loss (88). While the effects of glibenclamide on vascular tone or other targets may contribute to the lack of urinary $\mathrm{K}^{+}$loss with sulfonylureas (267), patch-clamp experiments have confirmed that glibenclamide inhibits the $35-\mathrm{pS} \mathrm{K} \mathrm{K}^{+}$channel in the rat TAL $(588,589)$. The sensitivity of the native $\mathrm{K}^{+}$channel in TAL to sulfonylureas is, however, much less than in other $\mathrm{K}_{\mathrm{ATP}}$ channels (384).

In $\mathrm{K}_{\mathrm{ATP}}$ channels, the $\mathrm{ABC}$ protein subunit, SUR, and not the pore-forming Kir subunit, provides the receptor for sulfonylurea drugs (6). Thus the ability of glibenclamide to inhibit the renal $\mathrm{K}^{+}$secretory channel suggests that an SUR (or SUR-like) protein is associated with this channel and mediates the effect of glibenclamide. What is the nature of the SUR-like protein that interacts with ROMK? Both SUR2b $(115,544)$ and the CFTR $(370,462,544)$ have been proposed to be the ABC partner of ROMK in PC and TAL cells. SUR2B is a subunit of the cardiac $\mathrm{K}_{\mathrm{ATP}}$ channel (230), and CFTR is known to regulate the activities of other ion channels $(200,499)$, and $\mathrm{Cl}^{-}$currents mediated by CFTR can be inhibited by sulfonylureas like glibenclamide (491). Furthermore, CFTR mRNA and protein are expressed in the same apical regions as ROMK channels in the CTAL and CCD $(96,363,386,556)$, and a functional truncated hemi-CFTR is also expressed in the mTAL (386). CFTR transcripts are also expressed in distal nephron segments in fetal human kidney (109). Consistent with ROMK-ABC protein interactions, ROMK $\mathrm{K}^{+}$currents in oocytes are significantly inhibited by glibenclamide only when ROMK is coexpressed with CFTR $\left(72,370,372,462 ; \mathrm{EC}_{50} \sim 1-30 \mu \mathrm{M}\right)$ or SUR2B (544), although this view has been challenged (278). Moreover, this effect of CFTR on ROMK requires a low external $\mathrm{K}^{+}$concentration (generally $\leq 1 \mathrm{mM}$; Ref. 370 ), is abrogated by 
increasing PKA phosphorylation processes using forskolin (370), and requires a functional nucleotide binding domain, NBD1, on CFTR (372).

Fewer data are available concerning the physical and functional interactions of ROMK and SUR2B. Immunostaining with anti-SUR2B antibody in mouse kidney detected SUR2B in distal nephron segments that express ROMK (i.e., TAL and CCD), although the precise apical versus basolateral pattern could not be discerned (39). In rat kidney, SUR2B transcripts are expressed in cortical TAL and CCD, but not in the medullary TAL (544). With the use of an in vitro antibody-based "pull-down" approach, ROMK2, but not ROMK1 or ROMK3, directly interacts with SUR2B (544). An amino acid triplet "IRA" in the amino-terminal extensions of ROMK1 and ROMK3 prevented the direct interaction of ROMK1/3 with SUR2B and the resultant glibenclamide sensitivity (115). The $\mathrm{EC}_{50}(150-200 \mu \mathrm{M})$ for glibenclamide inhibition of ROMK2-SUR2b K ${ }^{+}$currents in oocytes (544) was much higher than that with CFTR $(372,544)$. While it is possible that ROMK2 could be interacting either with CFTR or SUR2B under certain circumstances, ROMK1 (specific for principal cells) and ROMK3 (specific for TAL cells) cannot interact with SUR2B $(115,544)$. Thus it is likely that CFTR is the major $\mathrm{ABC}$ protein subunit of ROMK in TAL and principal cells.

\section{B) FUNCTIONAL CONSEQUENCES OF ABC PROTEIN-ROMK INTERACTIONS:}

What roles could CFTR play in ROMK function? Based on the Kir6.x-SUR model of a $\mathrm{K}_{\mathrm{ATP}}$ channel $(17,69)$, interaction of ROMK with an ABC protein (CFTR and/or SUR2b) is likely to alter metabolic (ATP/ADP) sensing by ROMK. Increasing intracellular ATP inhibits the activity of ATP-sensitive $\mathrm{K}^{+}$channels $\left(\mathrm{K}_{\mathrm{ATP}}\right)$ by direct interaction with the pore-forming (Kir) subunits $(120,282,374,509,542,559,565,566)$, while activation of $\mathrm{K}_{\mathrm{ATP}}$ channels by ADP and modulation by sufonylureas (e.g., glibenclamide) or $\mathrm{K}^{+}$channel opening agents (e.g., minoxidil) requires the associated SUR or CFTR (17). Thus the ATP/ADP ratio is thought to be the important link between metabolism and $\mathrm{K}_{\mathrm{ATP}}$ channel activity. When ROMK is expressed alone in oocytes, high millimolar concentrations ( $>2 \mathrm{mM}$ ) of Mg-ATP are required to inhibit partially the $\mathrm{K}^{+}$current (374). Coexpression of ROMK1 with CFTR dramatically increases the sensitivity of ROMK1 K+ currents to Mg-ATP (462) with an $\mathrm{EC}_{50}$ of $\sim 0.6 \mathrm{mM}$, an affinity that is similar to that for $35-\mathrm{pS} \mathrm{K}^{+}$channel in principal cells (592). In fact, coexpression of CFTR with ROMK1 was required for significant inhibition of ROMK1 currents by Mg-ATP in oocytes. Because NHERF-1/2 can bind to CFTR (503) and ROMK (643) and can increase surface expression of ROMK (643), it seems likely that the 35-pS $\mathrm{K}_{\mathrm{ATP}}$ channel in TAL and principal cells is formed by ROMK-NHERF-2-CFTR interactions $(212,643)$. Consistent with this notion, NHERF-2 has two PDZ domains, the first domain interacting with ROMK (643) and the second domain binding to CFTR (532). The observation that CFTR and ROMK can interact in X. laevis oocytes in the absence of NHERF (643) and that ROMK coimmunoprecipitates with CFTR in the absence of NHERF (643) suggests that ROMK and CFTR may directly interact with NHERF, enhancing this interaction by bringing the proteins together. Moreover, the interaction between NHERF and CFTR is regulated by serine-threonine kinases (448). Thus the modulation of $\mathrm{K}^{+}$channel glibenclamide sensitivity (due to interacting with CFTR) by activating PKA observed in ROMK2-CFTR coexpressing oocytes may have been due to disruption of CFTR interaction with ROMK (in this case with a Xenopus NHERF-like scaffolding protein).

\section{C) CFTR, ROMK, AND THE EPITHELIAL SODIUM CHANNEL INTERACTIONS:}

The epithelial $\mathrm{Na}^{+}$channel $(\mathrm{ENaC})$ forms the $\mathrm{Na}^{+}$channel in apical membranes of principal cells where it mediates $\mathrm{Na}^{+}$absorption. Sodium entry through $\mathrm{ENaC}$ makes the CCD lumen electrically negative compared with the interstitium, providing a favorable electrical gradient for $\mathrm{K}^{+}$secretion through 35-pS K $\mathrm{K}^{+}$(i.e., ROMK) channels. Recombinant expression studies have suggested that CFTR also interacts with $\mathrm{ENaC}$ (291) and that cAMP-mediated activation of CFTR inhibits $\mathrm{ENaC}$ (295), although this issue is controversial (394). A similar observation 
has been made in mouse CCD cells in culture (314). The inhibition of ENaC activity by CFTR activation may be mediated by a rise in cell $\mathrm{Cl}^{-}(277,292,294)$, although the specific mechanism is unclear. CFTR has been suggested to be a regulatory link between ENaC and ROMK (279) such that ENaC upregulates the surface expression of ROMK in a CFTR-dependent manner (279).

\section{Regulation and Developmental Changes of ROMK Expression}

1. Regulation-It is well established that dietary $\mathrm{K}^{+}$modulates renal $\mathrm{K}^{+}$secretion and excretion by altering the functional expression of $35-\mathrm{pS} \mathrm{K} \mathrm{K}^{+}$channels in the apical membrane of principal cells $(359,420,424,590)$. ROMK mRNA expression is reduced in both cortex and medulla by $\mathrm{K}^{+}$deficiency, while $\mathrm{K}^{+}$loading increases ROMK transcript abundance slightly, but only in medulla (581). Moreover, neither ROMK transcript (154) nor protein (378) abundance in the $\mathrm{CCD}$ was altered by a high- $\mathrm{K}^{+}$diet. Thus the high- $\mathrm{K}^{+}$diet-induced increase in density of active $35-\mathrm{pS} \mathrm{K}{ }^{+}$channels in principal cells in the CCD is not due to increased ROMK mRNA. Rather, changes in ROMK channel abundance in apical membranes due to regulated clathrin-dependent endocytosis have been identified as the major mechanism modulating $\mathrm{K}^{+}$secretion in the collecting duct by dietary $\mathrm{K}^{+}(590)$.

Mineralocorticoids also regulate ROMK abundance. Adrenalectomy decreased ROMK mRNA abundance in cortex but increased transcript abundance in the medulla (581). In this latter study, $\mathrm{K}^{+}$deficiency in adrenalectomized rats reduced ROMK mRNA to control levels, suggesting that the hyperkalemia associated with adrenalectomy was the cause for the increased ROMK message in medulla. Aldosterone administration by minipump to adrenal intact rats also has been shown to increase ROMK2, -3 , and -6 isoforms transcripts in whole kidney (37). The latter is consistent with mineralocorticoid-mediated regulation of ROMK mRNA abundance in cortex.

In the mTAL, ROMK protein abundance is increased by dDAVP in Brattleboro rats and by increasing $\mathrm{NaCl}$ intake in Sprague-Dawley rats (125). In contrast, a low $\mathrm{NaCl}$ intake reduced ROMK abundance in TAL (125). Thus chronic adaptive changes in ROMK abundance occur in the TAL with maneuvers that alter salt transport in this nephron segment.

2. Developmental expression of ROMK-Patch-clamp analysis in the maturing rabbit $\mathrm{CCD}$ demonstrated that the $35-\mathrm{pS} \mathrm{K}{ }^{+}$increased only after the third week after birth (478). This increase in apical $\mathrm{K}^{+}$channel activity correlated with the ability of the CCD to secrete $\mathrm{K}^{+}$ (477) and with ROMK mRNA abundance (43). Similar developmental increases in ROMK mRNA have been shown in the rat TAL and CCD (659). The low abundance of $\mathrm{K}^{+}$secretory capacity during the first few postnatal weeks is consistent with the necessity for $\mathrm{K}^{+}$ conservation during this phase of cell proliferation associated with rapid body growth.

\section{Lessons From Bartter's Syndrome}

1. Bartter's syndrome: a TAL tubulopathy-The role of Kir1.1 (ROMK) in renal $\mathrm{K}^{+}$ and $\mathrm{NaCl}$ handling was confirmed by finding $K C N J 1$ mutations in antenatal Bartter's syndrome $(143,259,513,579)$. Bartter's syndrome (29) comprises a set of autosomal recessive renal tubulopathies characterized by hypokalemic metabolic alkalosis, renal salt wasting, hyperreninemia, and hyperaldosteronism $(21,187,258,438,457)$. Antenatal Bartter's syndrome is the most severe form of Bartter's syndrome and is genetically heterogeneous resulting from mutations in at least four additional genes expressed in the TAL (see Fig. 19; Ref. 194): $S L C 12 \mathrm{Al}$ encoding the apical $\mathrm{Na}^{+}-\mathrm{K}^{+}-2 \mathrm{Cl}^{-}$cotransporter $(512,574) ; C L C K B$ encoding the basolateral $\mathrm{Cl}^{-}$channel (511); BSND encoding the $\beta$-subunit of CLCKB $(47,136)$; and CaSR encoding the extracellular CaSR that regulates the apical intermediate conductance $\mathrm{K}^{+}$channel in TAL $(573,609)$. The effect of loss-of-function mutations in KCNJI (see Fig. 20) on salt 
handling by the TAL can be understood, since apical $\mathrm{K}^{+}$recycling is crucial both to supplying $\mathrm{K}^{+}$to the $\mathrm{Na}^{+}-\mathrm{K}^{+}-2 \mathrm{Cl}^{-}$cotransporter and to generation of the lumen-positive transepithelial voltage that drives $50 \%$ of the reabsorbed sodium paracellularly $(49,181$; Fig. 6). Transient neonatal hyperkalemia with salt wasting, hyponatremia, and hyporeninemic hyperaldosteronism, mimicking pseudohypoaldosteronism type 1 , has been seen in some individuals with ROMK Bartter's syndrome $(81,148)$. This transient hyperkalemic phenotype is consistent with the role of ROMK in forming the $35-\mathrm{pS} \mathrm{K}^{+}$channels in both TAL and principal cells. These Bartter mutations in KCNJI result in alterations in channel PKA phosphorylation, $\mathrm{pH}$ sensing, channel gating, proteolytic processing, or trafficking to the apical membrane $\left(102,103,149,150,{ }^{240}, 331,437,486,497,521\right)$.

2. The mouse ROMK knockout-Deletion of the $K C N J 1$ gene in mice results in a severe renal $\mathrm{NaCl}$ and $\mathrm{K}^{+}$wasting phenotype, confirming the importance of ROMK in salt handling by the TAL $(333,342)$. Patch-clamp studies have shown that the small-conductance $\mathrm{K}^{+}$channel is absent in both TAL and principal cells (342), establishing that ROMK encodes the 35-pS $\mathrm{K}^{+}$channel (Figs. 6 and 7).

That loss-of-function mutations in ROMK (Kir1.1; KCNJ1) cause Bartter's syndrome raises some questions regarding the mechanism of $\mathrm{K}^{+}$handling by TAL and principal cells. First, the intermediate-conductance, $70-\mathrm{pS}, \mathrm{K}^{+}$channel forms the dominant apical $\mathrm{K}^{+}$conductance in rats and mice, at least under some conditions $(343,589)$. Thus deletion of ROMK would be expected to have only a modest effect on the apical $\mathrm{K}^{+}$conductance of TAL cells unless ROMK is a subunit of the intermediate conductance $\mathrm{K}^{+}$channel or in some other manner regulates the functional expression of that channel. The absence of the 70-pS $\mathrm{K}^{+}$channel in TAL from ROMK-deficient mice has also established that ROMK is required for expression of the intermediate-conductance $\mathrm{K}^{+}$channel in this nephron segment (341). Second, ROMK forms the apical 35- $\mathrm{pS} \mathrm{K}^{+}$channel in principal cells that mediates $\mathrm{K}^{+}$secretion in the collecting duct. Yet, most Bartter individuals with $K C N J 1$ mutations are hypokalemic and have a high rate of urinary $\mathrm{K}^{+}$excretion. ROMK knockout mice also have a high rate of urinary $\mathrm{K}^{+}$excretion. Several factors may contribute to the $\mathrm{K}^{+}$loss seen in ROMK null mutant mice and in ROMK Bartter individuals. These include 1 ) diminished reabsorption of $\mathrm{K}^{+}$in the TAL due to reduction in $\mathrm{Na}^{+}-\mathrm{K}^{+}-2 \mathrm{Cl}$ - function $\left.(216) ; 2\right) \mathrm{K}^{+}$secretion due to flow-dependent, $\mathrm{Ca}^{2+}$-activated $\mathrm{K}^{+}$ channels in the $\mathrm{CCD}(546,620)$; 3) $\mathrm{K}^{+}$secretion by $\mathrm{KCl}$ cotransport in the $\mathrm{CCD}(575)$; and 4) augmented paracellular $\mathrm{K}^{+}$backleak into the $\mathrm{CCD}$. Elucidation of these mechanisms will likely provide important insights to potassium handling by distal nephron segments including the collecting duct.

\section{OTHER POTASSIUM CHANNELS IN KIDNEY}

\section{A. 6-TM Renal K+ Channels}

Most $\mathrm{Kv}$ channels only open when the cell membrane depolarizes beyond $-60 \mathrm{mV}$ and therefore might not be expected to function in renal epithelial cells that have resting membrane potentials between -40 and $-75 \mathrm{mV}$. However, proximal tubule and cortical and medullary collecting duct cells can have large enough depolarizations to activate $\mathrm{Kv}$ channels when transporting certain charged solutes.

1. Proximal tubule-Activitation of electrogenic transporters in the proximal tubule results in significant cell membrane depolarization $(45,73,155)$. For instance, $\mathrm{Na}^{+}$entry is facilitated by a favorable electrical chemical gradient, and the apical membrane depolarizes by 10-15 $\mathrm{mV}$ during sodium-coupled glucose and amino acid uptake. Sustaining such electrogenic transport requires mechanisms that maintain the membrane potential to preserve the favorable electrochemical gradient for sodium. Voltage-gated $(\mathrm{Kv}) \mathrm{K}^{+}$channels are well suited for this task since their activation by membrane depolarization would result in repolarization. Several 
$\mathrm{Kv}$ channels have been detected in the apical membrane of the proximal tubule by patch clamp and immunocytochemistry (see Table 1 ). For example, $\mathrm{Ca}^{2+}$-activated, maxi- $\mathrm{K}^{+}$type have been observed in cultured proximal tubule cells $(42,204,205,262,380,548)$ and in proximal tubule bush-border membranes (666). In addition, calcium-insensitive, voltage-gated $\mathrm{K}^{+}$ channels have also been detected. Moreover, two other types of voltage-gated $\mathrm{K}^{+}$channels (KCNQ1 and KCNA10; see Table 1) have been detected using Northern blotting, in situ hybridization, and immunocytochemistry.

The 6-TM protein KCNQ1 forms a heteromultimeric complex with a single transmembrane segment subunit (KCNE1 or minK; Fig. $4 E$ ) to form a small-conductance (2-10 pS) voltagegated $\mathrm{K}^{+}$channel. KCNQ1 and KCNE1 are abundantly expressed in the proximal tubule (see Fig. 3). The KCNQ1-KCNE1 channel plays a crucial role in cardiac repolarization, and mutations of these genes cause long QT syndrome $(27,471,585)$. In proximal tubule, the KCNQ1-KCNE1 channel may also prevent depolarization following stimulation of electrogenic $\mathrm{Na}^{+}$-coupled glucose or amino acid transport (Fig. 21; Ref. 569). KCNE1deficient mice exhibit a reduction in glucose and amino acid uptake by the proximal tubule $(569,608)$.

Other $\mathrm{Kv}$ channels, such as $\mathrm{Ca}^{2+}$-activated, maxi- $\mathrm{K}^{+}$, and $\mathrm{KCNA} 10$ (see below), may also participate in stabilizing proximal tubule membrane potential during electrogenic $\mathrm{Na}^{+}$uptake (Fig. 21; Ref. 607). The 6-TM voltage-gated $\mathrm{K}^{+}$channel KCNA10 (300) has 58\% amino acid identity with Kv1.3 but also contains a putative cyclic nucleotide $(\mathrm{CN})$ binding domain at the carboxy terminus, suggesting that channel function may be regulated by cyclic nucleotides. KCNA10 protein has been detected in the apical membrane of the proximal tubule (642). KCNA10 channels are closed at the holding potential of $-80 \mathrm{mV}$ but are progressively activated by depolarization more positive than $-60 \mathrm{mV}$, with half-activation at $-20 \mathrm{mV}$. The human KCNA10 channel is inhibited by the classical $\mathrm{K}^{+}$channel blockers $\left(\mathrm{Ba}^{2+}, \mathrm{TEA}^{+}\right.$, and 4-AP) as well as by inhibitors (verapamil and pimozide) of cyclic nucleotide-gated (CNG) cation channels. KCNA10 has five putative PKC phosphorylation consensus sites (300), and activation of PKC reduces whole cell current. Two PKC sites are located in the putative cyclic nucleotide-binding domain, suggesting that cyclic nucleotides might modulate the effect of PKC on channel current. A small soluble protein of 141 amino acids, KCNA4B, with limited structural similarity to the $\mathrm{NAD}(\mathrm{P}) \mathrm{H}$-dependent oxidoreductase superfamily is a $\beta$-subunit of KCNA10 (552). $\mathrm{K}^{+}$current increases nearly threefold when KCNA4B is coinjected with KCNA10 and becomes more sensitive to activation by cAMP.

2. Distal tubule-While several Kv, Shaker-related genes are detected in kidney (104), Kv1.2 and Kv1.3 appear to be preferentially localized in the distal tubule, although on which membrane is not known (106, 638; Fig. 3;Table 1). Kv1.3 channel activity is modulated by phosphorylation (PKA, PKC, tyrosine kinase). Insulin inhibits channel activity via tyrosine phosphorylation of multiple residues $(58,92,137,214)$. The scorpion toxins, margatoxin and kaliotoxin, specifically inhibit Kv1.3 (159). PKC increases (86) and tyrosine kinase (TK) inhibits Kv1.3 channel activity (137). In the distal tubule and collecting duct, Kv1.3 could help stabilize the apical membrane potential closer to the $\mathrm{K}^{+}$equilibrium potential during electrogenic $\mathrm{Na}^{+}$entry via ENaC channels. Interestingly, Kv1.3 is activated by SGK that has been suggested to mediate the action of aldosterone in the distal tubule by stimulating the $\mathrm{ENaC}$ (606). SGK appears to mediate its effect on Kv1.3 by altering the rate of inactivation and by increasing the half-life of Kv1.3 protein in the plasma membrane. These observations suggest that Kv1.3 may link aldosterone-stimulated $\mathrm{Na}^{+}$reabsorption and $\mathrm{K}^{+}$secretion (Fig. 22) and probably contributes to the stabilization of the membrane potential under conditions of increased apical sodium entry. Finally, there are also functional data suggesting expression of $\mathrm{Kv}$ channels in the renal medulla (578). In the inner medulla, extracellular $\mathrm{K}^{+}$can reach levels 
greater than $40 \mathrm{mM}$ as a result of $\mathrm{K}^{+}$recycling. Membrane depolarization by this high extracellular $\mathrm{K}^{+}$may be sufficient to activate these $\mathrm{Kv}$ channels.

Several recent findings support the notion that $\mathrm{Kv} 1.3$ channels participate in $\mathrm{Na}^{+}$reabsorption and $\mathrm{K}^{+}$transport in the IMCD (Fig. 3; Table 1). Kv1.3-like currents have been detected in primary cultures of ICMD cells using perforated patch and conventional whole cell methods (135). Immunofluorescence studies also show that $\mathrm{Kv} 1.3$ protein colocalizes with $\mathrm{Na}^{+}-\mathrm{K}^{+}-$ ATPase at the basolateral membrane of IMCD cells. Kv1.3 may function in the reabsorption of $\mathrm{K}^{+}$in this part of the nephron in low- $\mathrm{K}^{+}$states (638). In addition, Kv1.3 may help stabilize the membrane potential during electrogenic $\mathrm{Na}^{+}$reabsorption. The latter could be especially important for the IMCD, which can be exposed to high extracellular $\mathrm{K}^{+}$concentrations (both luminal and interstitial) that would depolarize the cell and reduce the driving force for $\mathrm{Na}^{+}$ reabsorption. Finally, Kv1.3 channels could also play an important role in cell volume regulation (108).

Maxi- $\mathrm{K}^{+}$channels are another type of 6-TM $\mathrm{K}^{+}$channel thought to play a significant role in renal solute transport. Large $\mathrm{Ca}^{2+}$-activated $\mathrm{K}^{+}$currents have been detected in the apical membranes of principal cells in the CCD and TAL cells. The maxi- $\mathrm{K}^{+}$channel in the TAL is encoded by rbsoll, a mslo homolog (388) where it is thought to play a role in cell volume regulation. Maxi- $\mathrm{K}^{+}$channels also are thought to mediate flow-dependent $\mathrm{K}^{+}$secretion both in the connecting tubule and CCD. Support for the role of maxi- $\mathrm{K}^{+}$channels in $\mathrm{K}^{+}$excretion during high rates of distal tubule flow rate is that deletion of the gene encoding the $\beta 1$ accessory subunit of maxi- $\mathrm{K}^{+}$channels impairs $\mathrm{K}^{+}$excretion following acute volume expansion (440). While ROMK primarily mediates baseline $\mathrm{K}^{+}$secretion, maxi- $\mathrm{K}^{+}$channels and possibly other $\mathrm{Kv}$ channels could contribute to flow-dependent $\mathrm{K}^{+}$secretion (Fig. 22).

\section{B. 2-TM Renal K+ Channel (Non-ROMK)}

1. Kir2.3 channel-In CCD principal cells, the maintenance of the negative membrane potential depends, at least in part, on the activity of an inwardly rectifying $18-\mathrm{pS} \mathrm{K} \mathrm{K}^{+}$channel (Fig. 7). This basolateral $\mathrm{K}^{+}$channel has been suggested to be the inwardly rectifying $\mathrm{K}^{+}$ channel, Kir2.3 (614; Table 1). The kidney Kir2.3 was cloned from a mouse CCD cell line and its expression in kidney confirmed by Northern analysis (614). When the MDCK cells were transfected with Kir2.3, the channel is expressed in the basolateral membrane (306) and a basolateral sorting signal was identified at the carboxy-terminal tail $(307,411)$. Kir 2.3 shares some biophysical properties with the native $18-\mathrm{pS} \mathrm{K}{ }^{+}$channel such as high $P_{\mathrm{o}}$ and channel conductance, $14.5 \mathrm{pS}(614)$.

2. Kir4.1/4.2 and Kir5.1 channels-Recent evidence suggests that heteromeric Kir4.0/ Kir5.1 channels form the basolateral small-conductance $\mathrm{K}^{+}$channel in distal nephron segments (337; Table 1; Figs. 3 and 7). The inward rectifier $\mathrm{K}^{+}$channel, Kir4.1, was originally identified from rat brain and exhibits 53\% amino acid identity to ROMK1 (a.k.a., BIR10, $\mathrm{K}_{\mathrm{AB}}-2$ and BIRK1; Table 1; Refs. 55,540). The kidney also expresses Kir4.1 mRNA, and the channel protein has been immunolocalized to the basolateral membrane of distal nephron segments (DCT, CNT and ICD; Ref. 234). Subsequently, Kir4.1 was cloned from human kidney (507). Kir4. $1 \mathrm{~K}^{+}$channels expressed in $X$. laevis oocytes exhibited $\mathrm{Ba}^{2+}{ }_{- \text {sensitive }} \mathrm{K}^{+}$currents that are inhibited by internal (referred to as Kir1.2; Refs. 485,507,625,626), but not external (156), protons. Internal protons decrease Kir4.1 $\mathrm{K}^{+}$current by reducing $P_{\mathrm{o}}$; however, internal protons also increase channel conductance (635). Mice with deletion of the Kir4.1 gene (KCNJ10; Table 1) have been generated (272), but a specific renal phenotype, to our knowledge, has not been identified.

Kir4.2 was originally cloned from human kidney and called Kir1.3 (507). While this study reported that Kir4.2 channels were not functional in X. laevis oocytes (507), subsequent studies 
have shown that this protein forms inward rectifying $\mathrm{K}^{+}$channels that are inhibited by PKC and internal protons $(337,433)$. Kir4.2 mRNA is found in human (507) and mouse (337) kidney, and in the latter species, specifically in the DCT.

The inward rectifier $\mathrm{K}^{+}$channel, Kir5.1, was also cloned from rat brain but does not form functional $\mathrm{K}^{+}$channels by itself when expressed in X. laevis oocytes (a.k.a, BIR9; Ref. 55). Kir5.1 mRNA is present in kidney $(55,543)$, and channel protein is abundantly expressed in PT and in DCT and CCD segments (567) where Kir4.1 is also expressed (234). Recent studies have demonstrated that Kir4.1 or Kir4.2 with Kir5.1 form heteromeric inward-rectifying $\mathrm{K}^{+}$ channels with distinct properties in both heterologous expression systems $(280,337,543)$ and native kidney (543). The heteromeric interaction of Kir5.1 with other Kir $\mathrm{K}^{+}$channels is specific for Kir4.x channels and requires a small region in the proximal carboxy terminus of Kir4.1 (280). A recent study showed that the basolateral small-conductance $\mathrm{K}^{+}$channel in distal nephron segments is most similar to heteromeric Kir4.1(Kir4.2)/Kir5.1 channels (337). The most dramatic and specific effect of the Kir4.x-Kir5.1 assembly on $\mathrm{K}^{+}$channel function is the shift in the $\mathrm{p} K_{\mathrm{a}}$ for inhibition by internal protons from 6.0 to the physiologically relevant $\mathrm{p} K_{\mathrm{a}}$ of $7.4(435,543,567,625)$. Internal $\mathrm{pH}$ sensitivity of Kir4.1-Kir5.1 is modulated by $\mathrm{PIP}_{2}$ (636), similarly to Kir1.1 (ROMK; Ref. 315).

3. Kir6.1 channel-Kir6.1 (previously known as $\mathrm{uK}_{\mathrm{ATP}}-1$ ) was originally cloned from a rat pancreatic islet cell cDNA library using Kir3.1 as a probe (232) and belongs to the Kir6.0 (ATP-sensitive; $\mathrm{K}_{\mathrm{ATP}}$ ) subfamily of inwardly rectifying $\mathrm{K}^{+}$channels (Table 1; Refs. 398, 500). Exogenous expression of Kir6.1 channels in X. laevis oocytes forms ATP-sensitive channels only when coexpressed with a sulfonylurea receptor protein (SUR; Refs. 69,500). Although this inward rectifier is predominantly found in brain, heart, and vascular tissue, expression in kidney has been documented $(133,232)$. Kir6.1 has been localized to both mitochondria (533) and plasma membranes $(65,533)$. Upregulation of Kir6.1 mRNA has been observed following ischemic injury in rat kidney consistent with the proposed role of $\mathrm{K}_{\text {ATP }}$ channel activation in protection from ischemic damage (e.g., in the heart; Ref. 9). Recently, Kir6.1 was cloned from rabbit proximal tubule cDNA library, and expression of Kir6.1, SUR2A, and SUR2B in rabbit proximal tubule was confirmed by PCR (65). Functional studies in X. laevis oocytes suggested that Kir6.1 may form the basolateral ATP- and taurine-sensitive $\mathrm{K}^{+}$channel involved in the basolateral $\mathrm{K}^{+}$conductance of proximal tubules (Fig. 3; Ref. 65). Adenylate kinase, which promotes phosphoryl transfer between ATP and ADP and associates with $\mathrm{K}_{\mathrm{ATP}}$ channels (74), has been cloned from the rabbit proximal tubule library (64) and may associate with Kir6.1 in these cells to promote metabolic sensing.

4. Kir7.1 channel-The inward rectifier $\mathrm{K}^{+}$channel Kir7.1 was originally cloned from human brain cDNA libraries after searching the GenBank expressed sequence tag (EST) database using Kir1.1 and Kir6.2 (Table 1; Refs. 283,427). The Kir7.1 K ${ }^{+}$channel displays unusual $\mathrm{K}^{+}$permeation properties with a low single-channel conductance of $50 \mathrm{fS}$, low sensitivity to blocking by external $\mathrm{Ba}^{2+}$ or $\mathrm{Cs}^{+}$, and very low dependence of conductance on external $\mathrm{K}^{+}(118,283,427)$. PCR and Western blot analyses have identified Kir7.1 transcripts and protein, respectively, in rat, guinea pig, and human kidney $(100,283,413,427)$. Expression of Kir7.1 along the rat nephron was demonstrated by Western blots of microdissected nephron segments (413) and showed $\mathrm{K}^{+}$channel protein in TAL, DCT, CNT, CCD, OMCD, and IMCD (Fig. 3; Ref. 413). Immunostaining localized Kir7.1 to basolateral membranes of DCT and principal cells (413). In the guinea pig, Kir7.1 protein is expressed in basolateral membranes of proximal tubule and TAL cells (100). In the CCD, Kir7.1 is expressed in principal cells, but not intercalated cells. The unique pore properties of Kir7.1 and its localization close to $\mathrm{Na}^{+}-$ $\mathrm{K}^{+}$-ATPase suggested that this $\mathrm{K}^{+}$channel may be functionally coupled to $\mathrm{Na}^{+}-\mathrm{K}^{+}$-ATPase and involved in $\mathrm{K}^{+}$recycling across basolateral membranes $(396,413)$. 


\section{2-Pore $\mathrm{K}^{+}$Channels $\left(\mathrm{K}_{2 \mathrm{P}}\right)$}

Mammalian $\mathrm{K}_{2 \mathrm{P}}$ channels constitute the largest $\mathrm{K}^{+}$channel family. This family was discovered in 1995 with the first member (TOK1) identified in the sequence database of the yeast Saccharomyces cereviaiae $(265,453,655)$. Fourteen mammalian genes have been identified $\left(\mathrm{K}_{2 \mathrm{P}} 1.1-7.1,9.1,10.1,12.1,13.1,15.1-17.1\right)$. Each subunit has four transmembrane segments, containing two pore-forming "P" loops, and functions as a dimer $(174,312$; Fig. $4 D)$. These channels are thought to be responsible for background $\mathrm{K}^{+}$leak currents that are expected to play important roles in setting membrane potentials. $\mathrm{K}_{2 \mathrm{P}}$ channels are modulated by mechanical stimuli, cell volume, cytoplasmic and extracellular $\mathrm{pH}$, temperature, lipids, and volatile anesthetics $(174,175,408,428)$.

Eight $\mathrm{K}_{2 \mathrm{P}}$ genes $\left(\mathrm{K}_{2 \mathrm{P}} 1.1,3.1-5.1,10.1,12.1,13.1\right.$, and 15.1; Table 1$)$ are expressed in kidney, but their localization and roles largely remain to be elucidated. $\mathrm{K}_{2 \mathrm{P}} 1.1$ and $\mathrm{K}_{2 \mathrm{P}} 5.1$ transcripts have been observed in the proximal tubule (415), and protein for $\mathrm{K}_{2 \mathrm{P}} 1.1$ was immunolocalized to the brush border (90). They may function to stabilize the membrane potential toward the $\mathrm{K}^{+}$equilibrium potential in the face of depolarizing currents associated with electrogenic $\mathrm{Na}^{+}$reabsorption. $\mathrm{K}_{2 \mathrm{P}} 5.1$ may function as a potassium exit mechanism during the RVD response following cell swelling associated with solute transport in the PCT $(28,399)$. Consistent with this view, PCT cells from mice with deletion of the KCNK5 gene (163) lack cell swelling-induced $\mathrm{K}^{+}$currents (399). If $\mathrm{K}_{2 \mathrm{P}} 5.1$ is also present in apical membranes, the sensitivity of this channel to slight reductions in external $\mathrm{pH}(28,399)$ suggests that it may primarily function in the early PCT where luminal $\mathrm{pH}$ has not yet been reduced by bicarbonate reabsorption and where solute transport (glucose, amino acids, etc.) is highest.

$\mathrm{K}_{2 \mathrm{P}} 1.1$ and $\mathrm{K}_{2 \mathrm{P}} 5.1$ transcripts and protein are also expressed in distal tubules and collecting duct where they may serve to stabilize the membrane potential during electrogenic $\mathrm{Na}^{+}$ absorption though $\mathrm{ENaC}$ channels. $\mathrm{K}_{2 \mathrm{P}} 1.1$ immunostaining in the distal tubule and collecting duct is not altered, however, following restriction of dietary $\mathrm{Na}^{+}$or $\mathrm{K}^{+}(90)$. The extracellular $\mathrm{pH}$ sensitivity of $\mathrm{K}_{2 \mathrm{P}} 5.1$ suggests that it would not be functional in the CNT or CCD when luminal $\mathrm{pH}$ is reduced by acid secretion from $\alpha$-intercalated cells (e.g., during metabolic acidosis). In the future, we expect that mice with deletion of specific $\mathrm{K}_{2 \mathrm{P}}$ channel genes will provide insights into their roles in kidney function.

Although the specific nephron localization of $\mathrm{K}_{2 \mathrm{P}} 3.1$ (TASK1) is not known, this channel, like $\mathrm{K}_{2 \mathrm{P}} 5.1$, is inhibited by reductions in extracellular $\mathrm{pH}$. Interestingly, $\mathrm{K}_{2 \mathrm{P}} 3.1$ channel activity is reversibly inhibited by reduced $\mathrm{O}_{2}$ levels, suggesting that it may be involved in oxygen sensing in the nephron $(249,429)$.

\section{1-TM (CHIF, Channel Inducing Factor)}

CHIF is a single membrane-spanning protein that was originally identified in a rat colonic cDNA library and is most similar to the $\gamma$-subunit of $\mathrm{Na}^{+}-\mathrm{K}^{+}$-ATPase (Table 1; Ref. 22). However, a minK (IsK)-like $\mathrm{K}^{+}$channel activity was found when CHIF was expressed in $X$. laevis oocytes (22). Subsequently, CHIF was shown to be expressed at basolateral membranes of the OMCD and IMCD $(141,505)$ where it functions as a regulator of $\mathrm{Na}^{+}-\mathrm{K}^{+}$-ATPase activity, similarly the pump $\gamma$-subunit (157). CHIF mRNA is suppressed by a low- $\mathrm{K}^{+}$diet, independently of aldosterone, while a high- $\mathrm{K}^{+}$diet increases CHIF transcripts in an aldosterone-dependent manner (582). In an ischemic reperfusion injury model in rats, both CHIF and ROMK were downregulated and, thereby, could contribute to the hyperkalemia of acute renal failure (170). 


\section{CONCLUSIONS AND FUTURE DIRECTIONS}

While many $\mathrm{K}^{+}$channel genes are expressed in the mammalian kidney, there remains limited data on their distribution along the nephron, their localization in specific cell types within these nephron segments, and in which membrane domain (apical or basolateral) they are expressed. In addition, the identification of which gene/protein is responsible for what current identified by patch clamping in specific renal tubule cells remains largely unknown with few exceptions (e.g., ROMK). Moreover, the functional and molecular interactions among $\mathrm{K}^{+}$channel genes and other proteins, lipids, and metabolites is still in its infancy. Finally, we are just beginning to elucidate the arrays of regulators (kinases, phosphatases, lipids, metabolites, etc.) that modulate the activities of $\mathrm{K}^{+}$channels to changing dietary intakes and other homeostatic demands. We anticipate that deletions of specific $\mathrm{K}^{+}$channel genes in mice when coupled to functional studies (metabolic, cell biological, and electrophysiological) will continue to define the specific roles of each of these $\mathrm{K}^{+}$channels in renal $\mathrm{K}^{+}$handling.

\section{Acknowledgments}

Work in the authors' laboratories was supported by National Institutes of Health Grants DK-54999 and DK-17433 (to S. C. Hebert); DK-47402, DK-54983, and HL-34300 (to W. Wang); DK-54998 and DK-17433-30 (to G. Giebisch); and DK-48105-08, DK-065172-01, and VA Merit Award (to G. Desir).

\section{References}

1. Abbott GW, Butler MH, Bendahhou S, Dalakas MC, Ptacek LJ, Goldstein SA. MiRP2 forms potassium channels in skeletal muscle with Kv3.4 and its associated with periodic paralysis. Cell 2001;104:217231. [PubMed: 11207363]

2. Abbott GW, Goldstein SA, Sesti F. Do all voltage-gated potassium channels use MiRPs? Circ Res 2001;88:981-983. [PubMed: 11375265]

3. Abbott GWS. MiRP1 forms potassium channels with HERG $I_{\mathrm{Kr}}$ and is associated with cardiac arrhythmia. Cell 1999;97:175-187. [PubMed: 10219239]

4. Adu D, Turney J, Michael J, McMaster P. Hyperkalaemia in cyclosporin-treated renal allograft recipients. Lancet 1983;2:370-372. [PubMed: 6135874]

5. Aguilar-Bryan L, Clement JP, Gonzalez G, Kunjilwar K, Babenko A, Bryan J. Toward understanding the assembly and structure of $\mathrm{K}_{\text {ATP }}$ channels. Physiol Rev 1998;78:227-245. [PubMed: 9457174]

6. Aguilar-Bryan L, Nichols CG, Wechsler SW, Clement JP IV, Boyd AE III, González G, Herrera-Sosa H, Nguy K, Bryan J, Nelson DA. Cloning of the $\beta$ cell high-affinity sulfonylurea receptor: a regulator of insulin secretion. Science 1995;268:423-426. [PubMed: 7716547]

7. Aiyar J, Nguyen AN, Chandy KG, Grissmer S. The P-region and S6 of Kv3.1 contribute to the formation of the ion conduction pathway. Biophys J 1994;67:2261-2264. [PubMed: 7696467]

8. Aiyar J, Withka JM, Rizzi JP, Singleton DH, Andrews GC, Lin W, Boyd J, Hanson DC, Simon M, Dethlefs B, Lee CL, Hall JE, Gutman GA, Chandy KG. Topology of the pore-region of a $\mathrm{K}^{+}$channel revealed by the NMR-derived structures of scorpion toxins. Neuron 1995;15:1169-1181. [PubMed: 7576659]

9. Akao M, Otani H, Horie M, Takano M, Kuniyasu A, Nakayama H, Kouchi I, Murakami T, Sasayama S. Myocardial ischemia induces differential regulation of $\mathrm{K}_{\mathrm{ATP}}$ channel gene expression in rat hearts. J Clin Invest 1997;100:3053-3059. [PubMed: 9399952]

10. Ali S, Chen X, Lu M, Xu JC, Lerea KM, Hebert SC, Wang W. A kinase anchoring protein (AKAP) is required for mediating the effect of PKA on ROMK1. Proc Natl Acad Sci USA 1998;95:1027410278. [PubMed: 9707637]

11. Alvarez DLR, Coric T, Todorovic N, Shao D, Wang T, Canessa CM. Distribution and regulation of expression of serum- and glucocorticoid-induced kinase-1 in the rat kidney. J Physiol 2003;551:455466. [PubMed: 12816971]

12. Amorim JB, Malnic G. receptors in luminal action of $\mathrm{V}_{1}$ vasopressin on distal $\mathrm{K}^{+}$secretion. Am $\mathrm{J}$ Physiol Renal Physiol 2000;278:F809-F816. [PubMed: 10807593] 
13. Anderson RA, Boronenkov IV, Doughman SD, Kunz J, Loijens JC. Phosphatidylinositol phosphate kinases, a multifaceted family of signaling enzymes. J Biol Chem 1999;274:9907-9910. [PubMed: 10187762]

14. Anzai N, Izumida I, Inagaki N, Seino S, Kawahara K. Expression of uKATP -1 (Kir6.1) in neonatal rat kidney proximal tubule. Jpn J Physiol 1997;47(Suppl 1):S10-S11. [PubMed: 9266309]

15. Arrascue JF, Dobyan DC, Jamison RL. Potassium recycling in the renal medulla: effects of acute potassium chloride administration to rats fed a potassium-free diet. Kidney Int 1981;20:348-352. [PubMed: 7300124]

16. Arrighi I, Lesage F, Scimeca JC, Carle GF, Barhanin J. Structure, chromosome localization, and tissue distribution of the mouse $t$ wik $\mathrm{K}^{+}$channel gene. FEBS Lett 1998;425:310-316. [PubMed: 9559671]

17. Ashcroft SJ. The beta-cell $K_{\text {ATP }}$ channel. J Membr Biol 2000;176:187-206. [PubMed: 10931971]

18. Ashcroft SJH, Ashcroft FM. Properties and functions of ATP-sensitive K-channels. Cell Signal 1990;2:197-214. [PubMed: 2119205]

19. Ashcroft SJH, Ashcroft FM. The sulfonylurea receptor. Biochim Biophys Acta 1992;1175:45-59. [PubMed: 1482696]

20. Ashmole I, Goodwin PA, Stanfield PR. TASK-5, a novel member of the tandem pore $\mathrm{K}^{+}$channel family. Pflügers Arch 2001;442:828-833.

21. Asteria C. Molecular basis of Bartter's syndrome: new insights into correlation between genotype and phenotype. Eur J Endocrinol 1997;137:613-615. [PubMed: 9437224]

22. Attali B, Latter H, Rachamim N, Garty H. A corticosteroid-induced gene expressing an "IsK-like" $\mathrm{K}^{+}$channel activity in Xenopus oocytes. Proc Natl Acad Sci USA 1995;92:6092-6096. [PubMed: 7597086]

23. Attardi B, Takimoto K, Gealy R, Severns C, Levitan ES. Glucocorticoid induced up-regulation of a pituitary $\mathrm{K}^{+}$channel mRNA in vitro and in vivo. Receptors Channels 1993;1:287-293. [PubMed: 8081726]

24. Babenko AP, Aguilar-Bryan L, Bryan J. A view of sur/KIR6.X, K ATP channels. Annu Rev Physiol 1998;60:667-687. [PubMed: 9558481]

25. Bang H, Kim Y, Kim D. TREK-2, a new member of the mechanosensitive tandem-pore $\mathrm{K}^{+}$channel family. J Biol Chem 2000;275:17412-17419. [PubMed: 10747911]

26. Bapty BW, Dai LJ, Ritchie G, Canaff L, Hendy GN, Quamme GA. $\mathrm{Mg}^{2+} / \mathrm{Ca}^{2+}$ sensing inhibits hormone-stimulated $\mathrm{Mg}^{2+}$ uptake in mouse distal convoluted tubule cells. Am J Physiol Renal Physiol 1998;275:F353-F360.

27. Barhanin J, Lesage F, Guillemare E, Fink M, Lazdunski M, Romey G. KvLQT1 and IsK (minK) proteins associate to form the $I_{\mathrm{ks}}$ cardiac potassium current. Nature 1996;384:78-80. [PubMed: 8900282]

28. Barriere H, Belfodil R, Rubera I, Tauc M, Lesage F, Poujeol C, Guy N, Barhanin J, Poujeol P. Role of TASK2 potassium channels regarding volume regulation in primary cultures of mouse proximal tubules. J Gen Physiol 2003;122:177-190. [PubMed: 12860925]

29. Bartter FC, Pronove P, Gill JR Jr, MacCardle RC, Diller E. Hyperplasia of the juxtaglomerular complex with hyperaldosteronoism and hypokalemic alkalosis. Am J Med 1962;33:811-828. [PubMed: 13969763]

30. Baukrowitz T, Schulte U, Oliver D, Herlitze S, Krauter T, Tucker SJ, Ruppersberg JP, Fakler B. $\mathrm{PIP}_{2}$ and PIP as determinants for ATP inhibition of $\mathrm{K}_{\mathrm{ATP}}$ channels. Science 1998;282:1141-1144. [PubMed: 9804555]

31. Baukrowitz T, Tucker SJ, Schulte U, Benndorf K, Ruppersberg JP, Fakler B. Inward rectification in K ATP channels: a pH switch in the pore. EMBO J 1999;18:847-853. [PubMed: 10022827]

32. Baumann A, Frings S, Godde M, Seifert R, Kaupp UB. Primary structure and functional expression of a Drosophila cyclic nucleotide-gated channel present in eyes and antennae. EMBO J 1994;13:5040-5050. [PubMed: 7957070]

33. Beck JS, Breton S, Laprade R, Giebisch G. Volume regulation and intracellular calcium in the rabbit proximal convoluted tubule. Am J Physiol Renal Fluid Electrolyte Physiol 1991;260:F861-F867.

34. Beck JS, Breton S, Mairbaurl H, Laprade R, Giebisch G. Relationship between sodium transport and intracellular ATP in isolated perfused rabbit proximal convoluted tubule. Am J Physiol Renal Fluid Electrolyte Physiol 1991;261:F634-F639. 
35. Beck JS, Hurst AM, Lapointe JY, Laprade R. Regulation of basolateral K channels in proximal tubule studied during continuous microperfusion. Am J Physiol Renal Fluid Electrolyte Physiol 1993;264:F496-F501.

36. Beck JS, Laprade R, Lapointe JY. Coupling between transepithelial Na transport and basolateral K conductance in renal proximal tubule. Am J Physiol Renal Fluid Electrolyte Physiol 1994;266:F517F527.

37. Beesley AH, Hornby D, White SJ. Regulation of distal nephron $\mathrm{K}^{+}$channels (ROMK) mRNA expression by aldosterone in rat kidney. J Physiol 1998;509:629-634. [PubMed: 9596787]

38. Beesley AH, Ortega B, White SJ. Splicing of a retained intron within ROMK $\mathrm{K}^{+}$channel RNA generates a novel set of isoforms in rat kidney. Am J Physiol Cell Physiol 1999;276:C585-C592.

39. Beesley AH, Qureshi IZ, Giesberts AN, Parker AJ, White SJ. Expression of sulphonylurea receptor protein in mouse kidney. Pflügers Arch 1999;438:1-7.

40. Behrens R, Nolting A, Reimann F, Schwarz M, Waldschultz R, Pongs O. hKCNMB3 and hKCNMB4, cloning and characterization of two members of the large-conductance calcium-activated potassium channel beta subunit family. FEBS Lett 2000;474:99-106. [PubMed: 10828459]

41. Bell PD, Lapointe JY. Characteristics of membrane transport processes of macula densa cells. Clin Exp Pharmacol Physiol 1997;24:541-547. [PubMed: 9248675]

42. Bellemare F, Morier N, Sauvé R. Incorporation into a planar lipid bilayer of K channels from the luminal membrane of rabbit proximal tubule. Biochim Biophys Acta 1992;1105:10-18. [PubMed: 1567889]

43. Benchimol C, Zavilowitz B, Satlin LM. Developmental expression of ROMK mRNA in rabbit cortical collecting duct. Pediatr Res 2000;47:46-52. [PubMed: 10625082]

44. Bentrop D, Beyermann M, Wissman R, Fakler B. NMR structure of the "ball-and-chain" domain of KCNMB2, the $\beta 2$-subunit of large conductance $\mathrm{Ca}^{2+}$ - and voltage-activated potassium channels. $\mathrm{J}$ Biol Chem 2001;276:42116-42121. [PubMed: 11517232]

45. Biagi BA, Kubota T, Sohtell M, Giebisch G. Intracellular potentials in rabbit proximal tubules perfused in vitro. Am J Physiol Renal Fluid Electrolyte Physiol 1981;240:F200-F210.

46. Biel M, Zong X, Ludwig A, Sautter A, Hofmann F. Structure and function of cyclic nucleotide-gated channels. Rev Physiol Biochem Pharmacol 1999;135:151-171. [PubMed: 9932483]

47. Birkenhager R, Otto E, Schurmann MJ, Vollmer M, Ruf EM, Maier-Lutz I, Beekmann F, Fekete A, Omran H, Feldmann D, Milford DV, Jeck N, Konrad M, Landau D, Knoers NV, Antignac C, Sudbrak R, Kispert A, Hildebrandt F. Mutation of BSND causes Bartter syndrome with sensorineural deafness and kidney failure. Nat Genet 2001;29:310-314. [PubMed: 11687798]

48. Bleich M, Kottgen M, Schlatter E, Greger R. Effect of NH4+/NH3 on cytosolic $\mathrm{pH}$ and the $\mathrm{K}^{+}$ channels of freshly isolated cells from the thick ascending limb of Henle's loop. Pflügers Arch 1995;429:345-354.

49. Bleich M, Schlatter E, Greger R. The luminal $\mathrm{K}^{+}$channel of the thick ascending limb of Henle's loop. Pflügers Arch 1990;415:449-460.

50. Bleich M, Warth R. The very small-conductance $\mathrm{K}^{+}$channel KvLQT1 and epithelial function. Pflügers Arch 2000;440:202-206.

51. Bock JH, Shuck ME, Benjamin CW, Chee M, Bienkowski MJ, Slightom JL. Nucleotide sequence analysis of the human KCNJ1 potassium channel locus. Gene 1997;188:9-16. [PubMed: 9099852]

52. Bockenhauer D, Zilberberg N, Goldstein SA. KCNK2: reversible conversion of a hippocampal potassium leak into a voltage-dependent channel. Nat Neurosci 2001;4:486-491. [PubMed: 11319556]

53. Boim MA, Ho K, Shuck ME, Bienkowski MJ, Block JH, Slightom JL, Yang Y, Brenner BM, Hebert SC. The ROMK inwardly rectifying ATP-sensitive $\mathrm{K}^{+}$channel. II. Cloning and intra-renal distribution of alternatively spliced forms. Am J Physiol Renal Fluid Electrolyte Physiol 1995;268:F1132-F1140.

55. Bond CT, Pessia M, Xia XM, Lagrutta A, Kavanaugh MP, Adelman JP. Cloning and expression of a family of inward rectifier potassium channels. Receptors Channels 1994;2:183-191. [PubMed: 7874445]

56. Boudry JF, Stoner LC, Burg MB. Effect of acid lumen $\mathrm{pH}$ on potassium transport in renal cortical collecting tubules. Am J Physiol 1976;230:239-244. [PubMed: 3114] 
57. Bourbouze R, Baumann FC, Bonvalet JP, Farman N. Distribution of $N$-acetyl- $\beta$-D-glucosaminidase isoenzymes along the rabbit nephron. Kidney Int 1984;25:636-642. [PubMed: 6482167]

58. Bowlby MR, Fadool DA, Holmes TC, Levitan IB. Modulation of the kv1.3 potassium channel by receptor tyrosine kinases. J Gen Physiol 1997;110:601-610. [PubMed: 9348331]

59. Brahmajothi MV, Morales MJ, Liu S, Rasmusson RL, Campbell DL, Strausss HC. In situ hybridization reveals extensive diversity of $\mathrm{K}^{+}$channel mRNA in isolated ferret cardiac myocytes. Circ Res 1996;78:1083-1089. [PubMed: 8635239]

60. Brahmajothi MV, Morales MJ, Rasmusson RL, Campbell DL, Strauss HC. Heterogeneity in $\mathrm{K}^{+}$ channel transcript expression detected in isolated ferret cardiac myocytes. Pacing Clin Electrophysiol 1997;20:388-396. [PubMed: 9058843]

61. Brandis M, Keyes J, Windhager EE. Potassium-induced inhibition of proximal tubular fluid reabsorption in rats. Am J Physiol 1972;222:421-427. [PubMed: 5058384]

62. Brazier SP, Ramesh B, Haris PI, Lee DC, Srai SK. Secondary structure analysis of the putative membrane-associated domains of the inward rectifier $\mathrm{K}^{+}$channel ROMK1. Biochem $\mathrm{J}$ 1998;335:375-380. [PubMed: 9761737]

63. Breton S, Belachgar F, Marsolais M, Lapointe JY, Laprade R. Inhibition of basolateral potassium conductance by taurine in the proximal convoluted tubule. Am J Physiol Renal Fluid Electrolyte Physiol 1996;271:F1012-F1019.

64. Brochiero E, Coady MJ, Klein H, Laprade R, Lapointe JY. Activation of an ATP-dependent K ${ }^{+}$ conductance in Xenopus oocytes by expression of adenylate kinase cloned from renal proximal tubules. Biochim Biophys Acta 2001;1510:29-42. [PubMed: 11342145]

65. Brochiero E, Wallendorf B, Gagnon D, Laprade R, Lapointe JY. Cloning of rabbit Kir6.1, SUR2A, and SUR2B: possible candidates for a renal $\mathrm{K}_{\mathrm{ATP}}$ channel. Am J Physiol Renal Physiol 2002;282:F289-F300. [PubMed: 11788443]

66. Brown EM, Vassilev PM, Quinn S, Hebert SC. G-protein-coupled, extracellular $\mathrm{Ca}^{2+}{ }_{-}$-sensing receptor: a versatile regulator of diverse cellular functions. Vitamins Hormones 1999;55:1-71. [PubMed: 9949679]

67. Browne DL, Gancher ST, Nutt JG, Brunt ER, Smith EA, Kramer P, Litt M. Episodic ataxia/myokymia syndrome is associated with point mutations in the human potassium channel gene, KCNA1. Nat Genet 1994;8:136-140. [PubMed: 7842011]

68. Bryan J, Aguilar-Bryan L. The ABCs of ATP-sensitive potassium channels: more pieces of the puzzle. Curr Opin Cell Biol 1997;9:553-559. [PubMed: 9261054]

69. Bryan J, Aguilar-Bryan L. Sulfonylurea receptors: ABC transporters that regulate ATP-sensitive K + channels. Biochim Biophys Acta 1999;1461:285-303. [PubMed: 10581362]

70. Bryan-Aguilar L, Nelson DA, Vu QA, Humphrey MB, Boyd AE III. Photoaffinity labeling and partial purification of the $\beta$ cell sulfonylurea receptor using a novel, biologically active glyburide analog. $\mathrm{J}$ Biol Chem 1990;265:8218-8224. [PubMed: 2110566]

71. Butler A, Wei A, Baker K, Salkoff L. A family of putative potassium channel genes in Drosophila. Science 1989;243:943-947. [PubMed: 2493160]

72. Cahill P, Nason MW Jr, Ambrose C, Yao TY, Thomas P, Egan ME. Identification of the cystic fibrosis transmembrane conductance regulator domains that are important for interactions with ROMK2. J Biol Chem 2000;275:16697-16701. [PubMed: 10748197]

73. Cardinal J, Lapointe JY, Laprade R. Luminal and peritubular ionic substitutions and intracellular potential of the rabbit proximal convoluted tubule. Am J Physiol Renal Fluid Electrolyte Physiol 1984;247:F352-F364.

74. Carrasco AJ, Dzeja PP, Alekseev AE, Pucar D, Zingman LV, Abraham MR, Hodgson D, Bienengraeber M, Puceat M, Janssen E, Wieringa B, Terzic A. Adenylate kinase phosphotransfer communicates cellular energetic signals to ATP-sensitive potassium channels. Proc Natl Acad Sci USA 2001;98:7623-7628. [PubMed: 11390963]

75. Carroll MA, Sala A, Dunn CE, McGiff JC, Murphy RC. Structural identification of cytochrome $P 450$-dependent arachidonate metabolites formed by rabbit medullary thick ascending limb cells. J Biol Chem 1992;266:12306-12312. [PubMed: 1648091] 
76. Carroll MA, Schwartzman M, Baba M, Miller MJS, McGiff JC. Renal cytochrome P-450-related arachidonate metabolism in rabbit aortic coarctation. Am J Physiol Renal Fluid Electrolyte Phsyiol 1988;255:F151-F157.

77. Cassola AC, Giebisch G, Wang W. Vasopressin increases density of apical low-conductance $\mathrm{K}^{+}$ channels in rat CCD. Am J Physiol Renal Fluid Electrolyte Physiol 1993;264:F502-F509.

78. Chanchevalap S, Yang Z, Cui N, Qu Z, Zhu G, Liu C, Giwa LR, Abdulkadir L, Jiang C. Involvement of histidine residues in proton sensing of ROMK1 channel. J Biol Chem 2000;275:7811-7817. [PubMed: 10713095]

79. Chen CJ, Brown EM. The diltiazem analog TA-3090 mimics the actions of high extracellular $\mathrm{Ca}^{2+}$ on parathyroid function in dispersed bovine parathyroid cells. J Bone Miner Res 1990;5:581-587. [PubMed: 2166422]

80. Chepilko S, Zhou H, Sackin H, Palmer LG. Permeation and gating properties of a cloned renal $\mathrm{K}^{+}$ channel. Am J Physiol Cell Physiol 1995;268:C389-C401.

81. Cho JT, Guay-Woodford LM. Heterozygous mutations of the gene for Kir 11 (ROMK) in antenatal Bartter syndrome presenting with transient hyperkalemia, evolving to a benign course. J Korean Med Sci 2003;18:65-68. [PubMed: 12589089]

82. Choe H, Palmer LG, Sackin H. Structural determinants of gating in inward-rectifier $\mathrm{K}^{+}$channels. Biophys J 1999;76:1988-2003. [PubMed: 10096896]

83. Choe H, Sackin H, Palmer LG. Permeation and gating of an inwardly rectifying potassium channel. Evidence for a variable energy well. J Gen Physiol 1998;112:433-446. [PubMed: 9758862]

84. Choe H, Zhou H, Palmer LG, Sackin H. A conserved cytoplasmic region of ROMK modulates pH sensitivity, conductance, and gating. Am J Physiol Renal Physiol 1997;273:F516-F529.

85. Chu PY, Quigley R, Babich V, Huang CL. Dietary potassium restriction stimulates endocytosis of ROMK channel in rat cortical collecting duct. Am J Physiol Renal Physiol 2003;285:F1179-F1187. [PubMed: 12952855]

86. Chung I, Schlichter LC. Native Kv1.3 channels are upregulated by protein kinase C. J Membr Biol 1997;156:73-85. [PubMed: 9070466]

87. Clapham DE. Unlocking family secrets: $\mathrm{K}^{+}$channel transmembrane domains. Cell 1999;97:547-550. [PubMed: 10367883]

88. Clark MA, Humphrey SJ, Smith MP, Ludens JH. Unique natriuretic properties of the ATP-sensitive $\mathrm{K}^{+}$channel blocker glyburide in concious rats. J Pharmacol Exp Ther 1993;165:933-937. [PubMed: 8496833]

89. Clement JP, Kunjilwar K, Gonzalez G, Schwanstecher M, Panten U, Aguilar-Bryan L, Bryan J. Association and stoichiometry of $\mathrm{K}_{\mathrm{ATP}}$ channel subunits. Neuron 1997;18:827-838. [PubMed: 9182806]

90. Cluzeaud F, Reyes R, Escoubet B, Fay M, Lazdunski M, Bonvalet JP, Lesage F, Farman N. Expression of TWIK-1, a novel weakly inward rectifying potassium channel in rat kidney. Am J Physiol Cell Physiol 1998;275:C1602-C1609.

91. Conforti L, Bodi I, Nisbet JW, Millhorn DE. $\mathrm{O}_{2}$-sensitive $\mathrm{K}^{+}$channels: role of the Kv1.2-subunit in mediating the hypoxic response. J Physiol 2000;524:783-793. [PubMed: 10790158]

92. Cook KK, Fadool DA. Two adaptor proteins differentially modulate the phosphorylation and biophysics of Kv1.3 ion channel by SRC kinase. J Biol Chem 2002;277:13268-13280. [PubMed: 11812778]

93. Cooper GJ, Hunter M. Intracellular $\mathrm{pH}$ and calcium in frog early distal tubule: effects of transport inhibitors. J Physiol 1997;498.1:49-59. [PubMed: 9023767]

94. Cornejo M, Guggino SE, Guggino WB. Modification of $\mathrm{Ca}^{2+}$-activated $\mathrm{K}^{+}$channels in cultured medullary thick ascending limb cells by $N$-bromoacetamide. J Membr Biol 1987;99:147-155. [PubMed: 2448473]

95. Costanzo LS. Comparison of calcium and sodium transport in early and late distal tubules: effect of amiloride. Am J Physiol Renal Fluid Electrolyte Physiol 1984;246:F937-F945.

96. Crawford I, Maloney PC, Zeitlin PL, Guggino WB, Hyde SC, Turley H, Gatter KC, Harris A, Higgins CF. Immunocytochemical localization of the cystic fibrosis gene product CFTR. Proc Natl Acad Sci USA 1991;88:9262-9266. [PubMed: 1718002] 
97. Currie MG, Cole BR, De Schriver-Kecskemeti K, Holmberg S, Needlman P. Cell culture of renal epithelium derived from rabbit microdissected cortical collecting tubules. Am J Physiol Renal Fluid Electrolyte Physiol 1983;244:F724-F728.

98. Dai LJ, Ritchie G, Kerstan D, Kang HS, Cole DE, Quamme GA. Magnesium transport in the renal distal convoluted tubule. Physiol Rev 2001;81:51-84. [PubMed: 11152754]

99. De Rouffignac C, Quamme G. Renal magnesium handling and its hormonal control. Physiol Rev 1994;74:305-322. [PubMed: 8171116]

100. Derst C, Hirsch JR, Preisig-Muller R, Wischmeyer E, Karschin A, Doring F, Thomzig A, Veh RW, Schlatter E, Kummer W, Daut J. Cellular localization of the potassium channel Kir7.1 in guinea pig and human kidney. Kidney Int 2001;59:2197-2205. [PubMed: 11380822]

101. Derst C, Karschin A. Evolutionary link between prokaryotic and eukaryotic $\mathrm{K}^{+}$channels. J Exp Biol 1998;201:2791-2799.

102. Derst C, Konrad M, Köckerling A, Karschin A, Daut J, Seyberth HW. Mutations in the ROMK gene in antenatal Bartter syndrome are associated with impaired $\mathrm{K}^{+}$channel function. Biochem Biophys Res Commun 1997;230:641-645. [PubMed: 9015377]

103. Derst C, Wischmeyer E, Preisig-Muller R, Spauschus A, Konrad M, Hensen P, Jeck N, Seyberth HW, Daut J, Karschin A. A hyperprostaglandin E syndrome mutation in Kir1.1 (renal outer medullary potassium) channels reveals a crucial residue for channel function in Kir13 channels. J Biol Chem 1998;273:23884-23891. [PubMed: 9727001]

104. Desir G, Hamlin H, Puente E, Reilly R, Hildebrandt F, Igarashi P. Isolation of putative voltage-gated epithelial K-channel isoforms from rabbit kidney and LLC-PK 1 cells. Am J Physiol Renal Fluid Electrolyte Physiol 1992;262:F151-F157.

106. Desir GV, Velazquez H. Identification of a novel K-channel gene (KC22) that is highly expressed in distal tubule of rabbit kidney. Am J Physiol Renal Fluid Electrolyte Physiol 1993;264:F128F133.

107. Deutsch C. Potassium channel ontogeny. Annu Rev Physiol 2002;64:19-46. [PubMed: 11826262]

108. Deutsch C, Chen LQ. Heterologous expression of specific $\mathrm{K}^{+}$channels in T lymphocytes: functional consequences for volume regulation. Proc Natl Acad Sci USA 1993;90:10036-10040. [PubMed: 8234253]

109. Devuyst O, Burrow CR, Schwiebert EM, Guggino WB, Wilson PD. Developmental regulation of CFTR expression during human nephrogenesis. Am J Physiol Renal Fluid Electrolyte Physiol 1996;271:F723-F735.

110. Dhulipala PD, Kotlikoff MI. Cloning and characterization of the promoters of the maxiK channel alpha and beta subunits. Biochim Biophys Acta 1999;1444:254-262. [PubMed: 10023076]

111. Dobyan DC, Arrascue JF, Jamison RL. Terminal papillary collecting duct reabsorption of water, sodium, and potassium in Psammomys obesus. Am J Physiol Renal Fluid Electrolyte Physiol 1980;239:F539-F544.

112. Doi T, Fakler B, Schultz JH, Schulte U, Brandle U, Weidemann S, Zenner HP, Lang F, Ruppersberg JP. Extracellular $\mathrm{K}^{+}$and intracellular $\mathrm{pH}$ allosterically regulate renal Kir1.1 channels. J Biol Chem 1996;271:17261-17266. [PubMed: 8663367]

113. Dong F, Feldmesser M, Casadevall A, Rubin CS. Molecular characterization of a cDNA that encodes six isoforms of a novel murine A kinase anchor protein. J Biol Chem 1998;273:6533-6541. [PubMed: 9497389]

114. Dong K, Tang L, MacGregor GG, Hebert SC. Localization of the ATP/phosphatidylinositol 4,5 diphosphate-binding site to a 39-amino acid region of the carboxyl terminus of the ATP-regulated $\mathrm{K}^{+}$channel Kir1.1. J Biol Chem 2002;277:49366-49373. [PubMed: 12381730]

115. Dong K, Xu J, Vanoye CG, Welch R, MacGregor GG, Giebisch G, Hebert SC. An amino acid triplet in the $\mathrm{NH}_{2}$-terminus of rat ROMK1 determines interaction with SUR2B. J Biol Chem 2001;276:44347-44353. [PubMed: 11567030]

118. Doring F, Derst C, Wischmeyer E, Karschin C, Schneggenburger R, Daut J, Karschin A. The epithelial inward rectifier channel Kir7.1 displays unusual $\mathrm{K}^{+}$permeation properties. J Neurosci 1998;18:8625-8636. [PubMed: 9786970] 
119. Doyle DA, Cabral JM, Pfuetzner RA, Kuo A, Gulbis JM, Cohen SL, Chait BT, MacKinnon R. The structure of the potassium channel: molecular basis of $\mathrm{K}^{+}$conduction and selectivity. Science 1998;280:69-77. [PubMed: 9525859]

120. Drain P, Li L, Wang J. $K_{\text {ATP }}$ channel inhibition by ATP requires distinct functional domains of the cytoplasmic C terminus of the pore-forming subunit. Proc Natl Acad Sci USA 1998;95:1395313958. [PubMed: 9811907]

121. Dukes ID, Philipson LH. $\mathrm{K}^{+}$channels: generating excitement in pancreatic $\beta$-cells. Diabetes 1996;45:845-853. [PubMed: 8666132]

122. Duprat F, Lesage F, Fink M, Reyes R, Heurteaux C, Lazdunski M. TASK, a human background K + channel to sense external pH variations near physiological pH. EMBO J 1997;16:5464-5471. [PubMed: 9312005]

123. Dworetzky SI, Boissard CG, Lum-Ragan JT, McKay MC, Post-Munson DJ, Trojnacki JT, Chang $\mathrm{CP}$, Gribkoff VK. Phenotypic alteration of a human BK (hSlo) channel by hSlo $\beta$ subunit coexpression: changes in blocker sensitivity, activation/relaxation and inactivation kinetics, and protein kinase A modulation. J Neurosci 1996;16:4543-4550. [PubMed: 8764643]

124. Dworetzky SI, Trojnacki JT, Gribkoff VK. Cloning and expression of a human large-conductance calcium-activated potassium channel. Brain Res 1994;27:189-193.

125. Ecelbarger CA, Kim GH, Knepper MA, Liu J, Tate M, Welling PA, Wade JB. Regulation of potassium channel Kir 1.1 (ROMK) abundance in the thick ascending limb of Henle's loop. J Am Soc Nephrol 2001;12:10-18. [PubMed: 11134245]

129. Elalouf JM, Roinel N, De Rouffignac C. Effects of antidiuretic hormone on electrolyte reabsorption and secretion in distal tubules of the rat kidney. Pflügers Arch 1984;401:167-173.

130. Ellison DH, Velazquez H, Wright FS. Stimulation of distal potassium secretion by low lumen chloride in the presence of barium. Am J Physiol Renal Fluid Electrolyte Physiol 1985;248:F638F649.

131. Engbretson BG, Stoner LC. Flow-dependent potassium secretion by rabbit cortical collecting tubule in vitro. Am J Physiol Renal Fluid Electrolyte Physiol 1987;253:F896-F903.

132. Enkvetchakul D, Nichols CG. Gating mechanism of KATP channels: function fits form. J Gen Physiol 2003;122:471-480. [PubMed: 14581579]

133. Erginel-Unaltuna N, Yang WP, Blanar MA. Genomic organization and expression of KCNJ8/Kir6.1, a gene encoding a subunit of an ATP-sensitive potassium channel. Gene 1998;211:71-78. [PubMed: 9573340]

134. Escalante B, Erlij D, Falck JR, McGiff JC. Effect of cytochrome $P 450$ arachidonate metabolites on ion transport in rabbit kidney loop of Henle. Science 1991;251:799-802. [PubMed: 1846705]

135. Escobar LI, Martinez-Tellez JC, Salas M, Castilla SA, Carrisoza R, Tapia D, Vazquez M, Bargas J, Bolivar JJ. A voltage-gated $\mathrm{K}^{+}$current in renal inner medullary collecting duct cells. Am J Physiol Cell Physiol 2003;286:C965-C974. [PubMed: 14684382]

136. Estevez R, Boettger T, Stein V, Birkenhager R, Otto E, Hildebrandt F, Jentsch TJ. Barttin is a $\mathrm{Cl}^{-}$ channel beta-subunit crucial for renal $\mathrm{Cl}^{-}$reabsorption and inner ear $\mathrm{K}^{+}$secretion. Nature 2001;414:558-561. [PubMed: 11734858]

137. Fadool DA, Levitan IB. Modulation of olfactory bulb neuron potassium current by tyrosine phosphorylation. J Neurosci 1998;18:6126-6137. [PubMed: 9698307]

138. Fadool DA, Tucker K, Phillips JJ, Simmen JA. Brain insulin receptor causes activity-dependent current suppression in the ofactory bulb through multiple phosphorylation of Kv1.3. J Neurophysiol 2000;83:2332-2348. [PubMed: 10758137]

139. Fakler B, Bond CT, Adelman JP, Ruppersberg JP. Heterooligomeric assembly of inward-rectifier $\mathrm{K}^{+}$channels from subunits of different subfamilies: $\mathrm{K}_{\mathrm{ir}} 2.1$ (IRK1) and $\mathrm{K}_{\mathrm{ir}} 41$ (BIR10). Pflügers Arch 1996;433:77-83.

140. Fakler B, Schultz JH, Yang J, Schulte U, Brändle U, Zenner HP, Jan LY, Ruppersberg JP. Identification of a titratable lysine residue that determines sensitivity of kidney potassium channels (ROMK) to intracellular pH. EMBO J 1996;15:4093-4099. [PubMed: 8861938]

141. Farman N, Fay M, Cluzeaud F. Cell-specific expression of three members of the FXYD family along the renal tubule. Ann NY Acad Sci 2003;986:428-436. [PubMed: 12763861] 
142. Faux MC, Scott JD. Molecular glue: kinase anchoring and scaffold proteins. Cell 1996;85:9-12. [PubMed: 8620541]

143. Feldmann D, Alessandri JL, Deschenes G. Large deletion of the 5' end of the ROMK1 gene causes antenatal Bartter syndrome. J Am Soc Nephrol 1998;9:2357-2359. [PubMed: 9848791]

144. Ficker E, Taglialatela M, Wible BA, Henley CM, Brown AM. Spermine and spermidine as gating molecules for inward rectifier $\mathrm{K}^{+}$channels. Science 1994;266:1068-1072. [PubMed: 7973666]

145. Field MJ, Stanton BA, Giebisch G. Influence of ADH on renal potassium handling: a micropuncture and microperfusion study. Kidney Int 1984;25:502-511. [PubMed: 6737842]

146. Field MJ, Stanton BA, Giebisch GH. Differential acute effects of aldosterone, dexamethasone, and hyperkalemia on distal tubular potassium secretion in the rat kidney. J Clin Invest 1984;74:17921802. [PubMed: 6501571]

147. Filipovic D, Sackin H. A calcium-permeable stretch-activated cation channel in renal proximal tubule. Am J Physiol Renal Fluid Electrolyte Physiol 1991;260:F119-F129.

148. Finer G, Shalev H, Birk OS, Galron D, Jeck N, Sinai-Treiman L, Landau D. Transient neonatal hyperkalemia in the antenatal (ROMK defective) Bartter syndrome. J Pediatr 2003;142:318-323. [PubMed: 12640382]

149. Flagg TP, Tate M, Merot J, Welling PA. A mutation linked with Bartter's syndrome locks Kir 1.1a (ROMK1) channels in a closed state. J Gen Physiol 1999;114:685-700. [PubMed: 10532965]

150. Flagg TP, Yoo D, Sciortino CM, Tate M, Romero MF, Welling PA. Molecular mechanism of a COOH-terminal gating determinant in the ROMK channel revealed by a Bartter's disease mutation. J Physiol 2002;544:351-362. [PubMed: 12381810]

151. Folander K, Douglass J, Swanson R. Confirmation of the assignment of the gene encoding Kv1.3, a voltage-gated potassium channel (KCNA3) to the proximal short arm of human chromosome 1. Genomics 1994;23:295-296. [PubMed: 7829094]

152. Frindt G, Palmer LG. Ca-activated K channels in apical membrane of mammalian CCT, and their role in K secretion. Am J Physiol Renal Fluid Electrolyte Physiol 1987;252:F458-F467.

153. Frindt G, Palmer LG. Low-conductance K channels in apical membrane of rat cortical collecting tubule. Am J Physiol Renal Fluid Electrolyte Physiol 1989;256:F143-F151.

154. Frindt G, Zhou H, Sackin H, Palmer LG. Dissociation of K channel density and ROMK mRNA in rat cortical collecting tubule during K adaptation. Am J Physiol Renal Physiol 1998;274:F525F531.

155. Fromter E. Electrophysiological analysis of rat renal sugar and amino acid transport. I. Basic phenomena. Pflügers Arch 1982;392:179-189.

156. Fujita A, Horio Y, Higashi K, Mouri T, Hata F, Takeguchi N, Kurachi Y. Specific localization of an inwardly rectifying $\mathrm{K}^{+}$channel, Kir4.1, at the apical membrane of rat gastric parietal cells: its possible involvement in $\mathrm{K}^{+}$recycling for the $\mathrm{H}^{+}-\mathrm{K}^{+}$-pump. J Physiol 2002;540:85-92. [PubMed: 11927671]

157. Fuzesi M, Goldshleger R, Garty H, Karlish SJ. Defining the nature and sites of interaction between FXYD proteins and Na, K-ATPase. Ann NY Acad Sci 2003;986:532-533. [PubMed: 12763879]

158. Gallazzini M, Attmane-Elakeb A, Mount DB, Hebert SC, Bichara M. Regulation by glucocorticoids and osmolality of expression of ROMK (Kir 1.1), the apical K channel of thick ascending limb. Am J Physiol Renal Physiol 2003;284:F977-F986. [PubMed: 12540364]

159. Garcia-Calvo M, Leonard RJ, Novick J, Stevens SP, Schmalhofer W, Kaczorowski GJ, Carcia ML. Purification, characterization, and biosynthesis of margatoxin, a component of Centruroides margaritatus venom that selectively inhibits voltage-dependent potassium channels. J Biol Chem 1993;268:18866-18874. [PubMed: 8360176]

160. Gebremedhin D, Kaldunski M, Jacobs ER, Harder DR, Roman RJ. Coexistence of two types of Caactivated $\mathrm{K}$ channels in rat renal arterioles. Am J Physiol Renal Fluid Electrolyte Physiol 1996;270:F69-F81.

161. Geibel J, Zweifach A, White S, Wang W, Giebisch G. $\mathrm{K}^{+}$channels of the mammalian collecting duct. Renal Physiol Biochem 1990;13:59-69. [PubMed: 1689862]

162. Gelband CH, Ishikawa T, Post JM, Keef KD, Hume JR. Intracellular divalent cations block smooth muscle $\mathrm{K}^{+}$channels. Circ Res 1993;73:24-34. [PubMed: 7685253] 
163. Gerstin KM, Gong DH, Abdallah M, Winegar BD, Eger EI, Gray AT. Mutation of KCNK5 or Kir3.2 potassium channels in mice does not change minimum alveolar anesthetic concentration. Anesth Analg 2003;96:1345-1349. [PubMed: 12707131]

164. Giebisch G. Renal potassium transport: mechanisms and regulation. Am J Physiol Renal Physiol 1998;274:F817-F833.

165. Giebisch G. Physiological roles of renal potassium channels. Semin Nephrol 1999;19:458-471. [PubMed: 10511385]

166. Giebisch G, Hebert SC, Wang WH. New aspects of renal potassium transport. Pflügers Arch 2003;446:289-297.

167. Giebisch G, Wang W. Renal tubule potassium channels: function, regulation and structure. Acta Physiol Scand 2000;170:153-173. [PubMed: 11114953]

168. Giebisch G, Wang WH. Potassium transport: from clearance to channels and pumps. Kidney Int 1996;49:1624-1631. [PubMed: 8743466]

169. Giebisch GH. A trail of research on potassium. Kidney Int 2002;62:1498-1512. [PubMed: 12371944]

170. Gimelreich D, Popovtzer MM, Wald H, Pizov G, Berlatzky Y, Rubinger D. Regulation of ROMK and channel-inducing factor (CHIF) in acute renal failure due to ischemic reperfusion injury. Kidney Int 2001;59:1812-1820. [PubMed: 11318952]

171. Goegelein H. Ion channels in mammalian proximal renal tubules. Renal Physiol Biochem 1990;13:8-25. [PubMed: 1689864]

172. Gögelein H, Greger R. Properties of single $\mathrm{K}^{+}$channels in the basolateral membrane of rabbit proximal straight tubules. Pflügers Arch 1987;410:288-295.

173. Goldsmith SR, Cowley AW Jr, Francis GS, Cohn JN. Effect of increased intracardiac and arterial pressure on plasma vasopressin in humans. Am J Physiol Heart Circ Physiol 1984;246:H647-H651.

174. Goldstein SA, Bockenhauer D, O'Kelly I, Zilberberg N. Potassium leak channels and the KCNK family of two-P-domain subunits. Nat Rev Neurosci 2001;2:175-184. [PubMed: 11256078]

175. Goldstein SA, Wang KW, Ilan N, Pausch MH. Sequence and function of the two P domain potassium channels: implications of an emerging superfamily. J Mol Med 1998;76:13-20. [PubMed: 9462864]

176. Goldstein SAN, Price LA, Rosenthal DN, Pausch MH. ORK1, a potassium-selective leak channel with two pore domains cloned from Drosophila melanogaster by expression in Saccharomyces cerevisiae. Proc Natl Acad Sci USA 1996;93:13256-13261. [PubMed: 8917578]

177. Good DW, Wright FS. Luminal influences on potassium secretion: sodium concentration and fluid flow rate. Am J Physiol Renal Fluid Electrolyte Physiol 1979;236:F192-F205.

178. Gordon RD. Syndrome of hypertension and hyperkalemia with normal glomerular filtration rate. Hypertension 1986;8:93-102. [PubMed: 3002982]

179. Gosset P, Ghezala GA, Korn B, Yaspo ML, Poutska A, Lehrach H, Sinet PM, Creau N. A new inward rectifier potassium channel gene (KCNJ15) localized on chromosome 21 in the Down syndrome chromosome region 1 (DCR1). Genomics 1997;44:237-241. [PubMed: 9299242]

180. Greger R. Ion transport mechanisms in thick ascending limb of Henle's loop of mammalian nephron. Physiol Rev 1985;65:760-797. [PubMed: 2409564]

181. Greger R, Bleich M, Schlatter E. Ion channels in the thick ascending limb of Henle's loop. Renal Physiol Biochem 1990;13:37-50. [PubMed: 1689860]

182. Grissmer S, Nguyen AN, Aiyar J, Hanson DC, Mather RJ, Gutman GA, Karmilowicz MJ, Auperin $\mathrm{DD}$, Chandy KG. Pharmacological characterization of five cloned voltage-gated $\mathrm{K}^{+}$channels, types Kv1.1, 12, 13, 15, and 31, stably expressed in mammalian cell lines. Mol Pharmacol 1994;45:12271234. [PubMed: 7517498]

183. Gu RM, Wang WH. Arachidonic acid inhibits $\mathrm{K}$ channels in basolateral membrane of the thick ascending limb. Am J Physiol Renal Physiol Renal Physiol 2002;283:F407-F414.

184. Gu RM, Wei Y, Falck JR, Krishna UM, Wang WH. Effects of protein tyrosine kinase and protein tyrosine phosphatase on apical $\mathrm{K}^{+}$channels in the TAL. Am J Physiol Cell Physiol 2001;281:C1188-C1195. [PubMed: 11546655] 
185. Gu RM, Wei Y, Jiang H, Balazy M, Wang WH. The role of 20-HETE in mediating the effect of dietary K intake on the apical K channels in the mTAL. Am J Physiol Renal Physiol 2001;280:F223F230. [PubMed: 11208597]

186. Gu W, Schlichthorl G, Hirsch JR, Engels H, Karschin C, Karschin A, Derst C, Steinlein OK, Daut J. Expression pattern and functional characteristics of two novel splice variants of the two-poredomain potassium channel TREK-2. J Physiol 2002;539:657-668. [PubMed: 11897838]

187. Guay-Woodford LM. Molecular insights into the pathogenesis of inherited renal tubular disorders. Curr Opin Nephrol Hypertens 1995;4:121-129. [PubMed: 7600042]

188. Guggino SE, Guggino WB, Green N, Sacktor B. Blocking agents of $\mathrm{Ca}^{2+}$-activated $\mathrm{K}^{+}$channels in cultured medullary thick ascending limb cells. Am J Physiol Cell Physiol 1987;252:C128-C137.

189. Gulbis JM, Zhou M, Mann S, MacKinnon R. Structure of the cytoplasmic beta subunit-T1 assembly of voltage-dependent $\mathrm{K}^{+}$channels. Science 2000;289:123-127. [PubMed: 10884227]

190. Gutman GA, Chandy KG, Adelman JP, Aiyar J, Bayliss DA, Clapham DE, Covarriubias M, Desir GV, Furuichi K, Ganetzky B, Garcia ML, Grissmer S, Jan LY, Karschin A, Kim D, Kuperschmidt S, Kurachi Y, Lazdunski M, Lesage F, Lester HA, McKinnon D, Nichols CG, O'Kelly I, Robbins J, Robertson GA, Rudy B, Sanguinetti M, Seino S, Stuehmer W, Tamkun MM, Vandenberg CA, Wei A, Wulff H, Wymore RS. International Union of Pharmacology. XLI. Compendium of voltagegated ion channels: potassium channels. Pharmacol Rev 2003;55:583-586. [PubMed: 14657415]

191. Guy RH, Warmke J, Drysdale R, Ganetzky B. Similarities in amino acid sequences of Drosophila eag and cyclic nucleotide-gated channels. Science 1991;254:730. [PubMed: 1658932]

192. Hamilton KL, Eaton DC. cAMP-induced potassium channel activity in apical membrane of cultured A6 kidney cells. Am J Physiol Renal Fluid Electrolyte Physiol 1991;261:F1055-F1062.

193. Hanaoka K, Wright JM, Cheglakov IB, Morita T, Guggino WB. A 59 amino acid insertion increases $\mathrm{Ca}^{2+}$ sensitivity of rbslo1, a Ca ${ }^{2+}$-activated $\mathrm{K}^{+}$channel in renal epithelia. J Membr Biol 1999;172:193-201. [PubMed: 10568789]

194. Hebert SC. Bartter syndrome. Curr Opin Nephrol Hypertens 2003;12:527-532. [PubMed: 12920401]

195. Hebert SC, Andreoli TE. Control of $\mathrm{NaCl}$ transport in the thick ascending limb. Am J Physiol Renal Fluid Electrolyte Physiol 1984;246:F745-F756.

196. Hebert SC, Andreoli TE. Effects of antidiuretic hormone on cellular conductive pathways in mouse medullary thick ascending limbs of Henle. II. Determinants of the ADH-mediated increases in transepithelial voltage and in net $\mathrm{Cl}^{-}$absorption. J Membr Biol 1984;80:221-233. [PubMed: 6094817]

197. Hebert SC, Friedman PA, Andreoli TE. Effects of antidiuretic hormone on cellular conductive pathways in mouse medullary thick ascending limbs of Henle. I. ADH increases transcellular conductive pathways. J Membr Biol 1984;80:201-219. [PubMed: 6094816]

198. Heginbotham L, Abramson T, MacKinnon R. A functional connection between the pores of distantly related ion channels as revealed by mutant $\mathrm{K}^{+}$channels. Science 1992;258:1152-1155. [PubMed: 1279807]

199. Heginbotham L, Lu Z, Abramson T, MacKinnon B. Mutations in the $\mathrm{K}^{+}$channel signature sequence. Biophys J 1991;66:1061-1067. [PubMed: 8038378]

200. Higgins CF. The ABC of channel regulation. Cell 1995;82:693-696. [PubMed: 7671298]

201. Hilgemann DW, Ball R. Regulation of cardiac $\mathrm{Na}^{+}, \mathrm{Ca}^{2+}$ exchange and $\mathrm{K}_{\mathrm{ATP}}$ potassium channels by $\mathrm{PIP}_{2}$. Science 1996;273:956-959. [PubMed: 8688080]

202. Hilgemann DW, Feng S, Nasuhoglu C. The complex and intriguing lives of $\mathrm{PIP}_{2}$ with ion channels and transporters. Sci STKE 2001 2001:RE19.

203. Hille B, Armstrong CM, MacKinnon R. Ion channels: from idea to reality. Nature Med 1991;5:11051109. [PubMed: 10502800]

204. Hirano J, Nakamura K, Itazawa S, Sohma Y, Kubota T, Kubokawa M. Modulation of the $\mathrm{Ca}^{2+}$ activated large conductance $\mathrm{K}^{+}$channel by intracellular $\mathrm{pH}$ in human renal proximal tubule cells. Jpn J Physiol 2002;52:267-276. [PubMed: 12230803]

205. Hirano J, Nakamura K, Kubokawa M. Properties of a Ca(2+)-activated large conductance K(+) channel with ATP sensitivity in human renal proximal tubule cells. Jpn J Physiol 2001;51:481-489. [PubMed: 11564285] 
207. Hirsch J, Leipziger J, Frobe U, Schlatter E. Regulation and possible physiological role of the $\mathrm{Ca}^{2}$ ${ }^{+}$-dependent $\mathrm{K}^{+}$channel of cortical collecting ducts of the rat. Pflügers Arch 1993;422:492-498.

208. Hirsch J, Schlatter E. $\mathrm{K}^{+}$channels in the basolateral membrane of rat cortical collecting duct are regulated by a cGMP-dependent protein kinase. Pflügers Arch 1995;429:338-344.

209. Hirsch J, Schlatter E. $\mathrm{K}^{+}$channels in the basolateral membrane of rat cortical collecting duct. Pflügers Arch 1993;424:470-477.

210. Hirsch JR, Cermak R, Forssmann W, Kleta R, Kruhoffer M, Kuhn M, Shafer JA, Sun D, Schlatter E. Effects of sodium nitroprusside in the rat cortical collecting duct (CCD) are independent of the NO-pathway. Kidney Int 1997;51:473-476. [PubMed: 9027724]

211. Hirsch JR, Meyer M, Magert HJ, Forssmann WG, Mollerup S, Herter P, Weber G, Cermak R, Ankorina-Stark I, Schlatter E, Kruhoffer M. cGMP-dependent and -independent inhibition of a K + conductance by natriuretic peptides: molecular and functional studies in human proximal tubule cells. J Am Soc Nephrol 1999;10:472-480. [PubMed: 10073597]

212. Ho K. The ROMK-cystic fibrosis transmembrane conductance regulator connection: new insights into the relationship between ROMK and cystic fibrosis transmembrane conductance regulator channels. Curr Opin Nephrol Hypertens 1998;7:49-58. [PubMed: 9442363]

213. Ho K, Nichols CG, Lederer WJ, Lytton J, Vassilev PM, Kanazirska MV, Hebert SC. Cloning and expression of an inwardly rectifying ATP-regulated potassium channel. Nature 1993;362:31-38. [PubMed: 7680431]

214. Holmes TC, Fadool DA, Ren R, Levitan IB. Association of SRC tyrosine kinase with a human potassium channel mediated by SH3 domain. Science 1996;274:2089-2091. [PubMed: 8953041]

215. Hoshi T, Zagotta WN. Biophysical and molecular mechanisms of Shaker potassium channel inactivation. Science 1990;250:533-538. [PubMed: 2122519]

216. Hropot M, Fowler N, Karlmark B, Giebisch G. Tubular action of diuretics: distal effects on electrolyte transport and acidification. Kidney Int 1985;28:477-489. [PubMed: 4068482]

217. Huang CL, Feng S, Hilgemann DW. Direct activation of inward rectifier potassium channels by $\mathrm{PIP}_{2}$ and its stabilization by G $\beta \gamma$. Nature 1998;391:803-806. [PubMed: 9486652]

218. Hunter M. Potassium-selective channels in the basolateral membrane of single proximal tubule cells of frog kidney. Pflügers Arch 1991;418:26-34.

219. Hunter M, Lopes AG, Boulpaep EL, Giebisch G. Single channel recordings of calcium-activated potassium channels in the apical membrane of rabbit cortical collecting tubules. Proc Natl Acad Sci USA 1984;81:4237-4239. [PubMed: 6330754]

220. Hunter M, Lopes AG, Boulpaep EL, Giebisch G. Regulation of single potassium ion channels from apical membrane of rabbit collecting tubule. Am J Physiol Renal Fluid Electrolyte Physiol 1986;251:F725-F733.

221. Hurst AM, Beck JS, Laprade R, Lapointe JY. Na pump inhibition downregulates an ATP-sensitive $\mathrm{K}$ channel in rabbit proximal convoluted tubule. Am J Physiol Renal Fluid Electrolyte Physiol 1991;264:F760-F764.

222. Hurst AM, Duplain M, Lapointe JY. Basolateral membrane potassium channels in rabbit cortical thick ascending limb. Am J Physiol Renal Fluid Electrolyte Physiol 1992;263:F262-F267.

223. Hurst AM, Hunter M. Apical $\mathrm{K}^{+}$channels of frog diluting segment: inhibition by acidification. Pflügers Arch 1989;415:115-117.

224. Hurst AM, Hunter M. Acute changes in channel density of amphibian diluting segment. Am J Physiol Cell Physiol 1990;259:C1005-C1009.

225. Hurst AM, Hunter M. Apical membrane potassium channels in frog diluting segment: stimulation by furosemide. Am J Physiol Renal Fluid Electrolyte Physiol 1992;262:606-614.

226. Hurst AM, Lapointe JY, Laamarti A, Bell PD. Basic properties and potential regulators of the apical $\mathrm{K}^{+}$channel in macula densa. J Gen Physiol 1994;103:1055-1070. [PubMed: 7931137]

227. Imai M, Nakamura R. Function of distal convoluted and connecting tubules studied by isolated nephron fragments. Kidney Int 1982;22:465-472. [PubMed: 6130184]

228. Imredy JP, Chen C, MacKinnon R. A snake toxin inhibitor of inward rectifier potassium channel ROMK1. Biochemistry 1998;37:14867-14874. [PubMed: 9778362] 
229. Inagaki N, Gonoi T, Clement JP IV, Namba N, Inazawa J, Gonzalez G, Aguilar-Bryan L, Seino S, Bryan J. Reconstitution of $\mathrm{I}_{\mathrm{ATP}}$ : an inward rectifier subunit plus the sulfonylurea receptor. Science 1995;270:1166-1170. [PubMed: 7502040]

230. Inagaki N, Gonoi T, Clement JP, Wang CZ, Aguilar-Bryan L, Bryan J, Seino S. A family of sulfonylurea receptors determines the pharmacological properties of ATP-sensitive $\mathrm{K}^{+}$channels. Neuron 1996;16:1011-1017. [PubMed: 8630239]

231. Inagaki $\mathrm{N}$, Gonoi $\mathrm{T}$, Seino $\mathrm{S}$. Subunit stoichiometry of the pancreatic $\beta$-cell ATP-sensitive $\mathrm{K}^{+}$ channel. FEBS Lett 1997;409:232-236. [PubMed: 9202152]

232. Inagaki N, Tsuura Y, Namba N, Masuda K, Gonoi T, Horie M, Seino Y, Mizuta M, Seino S. Cloning and functional characterization of a novel ATP-sensitive potassium channel ubiquitously expressed in rat tissues, including pancreatic islets, pituitary, skeletal muscle, and heart. J Biol Chem 1995;270:5691-5694. [PubMed: 7890693]

233. Isacoff EY, Jan YN, Jan LY. Evidence for the formation of heteromultimeric potassium channels in Xenopus oocytes. Nature 1990;345:530-534. [PubMed: 2112229]

234. Ito M, Inanobe A, Horio Y, Hibino H, Isomoto S, Ito H, Mori K, Tonosaki A, Tomoike H, Kurachi $\mathrm{Y}$. Immunologicalization of an inwardly rectifying $\mathrm{K}^{+}$channel, $\mathrm{K}_{\mathrm{AB}}-2$ (Kir4.1), in the basolateral membrane of renal distal tubular epithelia. FEBS Lett 1996;388:11-15. [PubMed: 8654579]

235. Jan LY, Jan YN. Tracing the roots of ion channels. Cell 1992;715:715-718. [PubMed: 1375539]

236. Jan LY, Jan YN. Potassium channels and their evolving gates. Nature 1994;371:119-122. [PubMed: 8072541]

237. Jan LY, Jan YN. Voltage-gated and inwardly rectifying potassium channels. J Physiol 1997;505:267-282. [PubMed: 9423171]

238. Jan LY, Jan YN. Cloned potassium channels from eukaryotes and prokaryotes. Annu Rev Neurosci 1997;20:91-123. [PubMed: 9056709]

239. Jan LY, Jan YN. Voltage-sensitive ion channels. Cell 2002;56:13-25. [PubMed: 2463091]

240. Jeck N, Derst C, Wischmeyer E, Ott H, Weber S, Rudin C, Seyberth HW, Daut J, Karschin A, Konrad M. Functional heterogeneity of ROMK mutations linked to hyperprostaglandin E syndrome. Kidney Int 2001;59:1803-1811. [PubMed: 11318951]

241. Jesus Ferreira MC, Bailly C. Extracellular $\mathrm{Ca}^{2+}$ decreases chloride reabsorption in rat CTAL by inhibiting cAMP pathway. Am J Physiol Renal Physiol 1998;275:F198-F203.

242. Jesus Ferreira MC, Helies-Toussaint C, Imbert-Teboul M, Bailly C, Verbavatz JM, Bellanger AC, Chabardes D. Co-expression of a $\mathrm{Ca}^{2+}$-inhibitable adenylyl cyclase and of a $\mathrm{Ca}^{2+}$-sensing receptor in the cortical thick ascending limb cell of the rat kidney. Inhibition of hormone-dependent cAMP accumulation by extracellular $\mathrm{Ca}^{2+} \mathrm{J}$ Biol Chem 1998;273:15192-15202. [PubMed: 9614133]

244. Jiang Y, Lee A, Chen J, Cadene M, Chalt B, MacKinnon R. The open pore conformation of potassium channels. Nature 2002;417:523-526. [PubMed: 12037560]

245. Jiang Y, Lee A, Chen J, Ruta V, Cadene M, Chait BT, MacKinnon R. X-ray structure of a voltagedependent $\mathrm{K}^{+}$channel. Nature 2003;423:33-41. [PubMed: 12721618]

246. Jiang Y, Ruta V, Chen J, Lee A, MacKinnon R. The principle of gating charge movement in a voltage-dependent $\mathrm{K}^{+}$channel. Nature 2003;423:42-48. [PubMed: 12721619]

247. Jin W, Lu Z. A novel high-affinity inhibitor for inward-rectifier $\mathrm{K}^{+}$channels. Biochemistry 1998;37:13291-13299. [PubMed: 9748337]

248. Johnson MS. Comparisons of protein structures. Curr Opin Struct Biol 1991;1:334-344.

249. Johnson RP, O'Kelly IM, Fearon IM. System-specific $\mathrm{O}_{2}$ sensitivity of the tandem pore domain K + channel TASK-1. Am J Physiol Cell Physiol 2004;286:C391-C397. [PubMed: 14576090]

250. Jones PA, Tucker SJ, Ashcroft FM. Multiple sites of interaction between the intracellular domains of an inwardly rectifying potassium channel, Kir6.2. FEBS Lett 2001;508:85-89. [PubMed: 11707273]

251. Kahle KT, Wilson FH, Leng Q, Lalioti MD, O’Connell AD, Dong K, Rapson AK, MacGregor GG, Giebisch G, Hebert SC, Lifton RP. WNK4 regulates the balance between renal $\mathrm{NaCl}$ reabsorption and $\mathrm{K}^{+}$secretion. Nat Genet 2003;35:372-376. [PubMed: 14608358] 
252. Kaide JI, Zhang F, Wei Y, Jiang HL, Yu C, Wang WH, Balazy M, Abraham NG, Nasjletti A. Carbon monoxide of vascular origin attenuates the sensitivity of renal arterial vessels to vaso-constrictiors. J Clin Invest 2001;107:1163-1171. [PubMed: 11342580]

253. Kakei M, Kelly RP, Ashcroft SJH, Ashcroft FM. The ATP-sensitivity of $\mathrm{K}^{+}$channels in rat pancreatic B-cells is modulated by ADP. FEBS Lett 1986;208:63-66. [PubMed: 2429869]

254. Kamb A, Tseng-Crank J, Tanouye MA. Multiple products of the Drosophila Shaker gene may contribute to potassium channel diversity. Neuron 1988;1:421-430. [PubMed: 3272175]

255. Kamel KS, Ethier JH, Quaggin S, Levin A, Albert S, Carlisle EJ, Halperin ML. Studies to determine the basis for hyperkalemia in recipients of a renal transplant who are treated with cyclosporine. $\mathrm{J}$ Am Soc Nephrol 1992;2:1279-1284. [PubMed: 1627752]

256. Kanevsky M, Aldrich RW. Determinants of voltage-dependent gating and open-state stability in the S5 segment of Shaker potassium channels. J Gen Physiol 1999;114:215-242. [PubMed: 10435999]

257. Kang J, Wang L, Cai F, Rampe D. High affinity blockade of the HERG cardiac K(+) channel by the neuroleptic pimozide. Eur J Pharmacol 2000;392:137-140. [PubMed: 10762666]

258. Karolyi L, Koch MC, Grzeschik KH, Seyberth HW. The molecular genetic approach to "Bartter's syndrome. J Mol Med 1998;76:317-325. [PubMed: 9587066]

259. Karolyil L, Konrad M, Kockerling A, Ziegler A, Zimmermann DK, Roth B, Wieg C, Grzeschik KH, Koch MC, Seyberth HW, Vargus R, Forestier L, Jean G, Deschaux M, Rizzoni GF, Niaudet P, Antignac C, Feldman D, Lorridon F, Cougoureux E, Laroze F, Alessandri JL, David L, Saunier P, Deschenes G, Hildebrandt F, Vollmer M, Proesmans W, Brandis M, van den Heuvell LPWJ, Lemmink HH, Nillesen W, Monnens LAH, Knoers NVAM, Guay-Woodford LM, Wright CJ, Madrigal G, Hebert SC. Mutations in the gene encoding the inwardly-rectifying renal potassium channel, ROMK, cause the antenatal variant of Bartter syndrome: evidence for genetic heterogeneity. Hum Mol Genet 1997;6:17-26. [PubMed: 9002665]

260. Kawahara K. A stretch-activated $\mathrm{K}^{+}$channel in the basolateral membrane of Xenopus kidney proximal tubule cells. Pflügers Arch 1990;415:624-629.

261. Kawahara K, Hunter M, Giebisch G. Potassium channels in Necturus proximal tubule. Am J Physiol Renal Fluid Electrolyte Physiol 1987;253:F488-F494.

262. Kawahara K, Ogawa A, Suzuki M. Hyposmotic activation of Ca-activated K channels in cultured rabbit kidney proximal tubule cells. Am J Physiol Renal Fluid Electrolyte Physiol 1991;260:F27F33.

263. Kerr ID, Sansom MS. The pore-lining region of Shaker voltage-gated potassium channels: comparison of beta-barrel and alpha-helix bundle models. Biophys J 1997;73:581-602. [PubMed: 9251779]

264. Kerschensteiner D, Stocker M. Heteromeric asembly of Kv2.1 with Kv9.3: effect on the state dependence of inactivation. Biophys J 1999;77:248-257. [PubMed: 10388754]

265. Ketchum KA, Joiner WJ, Sellers AJ, Kaczmarek LK, Goldstein SAN. A new family of outwardly rectifying potassium channel proteins with two pore domains in tandem. Nature 1995;376:690-695. [PubMed: 7651518]

266. Khuri RN, Wiederholt M, Strieder N, Giebisch G. Effects of flow rate and potassium intake on distal tubular potassium transfer. Am J Physiol 1975;228:1249-1261. [PubMed: 1130523]

267. Kibble J, Neal A, White S, Green R, Evans S, Taylor C. Renal effects of glibenclamide in cystic fibrosis mice. J Am Soc Nephrol 2001;12:2507-2510. [PubMed: 11675429]

268. Kim D, Gnatenco C. TASK-5, a new member of the tandem-pore $\mathrm{K}(+)$ channel family. Biochem Biophys Res Commun 2001;284:923-930. [PubMed: 11409881]

269. Kim Y, Gnatenco C, Bang H, Kim D. Localization of TREK-2 $\mathrm{K}^{+}$channel domains that regulate channel kinetics and sensitivity to pressure, fatty acids and pHi. Pflügers Arch 2001;442:952-960.

270. Klemm MF, Lang RJ. Distribution of $\mathrm{Ca}^{2+}$-activated $\mathrm{K}^{+}$channel (SK2 and SK3) immunoreactivity in intestinal smooth muscles of the guinea-pig. Clin Exp Pharmacol Physiol 2002;29:18-25. [PubMed: 11906457]

271. Kobrinsky E, Mirshahi T, Zhang H, Jin T, Logothetis DE. Receptor-mediated hydrolysis of plasma membrane messenger $\mathrm{PIP}_{2}$ leads to $\mathrm{K}^{+}$-current desensitization. Nat Cell Biol 2000;2:507-514. [PubMed: 10934471] 
272. Kofuji P, Ceelen P, Zahs KR, Surbeck LW, Lester HA, Newman EA. Genetic inactivation of an inwardly rectifying potassium channel (Kir4.1 subunit) in mice: phenotypic impact in retina. $\mathrm{J}$ Neurosci 2000;20:5733-5740. [PubMed: 10908613]

273. Kohda Y, Ding W, Phan E, Housini I, Wang J, Star RA, Huang CL. Localization of the ROMK potassium channel to the apical membrane of distal nephron in rat kidney. Kidney Int 1998;54:12141223. [PubMed: 9767537]

274. Kohler M, Hirschberg B, Bond CT, Kinzie JM, Marrion NV, Maylie J, Adelman JP. Smallconductance, calcium-activated potassium channels from mammalian brain. Science 1996;273:1709-1714. [PubMed: 8781233]

275. Kokko JP. Role of the collecting duct in urinary concentration. Kidney Int 1987;31:606-610. [PubMed: 3550230]

276. Kondo C, Isomoto S, Matsumoto S, Yamada M, Horio Y, Yamashita S, Takemura-Kameda K, Matsuzawa Y, Kurachi Y. Cloning and functional expression of a novel isoform of ROMK inwardly rectifying ATP-dependent $\mathrm{K}^{+}$channel, ROMK6 (Kir1.1f). FEBS Lett 1996;399:122-126. [PubMed: 8980134]

277. Konig J, Schreiber R, Voelcker T, Mall M, Kunzelmann K. The cystic fibrosis transmembrane conductance regulator (CFTR) inhibits ENaC through an increase in the intracellular $\mathrm{Cl}^{-}$ concentration. EMBO Rep 2001;2:1047-1051. [PubMed: 11606421]

278. Konstas AA, Dabrowski M, Korbmacher C, Tucker SJ. Intrinsic sensitivity of Kir1.1 (ROMK) to glibenclamide in the absence of SUR2B. Implications for the identity of the renal ATP-regulated secretory K ${ }^{+}$channel. J Biol Chem 2002;277:21346-21351. [PubMed: 11927600]

279. Konstas AA, Koch JP, Tucker SJ, Korbmacher C. Cystic fibrosis transmembrane conductance regulator-dependent up-regulation of Kir1.1 (ROMK) renal $\mathrm{K}^{+}$channels by the epithelial sodium channel. J Biol Chem 2002;277:25377-25384. [PubMed: 11994290]

280. Konstas AA, Korbmacher C, Tucker SJ. Identification of domains which control the heteromeric assembly of Kir5.1/Kir40 potassium channels. Am J Physiol Cell Physiol 2003;284:C910-C917. [PubMed: 12456399]

281. Koster JC, Bentle KA, Nichols CG, Ho K. Assembly of ROMK1 (Kir1.1a) inward rectifier K ${ }^{+}$ channel subunits involves multiple interaction sites. Biophys J 1998;74:1821-1829. [PubMed: 9545044]

282. Koster JC, Sha Q, Shyng S, Nichols CG. ATP inhibition of $K_{\text {ATP }}$ channels: control of nucleotide sensitivity by the N-terminal domain of the Kir6.2 subunit. J Physiol 1999;515:19-30. [PubMed: 9925874]

283. Krapivinsky G, Medina I, Eng L, Krapivinsky L, Yang Y, Clapham DE. A novel inward rectifier K ${ }^{+}$channel with unique pore properties. Neuron 1998;20:995-1005. [PubMed: 9620703]

284. Krishnan SN, Desai T, Ward DC, Haddad GG. Isolation and chromosomal localization of a human ATP-regulated potassium channel. Hum Genet 1995;96:155-160. [PubMed: 7635463]

285. Kubo Y, Baldwin TJ, Jan YN, Jan LY. Primary structure and functional expression of a mouse inward rectifier potassium channel. Nature 1993;362:127-133. [PubMed: 7680768]

286. Kubo Y, Murata Y. Control of rectification and permeation by two distinct sites after the second transmembrane region in Kir2.1 $\mathrm{K}^{+}$channel. J Physiol 2001;531:645-660. [PubMed: 11251047]

287. Kubokawa M, McNicholas CM, Higgins MA, Wang WH, Giebisch G. Regulation of ATP-sensitive $\mathrm{K}^{+}$channel by membrane-bound protein phosphatases in rat principal tubule cell. Am J Physiol Renal Fluid Electrolyte Physiol 1995;269:355-362.

288. Kubokawa M, Mori Y, Kubota T. Modulation of inwardly rectifying ATP-regulated $\mathrm{K}^{+}$channel by phosphorylation process in opossum kidney cells. Jpn J Physiol 1997;47:111-119. [PubMed: 9159650]

289. Kubokawa M, Nakaya S, Yoshioka Y, Nakamura K, Sato F, Mori Y, Kubota T. Activation of inwardly rectifying $\mathrm{K}$ channel in OK proximal tubule cells involves cGMP-dependent phosphorylation process. Jpn J Physiol 1998;48:467-476. [PubMed: 10021500]

290. Kubokawa M, Wang W, McNicholas CM, Giebisch G. Role of $\mathrm{Ca}^{2+} / \mathrm{CaMK} \mathrm{II}$ in $\mathrm{Ca}^{2+}$-induced K + channel inhibition in rat CCD principal cell. Am J Physiol Renal Fluid Electrolyte Physiol 1995;268:F211-F219. 
291. Kunzelmann K. CFTR: interacting with everything? News Physiol Sci 2001;16:167-170. [PubMed: 11479366]

292. Kunzelmann $\mathrm{K}$. ENaC is inhibited by an increase in the intracellular $\mathrm{Cl}(-)$ concentration mediated through activation of $\mathrm{Cl}(-)$ channels. Pflügers Arch 2003;445:504-512.

293. Kunzelmann K, Bleich M, Warth R, Levy-Holzman R, Garty H, Schreiber R. Expression and function of colonic epithelial KvLQT1 K ${ }^{+}$channels. Clin Exp Pharmacol Physiol 2001;28:79-83. [PubMed: 11153543]

294. Kunzelmann K, Schreiber R, Boucherot A. Mechanisms of the inhibition of epithelial $\mathrm{Na}^{+}$channels by CFTR and purinergic stimulation. Kidney Int 2001;60:455-461. [PubMed: 11473626]

295. Kunzelmann K, Schreiber R, Nitschke R, Mall M. Control of epithelial $\mathrm{Na}^{+}$conductance by the cystic fibrosis transmembrane conductance regulator. Pflügers Arch 2000;440:193-201.

296. Kuo A, Gulbis JM, Antcliff JF, Rahman T, Lowe ED, Zimmer J, Cuthbertson J, Ashcroft FM, Ezaki T, Doyle DA. Crystal structure of the potassium channel KirBac1.1 in the closed state. Science 2003;300:1922-1926. [PubMed: 12738871]

297. Kuryshev YA, Gudz TI, Brown AM, Wible BA. KChAP as a chaperone for specific K(+) channels. Am J Physiol Cell Physiol 2000;278:C931-C941. [PubMed: 10794667]

298. Lang F, Henke G, Embark HM, Waldegger S, Palmada M, Bohmer C, Vallon V. Regulation of channels by the serum and glucocorticoid-inducible kinase: implications for transport, excitability and cell proliferation. Cell Physiol Biochem 2003;13:41-50. [PubMed: 12649601]

299. Lang F, Paulmichl M. Properties and regulation of ion channels in MDCK cells. Kidney Int 1995;48:1200-1205. [PubMed: 8569081]

300. Lang R, Lee G, Liu W, Tian S, Rafi H, Orias M, Segal AS, Desir GV. KCNA10: a novel ion channel functionally related to both voltage-gated potassium and CNG cation channels. Am J Physiol Renal Physiol 2000;278:F1013-F1021. [PubMed: 10836990]

301. Lapointe JY, Laamarti A, Bell PD. Ionic transport in macula densa cells. Kidney Int 1998;67:S58S64.

302. Ledwell JL, Aldrich RW. Mutations in the S4 region isolate the final voltage-dependent cooperative step in potassium channel activation. J Gen Physiol 1999;113:389-414. [PubMed: 10051516]

303. Lee WS, Hebert SC. The ROMK inwardly rectifying ATP-sensitive $\mathrm{K}^{+}$channel. I. Expression in rat distal nephron segments. Am J Physiol Renal Fluid Electrolyte Physiol 1995;268:F1124-F1131.

304. Leipziger J. Control of epithelial transport via luminal P2 receptors. Am J Physiol Renal Physiol 2003;284:F419-F432. [PubMed: 12556361]

305. Leipziger J, MacGregor GG, Cooper GJ, Xu J, Hebert SC, Giebisch G. PKA site mutations of ROMK2 channels shift the $\mathrm{pH}$ dependence to more alkaline values. Am J Physiol Renal Physiol 2000;279:F919-F926. [PubMed: 11053053]

306. Le Maout S, Brejon M, Olsen O, Merot J, Welling PA. Basolateral membrane targeting of a renalepithelial inwardly rectifying potassium channel from the cortical collecting duct, CCD-IRK3, in MDCK cells. Proc Natl Acad Sci USA 1997;94:13329-13334. [PubMed: 9371845]

307. Le Maout S, Welling PA, Brejon M, Olsen O, Merot J. Basolateral membrane expression of a $\mathrm{K}^{+}$ channel, Kir 2.3, is directed by a cytoplasmic COOH-terminal domain. Proc Natl Acad Sci USA 2001;98:10475-10480. [PubMed: 11504929]

308. Lesage F, Duprat F, Fink M, Guillemare E, Coppola T, Lazdunski M, Hugnot JP. Cloning provides evidence for a family of inward rectifier and G-protein coupled $\mathrm{K}^{+}$channels in the brain. FEBS Lett 1994;353:37-42. [PubMed: 7926018]

309. Lesage F, Guillemare E, Fink M, Duprat F, Lazdunski M, Romey G, Barhanin J. TWIK-1, a ubiquitous human weakly inward rectifying $\mathrm{K}^{+}$channel with a novel structure. EMBO J 1996;15:1004-1011. [PubMed: 8605869]

311. Lesage F, Lauritzen I, Duprat F, Reyes R, Fink M, Heurteaux C, Lazdunski M. The structure, function and distribution of the mouse TWIK-1 K+ channel. FEBS Lett 1997;402:28-32. [PubMed: 9013852]

312. Lesage F, Lazdunski M. Molecular and functional properties of two-pore-domain potassium channels. Am J Physiol Renal Physiol 2000;279:F793-F801. [PubMed: 11053038] 
313. Lesage F, Maingret F, Lazdunski M. Cloning and expression of human TRAAK, a polyunsaturated fatty acids-activated and mechanosensitive $\mathrm{K}(+)$ channel. FEBS Lett 2000;471:137-140. [PubMed: 10767409]

314. Letz B, Korbmacher C. cAMP stimulates CFTR-like $\mathrm{Cl}^{-}$channels and inhibits amiloride-sensitive $\mathrm{Na}^{+}$channels in mouse CCD cells. Am J Physiol Cell Physiol 1997;272:C657-C666.

315. Leung YM, Zeng WZ, Liou HH, Solaro CR, Huang CL. Phosphatidylinositol 4,5-bisphosphate and intracellular $\mathrm{pH}$ regulate the ROMK1 potassium channel via separate but interrelated mechanisms. J Biol Chem 2000;275:10182-10189. [PubMed: 10744702]

316. Levitan ES, Hershman KM, Sherman TG, Takimoto K. Dexamethasone and stress upregulate Kv1.5 $\mathrm{K}^{+}$channel gene expression in rat ventricular myocytes. Neuropharmacology 1996;35:1001-1006. [PubMed: 8938730]

317. Li N, Yi FX, Spurrier JL, Bobrowitz CA, Zou AP. Production of superoxide through NADH oxidase in thick ascending limb of Henle's loop in rat kidney. Am J Physiol Renal Physiol 2002;282:F1111F1119. [PubMed: 11997328]

318. Liman ER, Hess P, Weaver F, Koren G. Voltage-sensing residues in the S4 region of a mammalian $\mathrm{K}^{+}$channel. Nature 1991;353:752-756. [PubMed: 1944534]

319. Liman ER, Tytgat J, Hess P. Subunit stoichiometry of a mammalian $\mathrm{K}^{+}$channel determined by construction of multimeric cDNAs. Neuron 1992;9:861-871. [PubMed: 1419000]

320. Lin D, Sterling H, Lerea KM, Giebisch G, Wang WH. Protein kinase C (PKC)-induced phosphorylation of ROMK1 is essential for the surface expression of ROMK1 channels. J Biol Chem 2002;277:44278-44284. [PubMed: 12221079]

321. Lin DH, Sterling H, Lerea KM, Welling P, Jin L, Giebisch G, Wang WH. K depletion increases the protein tyrosine-mediated phosphorylation of ROMK. Am J Physiol Renal Physiol 2002;283:F671F677. [PubMed: 12217858]

322. Linas SL, Peterson LN, Anderson RJ, Aisenbrey GA, Simon FR, Berl T. Mechanism of renal potassium conservation in the rat. Kidney Int 1979;15:601-611. [PubMed: 222934]

323. Ling BN, Eaton DC. Cyclosporin A inhibits apical secretory $\mathrm{K}^{+}$channels in rabbit cortical collecting tubule principal cells. Kidney Int 1993;44:974-984. [PubMed: 8264157]

324. Ling BN, Hinton CF, Eaton DC. Potassium permeable channels in primary cultures of rabbit cortical collecting tubule. Kidney Int 1991;40:441-452. [PubMed: 1664902]

325. Ling BN, Webster CL, Eaton DC. Eicosanoids modulate apical $\mathrm{Ca}^{2+}$-dependent $\mathrm{K}^{+}$channels in cultured rabbit principal cells. Am J Physiol Renal Fluid Electrolyte Physiol 1992;263:F116-F126.

326. Liou HH, Zhou SS, Huang CL. Regulation of ROMK1 channel by protein kinase A via a phosphatidylinositol 4,5-bisphosphate-dependent mechanism. Proc Natl Acad Sci USA 1999;96:5820-5825. [PubMed: 10318968]

327. Liu H, Mount DB, Nasjletti A, Wang W. Carbon monoxide stimulates the apical 70-pS $\mathrm{K}^{+}$channel of the rat thick ascending limb. J Clin Invest 1999;103:963-970. [PubMed: 10194468]

328. Liu HJ, Wei Y, Ferreri N, Nasjletti A, Wang WH. Vasopressin and $\mathrm{PGE}_{2}$ regulate the apical $70 \mathrm{pS}$ K channel in the thick ascending limb of rat kidney. Am J Physiol Cell Physiol 2000;278:C905C913. [PubMed: 10794664]

329. Lock LF, Gilbert DJ, Street VA, Migeon MB, Jenkins NA, Copeland NG, Temple BL. Voltagegated potassium channel genes are clustered in paralogous regions of the mouse genome. Genomics 1994;20:354-362. [PubMed: 8034307]

330. Lopatin AN, Makhina EN, Nichols CG. Potassium channel block by cytoplasmic polyamines as the mechanism of intrinsic rectification. Nature 1994;372:366-369. [PubMed: 7969496]

331. Lopes CM, Zhang H, Rohacs T, Jin T, Yang J, Logothetis DE. Alterations in conserved Kir channel$\mathrm{PIP}_{2}$ interactions underlie channelopathies. Neuron 2002;34:933-944. [PubMed: 12086641]

332. Lorenz E, Alekseev AE, Krapivinsky GB, Carrasco AJ, Clapham DE, Terzic A. Evidence for direct physical association between a $\mathrm{K}^{+}$channel (Kir6.2) and ATP-binding cassette protein (SUR1) which affects cellular distribution and kinetic behavior of an ATP-sensitive $\mathrm{K}^{+}$channel. Mol Cell Biol 1998;18:1652-1659. [PubMed: 9488482]

333. Lorenz JN, Baird NR, Judd LM, Noonan WT, Andringa A, Doetschman T, Manning PA, Liu LH, Miller ML, Shull GE. Impaired renal $\mathrm{NaCl}$ absorption in mice lacking the ROMK potassium 
channel, a model for type II Bartter's syndrome. J Biol Chem 2002;277:37871-37880. [PubMed: 12122007]

337. Lourdel S, Paulais M, Cluzeaud F, Bens M, Tanemoto M, Kurachi Y, Vandewalle A, Teulon J. An inward rectifier $\mathrm{K}^{+}$channel at the basolateral membrane of the mouse distal convoluted tubule: similarities with Kir4-Kir5.1 heteromeric channels. J Physiol 2002;538:391-404. [PubMed: 11790808]

338. Lu M, Giebisch G, Wang W. Nitric oxide links the apical $\mathrm{Na}^{+}$transport to the basolateral $\mathrm{K}^{+}$ conductance in the rat cortical collecting duct. J Gen Physiol 1997;110:717-726. [PubMed: 9382898]

339. Lu M, Hebert SC, Giebisch G. Hydrolyzable ATP and PIP 2 modulate the small conductance $\mathrm{K}^{+}$ channel in apical membranes of rat cortical collecting duct (CCD). J Gen Physiol 2002;120:603615. [PubMed: 12407074]

340. Lu M, MacGregor GG, Wang W, Giebisch G. Extracellular ATP inhibits the small-conductance K channel on the apical membrane of the cortical collecting duct from mouse kidney. J Gen Physiol 2000;116:299-310. [PubMed: 10919872]

341. Lu M, Wang T, Yan Q, Wang W, Giebisch G, Hebert SC. ROMK is required for expression of the 70pS K channel in the thick ascending limb. Am J Physiol Renal Physiol 2003;286:F490-F495. [PubMed: 14600033]

342. Lu M, Wang T, Yan Q, Yang X, Dong K, Knepper MA, Wang W, Giebisch G, Shull GE, Hebert SC. Absence of small-conductance $\mathrm{K}^{+}$channel (SK) activity in apical membranes of thick ascending limb and cortical collecting duct in ROMK (Bartter's) knockout mice. J Biol Chem 2002;277:37881-37887. [PubMed: 12130653]

343. Lu M, Wang W. Two types of $\mathrm{K}^{+}$channels are present in the apical membrane of the thick ascending limb of the mouse kidney. Kidney Blood Press Res 2000;23:75-82. [PubMed: 10765108]

344. Lu M, Wang WH. Nitric oxide regulates the low-conductance $\mathrm{K}^{+}$channel in basolateral membrane of cortical collecting duct. Am J Physiol Cell Physiol 1996;270:C1336-C1342.

345. Lu M, Wang WH. Reaction of nitric oxide with superoxide inhibits basolateral $\mathrm{K}^{+}$channels in the rat CCD. Am J Physiol Cell Physiol 1998;275:C309-C316.

346. Lu M, Wang X, Wang W. Nitric oxide increases the activity of the apical 70-pS $\mathrm{K}^{+}$channel in TAL of rat kidney. Am J Physiol Renal Physiol 1998;274:F946-F950.

347. Lu Z, Klem AM, Ramu Y. Ion conduction pore is conserved among potassium channels. Nature 2001;413:809-813. [PubMed: 11677598]

348. Lu Z, MacKinnon R. Electrostatic tuning of $\mathrm{Mg}^{2+}$ affinity in an inward-rectifier $\mathrm{K}^{+}$channel. Nature 1994;371:243-246. [PubMed: 7915826]

349. Lundgren DW, Moore JJ, Chang SM, Collins PL, Chang AS. Gestational changes in the uterine expression of an inwardly rectifying $\mathrm{K}^{+}$channel, ROMK. Proc Soc Exp Biol Med 1997;216:5764. [PubMed: 9316611]

350. MacGregor GG, Xu J, McNicholas CM, Giebisch G, Hebert SC. Partially active channels produced by PKA site mutation of the cloned renal $\mathrm{K}^{+}$channel ROMK2. Am J Physiol Renal Physiol 1998;275:F415-F422.

351. MacGregor GG, Dong K, Vanoye CG, Tang L, Giebisch G, Hebert SC. Nucleotides and phospholipids compete for binding to the $\mathrm{C}$-terminus of $\mathrm{K}_{\mathrm{ATP}}$ channels. Proc Natl Acad Sci USA 2002;99:2726-2731. [PubMed: 11880626]

352. Macica CM, Yang Y, Hebert SC, Wang WH. Arachidonic acid inhibits the activity of the cloned renal K ${ }^{+}$channel, ROMK1. Am J Physiol Renal Physiol 1996;271:F588-F594.

353. Macica CM, Yang Y, Lerea K, Hebert SC, Wang W. Role of the $\mathrm{NH}_{2}$ terminus of the cloned renal $\mathrm{K}^{+}$channel, ROMK1, in arachidonic acid-mediated inhibition. Am J Physiol Renal Physiol 1997;274:F175-F181.

354. MacKinnon R. Pore loops: an emerging theme in ion channel structure. Neuron 1995;14:889-892. [PubMed: 7538310]

355. MacKinnon R, Heginbotham L, Abramson T. Mapping the receptor site for charybdotoxin, a poreblocking potassium channel inhibitor. Neuron 1990;5:767-771. [PubMed: 1702643]

356. MacKinnon R, Yellen G. Mutations affecting TEA blockade and ion permeation in voltage-activated $\mathrm{K}^{+}$channels. Science 1990;250:276-279. [PubMed: 2218530] 
357. Maingret F, Fosset M, Lesage F, Lazdunski M, Honore E. TRAAK is a mammalian neuronal mechano-gated K ${ }^{+}$channel. J Biol Chem 1999;274:1381-1387. [PubMed: 9880510]

358. Malnic G, Aires MM, Giebisch G. Potassium transport across renal distal tubules during acid-base disturbances. Am J Physiol 1971;221:1192-1208. [PubMed: 5111262]

359. Malnic G, Klose R, Giebisch G. Micropuncture study of renal potassium excretion in the rat. Am J Physiol 1964;206:674-686. [PubMed: 14166157]

360. Malnic G, Klose RM, Giebisch G. Micropuncture study of distal tubular potassium and sodium transport in rat nephron. Am J Physiol 1966;211:529-547. [PubMed: 5927880]

361. Martel J, Dupuis G, Deschenes P, Payet MD. The sensitivity of the human Kv1.3 (hKv13) lymphocyte $\mathrm{K}^{+}$channel to regulation by PKA and PKC is partially lost in HEK 293 host cells. J Membr Biol 1998;161:183-196. [PubMed: 9435274]

362. Martens JR, Gelband $\mathrm{CH}$. Alterations in rat interlobar artery membrane potential and $\mathrm{K}^{+}$channels in genetic and nongenetic hypertension. Circ Res 1996;79:295-301. [PubMed: 8756007]

363. Marvao P, Jesus Ferreira MC, Bailly C, Paulais M, Bens M, Guinamard R, Moreau R, Vandewalle A, Teulon $\mathrm{J} \mathrm{Cl}^{-}$absorption across the thick ascending limb is not altered in cystic fibrosis mice. A role for a pseudo-CFTR $\mathrm{Cl}^{-}$channel. J Clin Invest 1998;102:1986-1993. [PubMed: 9835624]

364. Mathur R, Zheng J, Yan Y, Sigworth FJ. Role of the S3-S4 linker in Shaker potassium channel activation. J Gen Physiol 1997;109:191-199. [PubMed: 9041448]

365. Matsunaga H, Yamashita N, Miyajima Y, Okuda T, Chang H, Ogata E, Kurokawa K. Ion channel activities of cultured rat mesangial cells. Am J Physiol Renal Fluid Electrolyte Physiol 1991;261:F808-F814.

366. Matsunaga H, Yamashita N, Okada T, Kurokawa K. Mesangial cell ion transport and tubuloglomerular feedback. Curr Opin Nephrol Hypertens 1994;3:518-522. [PubMed: 7804750]

367. Mauerer UR, Boulpaep EL, Segal AS. Properties of an inwardly rectifying ATP-sensitive K channel in the basolateral membrane of renal proximal tubule. J Gen Physiol 1998;111:139-160. [PubMed: 9417141]

368. McCobb DP, Fowler NL, Featherstone T, Lingle CJ, Saito M, Krause JE, Salkoff L. A human calcium-activated potassium channel gene expressed in vascular smooth muscle. Am J Physiol Heart Circ Physiol 1995;269:H767-H777.

369. McGiff JC. Cytochrome P-450 metabolism of arachidonic acid. Annu Rev Pharmacol Toxicol 1991;31:339-369. [PubMed: 1905908]

370. McNicholas CM, Guggino WB, Schwiebert EM, Hebert SC, Giebisch G, Egan ME. Sensitivity of a renal $\mathrm{K}^{+}$channel (ROMK2) to the inhibitory sulfonylurea compound, glibenclamide, is enhanced by co-expression with the ATP-binding cassette transporter cystic fibrosis transmembrane regulator. Proc Natl Acad Sci USA 1996;93:8083-8088. [PubMed: 8755607]

371. McNicholas CM, MacGregor GG, Islas LD, Yang Y, Hebert SC, Giebisch G. pH-dependent modulation of the cloned renal $\mathrm{K}^{+}$channel, ROMK. Am J Physiol Renal Physiol 1998;275:F972F981.

372. McNicholas CM, Nason MW, Guggino WB, Schwiebert EM, Hebert SC, Giebisch G, Egan ME. A functional CFTR-NBF1 is required for ROMK2-CFTR interaction. Am J Physiol Renal Physiol 1997;273:F843-F848.

373. McNicholas CM, Wang W, Ho K, Hebert SC, Giebisch G. Regulation of ROMK1 K ${ }^{+}$channel activity involves phosphorylation processes. Proc Natl Acad Sci USA 1994;91:8077-8081. [PubMed: 8058760]

374. McNicholas CM, Yang Y, Giebisch G, Hebert SC. Molecular site for nucleotide binding on an ATPsensitive renal K ${ }^{+}$channel (ROMK2). Am J Physiol Renal Physiol 1996;271:F275-F285.

375. Medhurst AD, Rennie G, Chapman CG, Meadows H, Duckworth MD, Kelsell RE, Gloger II, Pangalos MN. Distribution analysis of human two pore domain potassium channels in tissues of the central nervous system and periphery. Brain Res 2001;86:101-114.

376. Meera P, Wallner M, Jiang Z, Toro L. A calcium switch for the functional coupling between alpha (hslo) and beta subunits (Kv, cabeta) of maxi K channels. FEBS Lett 1996;385:127-128. [PubMed: 8641456] 
377. Meera P, Wallner M, Toro L. A neuronal beta subunit (KCNMB4) makes the large conductance, voltage- and $\mathrm{Ca}^{2+}$-activated $\mathrm{K}^{+}$channel resistant to charybdotoxin and iberiotoxin. Proc Natl Acad Sci USA 2000;97:5567.

378. Mennitt PA, Frindt G, Silver RB, Palmer LG. Potassium restriction downregulates ROMK expression in rat kidney. Am J Physiol Renal Physiol 2000;278:F916-F924. [PubMed: 10836979]

379. Mennitt PA, Wade JB, Ecelbarger CA, Palmer LG, Frindt G. Localization of ROMK channels in the rat kidney. J Am Soc Nephrol 1997;8:1823-1830. [PubMed: 9402083]

380. Merot J, Bidet M, Le Maout S, Tauc M, Poujeol P. Two types of $\mathrm{K}^{+}$channels in the apical membrane of rabbit proximal tubule in primary culture. Biochim Biophys Acta 1989;978:134-144. [PubMed: 2563329]

381. Merot J, Poncet V, Bidet M, Tauc M, Poujeol P. Apical membrane ionic channels in the rabbit cortical thick ascending limb in primary culture. Biochim Biophys Acta 1991;1070:387-400. [PubMed: 1684913]

382. Minor DL, Lin YF, Mobley BC, Avelar A, Jan YN, Jan LY, Berger JM. The polar T1 interface is linked to conformational changes that open the voltage-gated potassium channel. Cell 2000;102:657-670. [PubMed: 11007484]

383. Minor DL, Masseling SJ, Jan YN, Jan LY. Transmembrane structure of an inwardly rectifying potassium channel. Cell 1999;97:879-891. [PubMed: 10102275]

384. Misler S, Giebisch G. ATP-sensitive potassium channels in physiology, pathophysiology, and pharmacology. Curr Opin Nephrol Hypertens 1992;1:21-33. [PubMed: 1365828]

385. Moral Z, Dong K, Wei Y, Sterling H, Deng H, Ali S, Gu R, Huang XY, Hebert SC, Giebisch G, Wang WH. Regulation of ROMK1 channels by protein-tyrosine kinase and -tyrosine phosphatase. J Biol Chem 2001;276:7156-7163. [PubMed: 11114300]

386. Morales MM, Carroll TP, Morita T, Schwiebert EM, Devuyst O, Wilson PD, Lopes AG, Stanton BA, Dietz HC, Cutting GR, Guggino WB. Both the wild type and a functional isoform of CFTR are expressed in kidney. Am J Physiol Renal Fluid Electrolyte Physiol 1996;270:F1038-F1048.

387. Morishige K, Takahashi N, Jahangir A, Yamada M, Koyama H, Zanelli JS, Kurachi Y. Molecular cloning and functional expression of a novel brain-specific inward rectifier potassium channel. FEBS Lett 1994;346:251-256. [PubMed: 8013643]

388. Morita T, Hanaoka K, Morales MM, Montrose-Rafizadeh C, Guggino WB. Cloning and characterization of maxi $\mathrm{K}^{+}$channel alpha-subunit in rabbit kidney. Am J Physiol Renal Physiol 1997;273:F615-F624.

389. Morton MJ, O'Connell AD, Sivaprasadarao A, Hunter M. Determinants of $\mathrm{pH}$ sensing in the twopore domain $\mathrm{K}(+)$ channels TASK-1 and -2. Pflügers Arch 2003;445:577-583.

391. Muto S, Asano Y, Seldin D, Giebisch G. Basolateral $\mathrm{Na}^{+}$pump modulates apical $\mathrm{Na}^{+}$and $\mathrm{K}^{+}$ conductances in rabbit cortical collecting ducts. Am J Physiol Renal Physiol 1999;276:F143-F158.

392. Muto S, Giebisch G, Sansom S. An acute increase of peritubular K stimulates K transport through cell pathways of CCT. Am J Physiol Renal Fluid Electrolyte Physiol 1988;255:F108-F114.

393. Muto S, Sansom S, Giebisch G. Effects of a high potassium diet on electrical properties of cortical collecting duct from adrenalectomized rabbits. J Clin Invest 1988;81:376-380. [PubMed: 3339125]

394. Nagel G, Szellas T, Riordan JR, Friedrich T, Hartung K. Non-specific activation of the epithelial sodium channel by the CFTR chloride channel. EMBO Rep 2001;2:249-254. [PubMed: 11266369]

395. Nakamura K, Hirano J, Kubokawa M. An ATP-regulated and pH-sensitive inwardly rectifying K (+) channel in cultured human proximal tubule cells. Jpn J Physiol 2001;51:523-530. [PubMed: 11564289]

396. Nakamura N, Suzuki Y, Sakuta H, Ookata K, Kawahara K, Hirose S. Inwardly rectifying K ${ }^{+}$channel Kir7.1 is highly expressed in thyroid follicular cells, intestinal epithelial cells and choroid plexus epithelial cells: implication for a functional coupling with $\mathrm{Na}^{+}, \mathrm{K}^{+}$-ATPase. Biochem J 1999;342:329-336. [PubMed: 10455019]

397. Nichols CG, Ho K, Hebert SC. $\mathrm{Mg}^{2+}$-dependent inward rectification of ROMK1 potassium channels expressed in Xenopus oocytes. J Physiol 1994;476:399-409. [PubMed: 8057249]

398. Nichols CG, Lopatin AN. Inward rectifier potassium channels. Annu Rev Physiol 1997;59:171191. [PubMed: 9074760] 
399. Niemeyer MI, Cid LP, Barros LF, Sepulveda FV. Modulation of the two-pore domain acid-sensitive $\mathrm{K}^{+}$channel TASK-2 (KCNK5) by changes in cell volume. J Biol Chem 2001;276:43166-43174. [PubMed: 11560934]

400. Nishida M, MacKinnon R. Structural basis of inward rectification. Cytoplasmic pore of the G protein-gated inward rectifier GIRK1 at 18 A resolution. Cell 2002;111:957-965. [PubMed: 12507423]

404. Noda M, Shimizu S, Tanabe T, Takai T, Kayano T, Ikeda T, Takahashi H, Nakayama H, Kanaoka Y, Minamino N, Kangawa K, Matsuo H, Raftery MA, Hirose T, Inayama S, Hayashidal H, Miyata T, Numa S. Primary structure of Electrophorus electricus sodium channel deduced from cDNA sequence. Nature 1984;312:121-127. [PubMed: 6209577]

405. Noulin JF, Brochiero E, Lapointe JY, Laprade R. Two types of K channels at the basolateral membrane of proximal tubule: inhibitory effect of taurine. Am J Physiol Renal Physiol 1999;277:F290-F287.

406. Numa S, Noda M. Molecular structure of sodium channels. Ann NY Acad Sci 1986;479:338-355. [PubMed: 2434000]

407. Oberleithner H, Schneider SW, Henderson RM. Structural activity of a cloned potassium channel (ROMK1) monitored with the atomic force microscope: the "molecular-sandwich" technique. Proc Natl Acad Sci USA 1997;94:14144-14149. [PubMed: 9391167]

408. O’Connell AD, Morton MJ, Hunter M. Two-pore domain $\mathrm{K}^{+}$channels-molecular sensors. Biochim Biophys Acta 2002;1566:152-161. [PubMed: 12421546]

409. Ohno-Shosaku T, Kubota T, Yamaguchi J, Fujimoto M. Regulation of inwardly rectifying $\mathrm{K}^{+}$ channels by intracellular pH in opossium kidney cells. Pflügers Arch 1990;416:138-143.

410. Oliver D, Hahn H, Antz C, Ruppersberg JP, Fakler B. Interaction of permeant and blocking ions in cloned inward-rectifier $\mathrm{K}^{+}$channels. Biophys J 1998;74:2318-2326. [PubMed: 9591659]

411. Olsen O, Liu H, Wade JB, Merot J, Welling PA. Basolateral membrane expression of the Kir 2.3 channel is coordinated by PDZ interaction with Lin-7/CASK complex. Am J Physiol Cell Physiol 2002;282:C183-C195. [PubMed: 11742811]

412. O'Neil RG, Sansom S. Characterization of apical cell membrane $\mathrm{Na}^{+}$and $\mathrm{K}^{+}$conductances of cortical collecting duct using microelectrodes. Am J Physiol Renal Fluid Electrolyte Physiol 1984;247:F14-F24.

413. Ookata K, Tojo A, Suzuki Y, Nakamura N, Kimura K, Wilcox CS, Hirose S. Localization of inward rectifier potassium channel Kir7.1 in the basolateral membrane of distal nephron and collecting duct. J Am Soc Nephrol 2000;11:1987-1994. [PubMed: 11053473]

414. Orias M, Bray-Ward P, Curran ME, Keating MT, Desir GV. Genomic localization of the human gene for KCNA10, a cGMP-activated K channel. Genomics 1997;42:33-37. [PubMed: 9177773]

415. Orias M, Velazquez H, Tung F, Lee G, Desir GV. Cloning and localization of a double-pore K channel, KCNK1: exclusive expression in distal nephron segments. Am J Physiol Renal Physiol 1997;273:F663-F666.

416. Overturf KE, Russel SN, Carl A, Vogalis F, Hart PJ, Hume JR, Sanders KM, Horowitz B. Cloning and characterization of a $\mathrm{K}^{+}$channel from vascular and visceral $\mathrm{K}_{\mathrm{V}} 1.5$ delayed rectifier smooth muscles. Am J Physiol Cell Physiol 1994;267:C1231-C1238.

417. Ozaita A, Vega-Saenz DM. Cloning of two transcripts, HKT41a and HKT41b, from the human twopore $\mathrm{K}^{+}$channel gene KCNK4. Chromosomal localization, tissue distribution and functional expression. Brain Res 2002;102:18-27.

418. Pacha J, Frindt G, Sackin H, Palmer LG. Apical maxi K channels in intercalated cells of CCT. Am J Physiol Renal Fluid Electrolyte Physiol 1991;261:F696-F705.

419. Palmada M, Embark HM, Wyatt AW, Bohmer C, Lang F. Negative charge at the consensus sequence for the serum- and glucocorticoid-inducible kinase, SGK1, determines $\mathrm{pH}$ sensitivity of the renal outer medullary K ${ }^{+}$channel, ROMK1. Biochem Biophys Res Commun 2003;307:967-972. [PubMed: 12878206]

420. Palmer LG. Potassium secretion and the regulation of distal nephron K channels. Am J Physiol Renal Physiol 1999;277:F821-F825.

421. Palmer LG, Antonian L, Frindt G. Regulation of apical K and $\mathrm{Na}$ channels and Na/K pumps in rat cortical collecting tubule by dietary K. J Gen Physiol 1994;104:693-710. [PubMed: 7836937] 
422. Palmer LG, Choe H, Frindt G. Is the secretory K channel in the rat CCT ROMK? Am J Physiol Renal Physiol 1997;273:F404-F410.

423. Palmer LG, Frindt G. Regulation of apical K channels in rat cortical collecting tubule during changes in dietary K intake. Am J Physiol Renal Physiol 1999;277:F805-F812.

424. Palmer LG, Frindt G. Aldosterone and potassium secretion by the cortical collecting duct. Kidney Int 2000;57:1324-1328. [PubMed: 10760062]

425. Papazian DM, Shao XM, Seoh SA, Mock AF, Huang Y, Wainstock DH. Electrostatic interactions of S4 voltage sensor in Shaker $\mathrm{K}^{+}$channel. Neuron 1995;14:1293-1301. [PubMed: 7605638]

426. Parent L, Cardinal J, Sauvé R. Single-channel analysis of a K channel at basolateral membrane of rabbit proximal convoluted tubule. Am J Physiol Renal Fluid Electrolyte Physiol 1988;254:F105F113.

427. Partiseti M, Collura V, Agnel M, Culouscou JM, Graham D. Cloning and characterization of a novel human inwardly rectifying potassium channel predominantly expressed in small intestine. FEBS Lett 1998;434:171-176. [PubMed: 9738472]

428. Patel AJ, Honore E. Properties and modulation of mammalian $2 \mathrm{P}$ domain $\mathrm{K}^{+}$channels. Trends Neurosci 2001;24:339-346. [PubMed: 11356506]

429. Patel AJ, Honore E. Molecular physiology of oxygen-sensitive potassium channels. Eur Respir J 2001;18:221-227. [PubMed: 11510795]

430. Patel AJ, Lazdunski M, Honore E. Kv2.1/Kv9.3, an ATP-dependent delayed-rectifier $\mathrm{K}^{+}$channel in pulmonary artery myocytes. Ann NY Acad Sci 1999;868:438-441. [PubMed: 10414317]

431. Paulais M, Lourdel S, Teulon J. Properties of an inwardly rectifying $\mathrm{K}^{+}$channel in the basolateral membrane of mouse TAL. Am J Physiol Renal Physiol 2002;282:F866-F876. [PubMed: 11934697]

432. Pawson T, Scott JD. Signaling through scaffold, anchoring, and adaptor proteins. Science 1997;278:2075-2080. [PubMed: 9405336]

433. Pearson WL, Dourado M, Schreiber M, Salkoff L, Nichols CG. Expression of a functional Kir4 family inward rectifier $\mathrm{K}^{+}$channel from a gene cloned from mouse liver. J Physiol 1999;514:639_ 653. [PubMed: 9882736]

434. Perozo E, Santacruz Toloza L, Stefani E, Bezanilla F, Papazian DM. S4 mutations alter gating currents of Shaker K channels. Biophys J 1994;66:345-354. [PubMed: 8161688]

435. Pessia M, Imbrici P, D’Adamo MC, Salvatore L, Tucker SJ. Differential pH sensitivity of Kir4.1 and Kir42 potassium channels and their modulation by heteropolymerisation with Kir5.1. J Physiol 2001;532:359-367. [PubMed: 11306656]

436. Peter, K. Untersuchungen uber Bau und Entwickelung der Niere. Jena: Gustav Fisher; 1909. p. $1-358$.

437. Peters M, Ermert S, Jeck N, Derst C, Pechmann U, Weber S, Schlingmann KP, Seyberth HW, Waldegger S, Konrad M. Classification and rescue of ROMK mutations underlying hyperprostaglandin E syndrome/antenatal Bartter syndrome. Kidney Int 2003;64:923-932. [PubMed: 12911542]

438. Peters M, Jeck N, Reinalter S, Leonhardt A, Tonshoff B, Klaus GG, Konrad M, Seyberth HW. Clinical presentation of genetically defined patients with hypokalemic salt-losing tubulopathies. Am J Med 2002;112:183-190. [PubMed: 11893344]

439. Peterson LN, Wright FS. Effect of sodium intake on renal potassium excretion. Am J Physiol Renal Fluid Electrolyte Physiol 1977;233:F225-F234.

440. Pluznick JL, Wei P, Carmines PK, Sansom SC. Renal fluid and electrolyte handling in BKCa-beta1 -/- mice. Am J Physiol Renal Physiol 2003;284:F1274-F1279. [PubMed: 12620927]

441. Pongs O, Kecskemethy N, Muller R, Krah-Jentgens I, Baumann A, Klitz HH, Canal I, Llamazares S, Ferrus A. Shaker encodes a family of putative potassium channel proteins in the nervous system of Drosophila. EMBO J 1998;7:1087-1096. [PubMed: 2456921]

442. Pongs O, Leicher T, Berger M, Roeper J, Bahring R, Wray D, Giese KP, Silva AJ, Storm JF. Functional and molecular aspects of voltage-gated $\mathrm{K}^{+}$channel beta subunits. Ann NY Acad Sci 1999;868:344-355. [PubMed: 10414304]

443. Praetorius HA, Spring KR. Bending the MDCK cell primary cilium increases intracellular calcium. J Membr Biol 2001;184:71-79. [PubMed: 11687880] 
444. Prior HM, Yates MS, Beech DJ. Role of $\mathrm{K}$ channel in $\mathrm{A}_{2 \mathrm{~A}}$ adenosine receptor-mediated dilation of the pressurized renal arcuate artery. Br J Pharmacol 1999;126:494-500. [PubMed: 10077243]

445. Prior HM, Yates MS, Beech DJ. Function of large conductance Ca-activated (BKCa), delayed rectifier $(\mathrm{Kv})$ and background $\mathrm{K}$ channels in the control of membrane potential in rabbit renal arcuate artery. J Physiol 1998;15:159-169. [PubMed: 9679171]

446. Quamme GA, Dirks JH. Intraluminal and contraluminal magnesium on magnesium and calcium transfer in the rat nephron. Am J Physiol Renal Fluid Electrolyte Physiol 1980;238:F187-F198.

447. Raab-Graham KF, Vandenberg CA. Tetrameric subunit structure of the native brain inwardly rectifying potassium channel $\mathrm{K}_{\mathrm{ir}}$ 2.2. J Biol Chem 1998;273:19699-19707. [PubMed: 9677399]

448. Raghuram V, Hormuth H, Foskett JK. A kinase-regulated mechanism controls CFTR channel gating by disrupting bivalent PDZ domain interactions. Proc Natl Acad Sci USA 2003;100:9620-9625. [PubMed: 12881487]

449. Rajan S, Wischmeyer E, Karschin C, Preisig-Muller R, Grzeschik KH, Daut J, Karschin A, Derst C. THIK-1 and THIK-2, a novel subfamily of tandem pore domain $\mathrm{K}^{+}$channels. J Biol Chem 2001;276:7302-7311. [PubMed: 11060316]

450. Ramu Y, Klem AM, Lu Z. Titration of tertiapin-Q inhibition of ROMK1 channels by extracellular protons. Biochemistry 2001;40:3601-3605. [PubMed: 11297426]

451. Reeves WB, McDonald GA, Mehta P, Andreoli TE. Activation of $\mathrm{K}^{+}$channels in renal medullary vesicles by cAMP-dependent protein kinase. J Membr Biol 1989;109:65-72. [PubMed: 2769736]

452. Reeves WB, Shah SV. Activation of potassium channels contributes to hypoxic injury in proximal tubules. J Clin Invest 1994;94:2289-2294. [PubMed: 7989584]

453. Reid JD, Lukas W, Shafaatian R, Bertl A, Scheurmann-Kettner C, Guy HR, North RA. The $S$. cerevisiae outwardly-rectifying potassium channel (DUK1) identifies a new family of channels with duplicated pore domains. Receptors Channels 1996;4:51-62. [PubMed: 8723646]

454. Rettig J, Heinemann SH, Wunder F, Lorra C, Parcej DN, Dolly JO, Pongs O. Inactivation properties of voltage-gated $\mathrm{K}^{+}$channels altered by presence of $\beta$-subunit. Nature 1993;369:289-294. [PubMed: 8183366]

455. Reyes R, Duprat F, Lesage F, Fink M, Salinas M, Farman N, Lazdunski M. Cloning and expression of a novel $\mathrm{pH}$-sensitive two pore domain $\mathrm{K}^{+}$channel from human kidney. J Biol Chem 1998;273:30863-30869. [PubMed: 9812978]

456. Ro S, Hatton WJ, Koh SD, Horowitz B. Molecular properties of small-conductance $\mathrm{Ca}^{2+}$-activated $\mathrm{K}^{+}$channels expressed in murine colonic smooth muscle. Am J Physiol Gastrointest Liver Physiol 2001;281:G964-G973. [PubMed: 11557517]

457. Rodriguez-Soriano J. Bartter and related syndromes: the puzzle is almost solved. Pediatr Nephrol 1998;12:315-327. [PubMed: 9655365]

458. Rohacs T, Chen J, Prestwich GD, Logothetis DE. Distinct specificities of inwardly rectifying $\mathrm{K}^{+}$ channels for phosphoinositides. J Biol Chem 1999;274:36065-36072. [PubMed: 10593888]

459. Rohacs T, Lopes C, Mirshahi T, Jin T, Zhang H, Logothetis DE. Assaying phosphatidylinositol bisphosphate regulation of potassium channels. Methods Enzymol 2002;345:71-92. [PubMed: 11665643]

460. Roux B, MacKinnon R. The cavity and pore helices in the $\mathrm{KcsA} \mathrm{K}{ }^{+}$channel: electrostatic stabilization of monovalent cations. Science 1999;285:100-102. [PubMed: 10390357]

461. Roy M, Dumaine R, Brown AM. HERG, a primary human ventricular target of the nonsedating anihistamine terfenadine. Circulation 1996;94:817-823. [PubMed: 8772706]

462. Ruknudin A, Schulze DH, Sullivan SK, Lederer WJ, Welling PA. Novel subunit composition of a renal epithelial KATP channel. J Biol Chem 1998;273:14165-14171. [PubMed: 9603917]

463. Ruppersberg JP. Intracellular regulation of inward rectifier $\mathrm{K}^{+}$channels. Pflügers Arch 2000;441:111.

464. Ruppersberg JP, Schroter KH, Sakmann B, Stocker M, Sewing S, Pongs O. Heteromultimeric channels formed by rat brain potassium-channel proteins. Nature 1990;345:535-537. [PubMed: 2348860]

465. Sabirov RZ, Morishima S, Okada Y. Probing the water permeability of ROMK1 and amphotericin B channels using Xenopus oocytes. Biochim Biophys Acta 1998;1368:19-26. [PubMed: 9459580] 
466. Sackin H. A stretch-activated $\mathrm{K}^{+}$channel sensitive to cell volume. Proc Natl Acad Sci USA 1989;86:1731-1735. [PubMed: 2922408]

467. Sackin H. Mechanosensitive channels. Annu Rev Physiol 1995;57:333-353. [PubMed: 7539988]

468. Sackin H, Palmer LG. Basolateral potassium channels in renal proximal tubule. Am J Physiol Renal Fluid Electrolyte Physiol 1987;253:F476-F487.

469. Sackin H, Syn S, Palmer LG, Choe H, Walters DE. Regulation of ROMK by extracellular cations. Biophys J 2001;80:683-697. [PubMed: 11159436]

470. Sackin H, Vasilyev A, Palmer LG, Krambis M. Permeant cations and blockers modulate pH gating of ROMK channels. Biophys J 2003;84:910-921. [PubMed: 12547773]

471. Sanguinetti MC, Curran ME, Zou A, Shen J, Spector PS, Atkinson DL, Keating MT. Coassembly of $\mathrm{K}_{\mathrm{V}} \mathrm{LQT} 1$ and $\operatorname{minK}$ (IsK) proteins to form cardiac $I_{\mathrm{Ks}}$ potassium channel. Nature 1996;384:8083. [PubMed: 8900283]

472. Sanguinetti MC, Jiang C, Curran ME, Keating MT. A mechanistic link between an inherited and acquired cardiac arrhythmia: HERG encodes the $I_{\mathrm{Kr}}$ potassium channel. Cell 1995;81:299-307. [PubMed: 7736582]

473. Sansom S, O'Neil RG. Effects of mineralocorticoids on transport properties of cortical collecting duct basolateral membrane. Am J Physiol Renal Fluid Electrolyte Physiol 1986;251:F743-F757.

474. Sansom S, Stockand JD, Hall D, Williams B. Regulation of large calcium-activated potassium channels by protein phosphatase 2A. J Biol Chem 1997;272:9902-9906. [PubMed: 9092528]

475. Sansom SC, Mougouris T, Ono S, DuBose TD Jr. ATP-sensitive $\mathrm{K}^{+}$-selective channels of inner medullary collecting duct cells. Am J Physiol Renal Fluid Electrolyte Physiol 1994;267:F489-F496.

476. Sansom SC, Stockand JD. Physiological role of large, $\mathrm{Ca}^{2+}$-activated $\mathrm{K}^{+}$channels in human glomerular mesangial cells. Clin Exp Pharmacol Physiol 1996;23:76-82. [PubMed: 8713500]

477. Satlin LM. Regulation of potassium transport in the maturing kidney. Semin Nephrol 1999;19:155165. [PubMed: 10192248]

478. Satlin LM, Palmer LG. Apical K ${ }^{+}$conductance in maturing rabbit principal cell. Am J Physiol Renal Fluid Electrolyte Physiol 1997;272:F397-F404.

479. Schafer JA, Troutman SL. Potassium transport in cortical collecting tubules from mineralocorticoidtreated rat. Am J Physiol Renal Fluid Electrolyte Physiol 1987;253:F76-F88.

480. Schafer JA, Troutman SL, Schlatter E. Vasopressin and mineralocorticoid increase apical membrane driving force for $\mathrm{K}^{+}$secretion in rat CCD. Am J Physiol Renal Fluid Electrolyte Physiol 1990;258:F199-F210.

481. Schlatter E, Bleich M, Hirsch J, Greger R. pH-sensitive $\mathrm{K}^{+}$channels in the distal nephron. Nephrol Dialysis Transplant 1993;8:488-490.

482. Schlatter E, Haxelmans S, Hirsch J, Leipziger J. pH dependence of $\mathrm{K}^{+}$conductances of rat cortical collecting duct principal cells. Pflügers Arch 1994;428:631-640.

483. Schlatter E, Lohrmann E, Greger R. Properties of the potassium conductances of principal cells of rat cortical collecting ducts. Pflügers Arch 1992;420:39-45.

484. Schnermann J, Traynor T, Yang T, Arend L, Huang YG, Smart A, Briggs JP. Tubuloglomerular feedback: new concepts and developments. Kidney Int Suppl 1998;67:S40-S45. [PubMed: 9736251]

485. Schulte U, Fakler B. Gating of inward-rectifier $\mathrm{K}^{+}$channels by intracellular $\mathrm{pH}$. Eur J Biochem 2000;267:5837-5841. [PubMed: 10998042]

486. Schulte U, Hahn H, Konrad M, Jeck N, Derst C, Wild K, Weidemann S, Ruppersberg JP, Fakler B, Ludwig J. pH gating of ROMK ( $\left.\mathrm{K}_{\mathrm{ir}} 1.1\right)$ channels: control by an Arg-Lys-Arg triad disrupted in antenatal Bartter syndrome. Proc Natl Acad Sci USA 1999;96:15298-15303. [PubMed: 10611379]

487. Schulte U, Hahn H, Wiesinger H, Ruppersberg JP, Fakler B. pH-dependent gating of ROMK $\left(\mathrm{K}_{\mathrm{ir}} 1.1\right)$ channels involves conformational changes in both $\mathrm{N}$ and $\mathrm{C}$ termini. J Biol Chem 1998;273:34575-34579. [PubMed: 9852128]

488. Schulte U, Weidemann S, Ludwig J, Ruppersberg J, Fakler B. $\mathrm{K}^{+}$-dependent gating of K(ir)1.1 channels is linked to $\mathrm{pH}$ gating through a conformational change in the pore. J Physiol 2001;534:49_ 58. [PubMed: 11432991] 
491. Schultz BD, DeRoos ADG, Venglarik CJ, Singh AK, Frizzell RA, Bridges RJ. Glibenclamide blockade of CFTR chloride channels. Am J Physiol Lung Cell Mol Physiol 1996;271:L192-L200.

492. Schulze D, Krauter T, Fritzenschaft H, Soom M, Baukrowitz T. Phosphatidylinositol 4,5bisphosphate $\left(\mathrm{PIP}_{2}\right)$ modulation of ATP and $\mathrm{pH}$ sensitivity in Kir channels. A tale of an active and a silent PIP 2 site in the N terminus. J Biol Chem 2003;278:10500-10505. [PubMed: 12514171]

493. Schumacher MA, Rivard AF, Bachinger HP, Adelman JP. Structure of the gating domain of a $\mathrm{Ca}^{2}$ ${ }^{+}$-activated $\mathrm{K}^{+}$channel complexed with $\mathrm{Ca}^{2+} /$ calmodulin. Nature 2001;410:1120-1124. [PubMed: 11323678]

494. Schwab A. Ion channels and transporters on the move. News Physiol Sci 2001;16:29-33. [PubMed: 11390943]

495. Schwab A, Gabriel K, Finsterwalder F, Folprecht G, Greger R, Kramer A, Oberleithner H. Polarized ion transport during migration of transformed Madin-Darby canine kidney cells. Pflügers Arch 1995;430:802-807.

496. Schwab A, Geibel J, Wang W, Oberleithner H, Giebisch G. Mechanism of activation of $\mathrm{K}^{+}$channels by minoxidil-sulfate in Madin-Darby canine kidney cells. J Membr Biol 1993;132:125-136. [PubMed: 8496944]

497. Schwalbe RA, Bianchi L, Accili EA, Brown AM. Functional consequences of ROMK mutants linked to antenatal Bartter's syndrome and implications for treatment. Hum Mol Genet 1998;7:975-980. [PubMed: 9580661]

498. Schwarz TL, Tempel BL, Papazian DM, Jan YN, Jan LY. Multiple potassium channel components are produced by alternative splicing at the Shaker locus. Nature 1988;331:137-142. [PubMed: 2448635]

499. Schwiebert EM, Benos DJ, Egan M, stutts MJ, Guggino WB. CFTR is a conductance regulator as well as a chloride channel. Physiol Rev 1999;79:S145-S166. [PubMed: 9922379]

500. Seino S. ATP-sensitive potassium channels: a model of heteromultimeric potassium channel/ receptor assemblies. Annu Rev Physiol 1999;61:337-362. [PubMed: 10099692]

501. Sesti F, Tai KK, Goldstein SA. MinK endows the I(Ks) potassium channel pore with sensitivity to internal tetraethylammonium. Biophys J 2000;79:1369-1378. [PubMed: 10968999]

502. Shen NV, Chen X, Boyer MM, Pfaffinger PJ. Deletion analysis of $\mathrm{K}^{+}$channel assembly. Neuron 1993;11:67-76. [PubMed: 8338669]

503. Shenolikar S, Weinman EJ. NHERF: targeting and trafficking membrane proteins. Am J Physiol Renal Physiol 2001;280:F389-F395. [PubMed: 11181400]

504. Shepard AR, Rae JL. Electrically silent potassium channel subunits from human lens. Am J Physiol Cell Physiol 1999;277:C412-C424.

505. Shi H, Levy-Holzman R, Cluzeaud F, Farman N, Garty H. Membrane topology and immunolocalization of CHIF in kidney and intestine. Am J Physiol Renal Physiol 2001;280:F505F512. [PubMed: 11181413]

506. Shuck ME, Block JH, Benjamin CW, Tsai TD, Lee KS, Slightom JL, Bienkowski MJ. Cloning and characterization of multiple forms of the human kidney ROM-K potassium channel. J Biol Chem 1994;269:24261-24270. [PubMed: 7929082]

507. Shuck ME, Piser TM, Block JH, Slightom JL, Lee KS, Bienkowski MJ. Cloning and characterization of two $\mathrm{K}^{+}$inward rectifier $\left(\mathrm{K}_{\mathrm{ir}}\right) 1.1$ potassium channel homologs from human kidney $\left(\mathrm{K}_{\mathrm{ir}} 12\right.$ and

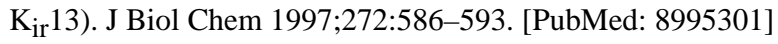

508. Shyng S, Barbieri A, Gumusboga A, Cukras C, Pike L, Davis JN, Stahl PD, Nichols CG. Modulation of nucleotide sensitivity of ATP-sensitive potassium channels by phosphatidylinositol-4-phosphate 5-kinase. Proc Natl Acad Sci USA 2000;97:937-941. [PubMed: 10639183]

509. Shyng SL, Cukras CA, Harwood J, Nichols CG. Structural determinants of PIP $_{2}$ regulation of inward rectifier $K_{\text {ATP }}$ channels. J Gen Physiol 2000;116:599-608. [PubMed: 11055989]

510. Shyng SL, Nichols CG. Membrane phospholipid control of nucleotide sensitivity of $\mathrm{K}_{\mathrm{ATP}}$ channels. Science 1998;282:1138-1141. [PubMed: 9804554]

511. Simon DB, Bindra RS, Mansfield TA, Nelson-Williams C, Mendonça E, Stone R, Schurman S, Nayir A, Alpay H, Bakkaloglu A, Rodriguez-Soriano J, Morales JM, Sanjad SA, Taylor CM, Pilz D, Brem A, Trachtman H, Griswold W, Richard GA, John E, Lifton RP. Mutations in the chloride 
channel gene, CLCNKB, cause Bartter's syndrome type III. Nature Genet 1997;17:171-178. [PubMed: 9326936]

512. Simon DB, Karet FE, Hamdan JM, DiPietro A, Sanjad SA, Lifton RP. Bartter's syndrome, hypokalaemic alkalosis with hypercalciuria, is caused by mutations in the $\mathrm{Na}-\mathrm{K}-2 \mathrm{Cl}$ cotransporter NKCC2. Nature Genet 1996;13:183-188. [PubMed: 8640224]

513. Simon DB, Karet FE, Rodriguez-Soriano J, Hamdan JH, Di-Pietro A, Trachtman H, Sanjad SA, Lifton RP. Genetic heterogeneity of Bartter's syndrome revealed by mutations in the $\mathrm{K}^{+}$channel, ROMK. Nature Genet 1996;14:152-156. [PubMed: 8841184]

514. Smith-Maxwell CJ, Ledwell JL, Aldrich RW. Uncharged s4 residues and cooperativity in voltagedependent potassium channel activation. J Gen Physiol 1998;111:421-439. [PubMed: 9482709]

515. Spassova M, Lu Z. Coupled ion movement underlies rectification in an inward-rectifier $\mathrm{K}^{+}$channel. J Gen Physiol 1998;112:211-221. [PubMed: 9689028]

516. Sprunger LK, Stewig NJ, O’Grady SM. Effects of charybdotoxin on $\mathrm{K}^{+}$channel (KV1.2) deactivation and inactivation kinetics. Eur J Pharmacol 1996;314:357-364. [PubMed: 8957259]

517. Standen NB, Quayle JM. $\mathrm{K}^{+}$channel modulation in arterial smooth muscle. Acta Physiol Scand 1998;164:549-557. [PubMed: 9887977]

518. Stanton, B.; Giebisch, G. Handbook of Physiology. Renal Physiology. Vol. I. Bethesda, MD: Am. Physiol. Soc; 1992. Renal potassium transport; p. 813-874.chapt. 19

519. Stanton BA. Effects of $\mathrm{pH}$ on potassium transport by renal distal tubule. Am J Physiol Renal Fluid Electrolyte Physiol 1982;242:F544-F551.

520. Stanton BA, Biemesderfer D, Wade JB, Giebisch G. Structural and functional study of the rat distal nephron: effects of potassium adaptation and depletion. Kidney Int 1981;19:36-48. [PubMed: 7218667]

521. Starremans PG, van der Kemp AW, Knoers NV, van den Heuvel LP, Bindels RJ. Functional implications of mutations in the human renal outer medullary potassium channel (ROMK2) identified in Bartter syndrome. Pflügers Arch 2002;443:466-472.

522. Stockand JD, Sansom SC. Glomerular mesangial cells: electrophysiology and regulation of contraction. Physiol Rev 1998;78:723-744. [PubMed: 9674692]

523. Stocker M, Hellwig M, Kerschensteiner D. Subunit assembly and domain analysis of electrically silent $\mathrm{K}^{+}$channel alpha-subunits of the rat Kv9 subfamily. J Neurochem 1999;72:1725-1734. [PubMed: 10098883]

524. Stocker M, Pedarzani P. Differential distribution of three $\mathrm{Ca}^{2+}$-activated $\mathrm{K}^{+}$channel subunits, SK1, SK2, and SK3, in the adult rat central nervous system. Mol Cell Neurosci 2000;15:476-493. [PubMed: 10833304]

525. Stoner LC, Morley GE. Effect of basolateral or apical hyposmolarity on apical maxi K channels of everted rat collecting tubule. Am J Physiol Renal Fluid Electrolyte Physiol 1995;268:F569-F580.

526. Stoner LC, Viggiano SC. Environmental $\mathrm{KCl}$ causes an upregulation of apical membrane Maxi $\mathrm{K}$ and ENaC channels in everted Ambystoma collecting tubule. J Membr Biol 1998;162:107-116. [PubMed: 9538504]

527. Stoner LC, Viggiano SC. Elevation of basolateral K induces K secretion by apical maxi K channels in Ambystoma collecting tubule. Am J Physiol Regul Integr Comp Physiol 1999;276:R616-R621.

528. Strange K. Volume regulation following $\mathrm{Na}^{+}$pump inhibition in CCT principal cells: apical $\mathrm{K}^{+}$loss. Am J Physiol Renal Fluid Electrolyte Physiol 1990;258:F732-F740.

529. Strange K, Spring KR. Basolateral cell membrane water permeability (Lp) in perfused rabbit cortical collecting ducts (CCD). Kidney Int 1985;27:334.

530. Su K, Kyaw H, Fan P, Zeng Z, Shell BK, Carter KC, Li Y. Isolation, characterization, and mapping of two human potassium channels. Biochem Biophys Res Commun 1997;241:675-681. [PubMed: 9434767]

531. Sun CW, Alonso-Galicia M, Taheri MR, Falck JR, Harder DR, Roman RJ. Nitric oxide-20hydroxyeicosatetraenoic acid interaction in the regulation of $\mathrm{K}^{+}$channel activity and vascular tone in renal arterioles. Circ Res 1998;83:1069-1079. [PubMed: 9831701]

532. Sun F, Hug MJ, Lewarchik CM, Yun CH, Bradbury NA, Frizzell RA. E3KARP mediates the association of ezrin and protein kinase A with the cystic fibrosis transmembrane conductance regulator in airway cells. J Biol Chem 2000;275:29539-29546. [PubMed: 10893422] 
533. Suzuki M, Kotake K, Fujikura K, Inagaki N, Suzuki T, Gonoi T, Seino S, Takata K. Kir6.1: a possible subunit of ATP-sensitive $\mathrm{K}^{+}$channels in mitochondria. Biochem Biophys Res Commun 1997;241:693-697. [PubMed: 9434770]

534. Suzuki M, Takahashi K, Sakai O. Regulation by GTP of a $\mathrm{Ca}^{2+}$-activated $\mathrm{K}^{+}$channel in the apical membrane of rabbit cortical collecting duct cells. J Membr Biol 1994;141:43-50. [PubMed: 7966244]

535. Taglialatela M, Ficker E, Wible BA, Brown AM. C-terminus determinants for $\mathrm{Mg}^{2+}$ and polyamine block of the inward rectifier $\mathrm{K}^{+}$channel IRK1. EMBO J 1995;14:5532-5541. [PubMed: 8521810]

536. Taglialatela M, Wible BA, Caporaso R, Brown AM. Specification of pore properties by the carboxyl terminus of inwardly rectifying $\mathrm{K}^{+}$channels. Science 1994;264:844-847. [PubMed: 8171340]

537. Takaichi K, Kurokawa K. High $\mathrm{Ca}^{2+}$ inhibits peptide hormone-dependent cAMP production specifically in thick ascending limbs of Henle. Miner Electrolyte Metab 1986;12:342-346. [PubMed: 3027519]

538. Takaichi K, Uchida S, Kurokawa K. High $\mathrm{Ca}^{2+}$ inhibits AVP-dependent cAMP production in thick ascending limbs of Henle. Am J Physiol Renal Fluid Electrolyte Physiol 1986;250:F770-F776.

539. Takimoto K, Levitan ES. Glucocorticoid induction of $\mathrm{Kv} 1.5 \mathrm{~K}^{+}$channel gene expression in ventricle of rat heart. Circ Res 1994;75:1006-1013. [PubMed: 7955140]

540. Takumi T, Ishii T, Horio Y, Morishige K, Takahashi N, Yamada M, Yamashita T, Kiyama H, Sohmiya K, Nakanishi S, Kurachi Y. A novel ATP-dependent inward rectifier potassium channel expressed predominantly in glial cells. J Biol Chem 1995;270:16339-16346. [PubMed: 7608203]

541. Tanabe K, Tucker SJ, Ashcroft FM, Proks P, Kioka N, Amachi T, Ueda K. Direct photoaffinity labeling of Kir6.2 by $\left[\gamma^{32}\right.$ P]ATP- $[\gamma] 4-$ azidoanilide. Biochem Biophys Res Commun 2000;272:316-319. [PubMed: 10833411]

542. Tanabe T, Tucker SJ, Matsuo M, Proks P, Ashcroft FM, Seino S, Amachi T, Ueda K. Direct photoaffinity labeling of the Kir6.2 subunit of the ATP-sensitive $\mathrm{K}^{+}$channel by 8-azido-ATP. J Biol Chem 1999;274:3931-3933. [PubMed: 9933580]

543. Tanemoto M, Kittaka N, Inanobe A, Kurachi Y. In vivo formation of a proton-sensitive $\mathrm{K}^{+}$channel by heteromeric subunit assembly of Kir5.1 with Kir4.1. J Physiol 2000;525:587-592. [PubMed: 10856114]

544. Tanemoto M, Vanoye CG, Dong K, Welch R, Abe T, Hebert SC, Xu JZ. Rat homolog of sulfonylurea receptor 2B determines glibenclamide sensitivity of ROMK2 in Xenopus laevis oocyte. Am J Physiol Renal Physiol 2000;278:F659-F666. [PubMed: 10751228]

545. Taniguchi J, Guggino WB. Membrane stretch: a physiological stimulator of $\mathrm{Ca}^{2+}$-activated $\mathrm{K}^{+}$ channels in thick ascending limb. Am J Physiol Renal Fluid Electrolyte Physiol 1989;257:F347F352.

546. Taniguchi J, Imai M. Flow-dependent activation of maxi $\mathrm{K}^{+}$channels in apical membrane of rabbit connecting tubule. J Membr Biol 1998;164:35-45. [PubMed: 9636242]

547. Taniguchi J, Yoshitomi K, Imai MK. ${ }^{+}$channel currents in basolateral membrane of distal convoluted tubule of rabbit kidney. Am J Physiol Renal Fluid Electrolyte Physiol 1989;256-25:F246-F254.

548. Tauc M, Congar P, Poncet V, Merot J, Vita C, Poujeol P. Toxin pharmacology of the largeconductance $\mathrm{Ca}^{2+}$-activated $\mathrm{K}^{+}$channel in the apical membrane of rabbit proximal convoluted tubule in primary culture. Pflügers Arch 1993;425:126-133.

550. Tempel BL, Jan YN. Cloning of a probable potassium channel gene from mouse brain. Nature 1988;332:837-839. [PubMed: 2451788]

551. Tempel BL, Papazian DM, Schwarz TL, Jan YN, Jan LY. Sequence of a probable potassium channel component encoded at the Shaker locus of Drosophila. Science 1987;237:770-775. [PubMed: 2441471]

552. Tian S, Liu W, Wu Y, Rafi H, Segal AS, Desir GV. Regulation of the voltage-gated K channel KCNA10 by KCNA4B, a novel beta subunit. Am J Physiol Renal Physiol 2002;283:F142-F149. [PubMed: 12060596]

553. Timpe LC, Schwartz TL, Tempel BL, Papazian DM, Jan YN, Jan LY. Expression of functional potassium channels from Shaker cDNA in Xenopus oocytes. Nature 1988;331:143-145. [PubMed: 2448636] 
554. Tinel N, Diochot S, Borsotto M, Lazdunski M, Barhanin J. KCNE2 confers background current characteristics to the cardiac KCNQ1 potassium channel. EMBO J 2000;19:6326-6330. [PubMed: 11101505]

555. Tinker A, Jan YN, Jan LY. Regions responsible for the assembly of inwardly rectifying potassium channels. Cell 1996;87:857-868. [PubMed: 8945513]

556. Todd-Turla KM, Rusvai E, Naray-Fejes-Toth A, Fejes-Toth G. CFTR expression in cortical collecting duct cells. Am J Physiol Renal Fluid Electrolyte Physiol 1996;270:F237-F244.

557. Toussaint $\mathrm{C}$, Vereerstraaeten P. Effects of blood $\mathrm{pH}$ changes on potassium excretion in the dog. Am J Physiol 1962;202:768-772. [PubMed: 13922162]

558. Trapp S, Ashcroft FM. A metabolic sensor in action: news from the ATP-sensitive $\mathrm{K}^{+}$-channel. News Physiol Sci 1997;12:255-263.

559. Trapp S, Proks P, Tucker SJ, Ashcroft FM. Molecular analysis of ATP-sensitive K channel gating and implications for channel inhibition by ATP. J Gen Physiol 1998;112:333-349. [PubMed: 9725893]

560. Trudeau MC, Warmke JW, Ganetzky B, Robertson GA. HERG, a human inward rectifier in the voltage-gated potassium channel family. Science 1995;269:92-96. [PubMed: 7604285]

561. Tsai TD, Shuck ME, Thompson DP, Bienkowski MJ, Lee KS. Intracellular $\mathrm{H}^{+}$inhibits a cloned rat kidney outer medulla $\mathrm{K}^{+}$channel expressed in Xenopus oocytes. Am J Physiol Cell Physiol 1995;268:C1173-C1178.

562. Tseng-Crank J, Foster CD, Krause JD, Mertz R, Godinot N, DiChiara TJ, Reinhart PH. Cloning, expression, and distribution of functionally distinct $\mathrm{Ca}^{2+}$-activated $\mathrm{K}^{+}$channel isoforms from human brain. Neuron 1994;13:1315-1330. [PubMed: 7993625]

563. Tsuchiya K, Wang W, Giebisch G, Welling PA. ATP is a coupling modulator of parallel Na/K ATPase-K channel activity in the renal proximal tubule. Proc Natl Acad Sci USA 1992;89:64186422. [PubMed: 1321439]

564. Tucker SJ, Ashcroft FM. A touching case of channel regulation: the ATP-sensitive $\mathrm{K}^{+}$channel. Curr Opin Neurobiol 1998;8:316-320. [PubMed: 9687347]

565. Tucker SJ, Gribble FM, Proks P, Trapp S, Ryder TJ, Haug T, Reimann F, Ashcroft FM. Molecular determinants of $\mathrm{K}_{\mathrm{ATP}}$ channel inhibition by ATP. EMBO J 1998;17:3290-3296. [PubMed: 9628866]

566. Tucker SJ, Gribble FM, Zhao C, Trapp S, Ashcroft FM. Truncation of Kir6.2 produces ATP-sensitive $\mathrm{K}^{+}$channels in the absence of the sulphonylurea receptor. Nature 1997;387:179-183. [PubMed: 9144288]

567. Tucker SJ, Imbrici P, Salvatore L, D’Adamo MC, Pessia M. pH dependence of the inwardly rectifying potassium channel, Kir5.1, and localization in renal tubular epithelia. J Biol Chem 2000;275:16404-16407. [PubMed: 10764726]

568. Ubl J, Murer H, Kolb HA. Hypotonic shock evokes opening of $\mathrm{Ca}^{2+}$-activated $\mathrm{K}$ channels in opossum kidney cells. Pflügers Arch 1988;412:551-553.

569. Vallon V, Grahammer F, Richter K, Bleich M, Lang F, Barhanin J, Volkl H, Warth R. Role of KCNE1-dependent $\mathrm{K}^{+}$fluxes in mouse proximal tubule. J Am Soc Nephrol 2001;12:2003-2011. [PubMed: 11562398]

570. Vallon V, Osswald H, Blantz RC, Thomson S. Potential role of luminal potassium in tubuloglomerular feedback. J Am Soc Nephrol 1997;8:1831-1837. [PubMed: 9402084]

571. Valverde MA, Rojas P, Amigo J, Cosmelli D, Orio P, Bahamonde MI, Mann GE, Vergara C, Latorre R. Acute activation of the Maxi-K channels (hSlo) by estradiol binding to the beta subunit. Science 1999;285:1929-1931. [PubMed: 10489376]

572. Vanoye CG, MacGregor GG, Dong K, Tang L, Buschmann AE, Hall AE, Lu M, Giebisch G, Hebert SC. The carboxyl termini of $\mathrm{K}_{\text {ATP }}$ channels bind nucleotides. J Biol Chem 2002;272:23260-23270. [PubMed: 11956191]

573. Vargas-Poussou R, Huang C, Hulin P, Houillier P, Jeunemaitre X, Paillard M, Planelles G, Dechaux M, Miller RT, Antignac C. Functional characterization of a calcium-sensing receptor mutation in severe autosomal dominant hypocalcemia with a Bartter-like syndrome. J Am Soc Nephrol 2002;13:2259-2266. [PubMed: 12191970] 
574. Vargus-Poussou R, Feldmann D, Vollmer M, Konrad M, Kelly RP, van den Heuvell LPWJ, Tebourbi L, Brandis M, Karolyil L, Hebert SC, Lemmink HH, Deschenes G, Hildebrandt F, Seyberth H, Guay-Woodford LM, Knoers NVAM, Antignac C. Novel molecular variants of the Na-K-2Cl cotransporter gene are responsible for antenatal Bartter syndrome. Am J Hum Genet 1998;62:1332_ 1340. [PubMed: 9585600]

575. Velazquez H, Ellison DH, Wright FS. Chloride-dependent potassium secretion in early and late distal tubules. Am J Physiol Renal Fluid Electrolyte Physiol 1987;253:F555-F562.

576. Velazquez H, Ellison DH, Wright FS. Luminal influences on potassium secretion: chloride, sodium, and thiazide diuretics. Am J Physiol Renal Fluid Electrolyte Physiol 1992;262:F1076-F1082.

577. Verissimo F, Jordan P. WNK kinases, a novel protein kinase subfamily in multi-cellular organisms. Oncogene 2001;20:5562-5569. [PubMed: 11571656]

578. Volk KA, Husted RF, Prachno CJ, Stokes JB. Functional and molecular evidence for Shaker-like $\mathrm{K}^{+}$channels in rabbit renal papillary epithelial cell line. Am J Physiol Renal Fluid Electrolyte Physiol 1994;267:F671-F678.

579. Vollmer M, Koehrer M, Topaloglu R, Strahm B, Omran H, Hildebrandt F. Two novel mutations of the gene for Kir 1.1 (ROMK) in neonatal Bartter syndrome. Pediatr Nephrol 1998;12:69-71. [PubMed: 9502574]

580. Wade JB, Welling PA, Donowitz M, Shenolikar S, Weinman EJ. Differential renal distribution of NHERF isoforms and their colocalization with NHE3, ezrin, and ROMK. Am J Physiol Cell Physiol 2001;280:C192-C198. [PubMed: 11121391]

581. Wald H, Garty H, Palmer LG, Popovtzer MM. Differential regulation of ROMK expression in kidney cortex and medulla by aldosterone and potassium. Am J Physiol Renal Physiol 1998;275:F239_ F245.

582. Wald H, Popovtzer MM, Garty H. Differential regulation of CHIF mRNA by potassium intake and aldosterone. Am J Physiol Renal Fluid Electrolyte Physiol 1997;272:F617-F623.

583. Waldegger S, Niemeyer G, Morike K, Wagner CA, Suessbrich H, Busch AE, Lang F, Eichelbaum M. Effect of verapamil enantiomers and metabolites on cardiac $\mathrm{K}^{+}$channels expressed in Xenopus oocytes. Cell Physiol Biochem 1999;9:81-89. [PubMed: 10394001]

584. Wang KW, Goldstein SAN. Subunit composition of MinK potassium channels. Neuron 1995;14:1303-1309. [PubMed: 7605639]

585. Wang Q, Curran ME, Splawski I, Burn TC, Millholland JM, VanRaay TJ, Shen J, Timothy KW, Vincent GM, de Jager T, Schwartz PJ, Toubin JA, Moss AJ, Atkinson DL, Landes GM, Connors TD, Keating MT. Positional cloning of a novel potassium channel gene: KVLQT1 mutations cause cardiac arrhythmias. Nature Genet 1996;12:17-23. [PubMed: 8528244]

586. Wang S, Raab RW, Schatz PJ, Guggino WB, Li M. Peptide binding consensus of the NHE-RFPDZ1 domain matches the C-terminal sequence of cystic fibrosis transmembrane conductance regulator (CFTR). FEBS Lett 1998;427:103-108. [PubMed: 9613608]

587. Wang T, Wang WH, Klein-Robbenhaar G, Giebisch G. Effects of a novel $\mathrm{K}_{\mathrm{ATP}}$ channel blocker on renal tubule function and K channel activity. J Pharmacol Exp Ther 1995;273:1382-1389. [PubMed: 7791111]

588. Wang T, Wang WH, Klein-Robbenhaar G, Giebisch G. Effects of glyburide on renal tubule transport and potassium-channel activity. Renal Physiol Biochem 1995;18:169-182. [PubMed: 7481068]

589. Wang W. Two types of $\mathrm{K}^{+}$channel in TAL of rat kidney. Am J Physiol Renal Fluid Electrolyte Physiol 1994;267:F599-F605.

590. Wang W. Regulation of renal K transport by dietary K intake. Ann Rev Med 2003;66:547-569.

591. Wang W, Cassola A, Giebisch G. Arachidonic acid inhibits the secretory $\mathrm{K}^{+}$channel of cortical collecting duct of rat kidney. Am J Physiol Renal Fluid Electrolyte Physiol 1992;262:F554-F559.

592. Wang W, Giebisch G. Dual effect of adenosine triphosphate on the apical small conductance $\mathrm{K}^{+}$ channel of the rat cortical collecting duct. J Gen Physiol 1991;98:35-61. [PubMed: 1940849]

593. Wang W, Hebert SC, Giebisch G. Renal K ${ }^{+}$channels: structure and function. Annu Rev Physiol 1997;59:413-436. [PubMed: 9074771]

594. Wang W, Henderson RM, Geibel J, White S, Giebisch G. Mechanism of aldosterone-induced increase of $\mathrm{K}^{+}$conductance in early distal renal tubule cells of the frog. J Membr Biol 1989;111:277289. [PubMed: 2557452] 
595. Wang W, Lerea KM, Chan M, Giebisch G. Protein tyrosine kinase regulates the number of renal secretory K channels. Am J Physiol Renal Physiol 2000;278:F165-F171. [PubMed: 10644668]

596. Wang W, Lu M. Effect of arachidonic acid on activity of the apical $\mathrm{K}^{+}$channel in the thick ascending limb of the rat kidney. J Gen Physiol 1995;106:727-743. [PubMed: 8576704]

597. Wang W, Sackin H, Giebisch G. Renal potassium channels and their regulation. Annu Rev Physiol 1992;54:81-96. [PubMed: 1562192]

598. Wang W, Schwab A, Giebisch G. Regulation of small-conductance $\mathrm{K}^{+}$channel in apical membrane of rat cortical collecting duct. Am J Physiol Renal Fluid Electrolyte Physiol 1990;259:F494-F502.

599. Wang W, White S, Geibel J, Giebisch G. A potassium channel in the apical membrane of rabbit thick ascending limb of Henle's loop. Am J Physiol Renal Fluid Electrolyte Physiol 1990;258:F244F253.

600. Wang WH. Regulation of the hyperpolarization-activated K channel in the lateral membrane of the cortical collecting duct. J Gen Physiol 1995;106:25-43. [PubMed: 7494137]

601. Wang WH. The cGMP-dependent protein kinase stimulates the basolateral $18 \mathrm{pS} \mathrm{K}$ channel of the rat CCD. Am J Physiol Cell Physiol 2000;278:C1212-C1217. [PubMed: 10837349]

602. Wang WH, Geibel J, Giebisch G. Mechanism of apical $\mathrm{K}^{+}$channel modulation in principal renal tubule cells. Effect of inhibition of basolateral $\mathrm{Na}^{+}-\mathrm{K}^{+}$-ATPase. J Gen Physiol 1993;101:673-694. [PubMed: 8393065]

603. Wang WH, Giebisch G. Dual modulation of renal ATP-sensitive $\mathrm{K}^{+}$channel by protein kinases A and C. Proc Natl Acad Sci USA 1991;88:9722-9725. [PubMed: 1946394]

604. Wang WH, Lu M, Hebert SC. Cytochrome $P-450$ metabolites mediate extracellular $\mathrm{Ca}^{2+}$-induced inhibition of apical K ${ }^{+}$channels in the TAL. Am J Physiol Cell Physiol 1996;271:C103-C111.

605. Wang WH, McNicholas CM, Segal AS, Giebisch G. A novel approach allows identification of K channels in the lateral membrane of rat CCD. Am J Physiol Renal Fluid Electrolyte Physiol 1994;266:F813-F822.

606. Warntges S, Friedrich B, Henke G, Duranton C, Lang A, Waldegger S, Meyermann R, Kuhl D, Speckmann J, Obermuller N, Witzgall R, Mack F, Wagner J, Wagner A, Broer S, Lang F. Cerebral localization and regulation of the cell volume-sensitive serum- and glucocorticoid-dependent kinase SGK1. Pflügers Arch 2002;443:617-624.

607. Warth R. Potassium channels in epithelial transport. Pflügers Arch 2003;446:505-513.

608. Warth R, Barhanin J. The multifaceted phenotype of the knockout mouse for the KCNE1 potassium channel gene. Am J Physiol Regul Integr Comp Physiol 2002;282:R639-R648. [PubMed: 11832382]

609. Watanabe S, Fukumoto S, Chang H, Takeuchi Y, Hasegawa Y, Okazaki R, Chikatsu N, Fujita T. Association between activating mutations of calcium-sensing receptor and Bartter's syndrome. Lancet 2002;360:692-694. [PubMed: 12241879]

610. Wei Y, Bloom P, Gu R, Wang W. Protein-tyrosine phosphatase reduces the number of apical small conductance $\mathrm{K}^{+}$channels in the rat cortical collecting duct. J Biol Chem 2000;275:20502-20507. [PubMed: 10787405]

611. Wei Y, Bloom P, Lin DH, Gu RM, Wang WH. Effect of dietary K intake on the apical smallconductance K channel in the CCD: role of protein tyrosine kinase. Am J Physiol Renal Physiol 2001;281:F206-F212. [PubMed: 11457712]

612. Weinstein AM. Modeling the proximal tubule: complications of the paracellular pathway. Am J Physiol Renal Fluid Electrolyte Physiol 1988;254:F297-F305.

613. Welling PA. Cross-talk and the role of $\mathrm{K}_{\mathrm{ATP}}$ channels in the proximal tubule. Kidney Int 1995;48:1017-1023. [PubMed: 8569062]

614. Welling PA. Primary structure and functional expression of a cortical collecting duct $\mathrm{K}_{\mathrm{ir}}$ channel. Am J Physiol Renal Physiol 1997;273:F825-F836.

615. Wible B, Murawsky MK, Crumb WJ Jr, Rampe D. Stable expression and characterization of the human brain potassium channel Kv2.1: blockade by antipsychotic agents. Brain Res 1997;761:4250. [PubMed: 9247064]

616. Wible BA, Taglialatela M, Ficker E, Brown AM. Gating of inwardly rectifying $\mathrm{K}^{+}$channels localized to a single negatively charged residue. Nature 1994;371:246-249. [PubMed: 8078584] 
617. Wible BA, Yang Q, Kuryshev YA, Accili EA, Brown AM. Cloning and expression of a novel K ${ }^{+}$ channel regulatory protein, KChAP. J Biol Chem 1998;273:11745-11751. [PubMed: 9565597]

618. Wilson FH, Kahle KT, Sabath E, Lalioti MD, Rapson AK, Hoover RS, Hebert SC, Gamba G, Lifton RP. Molecular pathogenesis of inherited hypertension with hyperkalemia: the Na-Cl cotransporter is inhibited by wild-type but not mutant WNK4. Proc Natl Acad Sci USA 2003;100:680-684. [PubMed: 12515852]

619. Wingo CS, Smolka AJ. Function and structure of H-K-ATPase in the kidney. Am J Physiol Renal Fluid Electrolyte Physiol 1995;269:F1-F16.

620. Woda CB, Bragin A, Kleyman TR, Satlin LM. Flow-dependent $\mathrm{K}^{+}$secretion in the cortical collecting duct is mediated by a maxi-K channel. Am J Physiol Renal Physiol 2001;280:F786-F793. [PubMed: 11292620]

621. Woda CB, Leite M Jr, Rohatgi R, Satlin LM. Effects of luminal flow and nucleotides on $\left[\mathrm{Ca}^{2+}\right]_{\mathrm{i}}$ in rabbit cortical collecting duct. Am J Physiol Renal Physiol 2002;283:F437-F446. [PubMed: 12167594]

622. Woda CB, Miyawaki N, Ramalakshmi S, Ramkumar M, Rojas R, Zavilowitz B, Kleyman TR, Satlin LM. Ontogeny of flow-stimulated potassium secretion in rabbit cortical collecting duct: functional and molecular aspects. Am J Physiol Renal Physiol 2003;285:F629-F639. [PubMed: 12824078]

623. Wu Q, Delpire E, Hebert SC, Strange K. Functional demonstration of $\mathrm{Na}^{+}-\mathrm{K}^{+}-2 \mathrm{Cl}^{-}$cotransporter activity in isolated, polarized choroid plexus cells. Am J Physiol Cell Physiol 1998;275:C1565C1572.

624. Wymore RS, Korenberg JR, Kinoshita KD, Aiyar J, Coyne C, Chen XN, Hustad CM, Copeland NG, Gutman GA, Jenkins NA. Genomic organization, nucleotide sequence, biophysical properties, and localization of the voltage-gated $\mathrm{K}^{+}$channel gene KCNA4/Kv14 to mouse chromosome 2/human $11 \mathrm{p} 14$ and mapping of $\mathrm{KCNC} 1 / \mathrm{Kv} 31$ to mouse 7/human 11p143-p152 and KCNA/Kv11 to human 12p13. Genomics 1994;20:191-202. [PubMed: 8020965]

625. Xu H, Cui N, Yang Z, Qu Z, Jiang C. Modulation of kir 4.1 and kir 5.1 by hypercapnia and intracellular acidosis. J Physiol 2000;524:725-735. [PubMed: 10790154]

626. Xu H, Yang Z, Cui N, Chanchevalap S, Valesky WW, Jiang C. A single residue contributes to the difference between Kir4.1 and Kir11 channels in pH sensitivity, rectification and single channel conductance. J Physiol 2000;528:267-277. [PubMed: 11034617]

627. Xu H, Yang Z, Cui N, Giwa LR, Abdulkadir L, Patel M, Sharma P, Shan G, Shen W, Jiang C. Molecular determinants for the distinct $\mathrm{pH}$ sensitivity of Kir1.1 and Kir41 channels. Am J Physiol Cell Physiol 2000;279:C1464-C1471. [PubMed: 11029294]

628. Xu J, Yu W, Jan YN, Jan LY, Li M. Assembly of voltage-gated potassium channels. Conserved hydrophobic motifs determine subfamily-specific interactions. J Biol Chem 1995;270:2476124768. [PubMed: 7559593]

629. Xu JZ, Hall AE, Peterson LN, Bienkowski MJ, Eessalu TE, Hebert SC. Localization of the ROMK protein on apical membranes of rat kidney nephron segments. Am J Physiol Renal Physiol 1997;273:F739-F748.

630. Xu ZC, Yang Y, Hebert SC. Phosphorylation of the ATP-sensitive, inwardly rectifying $\mathrm{K}^{+}$channel, ROMK, by cyclic AMP-dependent protein kinase. J Biol Chem 1996;271:9313-9319. [PubMed: 8621594]

632. Yang CL, Angell J, Mitchell R, Ellison DH. WNK kinases regulate thiazide-sensitive Na-Cl cotransport. J Clin Invest 2003;111:947-950. [PubMed: 12671041]

633. Yang J, Jan YN, Jan LY. Control of rectification and permeation by residues in two distinct domains in an inward rectifier $\mathrm{K}^{+}$channel. Neuron 1995;14:1047-1054. [PubMed: 7748552]

634. Yang J, Jan YN, Jan LY. Determination of the subunit stoichiometry of an inwardly rectifying potassium channel. Neuron 1995;15:1441-1447. [PubMed: 8845166]

635. Yang Z, Jiang C. Opposite effects of $\mathrm{pH}$ on open-state probability and single channel conductance of kir4.1 channels. J Physiol 1999;520:921-927. [PubMed: 10545154]

636. Yang Z, Xu H, Cui N, Qu Z, Chanchevalap S, Shen W, Jiang C. Biophysical and molecular mechanisms underlying the modulation of heteromeric Kir4.1-Kir51 channels by $\mathrm{CO}_{2}$ and $\mathrm{pH}$. J Gen Physiol 2000;116:33-45. [PubMed: 10871638] 
637. Yano H, Philipson LH, Kugler JL, Tokuyama Y, Davis EM, Le Beau MM, Nelson DJ, Bell GI, Takeda J. Alternative splicing of human inwardly rectifying $\mathrm{K}^{+}$channel ROMK1 mRNA. Mol Pharmacol 1994;45:854-860. [PubMed: 8190102]

638. Yao X, Chang AY, Boulpaep EL, Segal AS, Desir GV. Molecular cloning of a glibenclamidesensitive, voltage-gated potassium channel expressed in rabbit kidney. J Clin Invest 1996;97:25252533. [PubMed: 8647945]

639. Yao X, Huang Y, Kwan HY, Chan P, Desir G. Characterization of a regulatory region in the Nterminus of rabbit kv1.3. Biochem Biophys Res Commun 1998;249:492-498. [PubMed: 9712724]

640. Yao X, Liu Y, Tung F, Desir GV. Genomic structure and regulation of Kcn1, a cGMP-gated potassium channel. Am J Physiol Renal Fluid Electrolyte Physiol 1996;271:F37-F41.

641. Yao X, Segal AS, Welling P, Zhang X, McNicholas CM, Engel D, Boulpaep EL, Desir GV. Primary structure and functional expression of a cGMP-gated potassium channel. Proc Natl Acad Sci USA 1995;92:11711-11715. [PubMed: 8524834]

642. Yao X, Tian S, Chan HY, Biemesderfer D, Desir GV. Expression of KCNA10, a voltage-gated K channel, in glomerular endothelium and at the apical membrane of the renal proximal tubule. J Am Soc Nephrol. In press.

643. Yoo D, Flagg TP, Olsen O, Raghuram V, Foskett JK, Welling PA. Assembly and trafficking of a multiprotein ROMK (Kir1.1) channel complex by PDZ interactions. J Biol Chem. In press.

644. Yoo D, Kim BY, Campo C, Nance L, King A, Maouyo D, Welling PA. Cell surface expression of the ROMK (Kir 1.1) channel is regulated by the aldosterone-induced kinase, SGK-1, and protein kinase A. J Biol Chem 2003;278:23066-23075. [PubMed: 12684516]

645. Yue H, Devidas S, Guggino WB. The two halves of CFTR form a dual-pore ion channel. J Biol Chem 2000;275:10030-10034. [PubMed: 10744680]

646. Yun CC, Palmada M, Embark HM, Fedorenko O, Feng Y, Henke G, Setiawan I, Boehmer C, Weinman EJ, Sandrasagra S, Korbmacher C, Cohen P, Pearce D, Lang F. The serum and glucocorticoid-inducible kinase SGK1 and the $\mathrm{Na}^{+} / \mathrm{H}^{+}$exchange regulating factor NHERF2 synergize to stimulate the renal outer medullary $\mathrm{K}^{+}$channel ROMK1. J Am Soc Nephrol 2002;13:2823-2830. [PubMed: 12444200]

647. Zeng WZ, Babich V, Ortega B, Quigley R, White SJ, Welling PA, Huang CL. Evidence for endocytosis of ROMK potassium channel via clathrin-coated vesicles. Am J Physiol Renal Physiol 2002;283:F630-F639. [PubMed: 12217853]

648. Zeng WZ, Li XJ, Hilgemann DW, Huang CL. Protein kinase C inhibits ROMK1 channel activity via a phosphatidylinositol 4,5-bisphosphate-dependent mechanism. J Biol Chem 2003;278:1685216856. [PubMed: 12615924]

649. Zeng WZ, Liou HH, Krishna UM, Falck JR, Huang CL. Structural determinants and specificities for ROMK1-phosphoinositide interaction. Am J Physiol Renal Physiol 2002;282:F826-F834. [PubMed: 11934692]

650. Zhang H, He C, Yan X, Mirshahi T, Logothetis DE. Activation of inwardly rectifying $\mathrm{K}^{+}$channels by distinct PtdIns(4,5) $\mathrm{P}_{2}$ interactions. Nat Cell Biol 1999;1:183-188. [PubMed: 10559906]

651. Zhou H, Chepilko S, Schutt W, Chloe H, Palmer LG, Sackin H. Mutations in the pore region of ROMK enhance $\mathrm{Ba}^{2+}$ block. Am J Physiol Cell Physiol 1996;271:C1949-C1956.

652. Zhou H, Tate SS, Palmer LG. Primary structure and functional properties of an epithelial K channel. Am J Physiol Cell Physiol 1994;266:C809-C824.

653. Zhou X, Lynch IJ, Xia SL, Wingo CS. Activation of H-K-ATPase by $\mathrm{CO}_{2}$ requires a basolateral $\mathrm{Ba}^{2+}$-sensitive pathway during K restriction. Am J Physiol Renal Physiol 2000;279:F153-F160. [PubMed: 10894797]

654. Zhou X, Wingo CS. Stimulation of total $\mathrm{CO}_{2}$ flux by $10 \% \mathrm{CO}_{2}$ in rabbit CCD: role of an apical Sch-28080- and Ba-sensitive mechanism. Am J Physiol Renal Fluid Electrolyte Physiol 1994;267:F114-F120.

655. Zhou XL, Vaillant B, Loukin SH, Kung C, Saimi Y. YKC1 encodes the depolarization-activated K ${ }^{+}$channel in the plasma membrane of yeast. FEBS Lett 1995;373:170-176. [PubMed: 7589459]

656. Zhou Y, MacKinnon R. Ion binding affinity in the cavity of the KcsA potassium channel. Biochemistry 2004;43:4978-4982. [PubMed: 15109256] 
657. Zhou Y, Morais-Cabral J, Kaufman A, MacKinnon R. Chemistry of ion coordination and hydration revealed by a K channel Fab complex at 2.0 A resolution. Nature 2001;414:43-48. [PubMed: 11689936]

658. Zhu G, Liu C, Qu Z, Chanchevalap S, Xu H, Jiang C. $\mathrm{CO}_{2}$ inhibits specific inward rectifier $\mathrm{K}^{+}$ channels by decreases in intra-and extracellular pH. J Cell Physiol 2000;183:53-64. [PubMed: 10699966]

659. Zolotnitskaya A, Satlin LM. Developmental expression of ROMK in rat kidney. Am J Physiol Renal Physiol 1999;276:F825-F836.

660. Zou AP, Fleming JT, Falck JR, Jacobs ER, Gebremedhin D, Harder DR, Roman RJ. 20-HETE is an endogenous inhibitor of the large-conductance $\mathrm{Ca}^{2+}$-activated $\mathrm{K}^{+}$channel in renal arterioles. Am J Physiol Regul Integr Comp Physiol 1996;270:R228-R237.

665. Zou AP, Fleming JT, Falck JR, Jacobs ER, Gebremedhin D, Harder DR, Roman RJ. Stereospecific effects of epoxyeicosatrienoic acids on renal vascular tone and $\mathrm{K}$ channel activity. Am J Physiol Renal Fluid Electrolyte Physiol 1996;270:F822-F832.

666. Zweifach A, Desir GV, Aronson PS, Giebisch G. A Ca-activated K channel from rabbit renal brushborder membrane vesicles in planar lipid bilayers. Am J Physiol Renal Fluid Electrolyte Physiol 1991;261:F187-F196. 


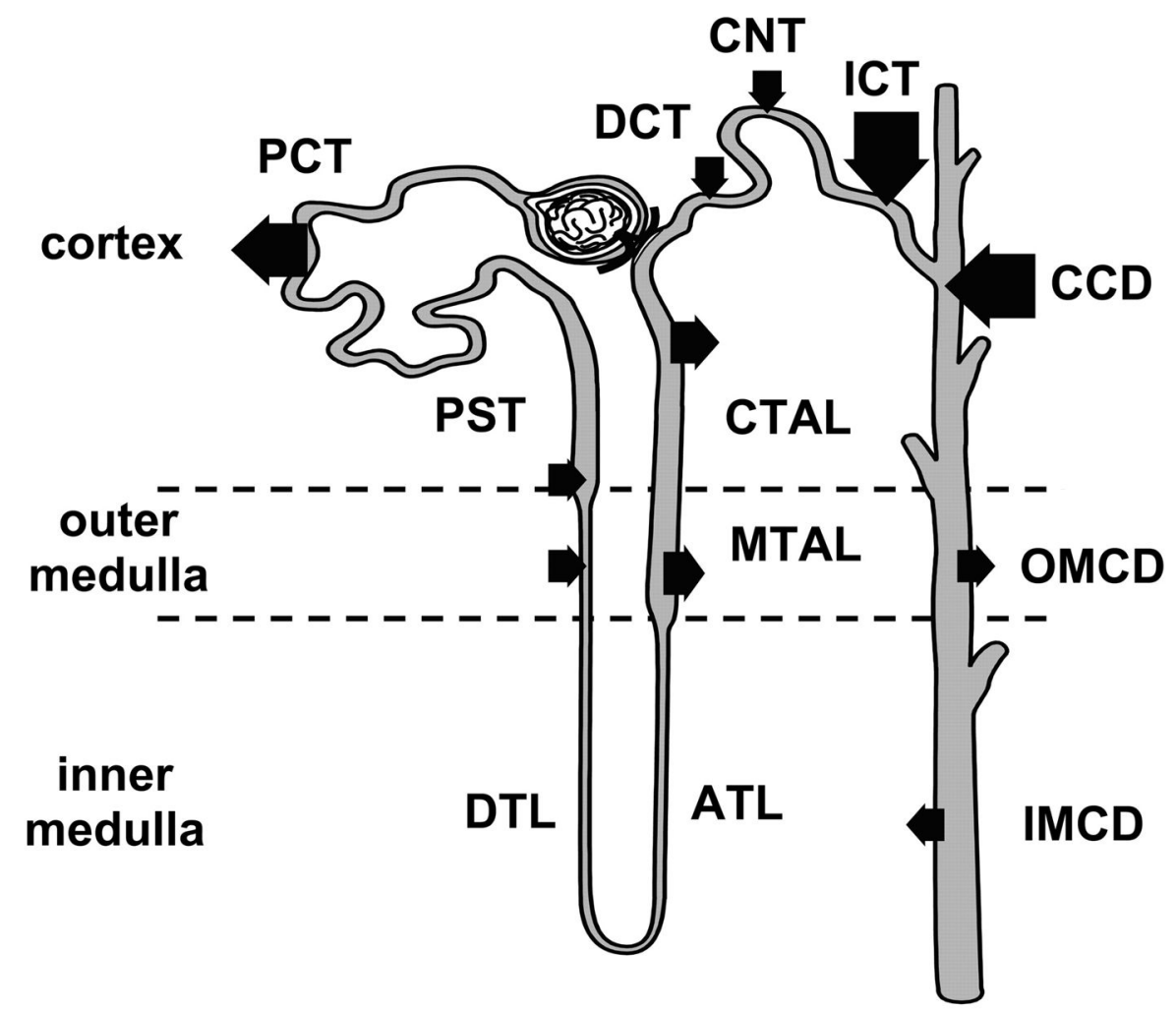

FIG. 1.

Potassium transport along a simplified nephron. $\mathrm{K}^{+}$is filtered and extensively reabsorbed along the proximal convoluted tubule (PCT). Some $\mathrm{K}^{+}$enters the proximal straight tubule (PST) and the thin, descending limb of Henle's loop (DTL). But extensive $\mathrm{K}^{+}$reabsorption along the ascending thin limb of Henle (ATL) and along both the medullary (MTAL) and cortical (CTAL) portions of the thick ascending limb sharply reduce the amount of $\mathrm{K}^{+}$by the time fluid has reached the beginning of the distal convoluted tubule (DCT). Regulated $\mathrm{K}^{+}$secretion takes place in the connecting tubule (CNT), DCT, initial collecting duct (ICD), and cortical collecting duct (CCD), and reabsorption may occur in the terminal nephron segments, the outer (OMCD) and inner (IMCD) medullary collecting duct. The reabsorptive and secretory components of $\mathrm{K}^{+}$transport in the loop of Henle and the further distally located nephron segments are subject to regulation, but transport in the proximal tubule does not control urinary $\mathrm{K}^{+}$excretion. The arrow size represents relative magnitudes of $\mathrm{K}^{+}$secretion and reabsorption. 


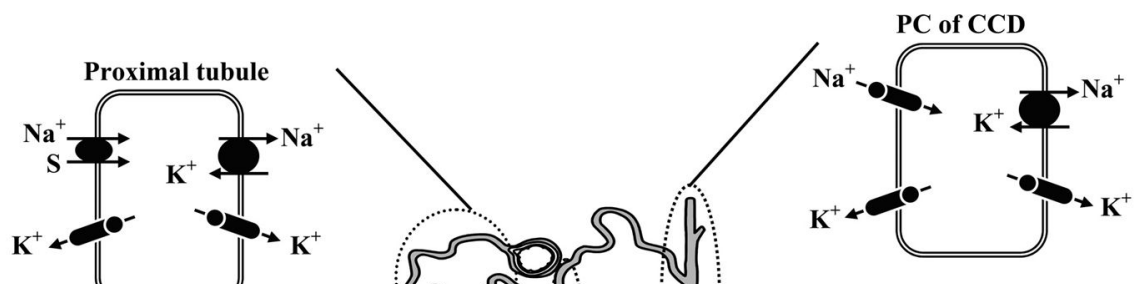

1. Membrane potential

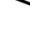

2. Volume regulation

3. Coupling to Na-K-ATPase
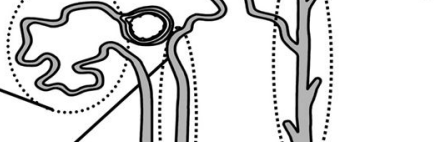

1. Membrane potential

2. K secretion

3. Coupling to Na-K-

ATPase

4. Volume regulation

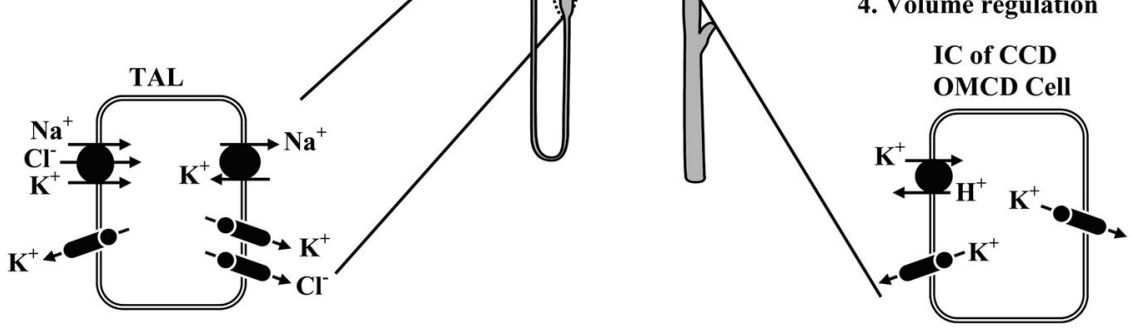

1. Membrane potential

2. $\mathrm{K}^{+}$recycling

1. $\mathrm{K}^{+}$recycling

3. Maintaining $\mathrm{Cl}^{-}$driving force

4. Volume regulation

2. Volume regulation

3. $\mathrm{K}^{+}$reabsorption

FIG. 2.

A model of a single nephron showing the function of renal $\mathrm{K}^{+}$channels in proximal tubules, thick ascending limb (TAL), and cortical and outer medullary collecting duct (CCD). 


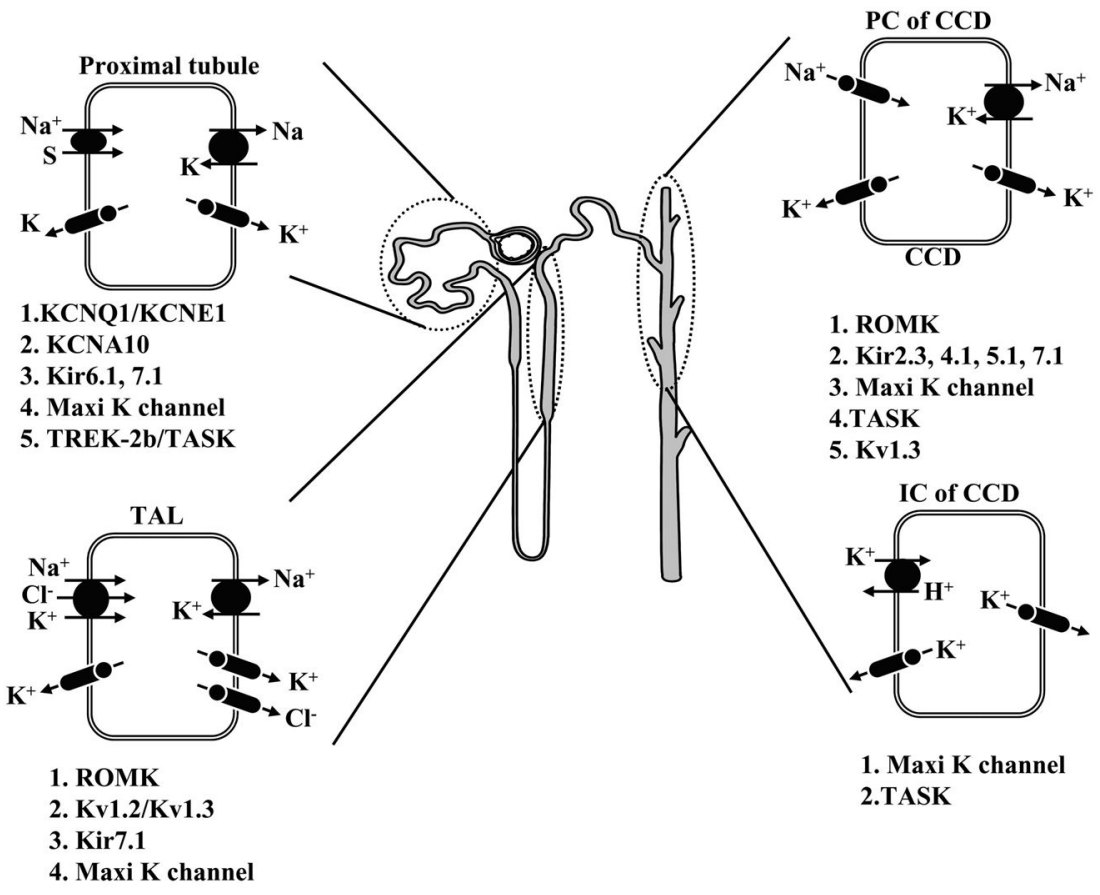

FIG. 3.

A model of a single nephron demonstrating the expression of currently known $\mathrm{K}^{+}$channel genes. 


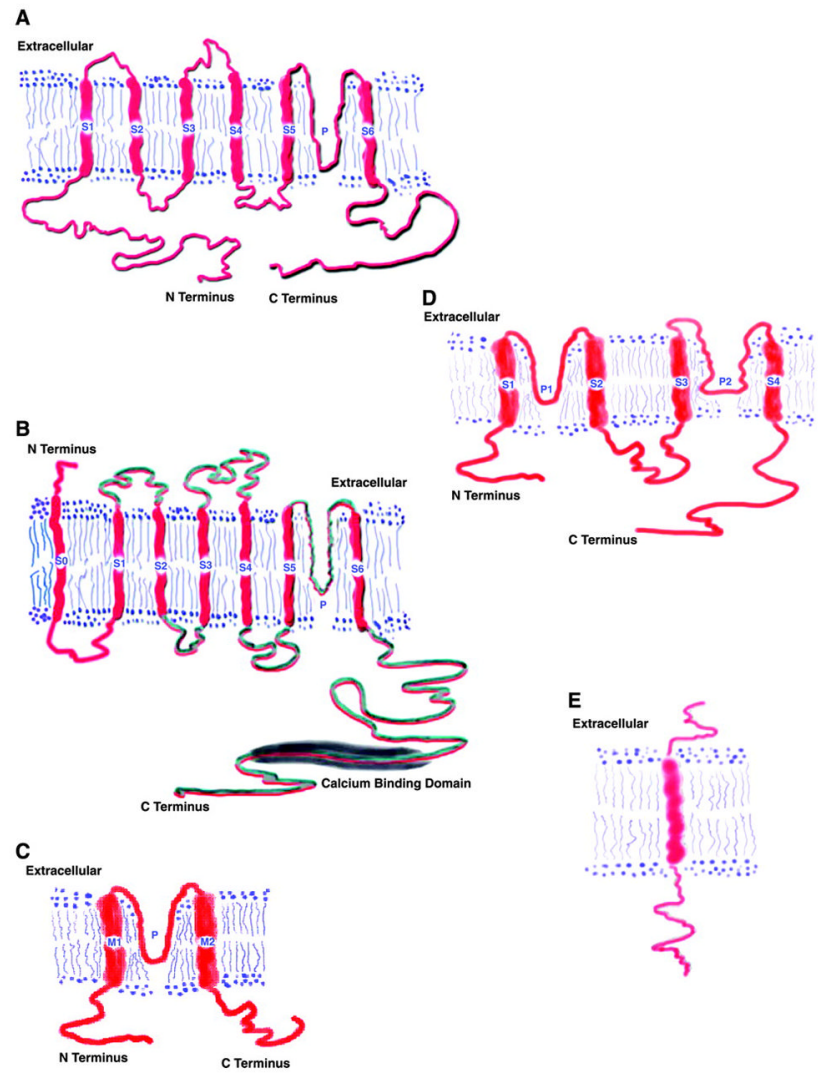

FIG. 4.

Classification of $\mathrm{K}^{+}$channels and schematic representation of their secondary structure. $A$ : the $\alpha$-subunit of the 6-TM class of $\mathrm{K}^{+}$channels: six transmembrane segments (S1-S6) and one pore $(\mathrm{P})$. S4 represents the voltage sensor of $\mathrm{Kv}$ channels. The active channel is a tetramer and can also contain accessory $(\beta)$ subunits. $\mathrm{K}^{+}$channels belonging to this class include $\mathrm{Kv} 1.1-$ 1.10, IKCa, HERG, and KvLQT. $B$ : unlike the other members of the 6-TM class, hSlo appears to have seven transmembrane segments (S0-S6) and the amino terminus is predicted to be located extracellulary. The S4 segment is well conserved, and the cytoplasmic tail contains a calcium-binding domain. The active channel is a heterotetramer and contains accessory $(\beta)$ subunits. $C$ : the $\alpha$-subunit of the 2 -P class of $\mathrm{K}^{+}$channels: 4 transmembrane segments (S1-S4) and 2 pores (P1, P2). These channels do not have an $\mathrm{S} 4$ segment. $\mathrm{K}^{+}$channels belonging to this class include TWIK, TRAAK, TASK, and TREK. D: MinK and the MinK-related peptides (MiRPs) contain a single transmembrane segment and function as accessory subunits for a variety of 6-TM channels. $E$ : the single transmembrane subunit MinK (KCNE1). 


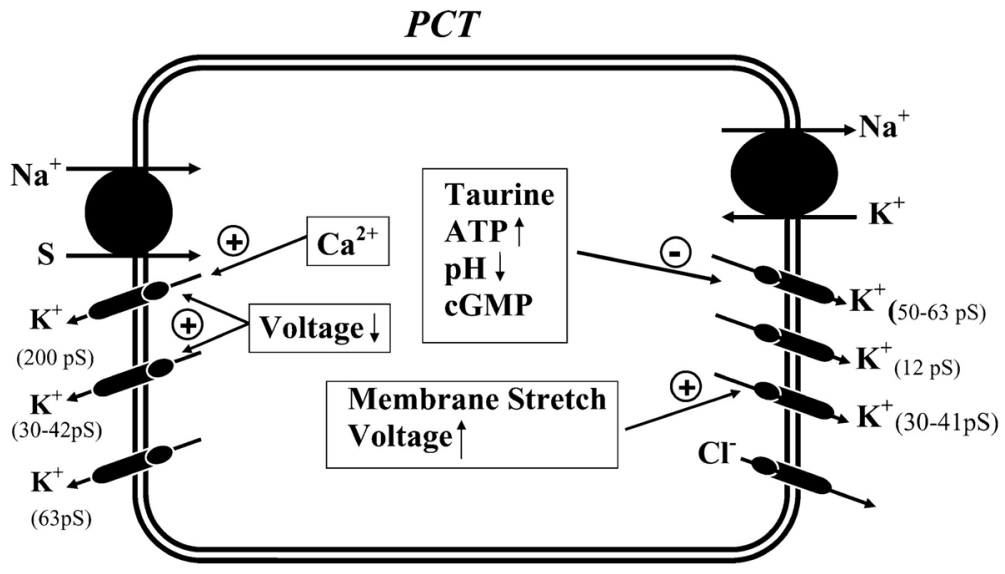

FIG. 5.

A model of proximal tubule cell illustrating the location and regulation of $\mathrm{K}^{+}$channels. The single-channel conductance of the $\mathrm{K}^{+}$channels is indicated. The luminal $\mathrm{Na}^{+}$-dependent glucose and other amino acid transporters are indicated by $\mathrm{Na} / \mathrm{S}$. The basolateral $\mathrm{Na}^{+}-\mathrm{K}^{+}-$ ATPase is also shown. 


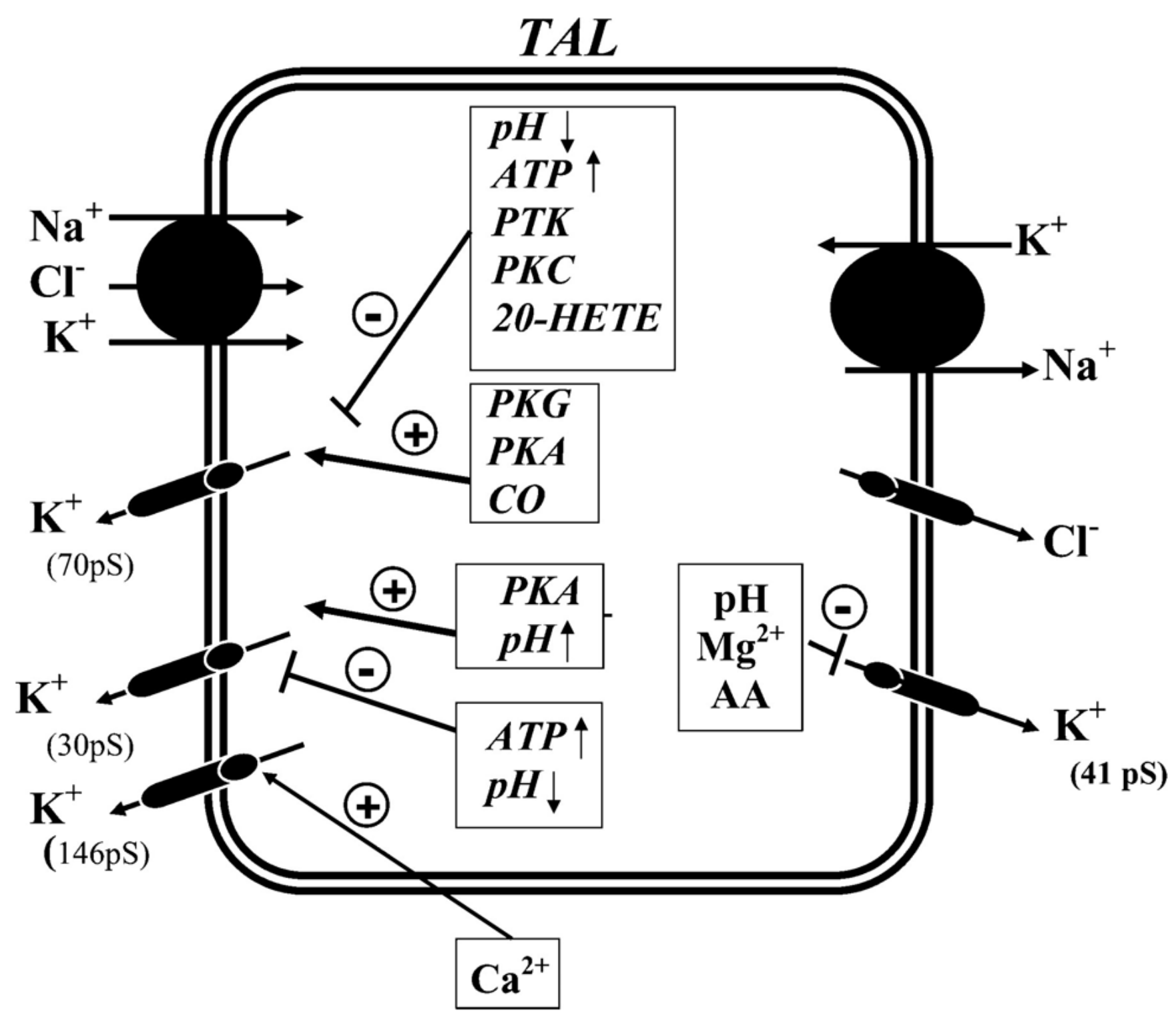

FIG. 6.

A model of TAL cell showing $\mathrm{K}^{+}$channels and their regulation. The single-channel conductance of the $\mathrm{K}^{+}$channels is indicated. The luminal $\mathrm{Na}^{+}-\mathrm{K}^{+}-\mathrm{Cl}^{-}$cotransporter and the basolateral $\mathrm{Na}^{+}-\mathrm{K}^{+}$-ATPase are shown. 20-HETE, 20-hydroxyeicosatetraenoic acid; PKC, protein kinase $\mathrm{C}$; PKA, protein kinase A; PKG, cGMP-dependent protein kinase; PTK, protein tyrosine kinase; $\mathrm{CO}$, carbon monoxide; $\mathrm{AA}$, arachidonic acid. 


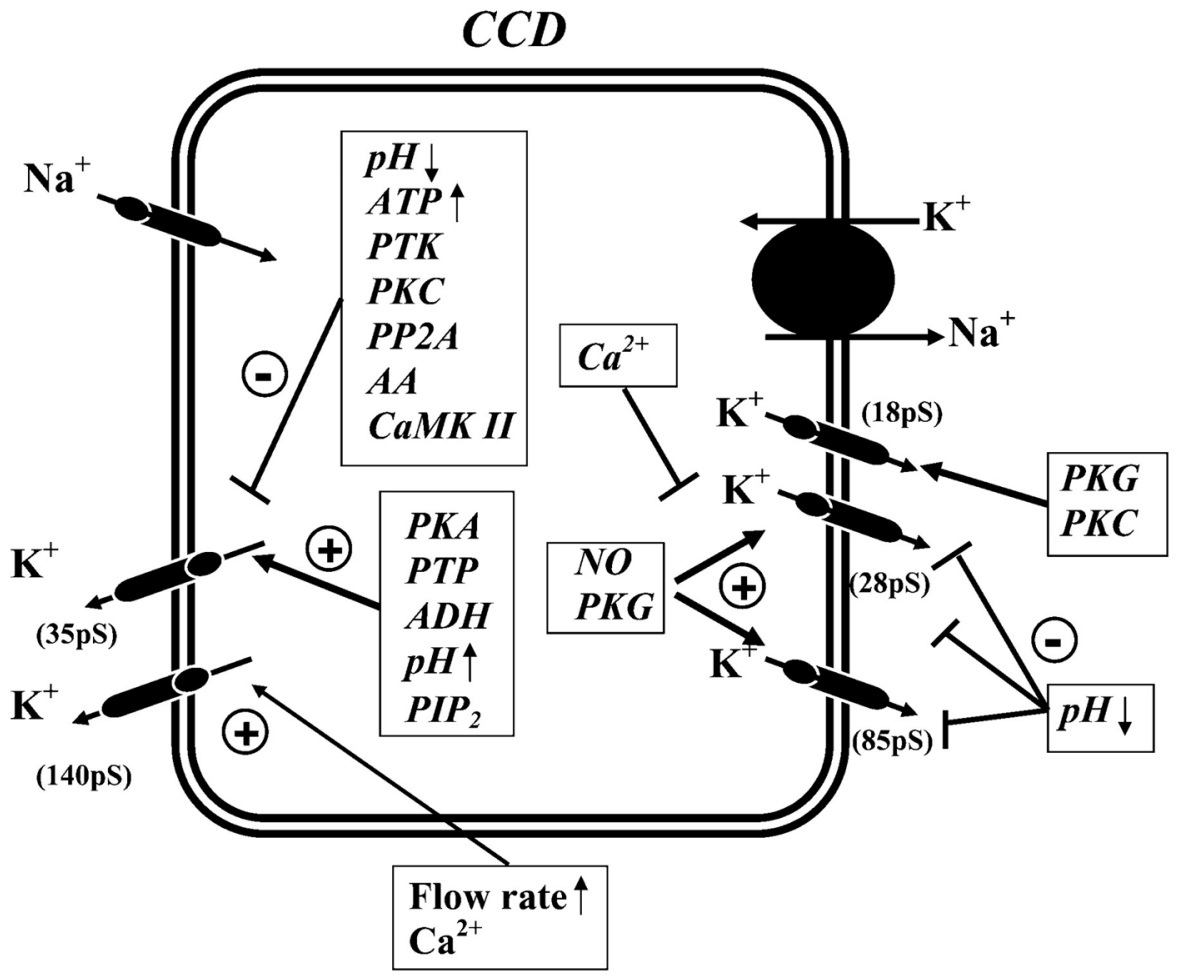

FIG. 7.

A model illustrating the $\mathrm{K}^{+}$channels and their regulation in principal cells from the $\mathrm{CCD}$. The luminal epithelial $\mathrm{Na}^{+}$channel $(\mathrm{ENaC})$ and the basolateral $\mathrm{Na}^{+}-\mathrm{K}^{+}$-ATPase are shown. PKC, protein kinase C; PKA, protein kinase A; PKG, cGMP-dependent protein kinase; PTK, protein tyrosine kinase; PTP, protein tyrosine phosphatase; CaMK II, calcium and calmodulindependent kinase II; CO, carbon monoxide; NO, nitric oxide; AA, arachidonic acid; PP2A, protein phosphatase $2 \mathrm{~A}$; $\mathrm{ADH}$, antidiuretic hormone. 


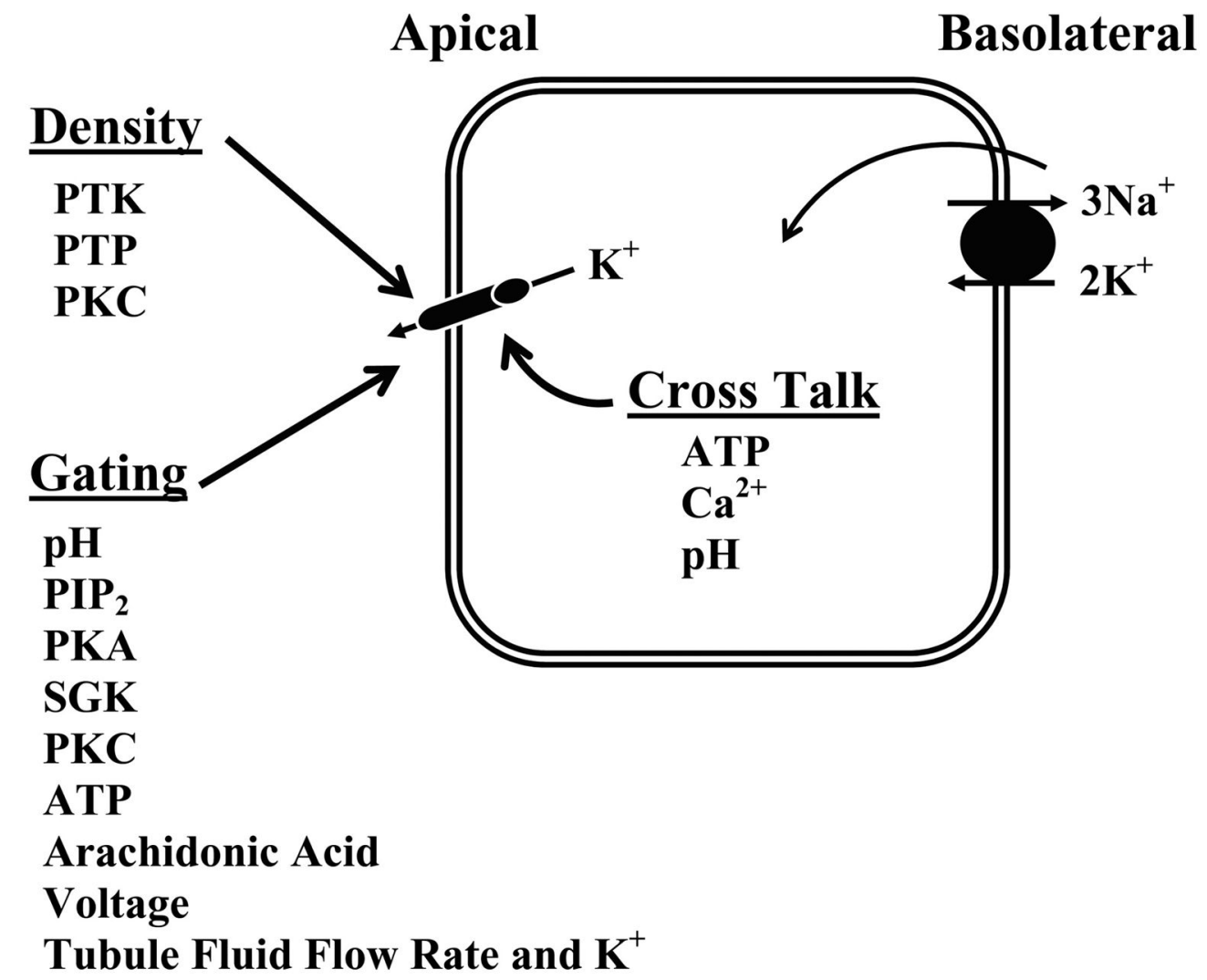

FIG. 8.

A cell model showing the mechanisms regulating the activity of apical $\mathrm{K}^{+}$channels in the kidney. Possible mechanisms for interaction between basolateral $\mathrm{Na}^{+}-\mathrm{K}^{+}$-ATPase and apical $\mathrm{K}^{+}$channels are illustrated (cross talk). 


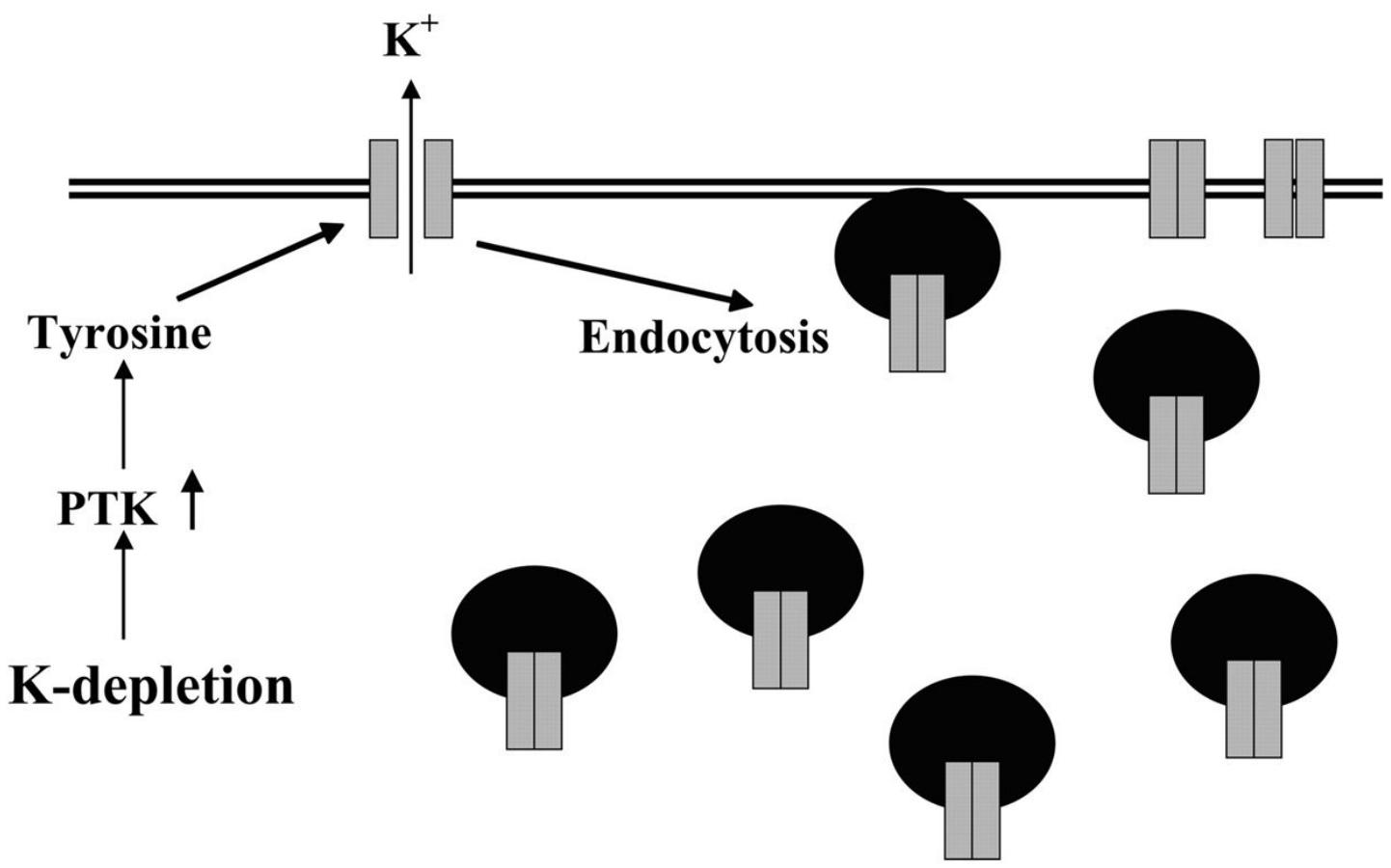

FIG. 9.

A scheme illustrating the mechanism by which a low- $\mathrm{K}^{+}$diet decreases the surface expression of ROMK channels in principal cells from the CCD. With adaptation to a low $\mathrm{K}^{+}$intake, protein tyrosine kinase (PTK) activity increases. The augmented PTK increases the rate of endocytosis, thereby reducing the number of $\mathrm{K}^{+}$channels in the apical membrane. 

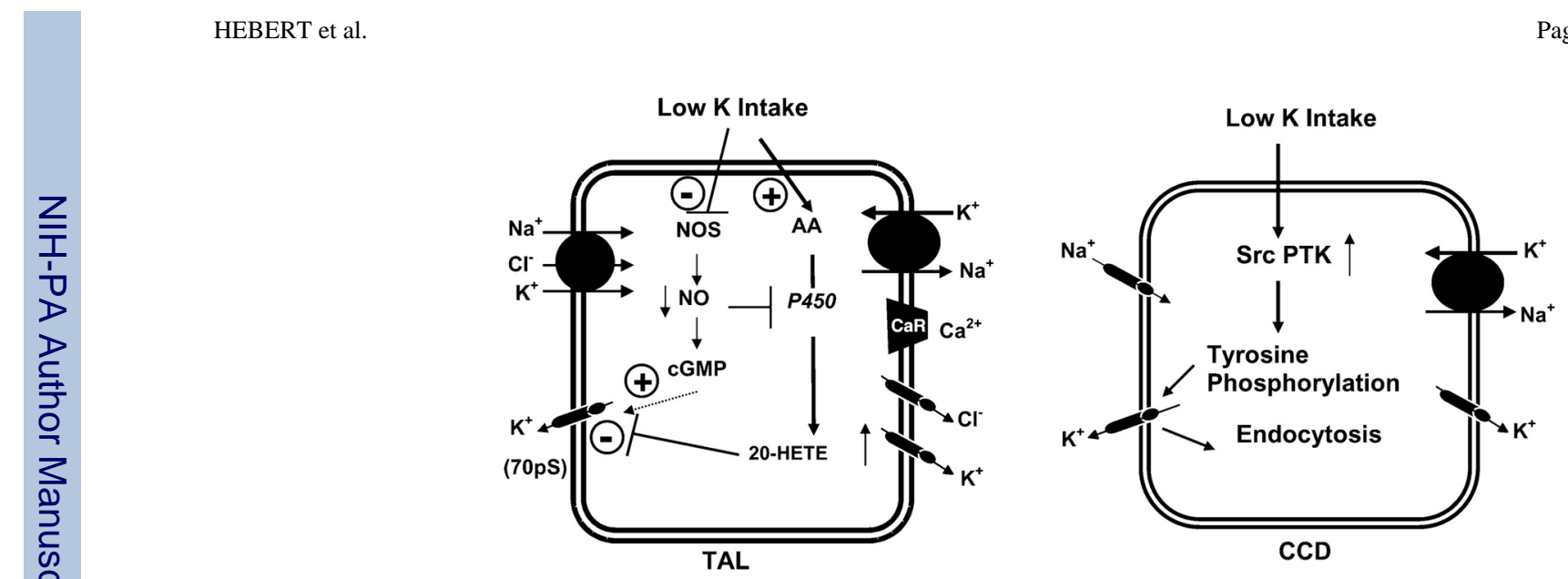

FIG. 10.

Cell models showing the signaling pathways involved in modulation of apical $\mathrm{K}^{+}$channels in principal cells by low $\mathrm{K}^{+}$intake. See text for discussion. 


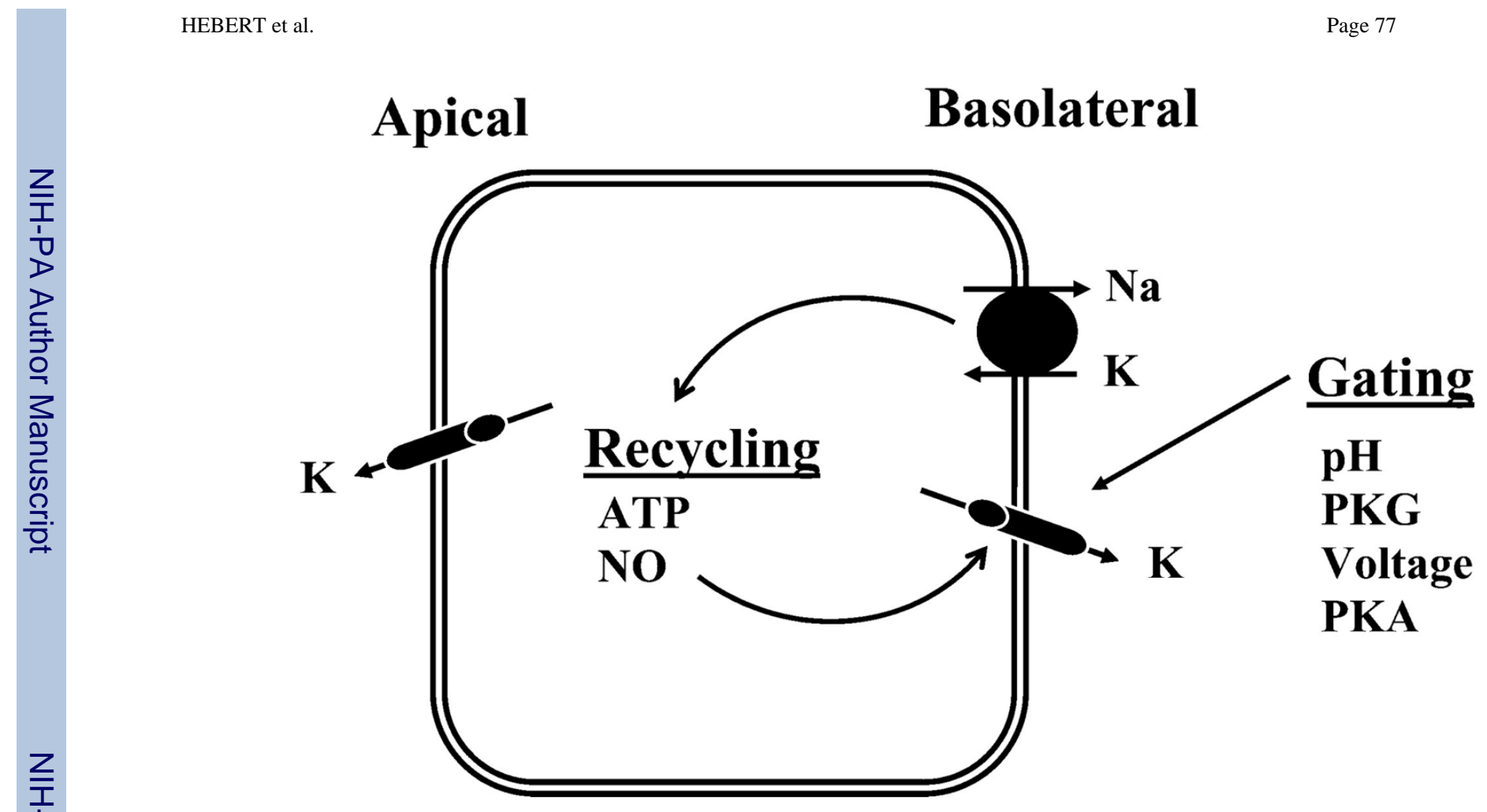

FIG. 11.

A cell model showing the signaling pathways involved in modulation of basolateral $\mathrm{K}^{+}$ channels in principal cells. 

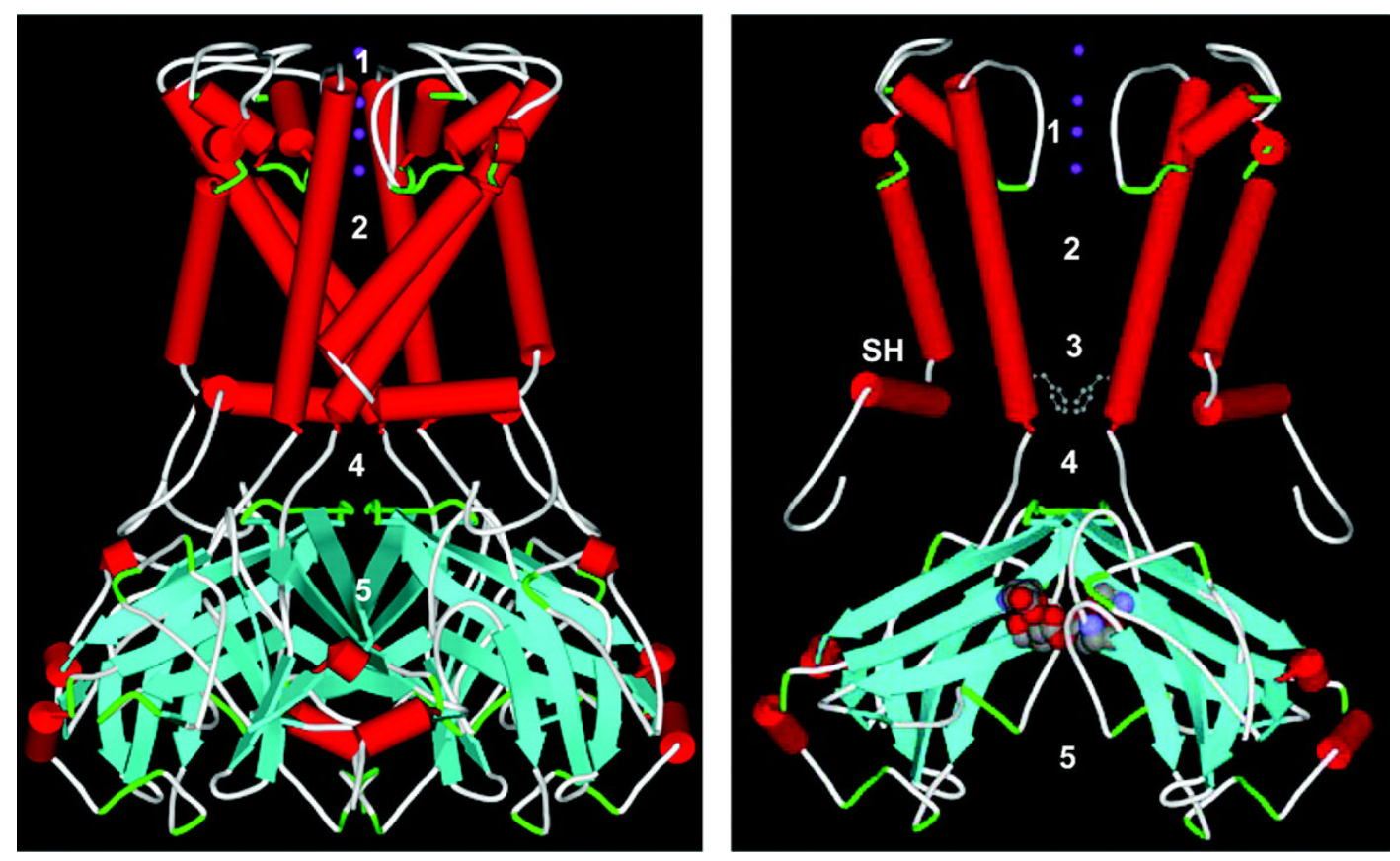

FIG. 12.

Structure of the bacterial inward rectifier $\mathrm{K}^{+}$channel KirBac1.1, illustrating the five structural regions of the pore. Mammalian inwardly rectifying $\mathrm{K}^{+}$channels like ROMK are believed to be structurally similar. 
A
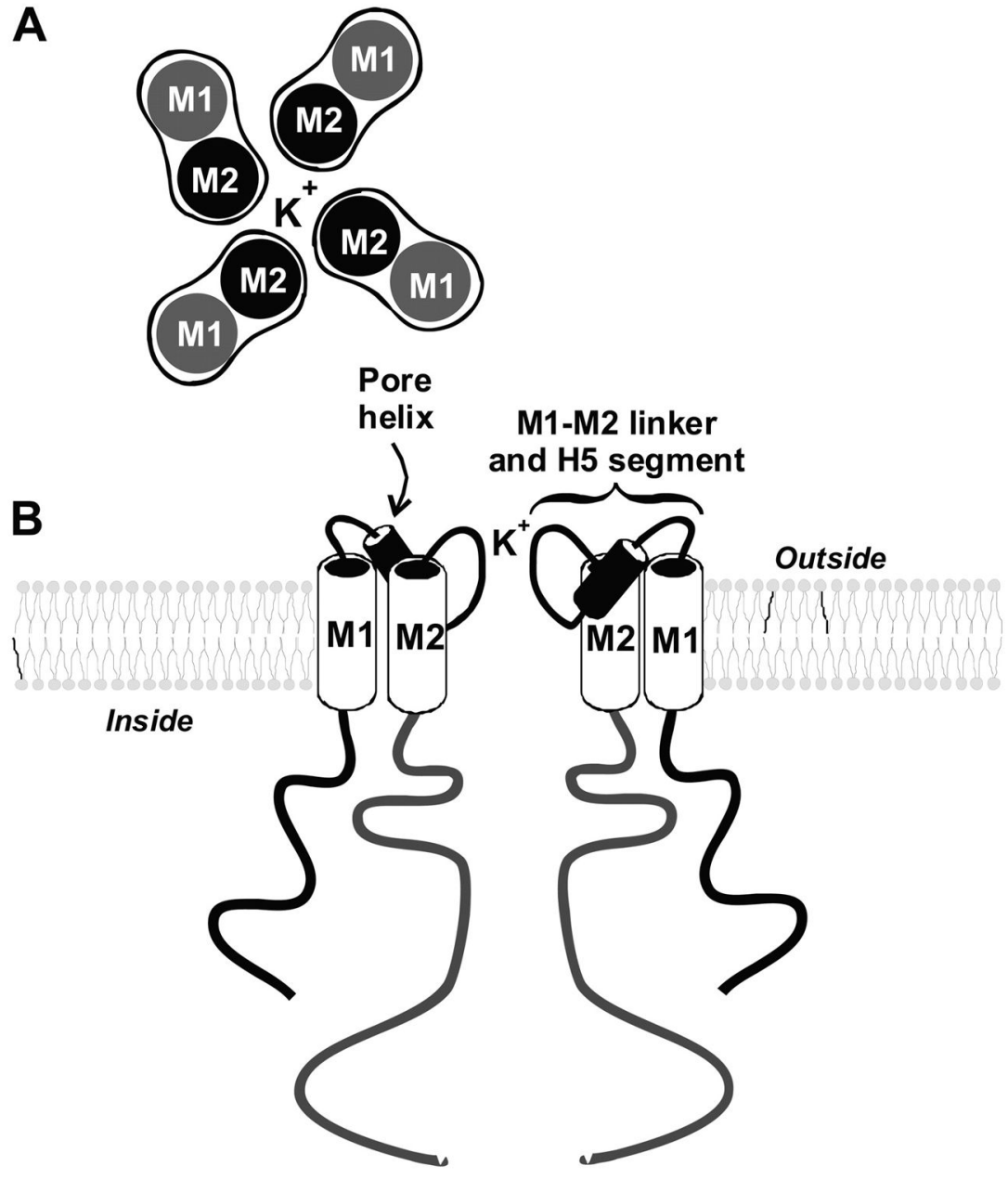

FIG. 13.

A schematic model of ROMK. A: the proposed subunit structure with the 2nd transmembrane helices, M2, lining the pore. $B$ : two of the four subunits forming the channel illustrating the pore helix in the M1-M2 linker. 


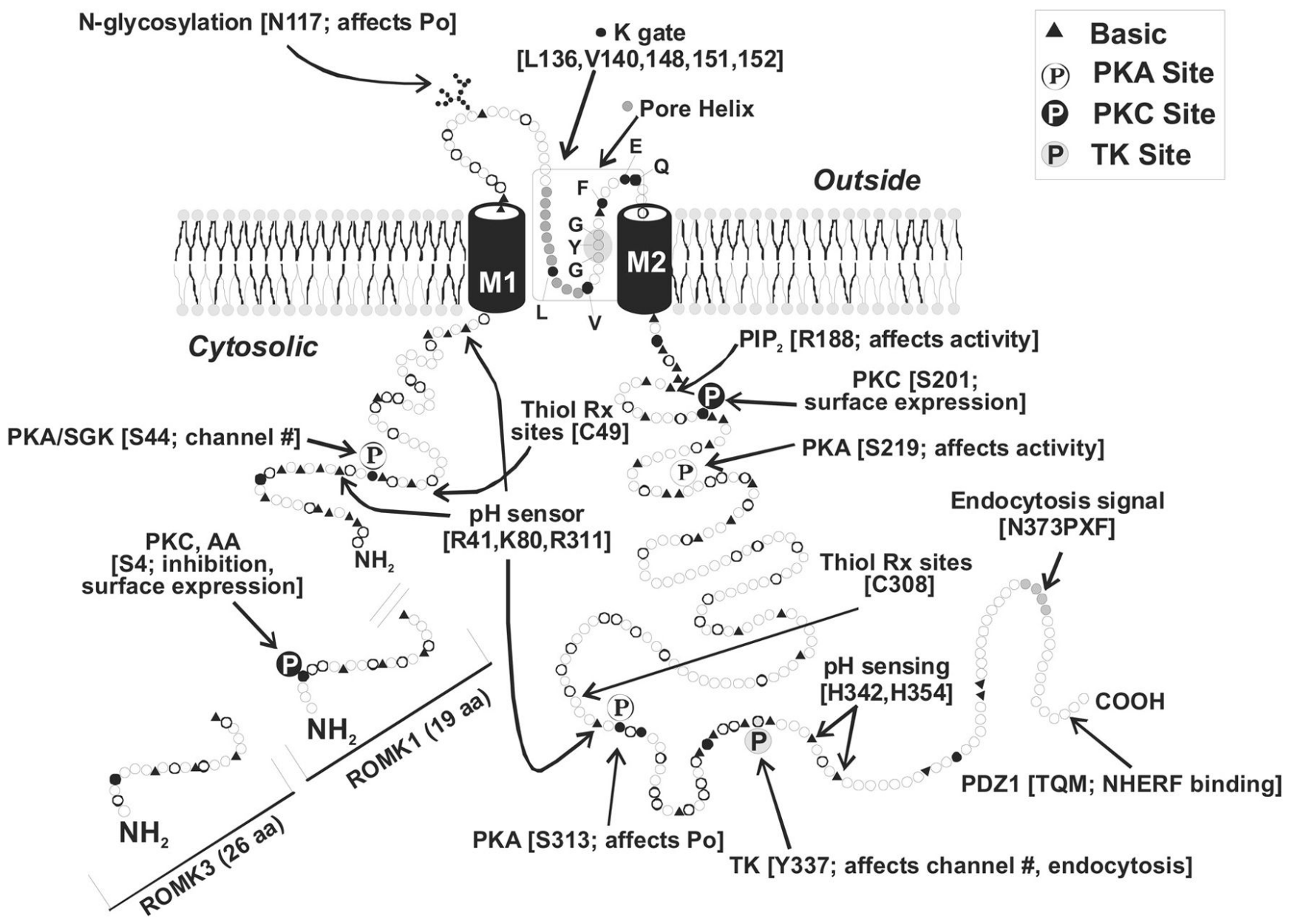

FIG. 14.

A schematic model of a single ROMK subunit in the channel tetramer showing the aminoterminal extentions forming ROMK1 and ROMK3, as well as the amino acids that mediate regulation of this channel. 

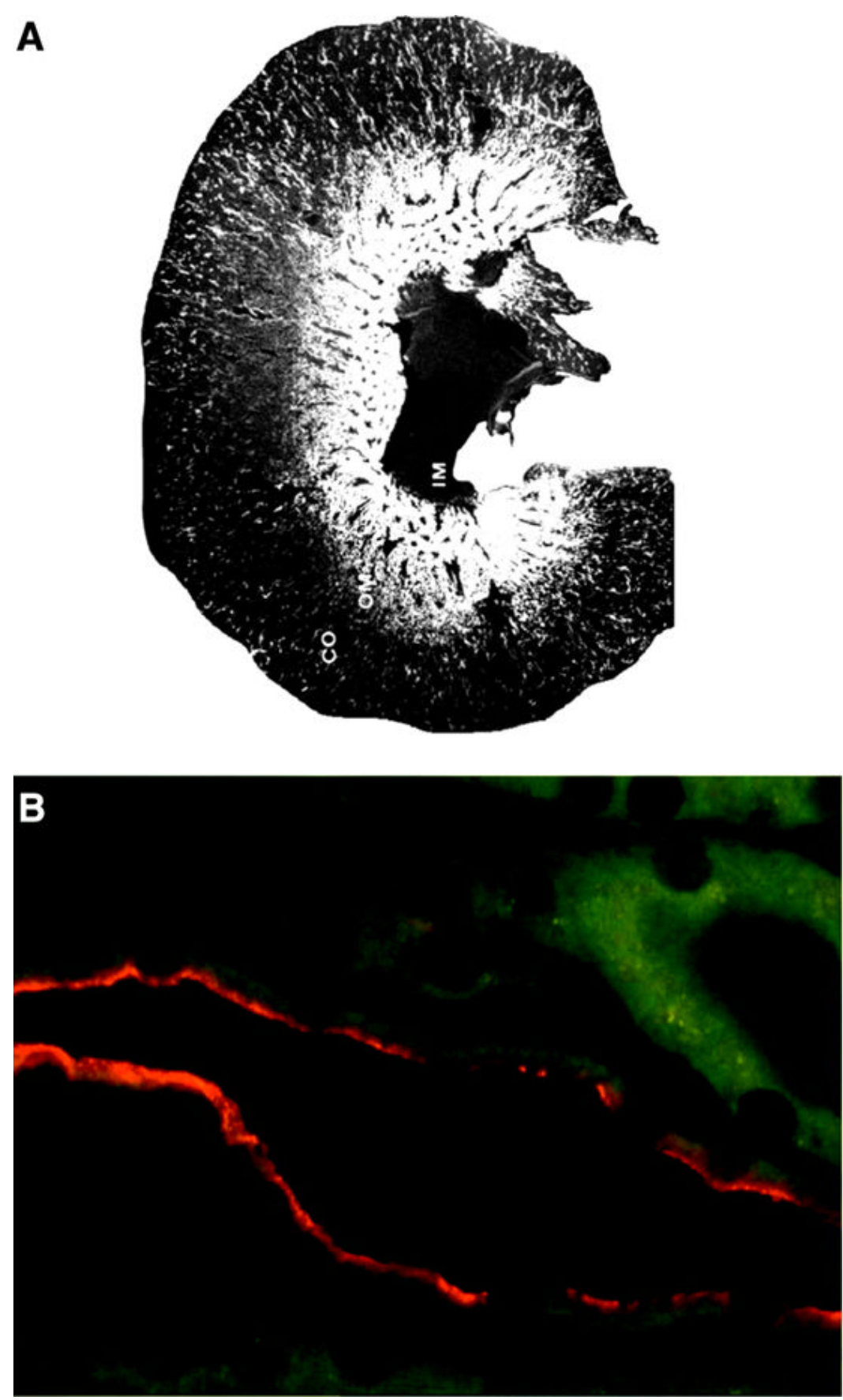

FIG. 15 .

Expression of ROMK in the rat kidney. $A$ : in situ hybridization showing the wide expression of ROMK in cortex, mainly in medullary rays, and in outer medulla. $B$ : Western blot showing the apical expression of ROMK in the medullary thick ascending limb (MTAL). 
ROMK1

ROMK2

ROMK3

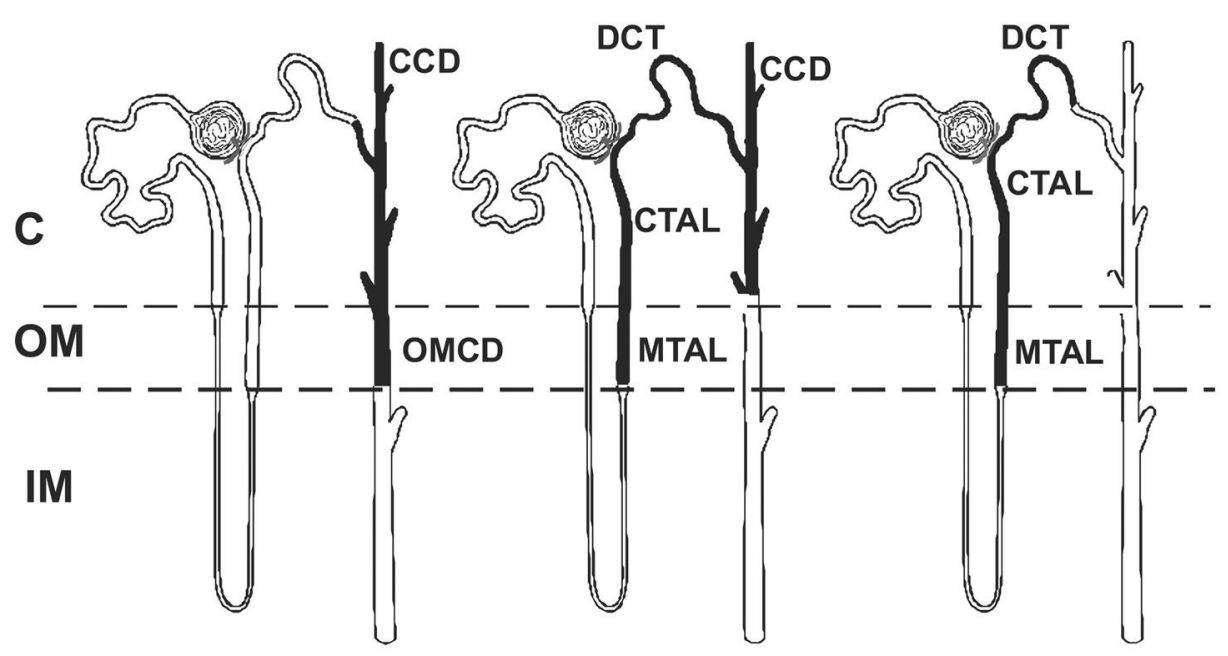

FIG. 16 .

Distribution of ROMK isoforms along the nephron. 
A

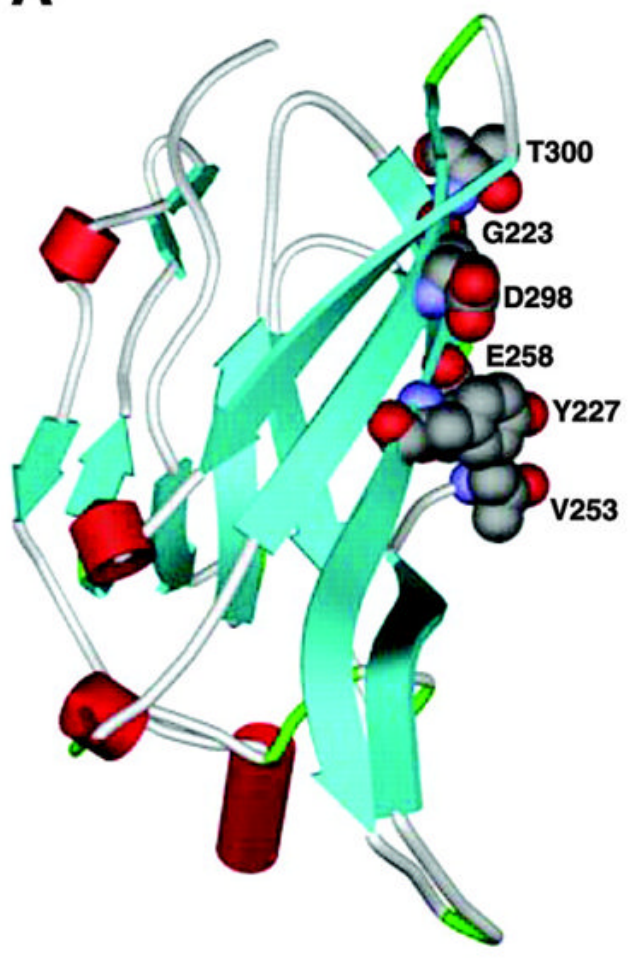

FIG. 17.
B

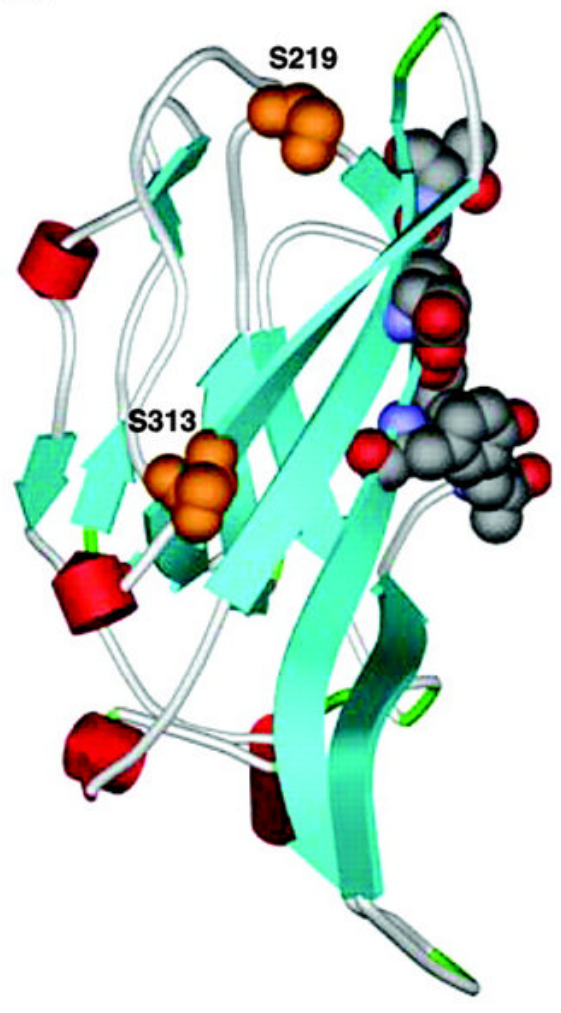

C

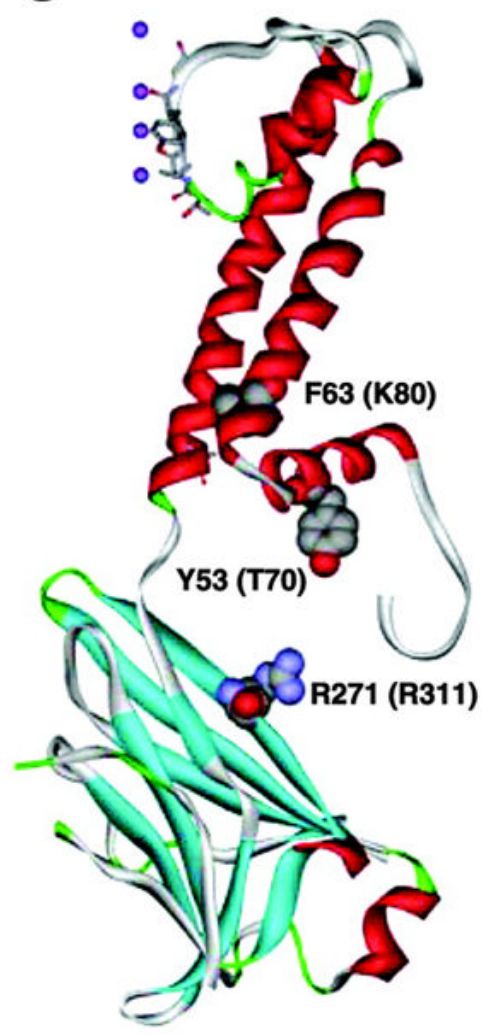

$A$ and $B$ are computer-generated models of the structure of the cytoplasmic carboxy terminus of ROMK produced by threading ROMK using Kir-Bac1.1 as a template (Swiss-Model). A: the residues that have been identified to line the cytoplasmic pore and involved in interaction with cations mediating inward rectification. $B$ : the carboxy-terminal serine residues that are phosphorylated by protein kinase A. $C$ : localization of the equivalent residues on KirBac1.1 that form the $\mathrm{pH}$ sensor on ROMK. 


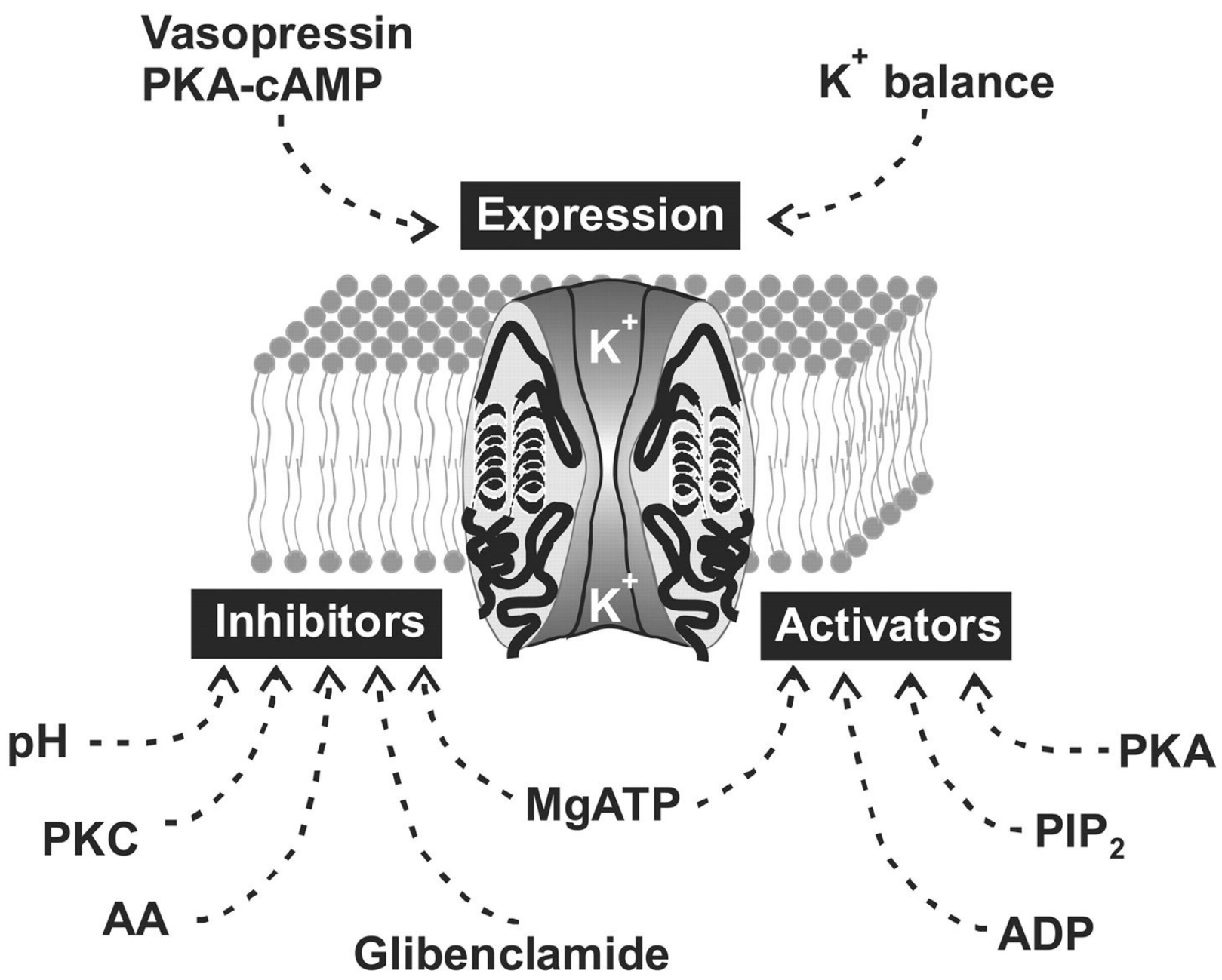

FIG. 18.

Overview of the factors and mechanisms of regulation of ROMK. 


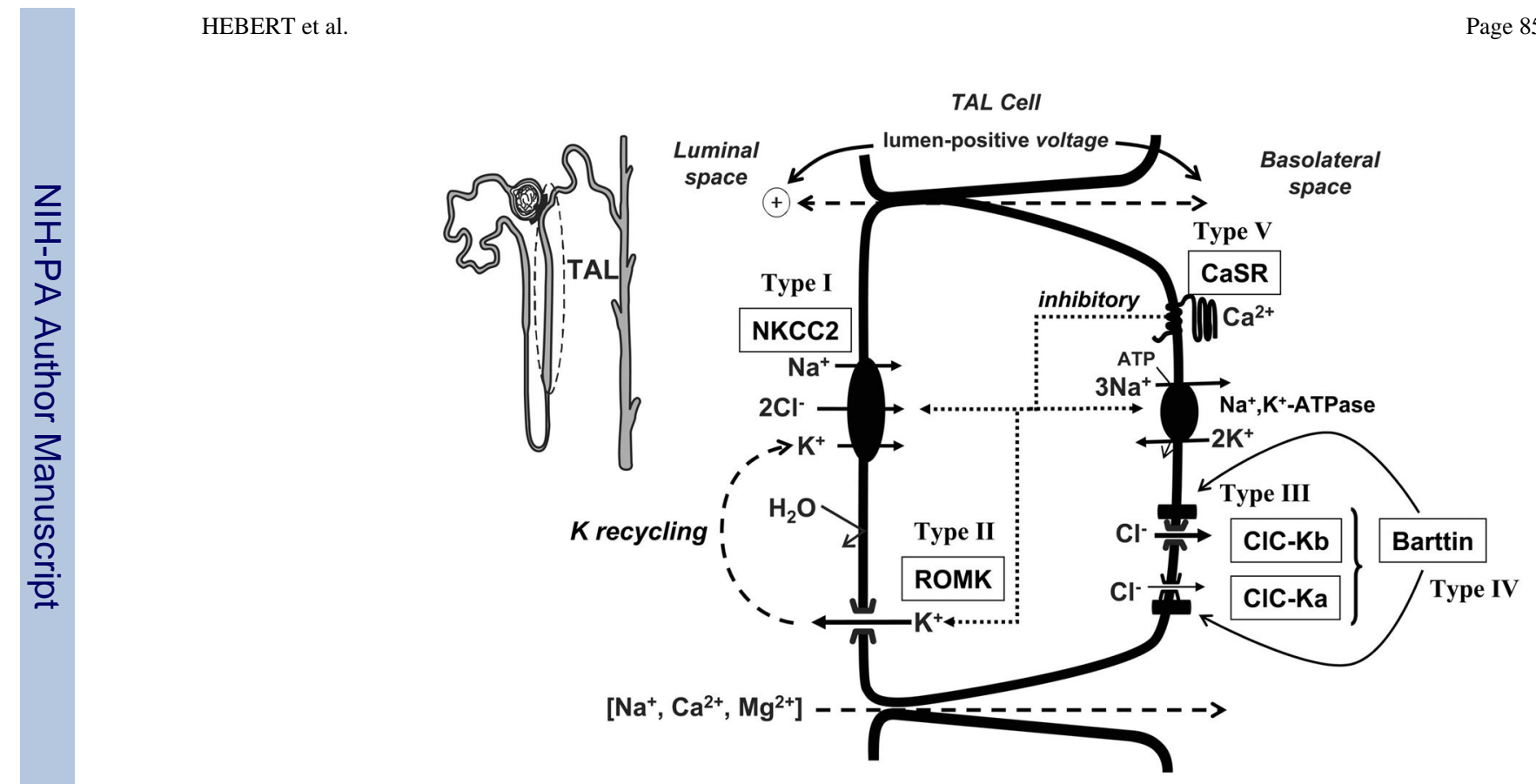

FIG. 19.

Schematic model of the TAL illustrating the transporters that cause Bartter's syndrome. 


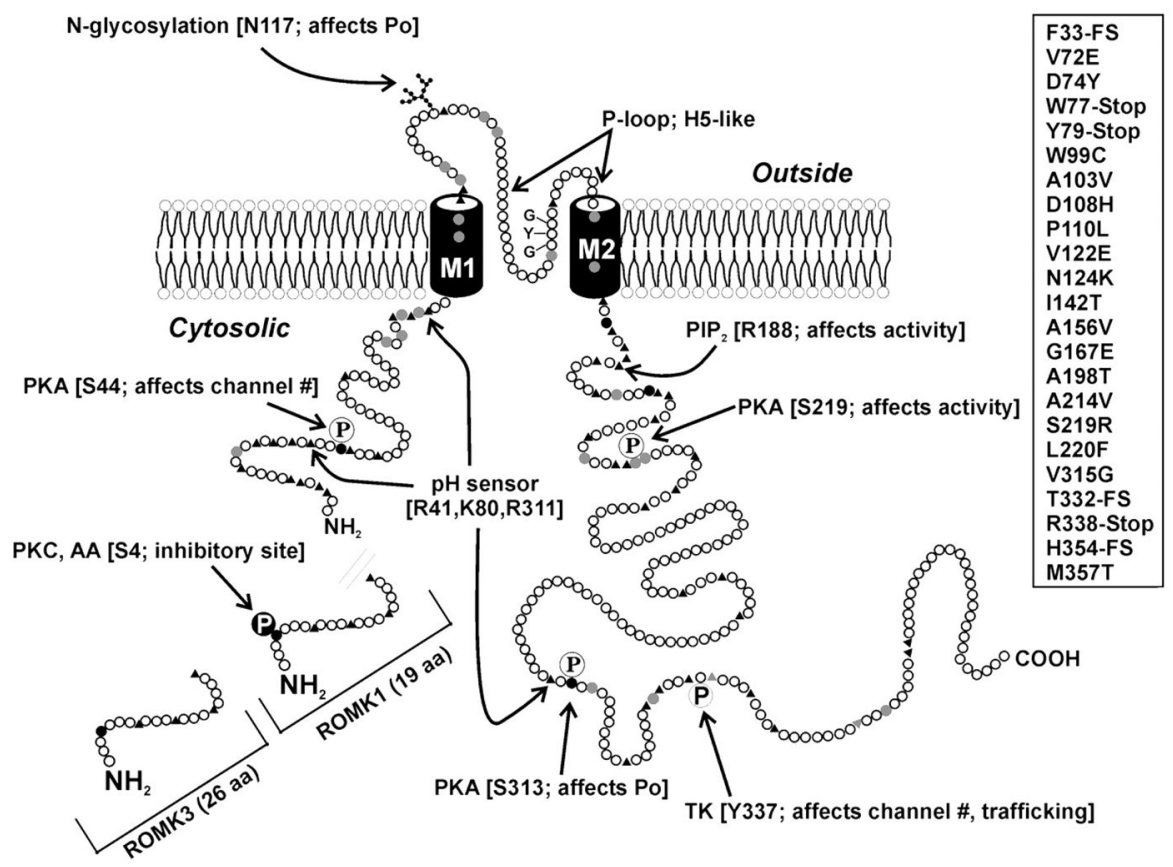

FIG 20.

Mutations in ROMK that are associated with Bartter's syndrome. 


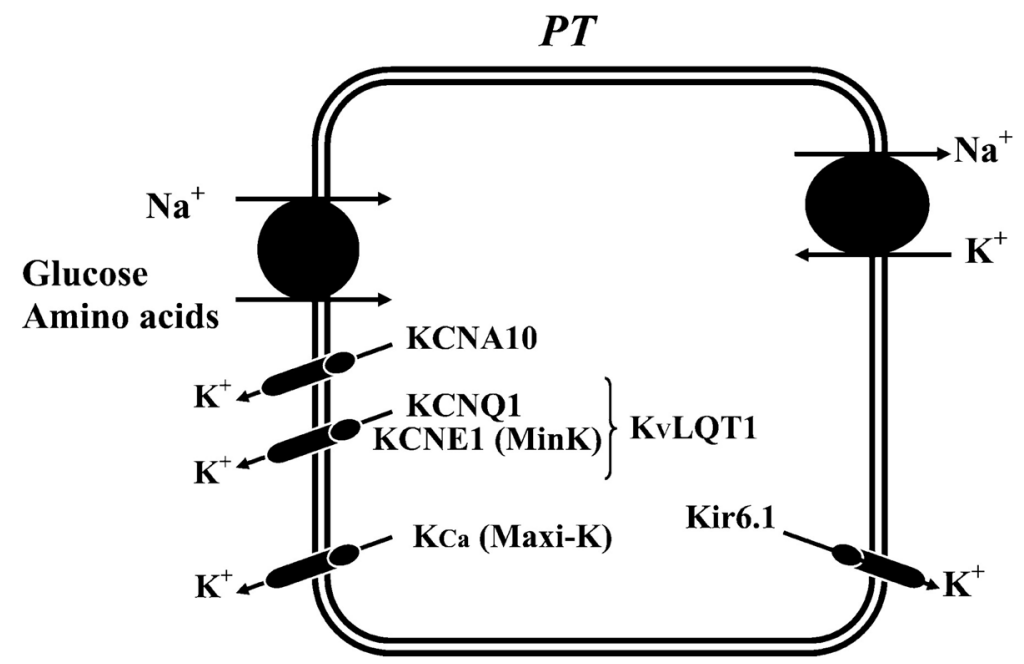

FIG. 21.

Localization of 6-TM channels in the apical membrane of the proximal tubule. Also shown is the single TM subunit KCNE1 (MinK) that forms the KVLQT1 channel with the 6-TM subunit $\mathrm{KCNQ1}$. These $\mathrm{K}^{+}$channels are thought to stabilize the apical membrane potential that supports entry of amino acids and glucose via their respective $\mathrm{Na}^{+}$-coupled electrogenic transporters. 


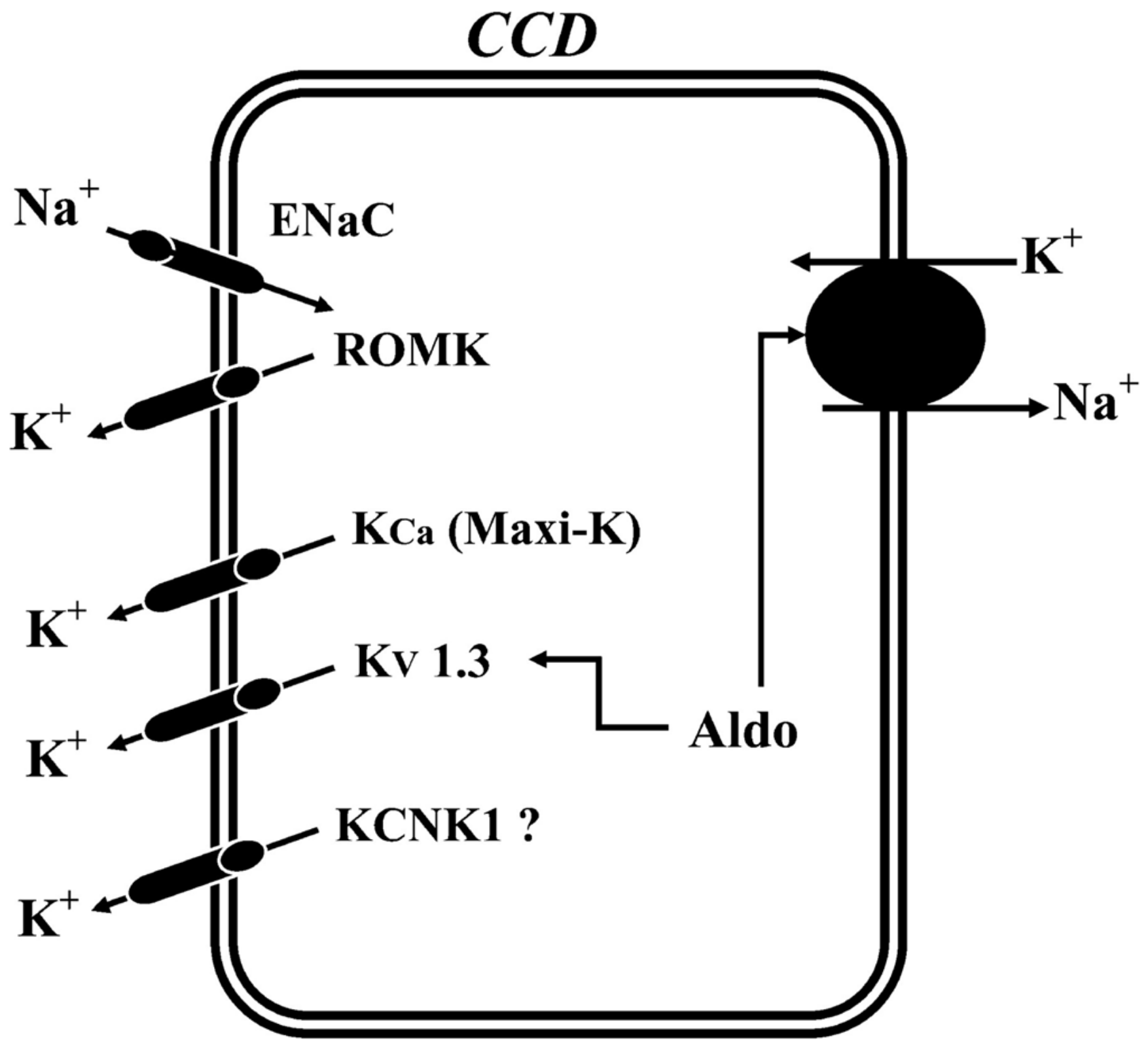

FIG. 22.

Localization of 6-TM channels in the apical and basolateral membranes of distal tubular cells. These channels may help stabilize the apical membrane potential when $\mathrm{Na}^{+}$entry (via the epithelial channel, $\mathrm{ENaC}$ ) activity is increased by aldosterone (Aldo). 


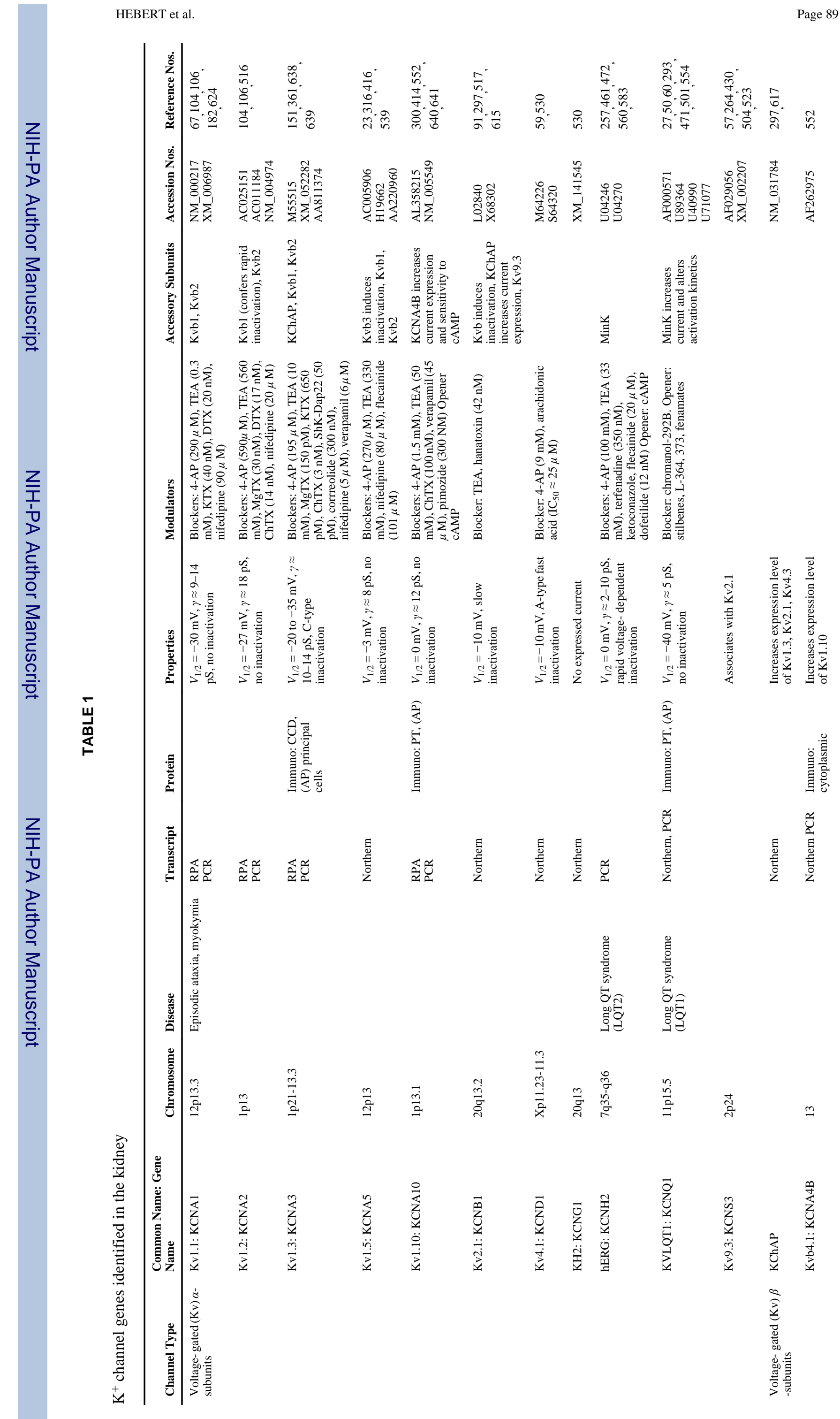




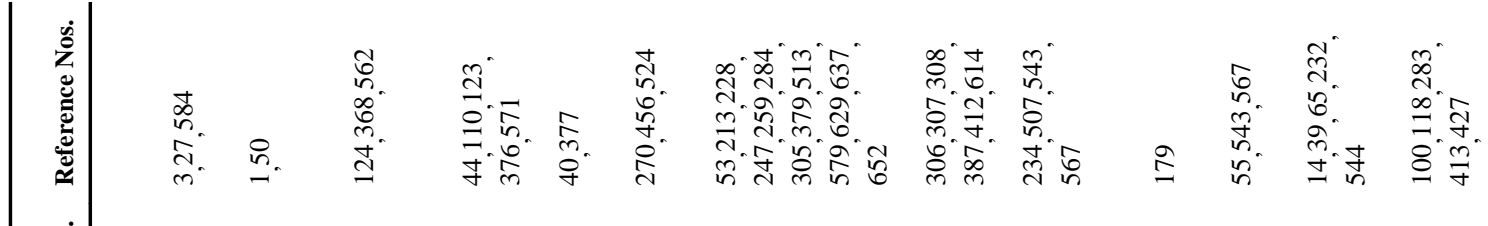

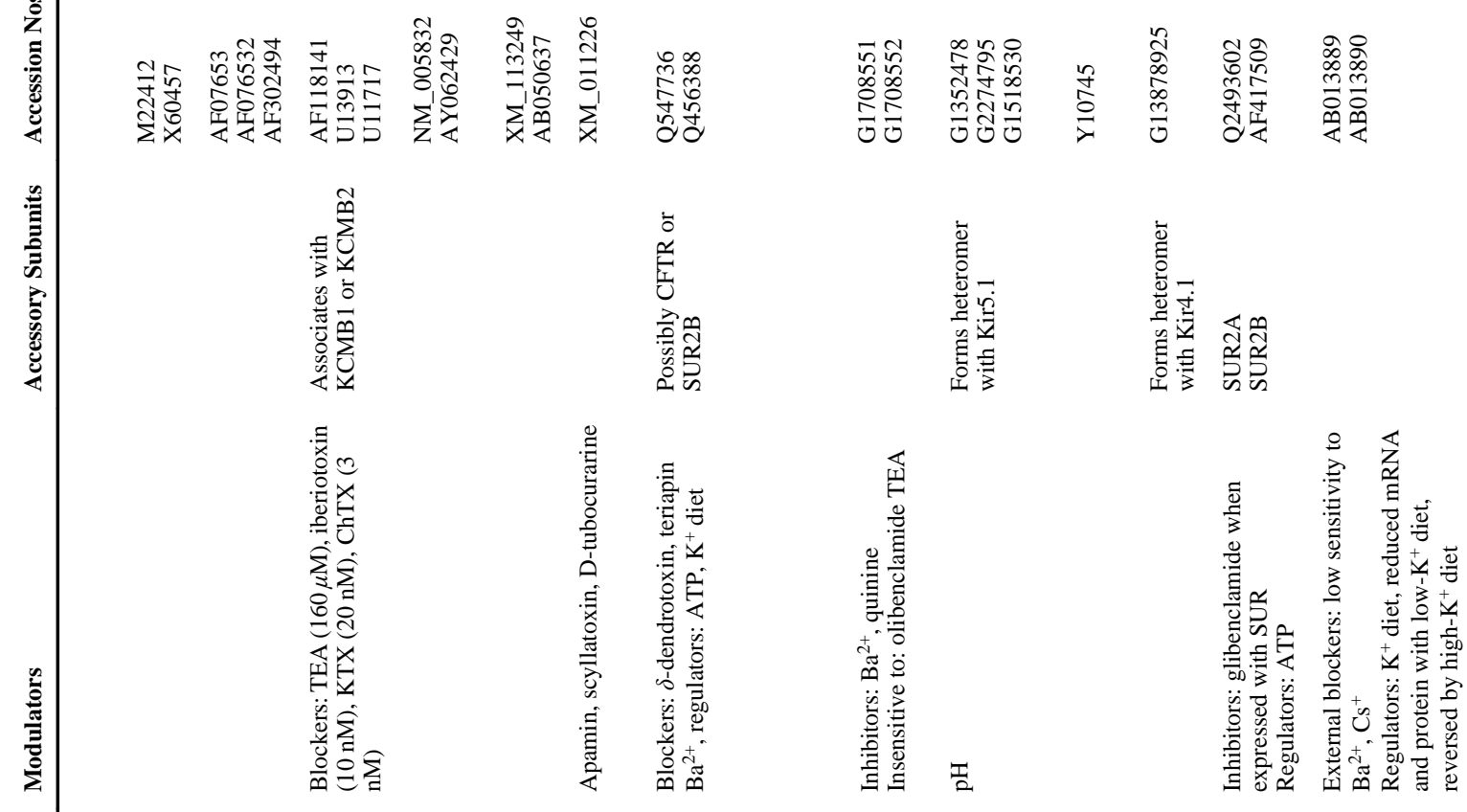
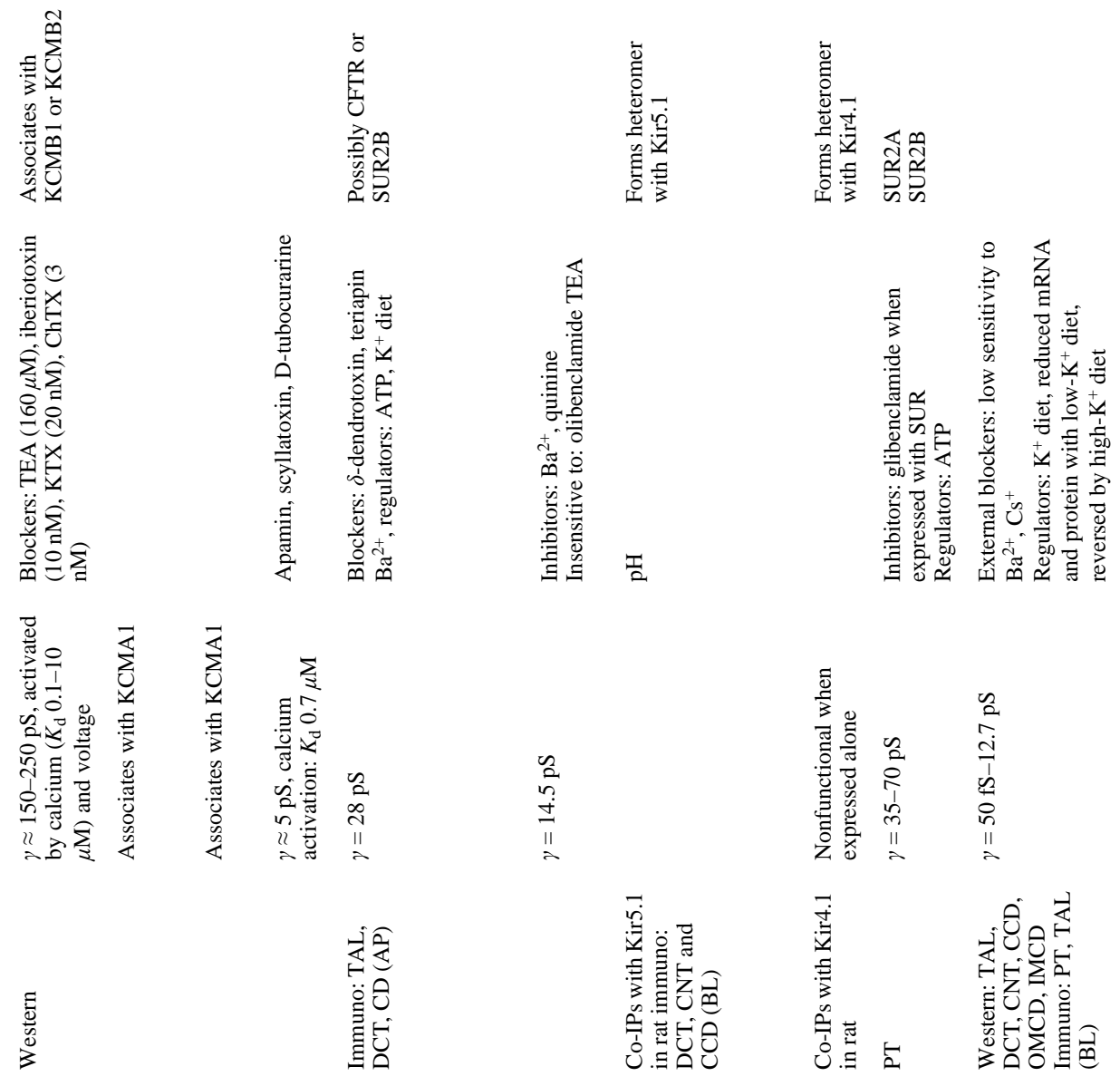

(3)

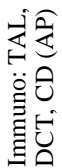<smiles>C1CCCC1</smiles>

$\approx$

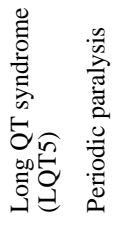<smiles>C1CCCCC1</smiles>

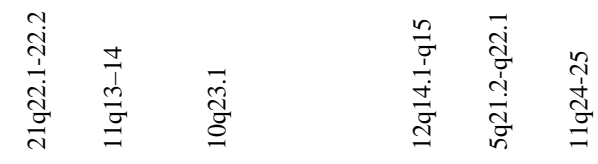

हू

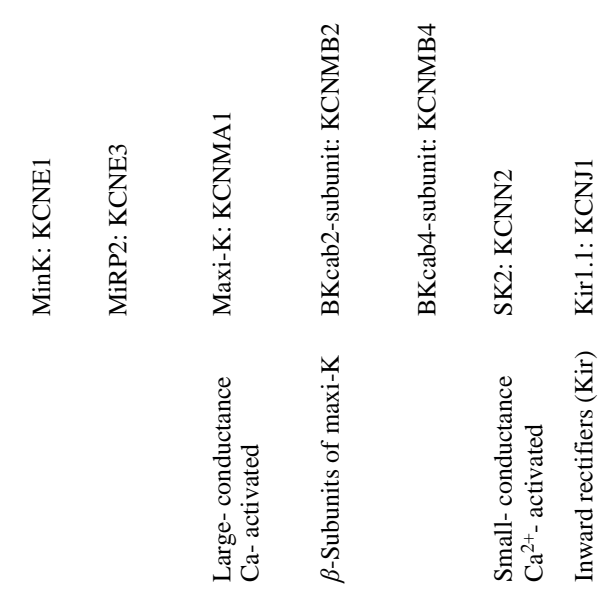




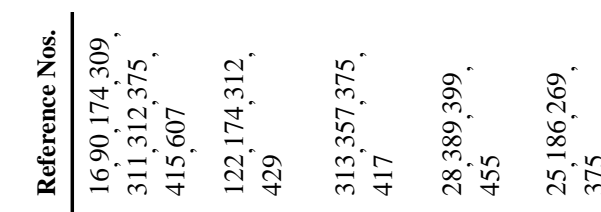

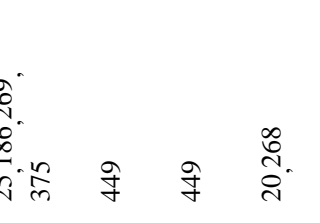

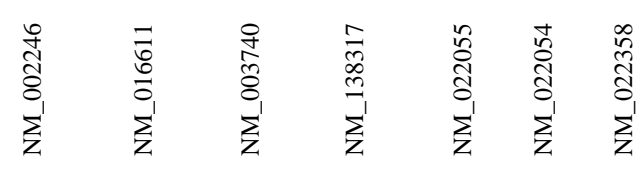

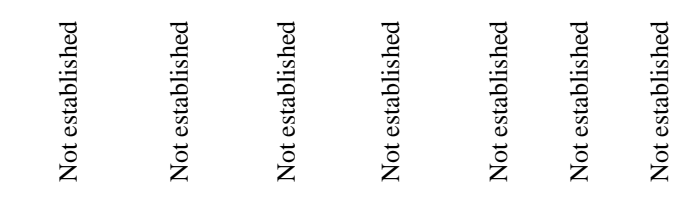

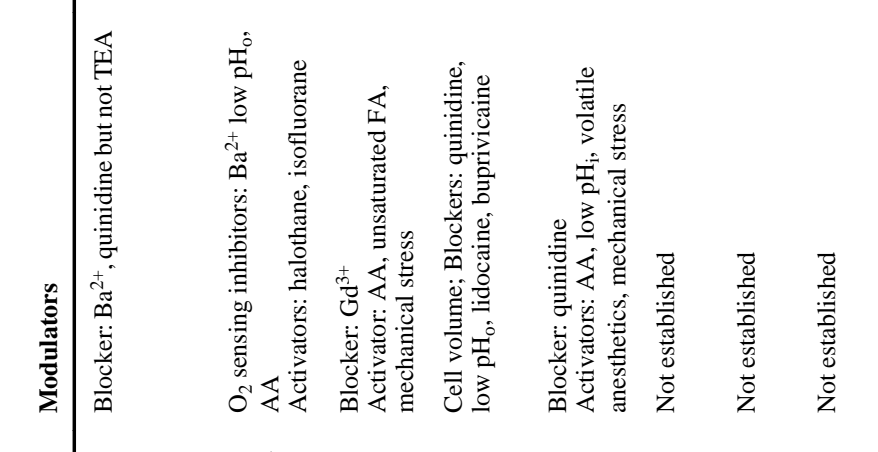

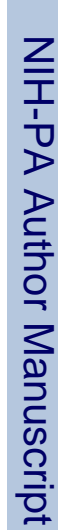

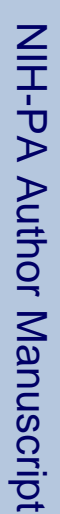

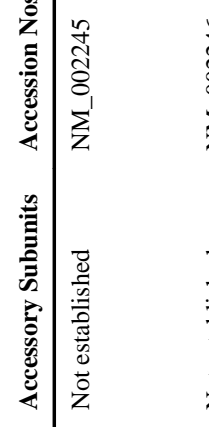

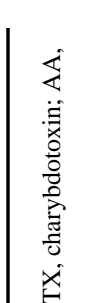

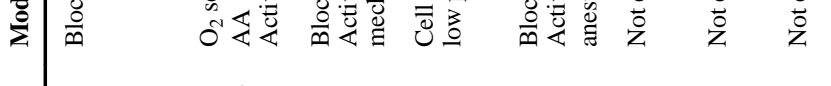

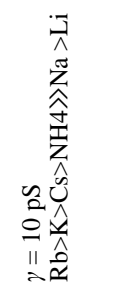

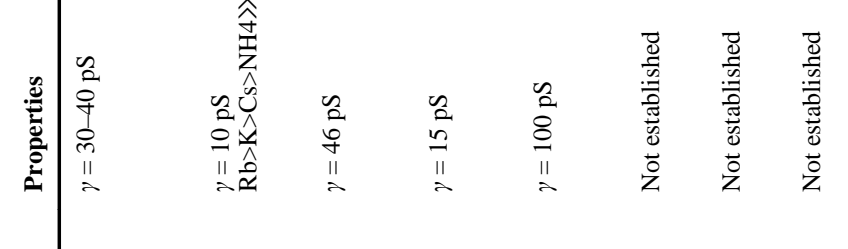

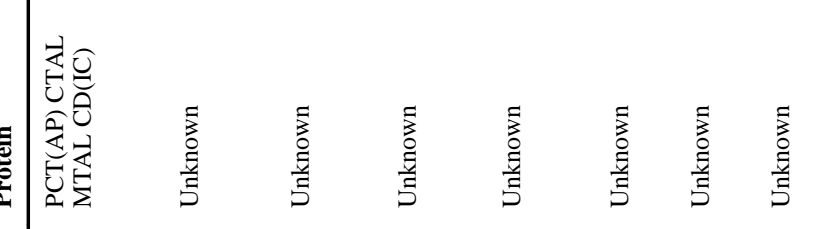

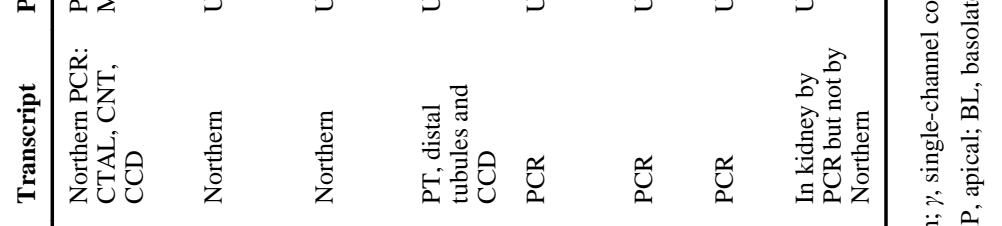

章

|| IIIIIII

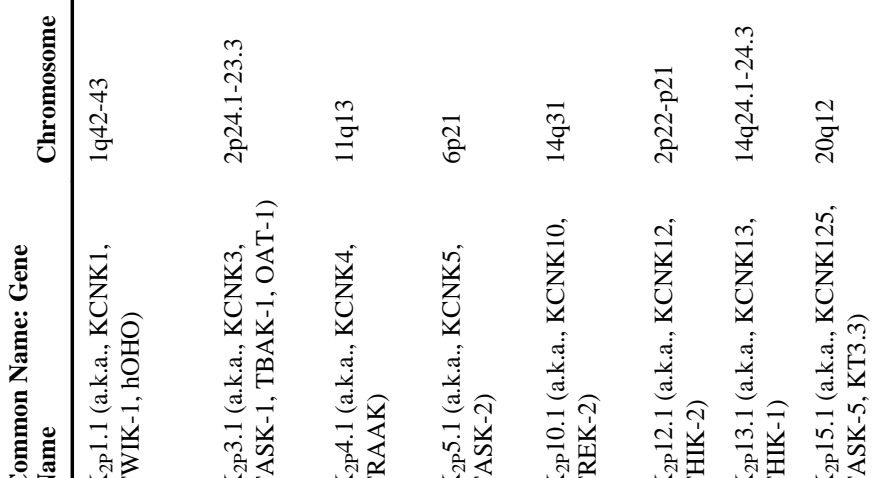

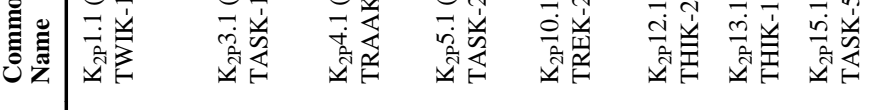

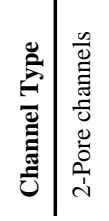




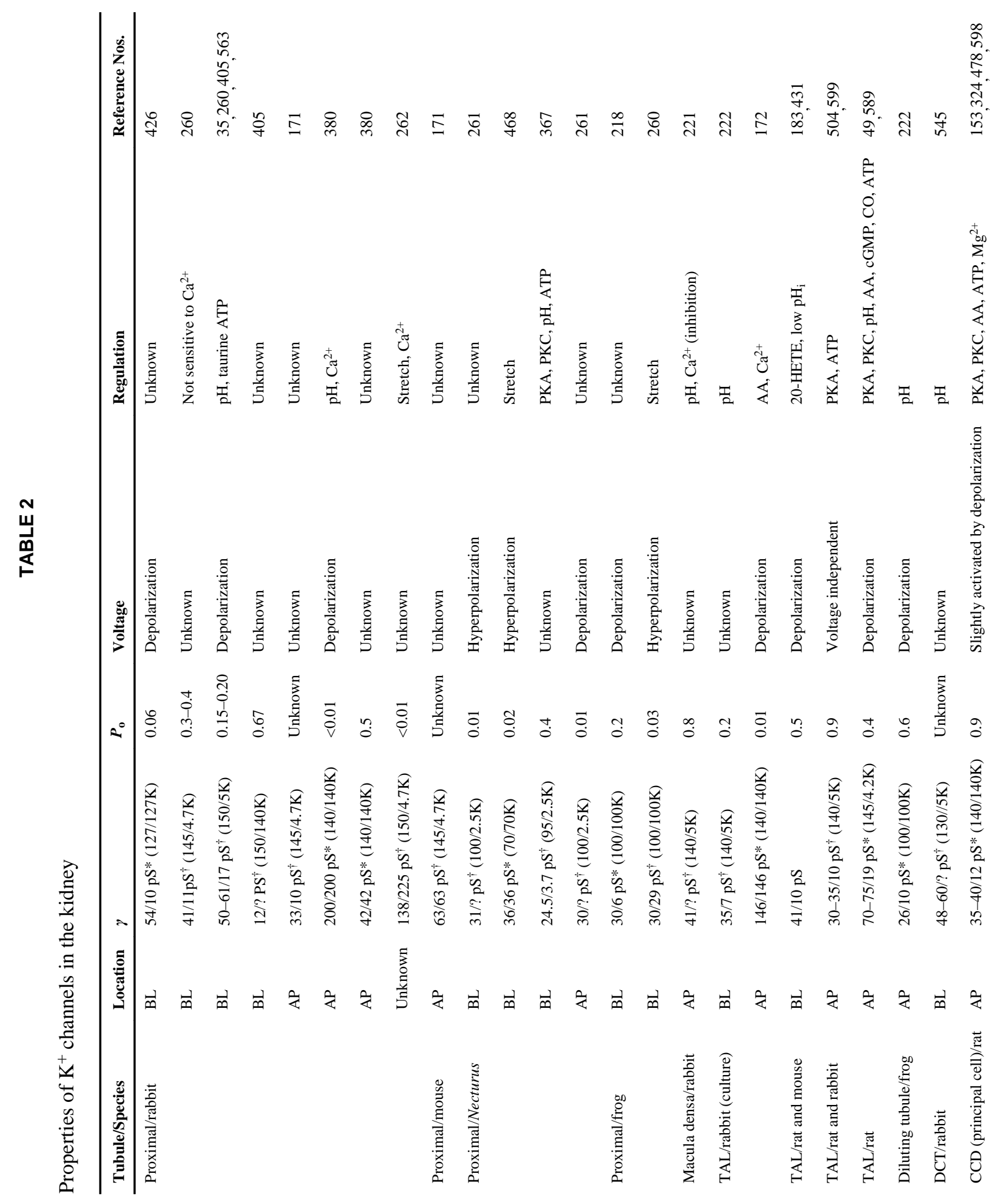




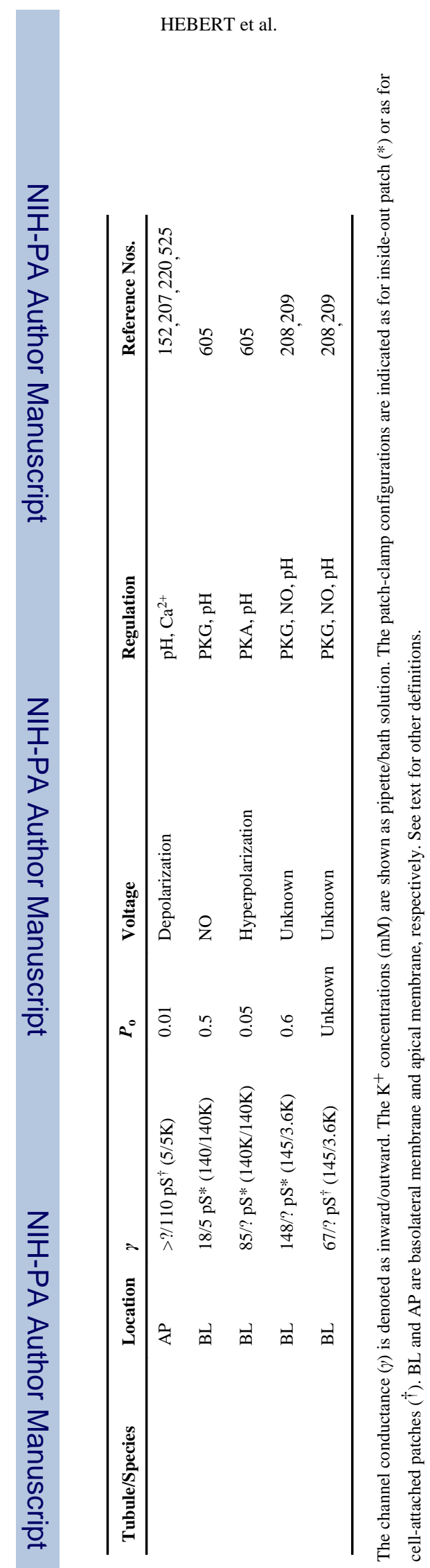

Page 93 